\title{
Understanding the diastereopreference of intermediates in aminocatalysis: application to the chiral resolution of lactols
}

\author{
Carla Alamillo-Ferrer, ${ }^{\mathrm{a}}$ Christian D.-T. Nielsen, ${ }^{\mathrm{b}}$ Andrea Salzano, ${ }^{\mathrm{a}}$ Xavier Companyó, ${ }^{\mathrm{bc}}$ \\ Riccardo Di Sanza, ${ }^{\text {bd }}$ Alan C. Spivey, ${ }^{\mathrm{b}}$ Henry S. Rzepa, ${ }^{\mathrm{b}}$ and Jordi Burés ${ }^{\star a b}$ \\ ${ }^{a}$ Department of Chemistry, University of Manchester, Oxford Road, Manchester M13 9PL, UK. \\ ${ }^{\mathrm{b}}$ Imperial College London, White City Campus, 80 Wood Lane, London, W12 OBZ, UK. \\ ${ }^{\mathrm{C}}$ Department of Inorganic and Organic Chemistry, Section of Organic Chemistry, University of \\ Barcelona, Martí i Franquès 1-11, 08028 Barcelona, Spain. \\ ${ }^{d}$ ICIQ - Institute of Chemical Research of Catalonia, The Barcelona Institute of Science and \\ Technology, Avinguda Països Catalans 16, 43007, Tarragona, Spain \\ jordi.bures@manchester.ac.uk
}

\section{Table of contents}

1. Literature intermediates

2. $C C D C$ structures

3. General Procedures Schemes

4. Resolution of racemic $\delta$-hexalactol $( \pm)$-1b with different amines

5. Formation of a single diastereoisomer of the hemiaminal ether $(S, R, R)$-3aa

6. Study of the reversibility of the condensation reaction of formation of hemiaminal ether $(S, R, R)-3$ aa

7. Chiral resolution of lactols to obtain high ee

8. Chiral resolution of lactols to obtain scalemic mixtures

9. NMR spectra

10. HPLC data

11. References 
1 Literature intermediates

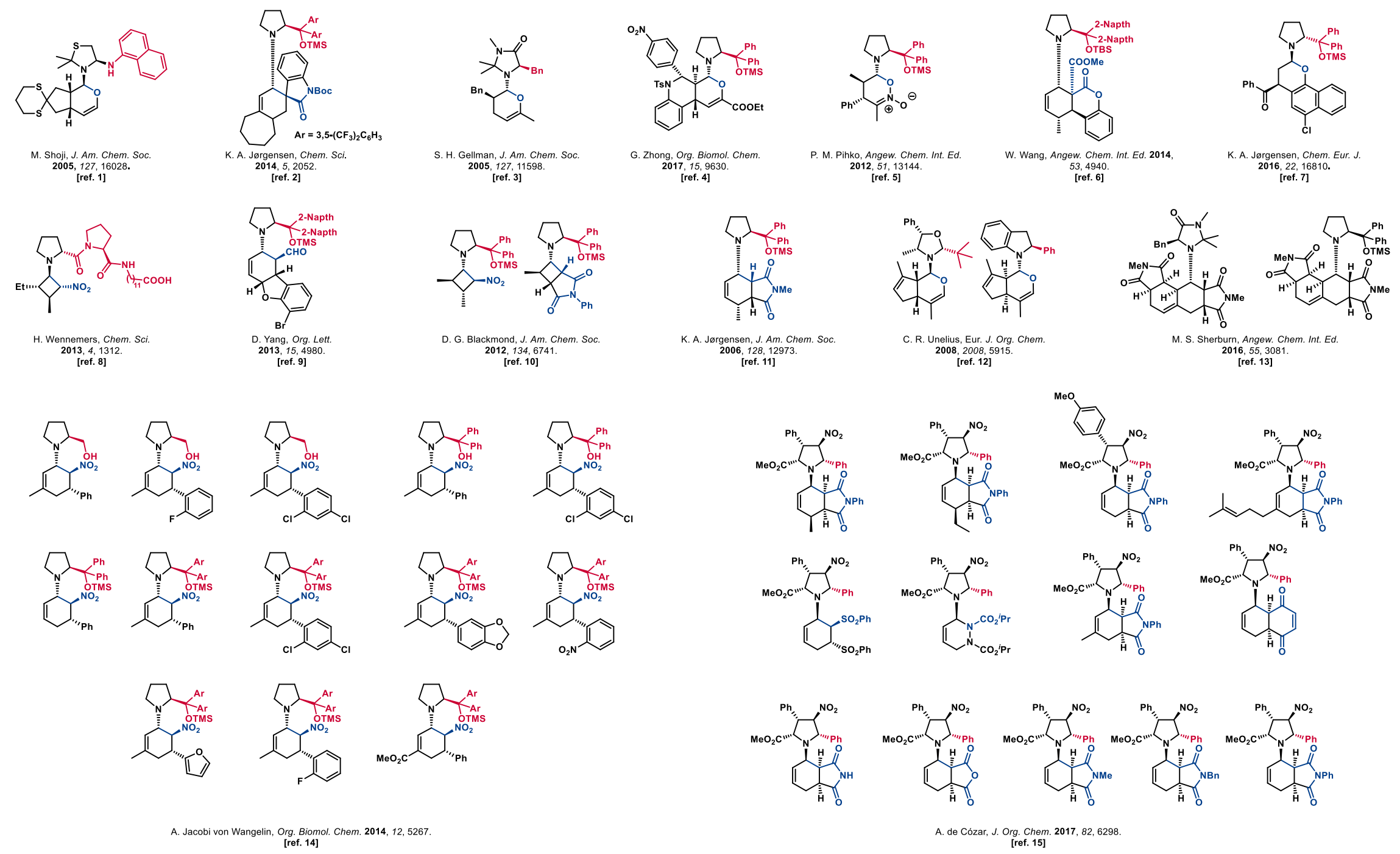

Figure S1. Intermediates involved in aminocatalytic reactions and analogous compounds arising from enamine activation. 

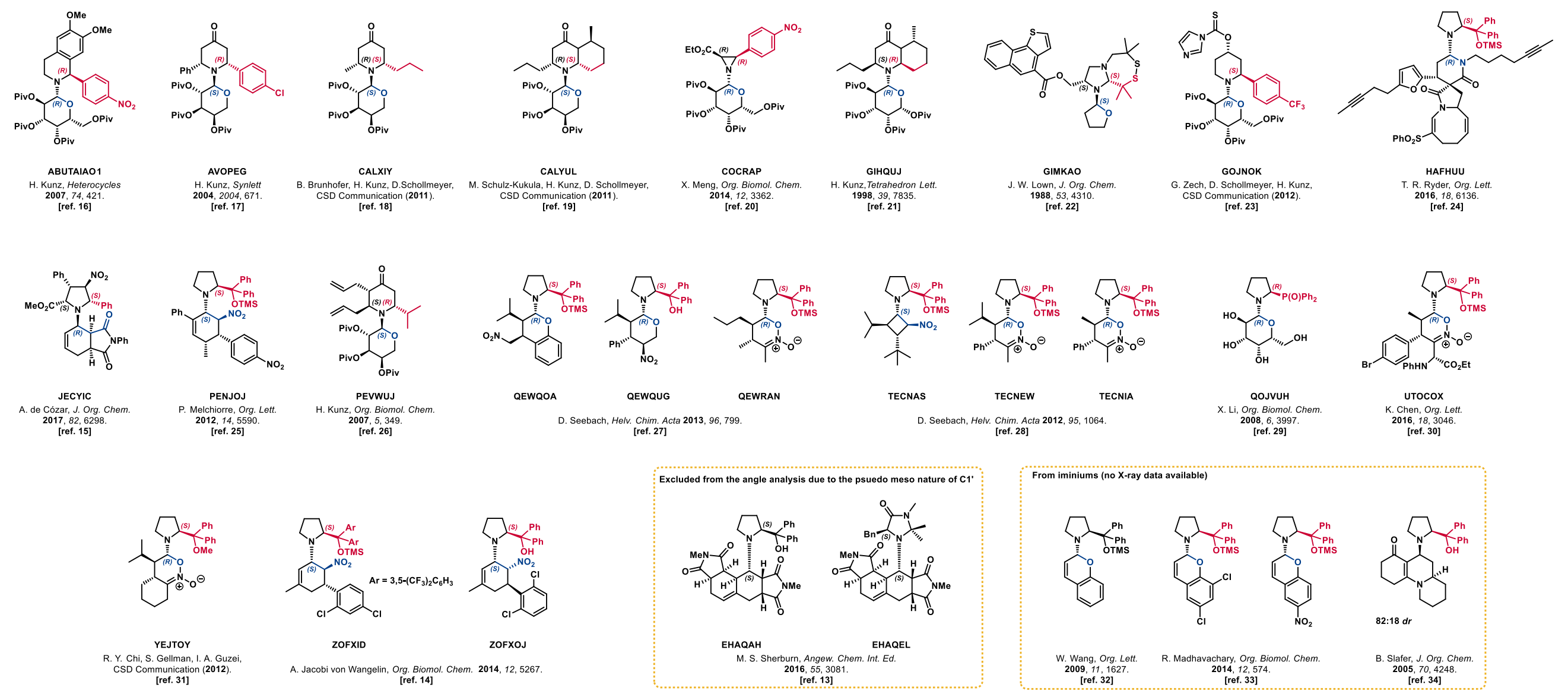

Figure S2. Structures that have been reported in high diastereopurity in the literature that arise by iminum or enamine modes of reactivity or condensation. Structures from the CSD in which absolute stereochemistry can be extracted and bond angles measured. 


\section{CCDC structures}

\subsection{Searching the CCDC}

Compounds were first located using the Conquest application searching database version 5.4 (November 2018). In order to constrict our search, the following query (Query_1_367) was applied.<smiles>[R]C([R])[AlH]N([C@H]([Z])C)C([Z])([R])C</smiles>

3D

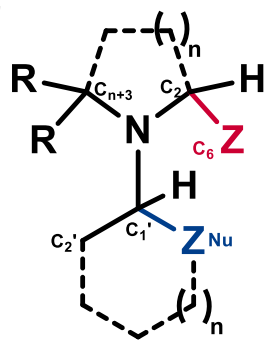

Figure S3. Criteria used in the CCDC search.

This is shown above in which $\mathrm{R}=\mathrm{C}$ or $\mathrm{H}$ and $\mathrm{Z} \neq \mathrm{H}$, the nitrogen is 3 coordinate and part of a cycle which is attached to a second cycle i.e. $\mathrm{C}-\mathrm{C}(\mathrm{H})-\mathrm{Z}$ form a cyclic system (Figure S3). This search returned 367 hits in total. From this hits, structures were manually removed based upon the unfulfilment of any of the following criteria:

1) The nitrogen containing ring was chiral.

2) This chirality was due to substitution $\alpha$ to the $N$.

3) The second (carbon containing) cycle was chiral.

4) $Z$ was a suitable leaving group/able to stabilize a negative charge.

\subsection{Results from Conquest search}

Applying the above search criteria, we then carried out angle analysis on all chemically distinct molecules with coordinates (25 compounds). Due to the pseudo symmetry in either the amine ring or the ring bonded to the amine, 3 compounds (AVOPEG, EHAQAH and EHAQEL, Figure S4) were excluded from angle analysis and so analysis was undertaken on 22 compounds. 


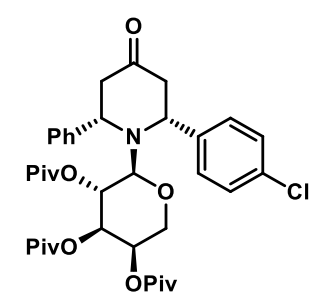

AVOPEG

H. Kunz, Synlett 2004, 2004, 671 . [ref. 17]

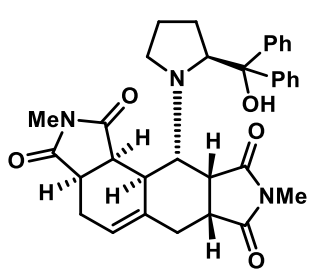

EHAQAH

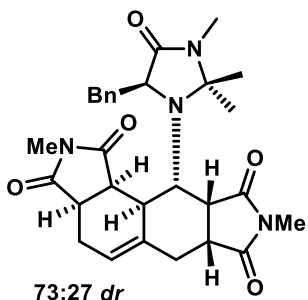

EHAQEL

M. S. Sherburn, Angew. Chem. Int. Ed. 2016, 55, 3081. [ref. 13]

Figure S4. Compounds excluded for the analysis.

When inspecting the X-ray structure of compounds, it became apparent that all adopt the same conformation and configuration (Figure S5). Crucially:

1) $\mathrm{N}$ was pyramidalized, with its configuration set by the steric unit

2) Hyperconjugation with the nitrogen lone pair (invisible by X-ray analysis but inferred by orientation of $\mathrm{C1}^{\prime}, \mathrm{C} 2$ and $\mathrm{C}_{\mathrm{x}}$ ) donated into the $\sigma^{*}$ of the $\mathrm{C} 1^{\prime}-\mathrm{Z}$ bond ( $\mathrm{Z}$ being the group able to stabilize the negative charge)

3) C1' has stereochemistry such that locates the newly formed ring in the less sterically encumbered side of the amine ring.

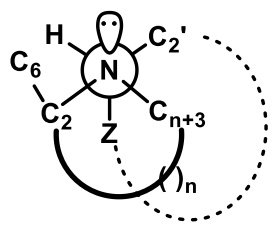

Figure S5. Conformation and configuration that most of the x-ray compounds adopted.

In order to quantify these structural features, we set out to measure 3 angles (Figure S6).
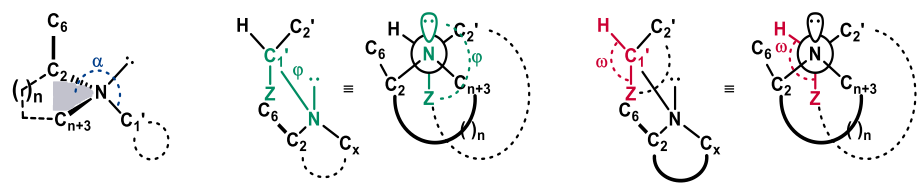

Figure S6. Structural features responsible for the predominance of diastereoisomers.

In order to demonstrate that the steric unit $C_{6}$ was on the same face as the lone pair and that the nitrogen was pyramidalized, we measured the angle $\alpha$ between the plane of $C_{2}-N-C_{x}$ and $C_{1}$. This was done by creating a plane between $\mathrm{C}_{2}-\mathrm{N}-\mathrm{C}_{\mathrm{x}}$. By measuring the perpendicular distance from $\mathrm{C}_{1}{ }^{\prime}$ to this plane and the $\mathrm{C}_{1}^{\prime}-\mathrm{N}$ bond length, we were able to calculate this acute internal angle. Adding $180^{\circ}$ to complete the angle from the plane of $\mathrm{C}_{2}-\mathrm{N}-\mathrm{C}_{\mathrm{x}}$ to $\mathrm{C}_{1}{ }^{\prime}$ led to $\alpha$. 
In order to demonstrate the effective overlap of the lone pair of the $\mathrm{N}$ into the $\sigma^{*}$ of $Z$ (the group able to stabilize the negative charge), we measured the torsions $Z-C_{1}{ }^{\prime}-N-C_{2}$ and $Z-C_{1}{ }^{\prime}-N-C_{x}$ and averaged these to infer the torsion $\mathrm{Z}-\mathrm{C}_{1}{ }^{\prime}-\mathrm{N}-\mathrm{Ip}(\varphi)$.

Finally, to show that the steric unit $\mathrm{C}_{6}$ dictated the orientation of the second cycle away from it, we measured the torsion between the planes $\mathrm{H}-\mathrm{C}_{1}{ }^{\prime}-\mathrm{N}$ and $\mathrm{Z}-\mathrm{C}_{1}{ }^{\prime}-\mathrm{N}(\omega)$.

\subsection{Construction of Figure $2 a$ in the main manuscript}

a) The configuration of the $\mathrm{N}$ atom is controlled by the amine substituent

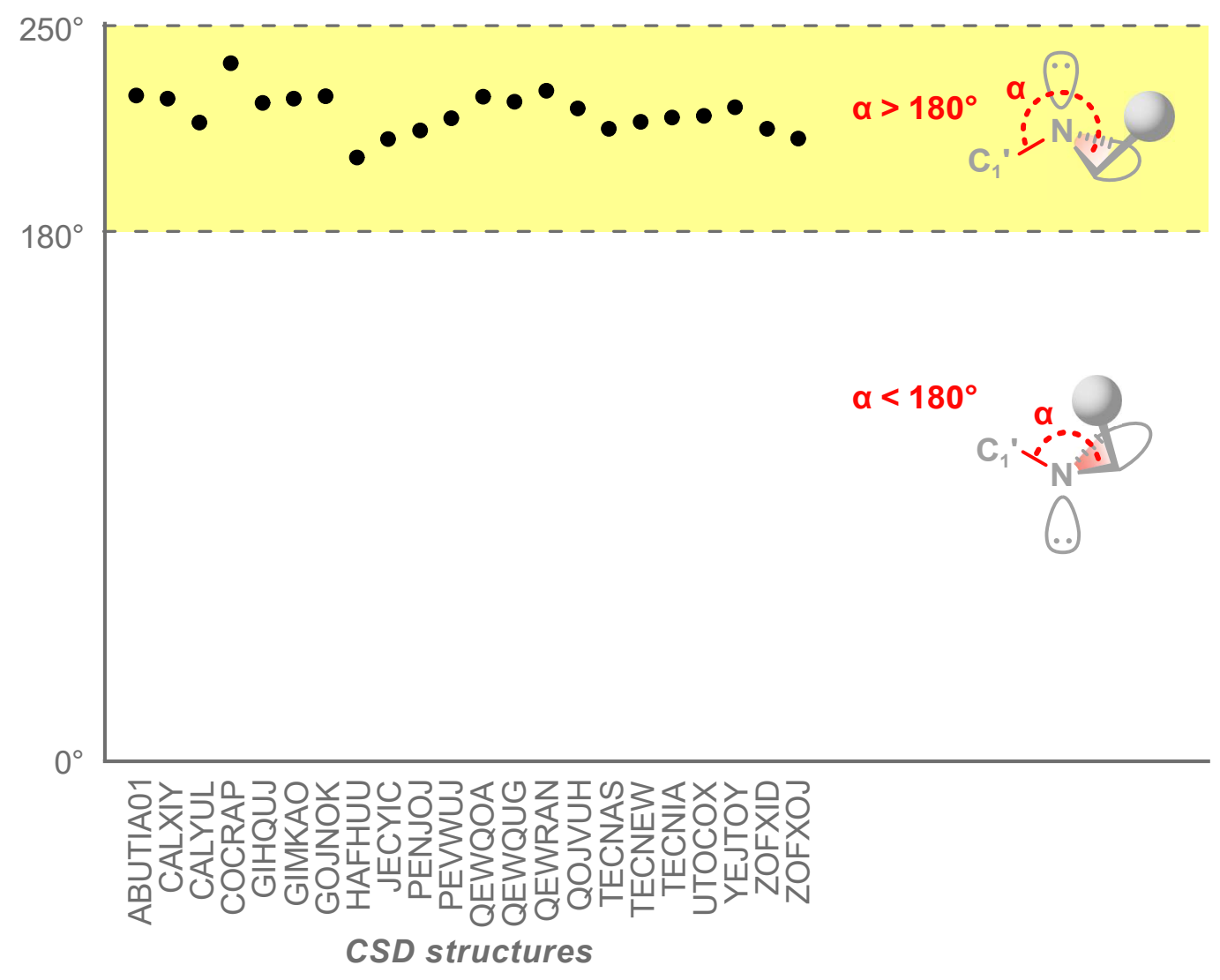

Figure S7. The configuration of the $N$ atom is controlled by the amine substituent. 
Table S1. Angles measured where the nitrogen of the aminocatalyst is pyramidalized and adopts the configuration that minimizes the steric clash of the substituent/s in the aminocatalyst and the new ring.

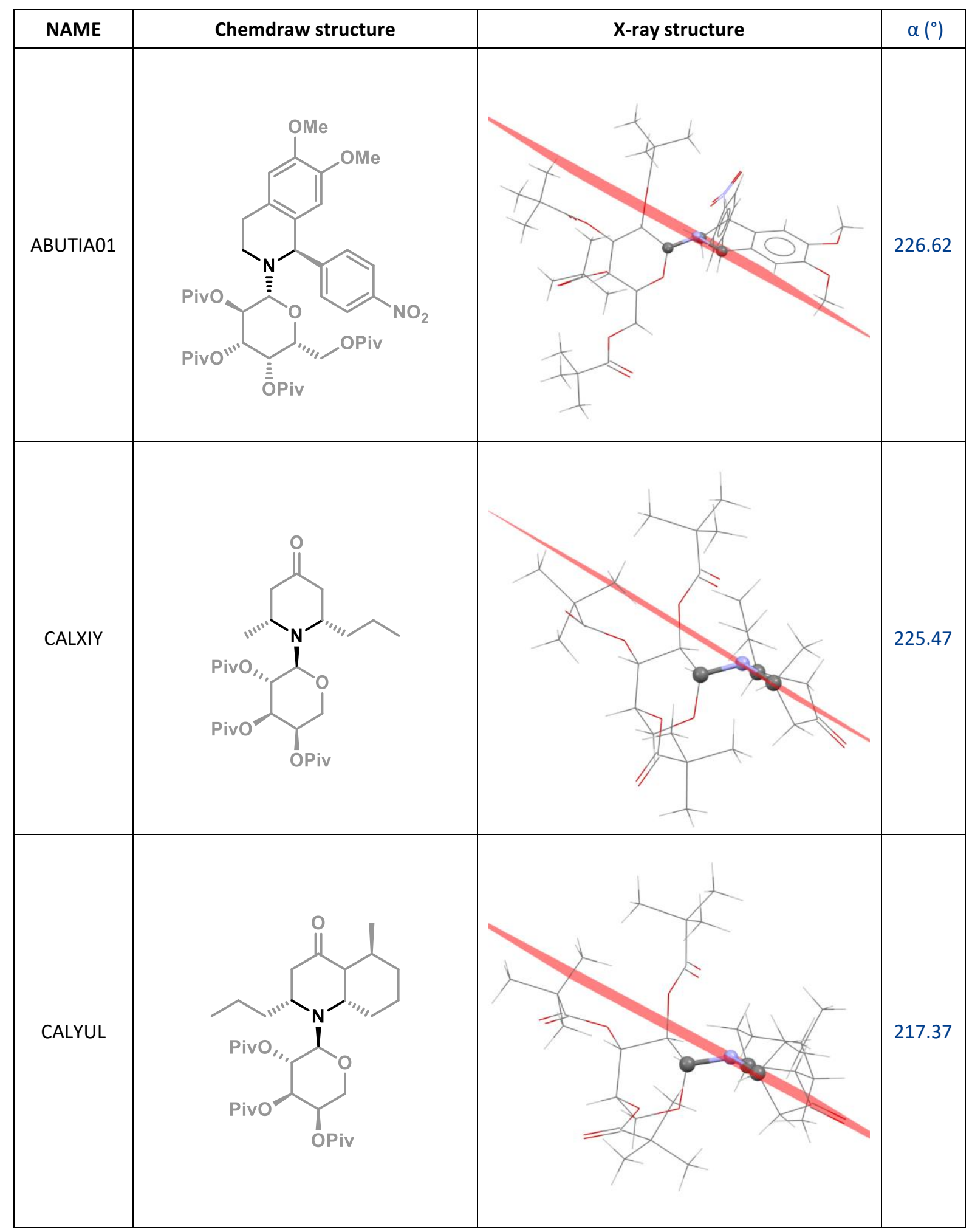




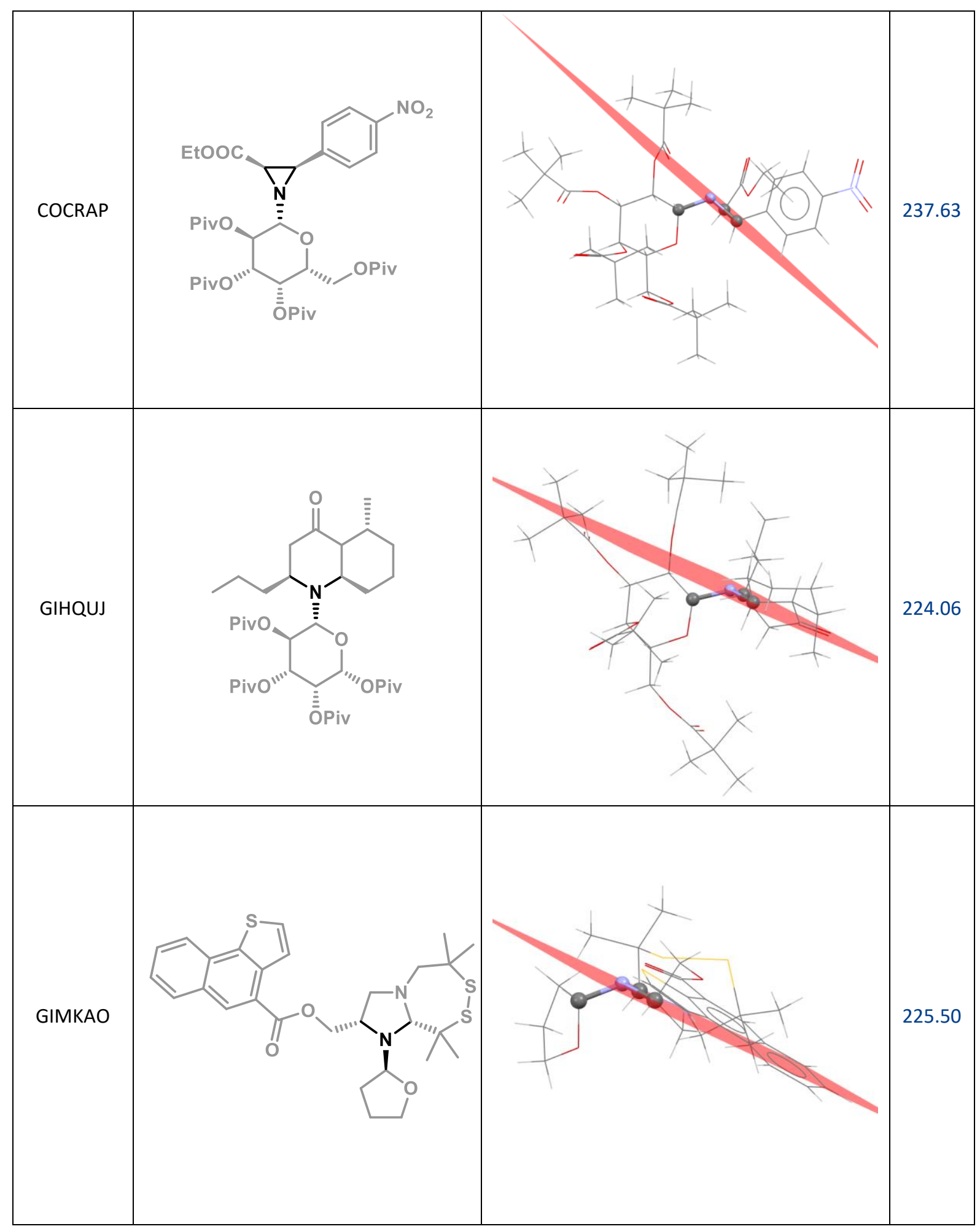




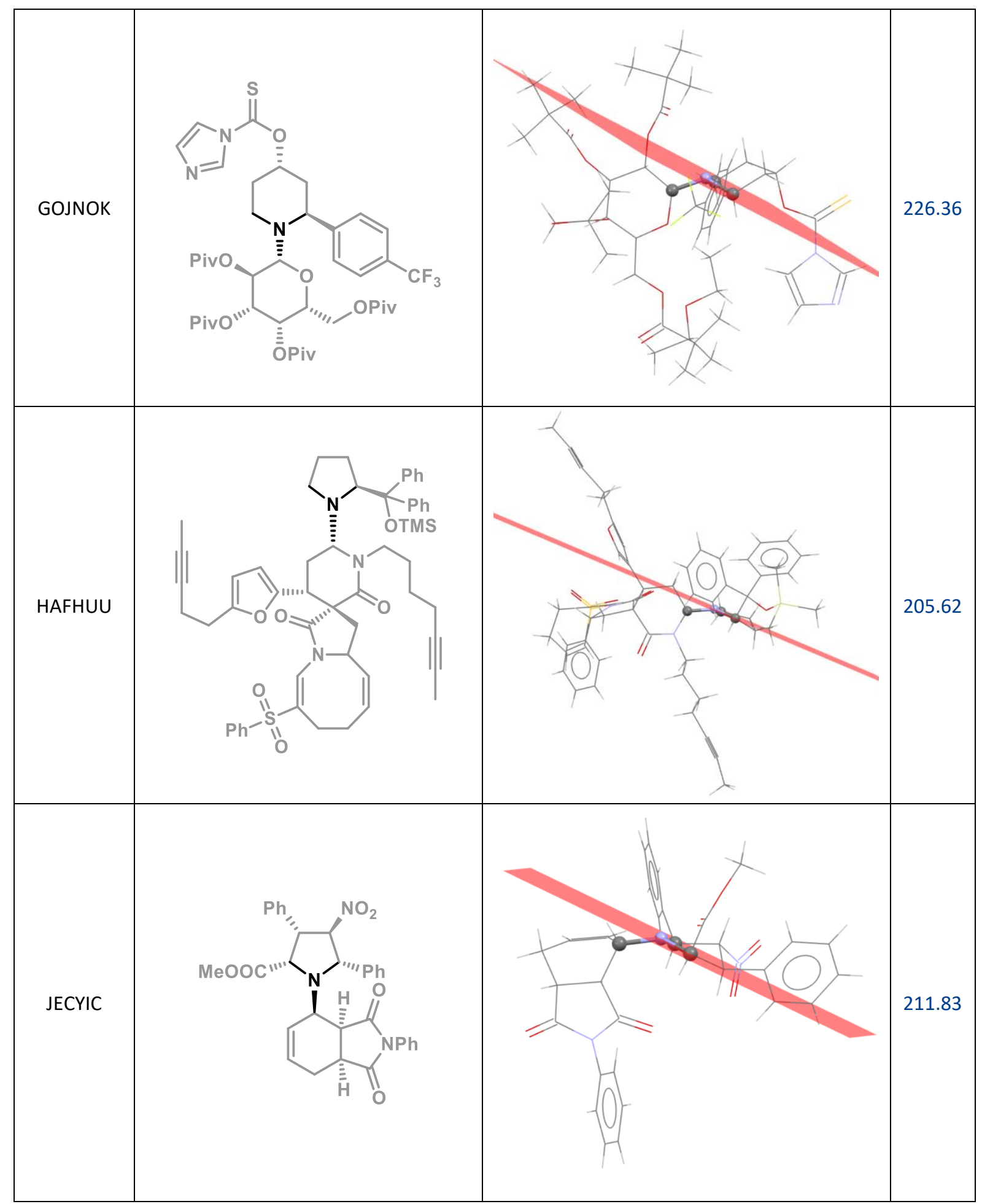




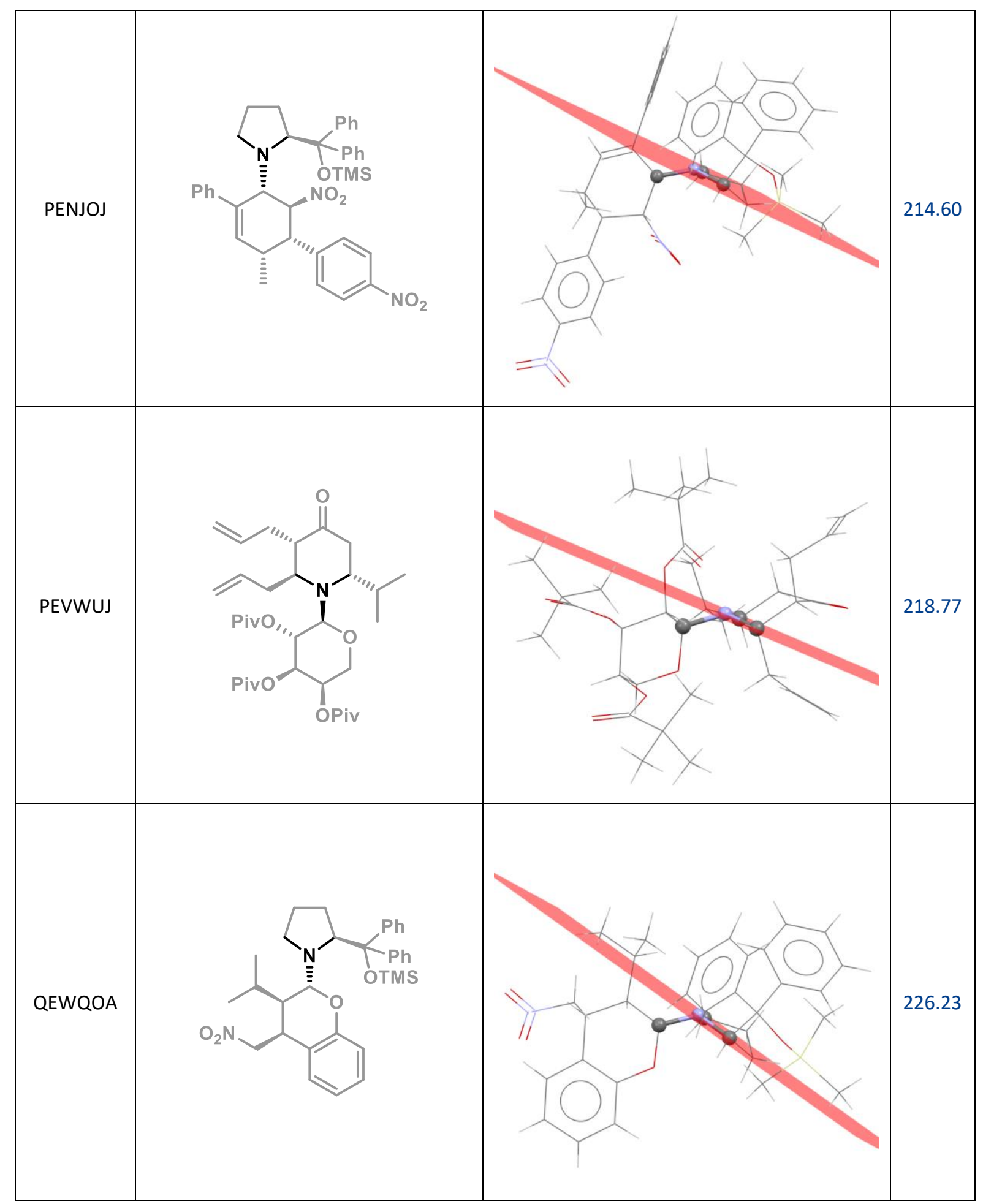




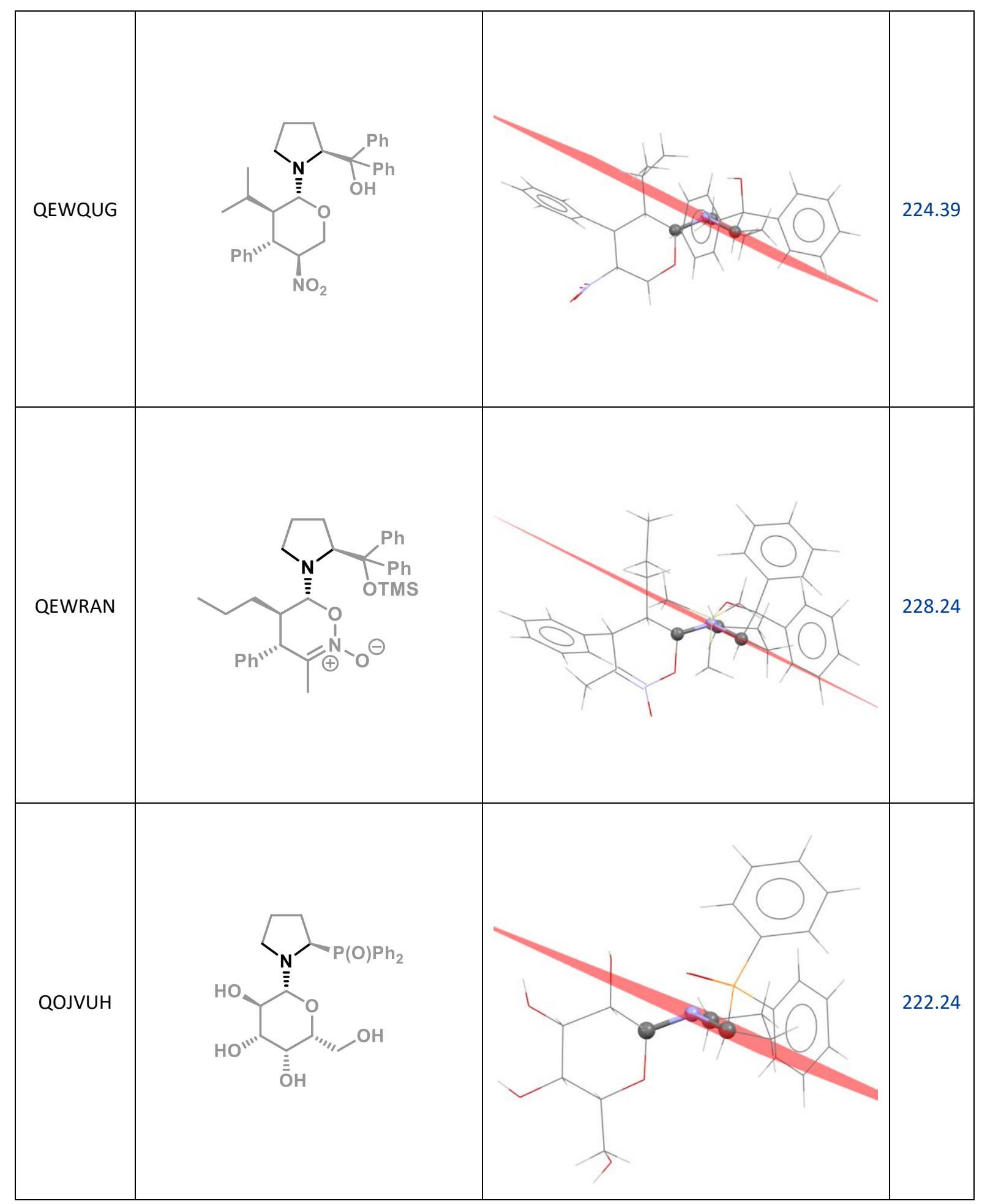




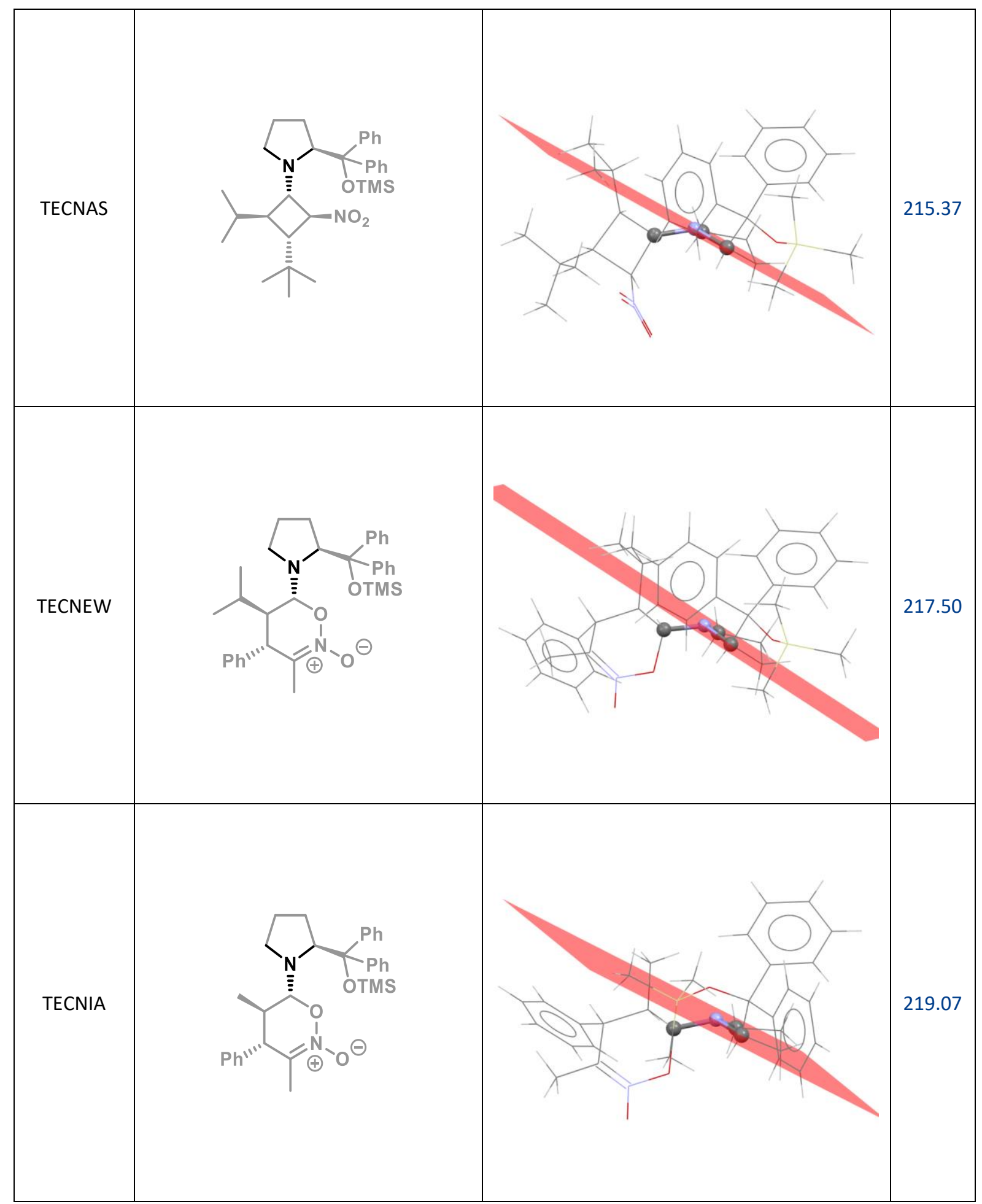




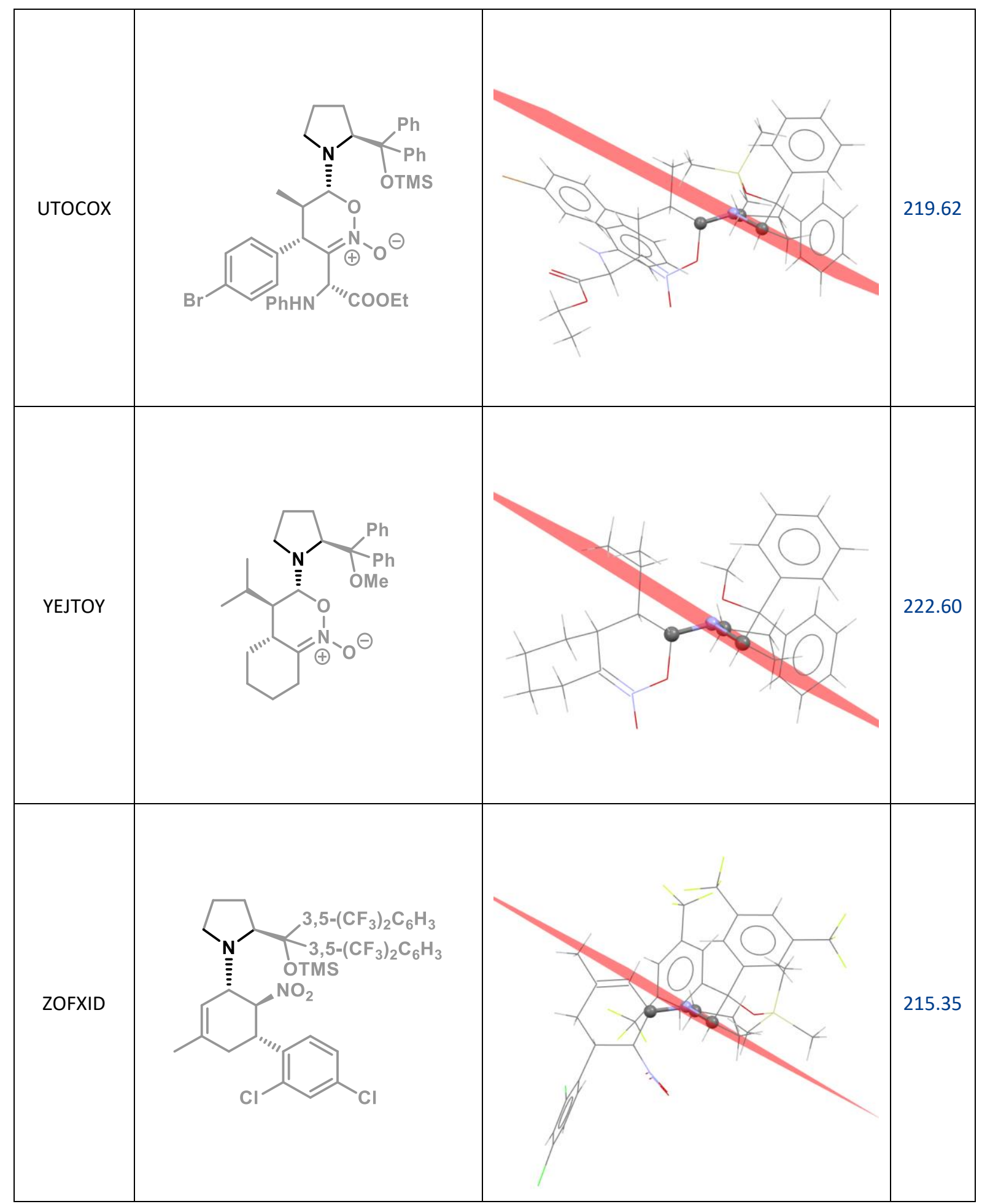




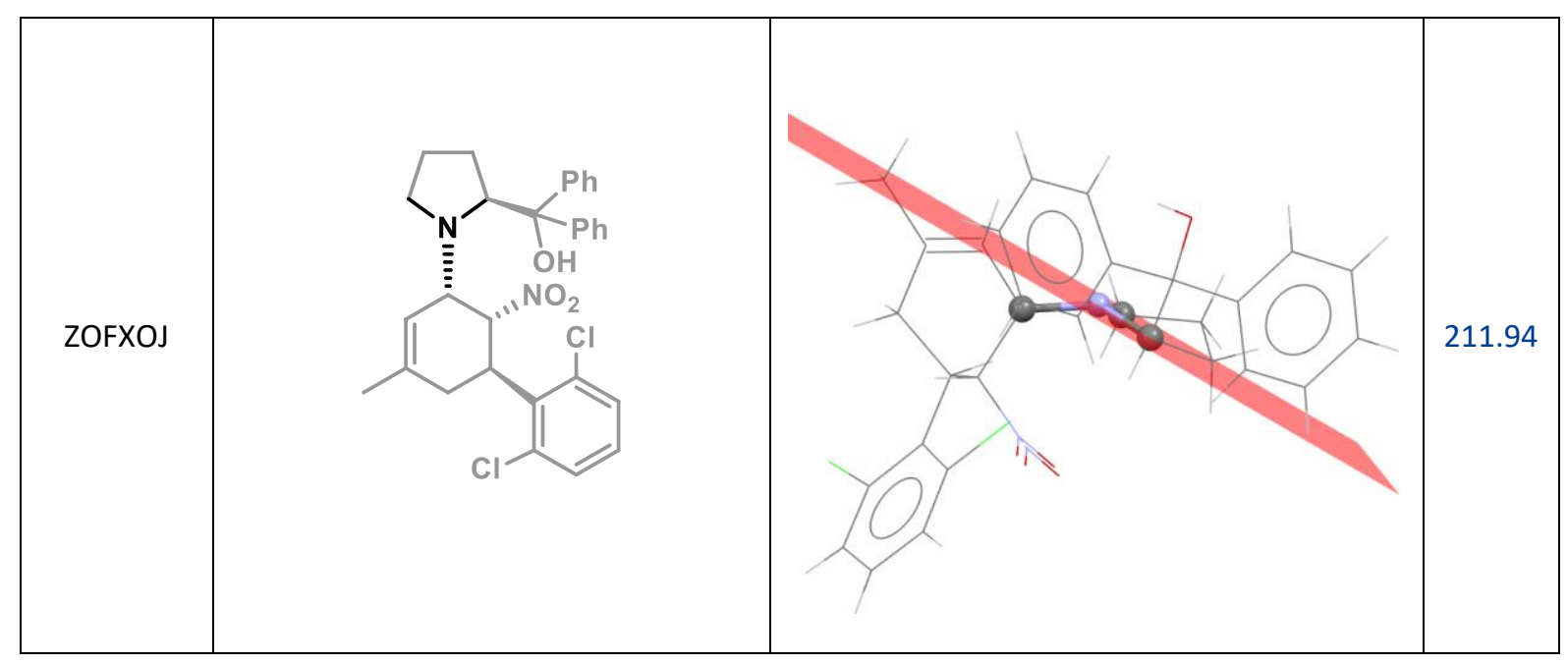


2.4. Construction of Figure $2 \mathrm{~b}$ in the main manuscript

b) There is hyperconjugation of the $n(N)$ with the $\sigma^{*}\left(C 1^{\prime}-N u\right)$

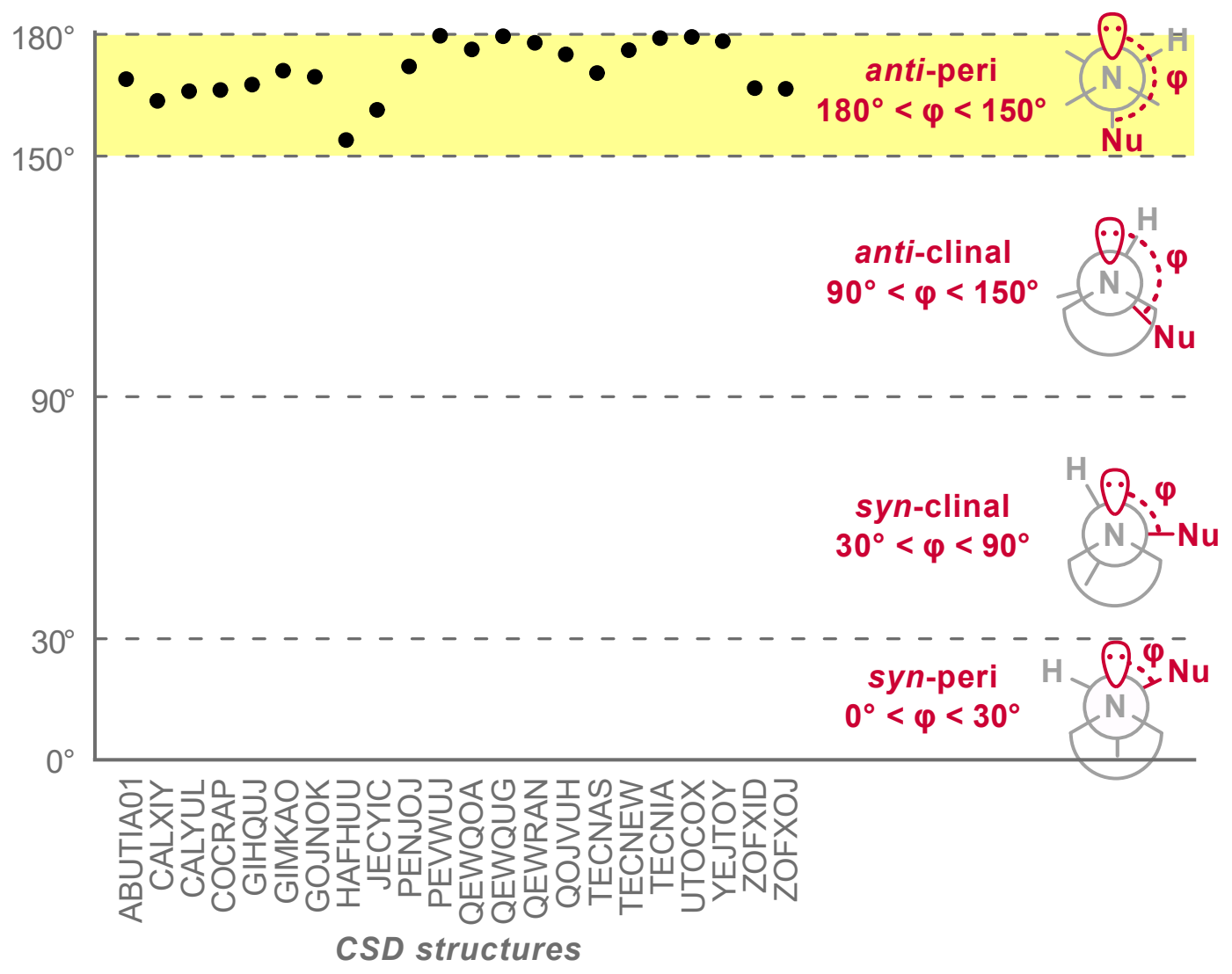

Figure S8. Hyperconjugation of the $n(\mathrm{~N})$ with the $\sigma^{*}\left(\mathrm{C} 1^{\prime}-\mathrm{Nu}\right)$. 
Table S2. Angles measured where the nucleophile and the lone pair of the nitrogen are antiperiplanar, allowing the negative hyperconjugation of the lone pair orbital with the $\sigma^{*} \mathrm{C1} 1^{\prime}-\mathrm{Nu}$

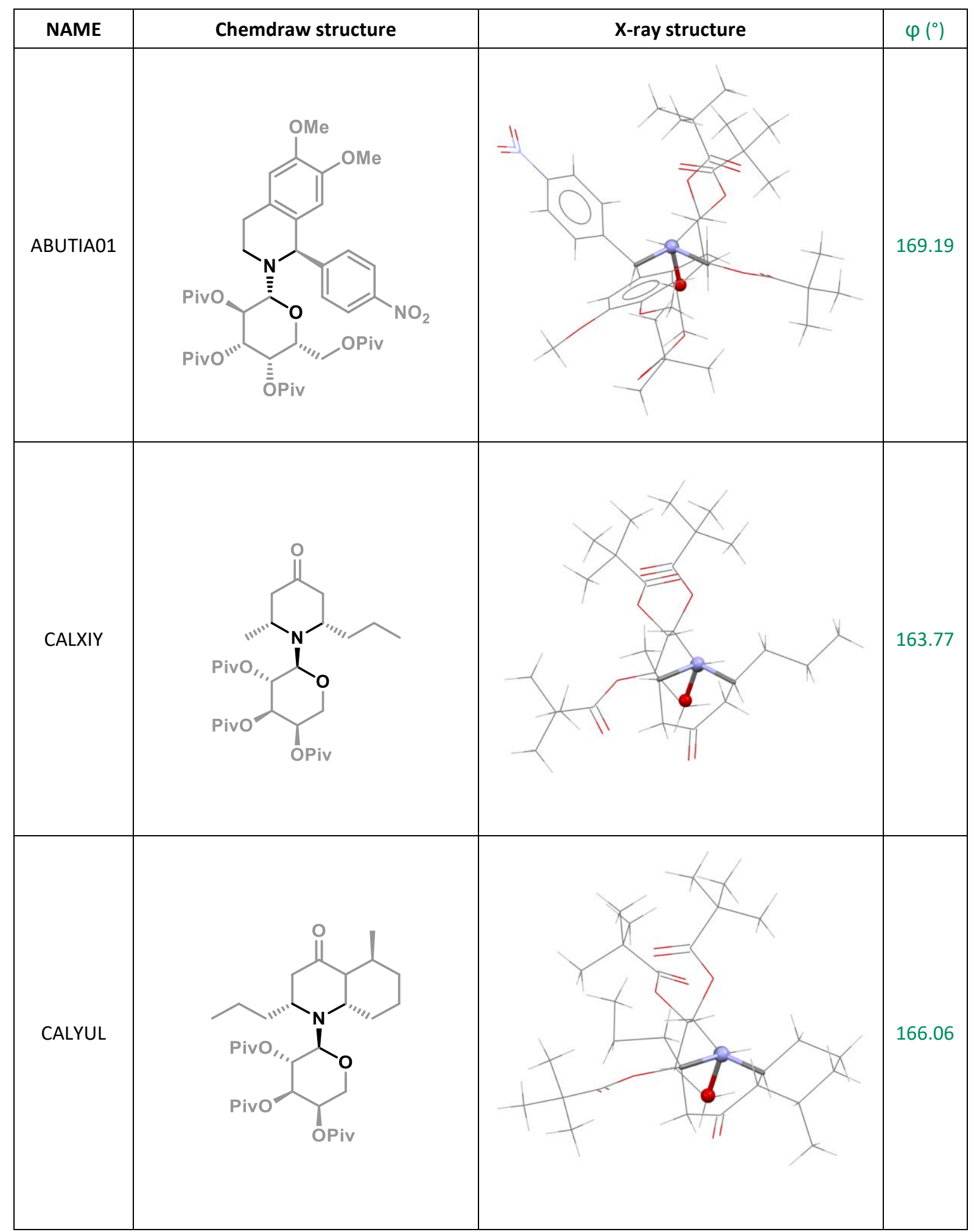




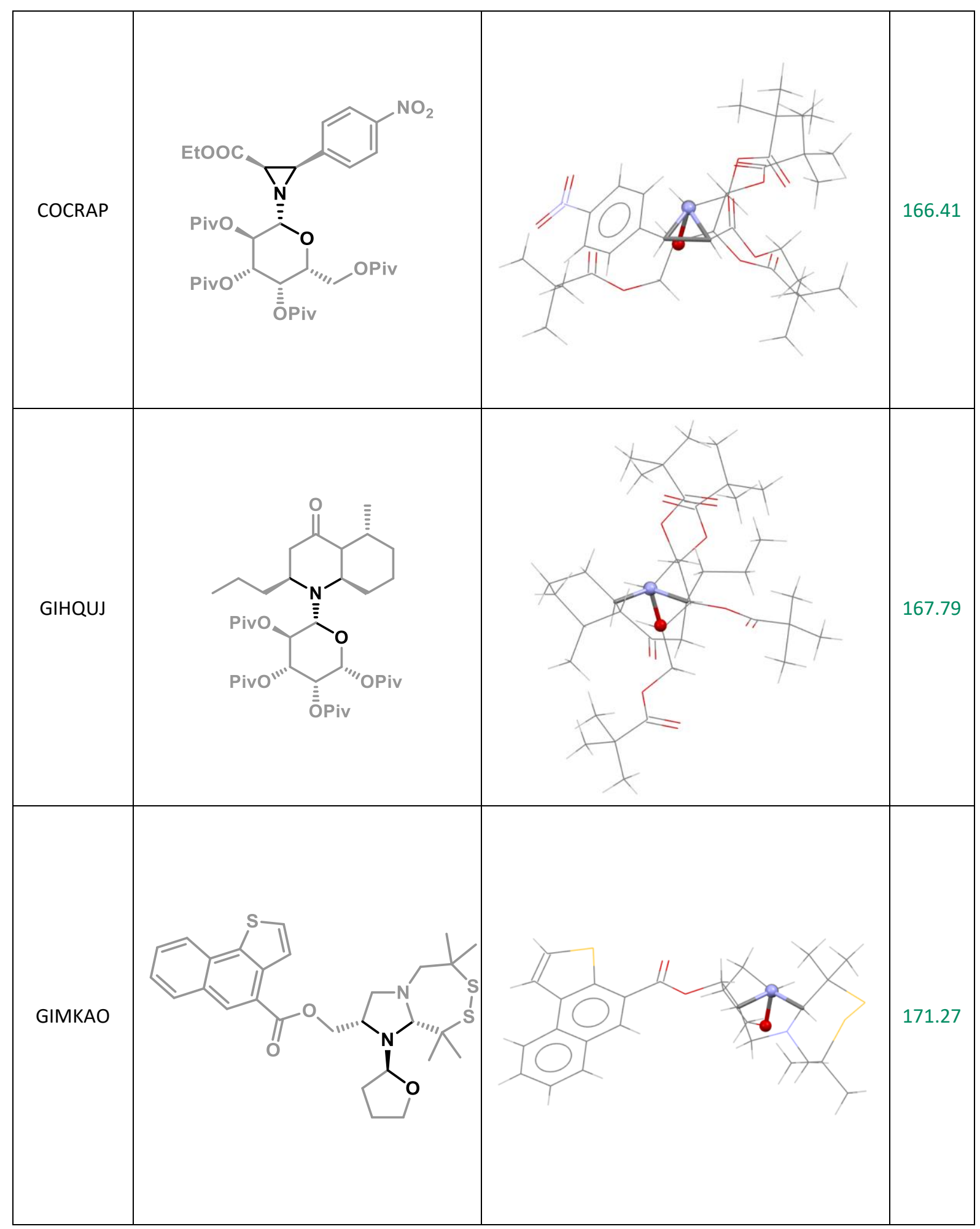




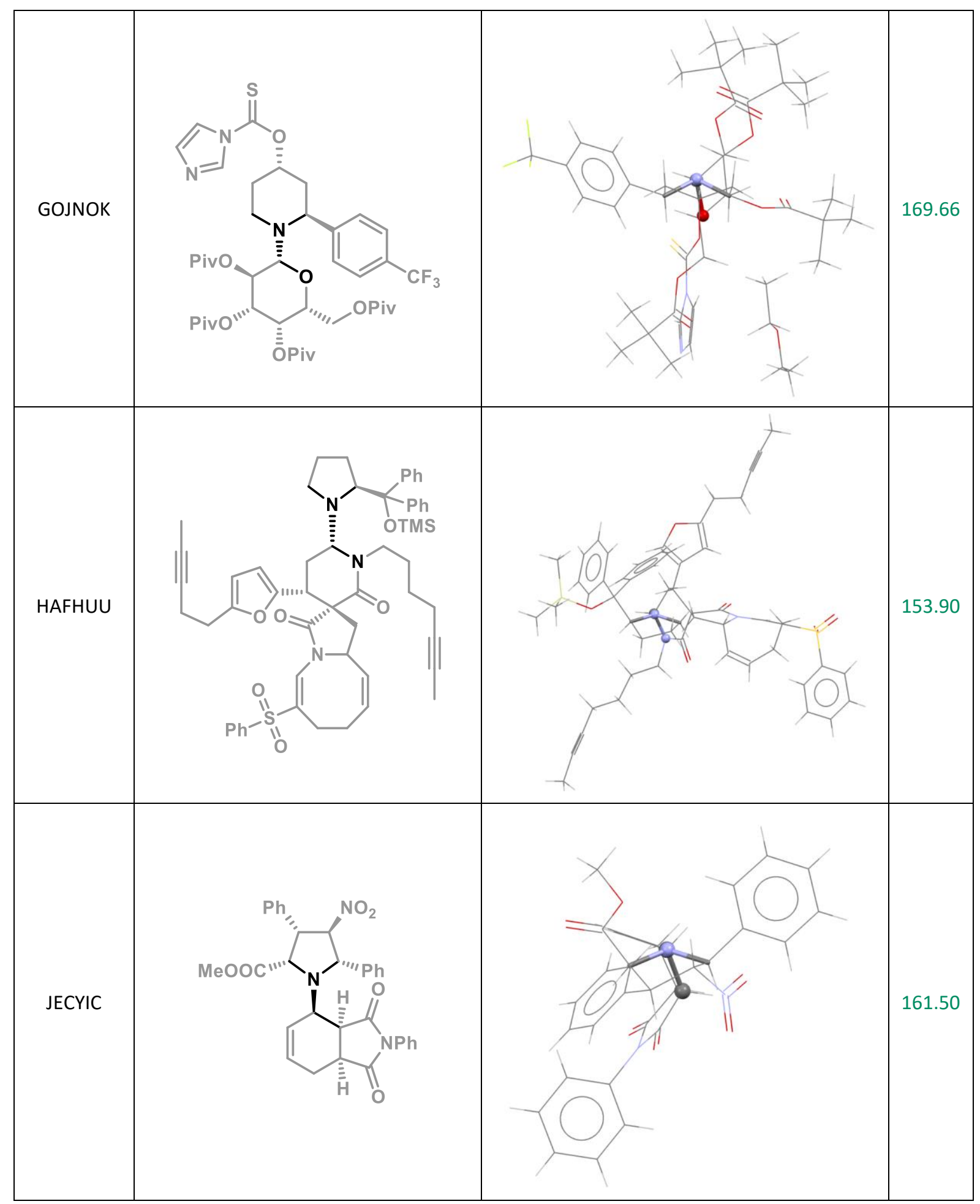




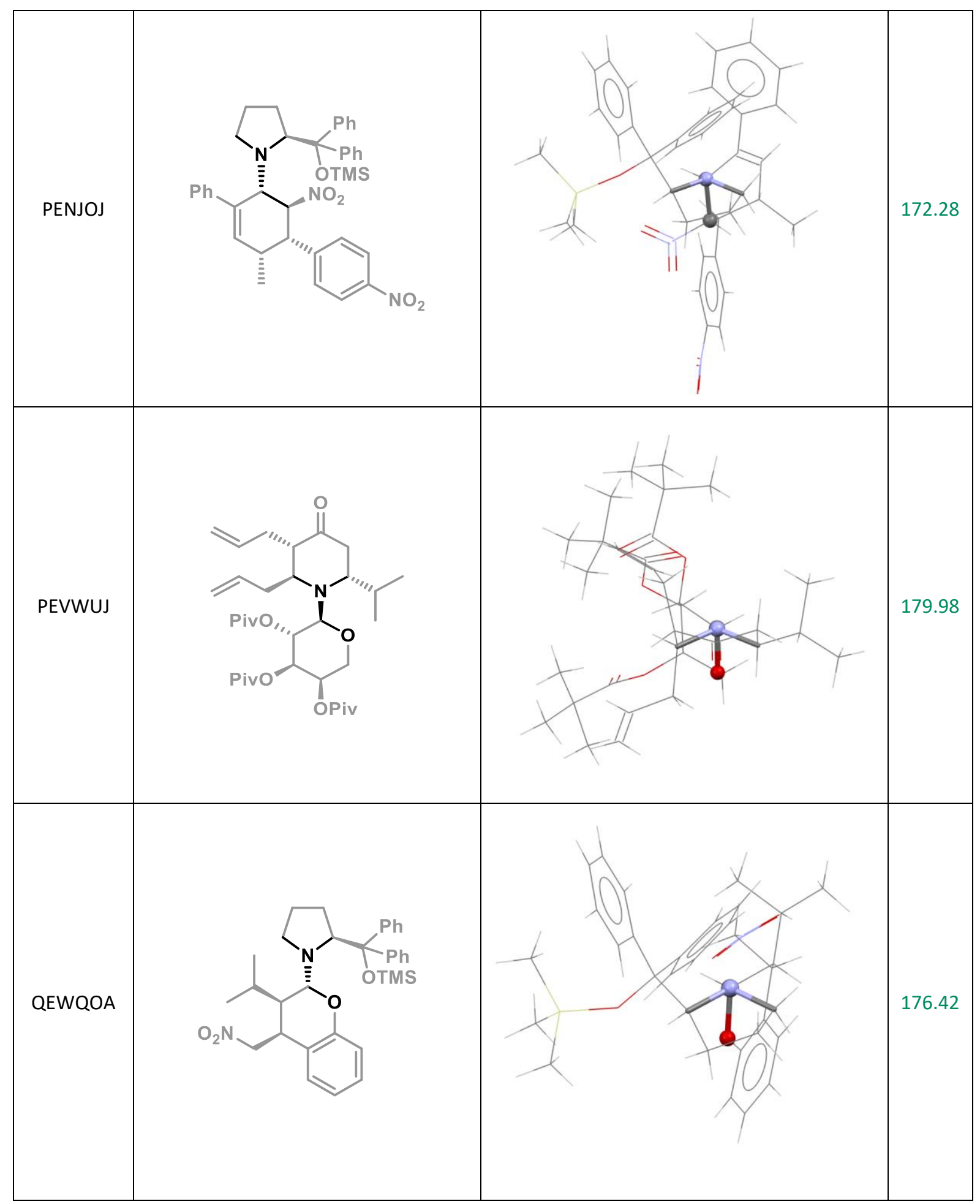




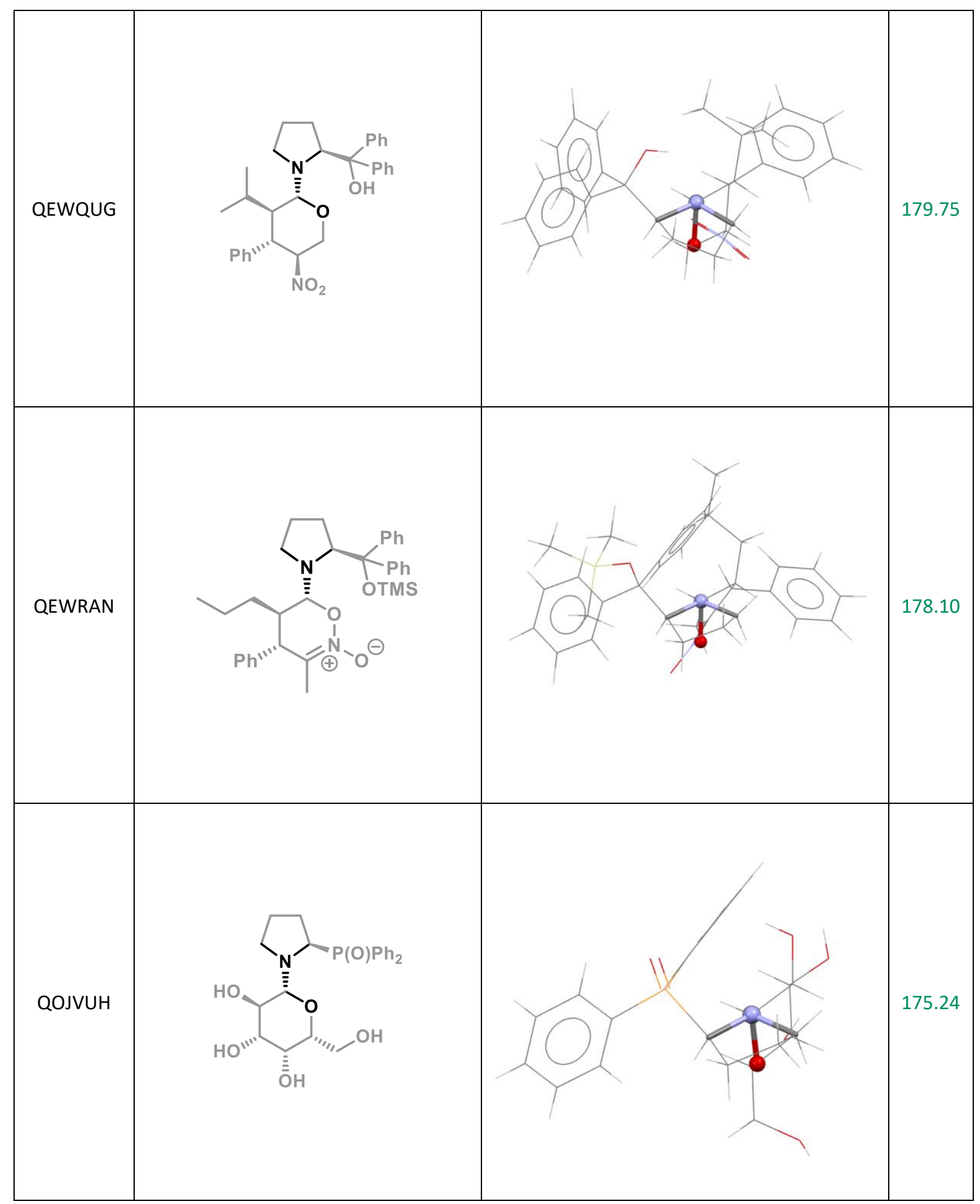




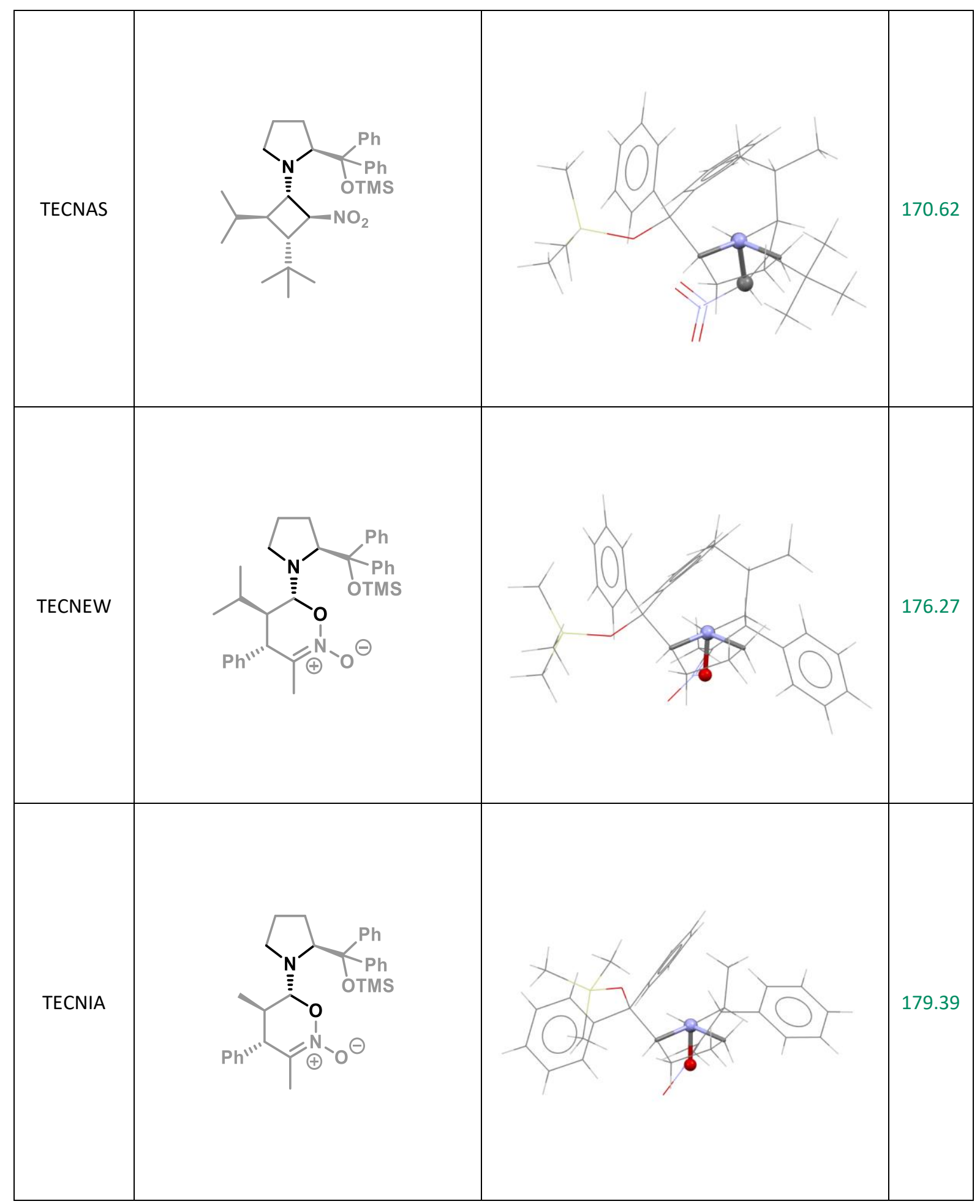




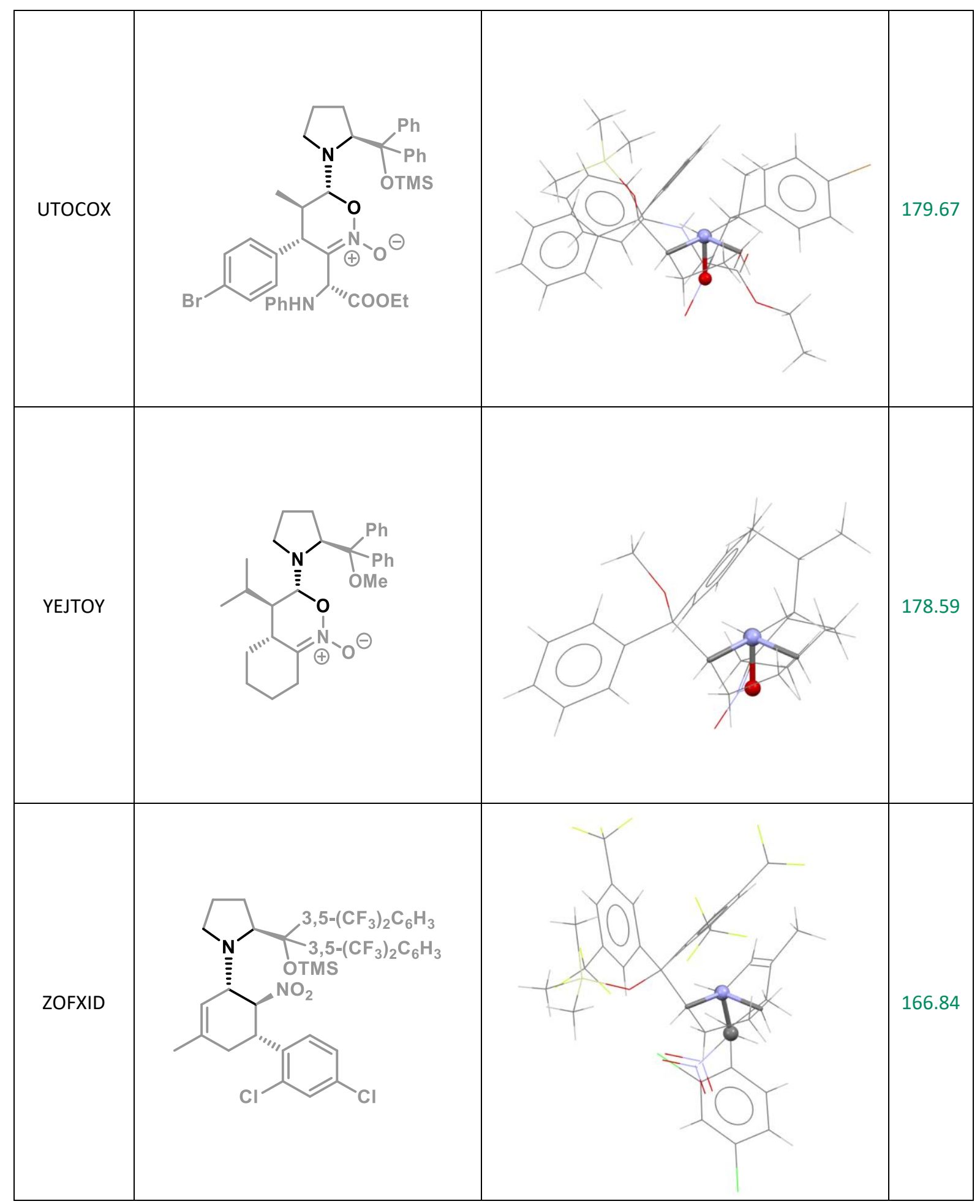




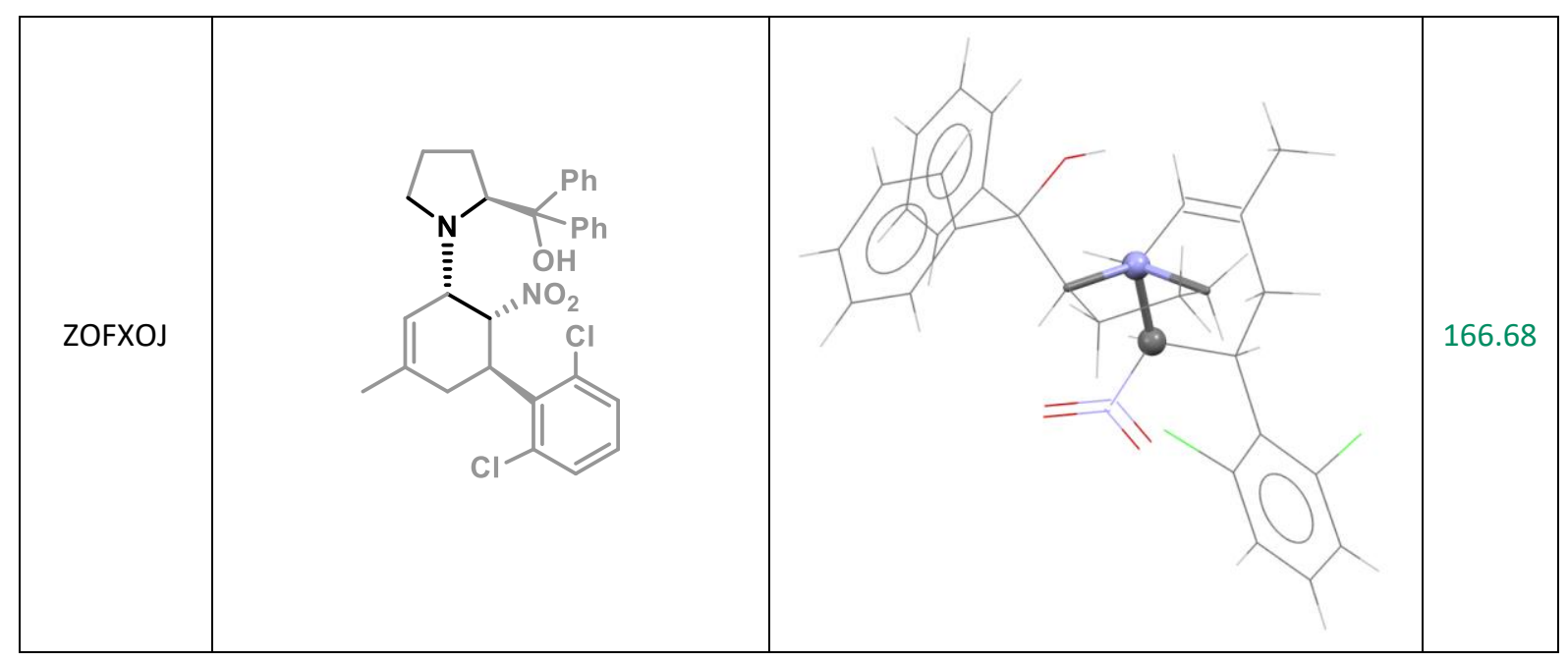


2.5. Construction of Figure $2 \mathrm{c}$ in the main manuscript

c) The hemiaminal carbon ( $\left.C 1^{\prime}\right)$ has the sterochemistry that locates the newly formed ring on the less sterically hindered side of the amine ring

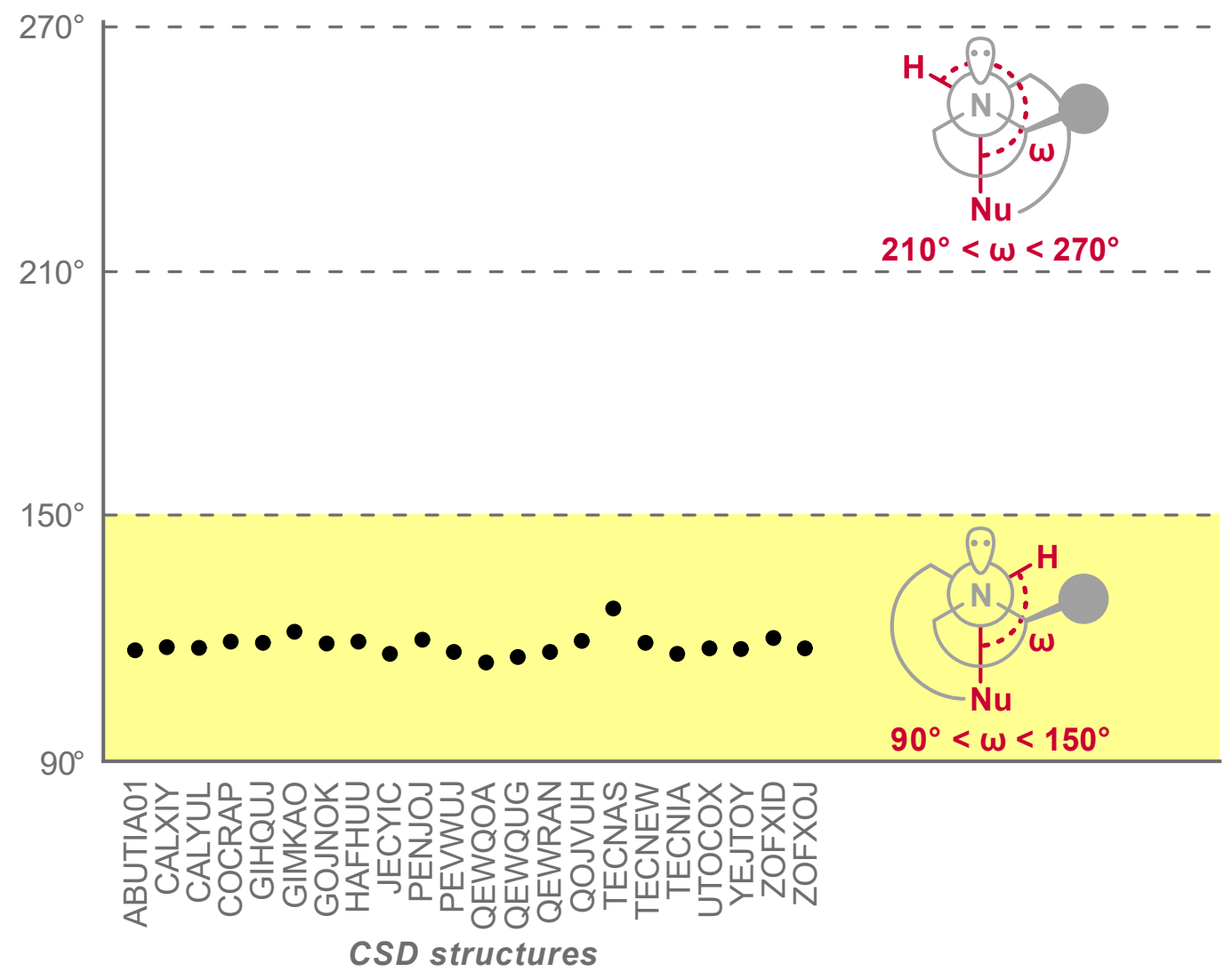

Figure S9. The hemiaminal carbon C1' has the stereochemistry that locates the newly formed ring on the less sterically hindered side of the amine ring. 
Table S3. Angles measured where is the configuration of $\mathrm{C1}^{\prime}$ is such that the newly formed cycle is located on the less sterically hindered side of the aminocatalyst, while maintaining the negative hyperconjugation between the lone pair orbital of the nitrogen and the $\sigma^{*} \mathrm{C} 1^{\prime}-\mathrm{Nu}$.

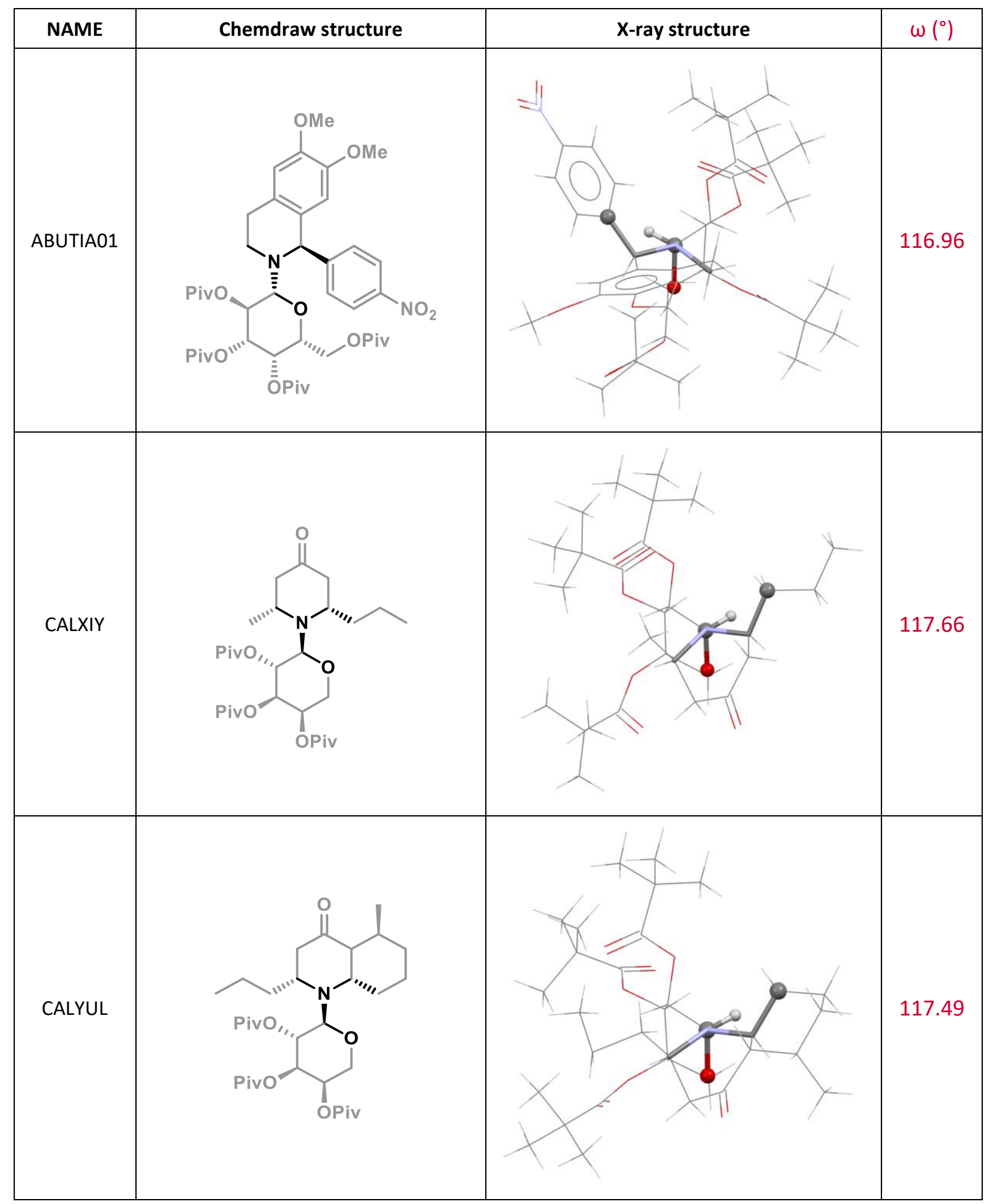




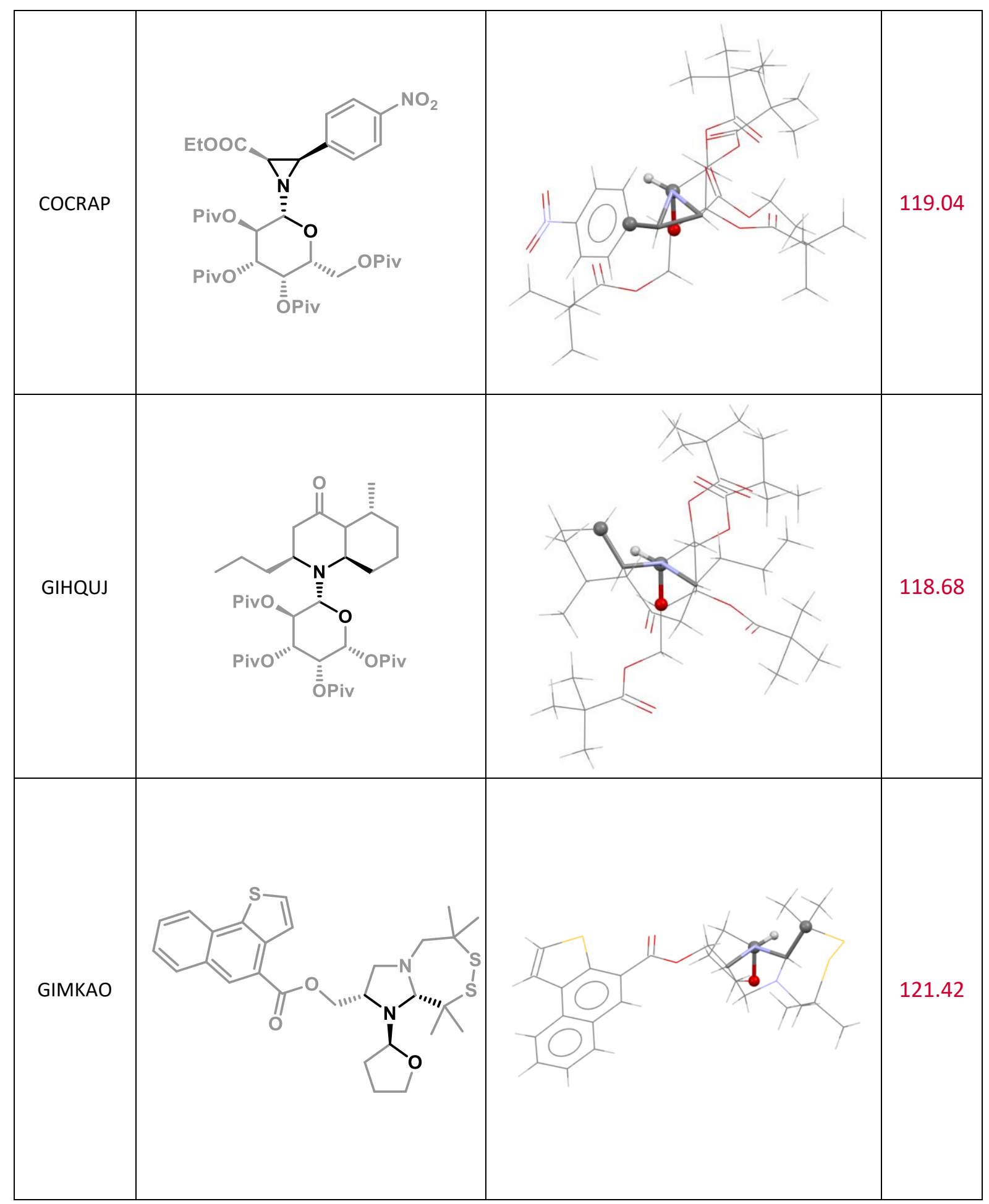




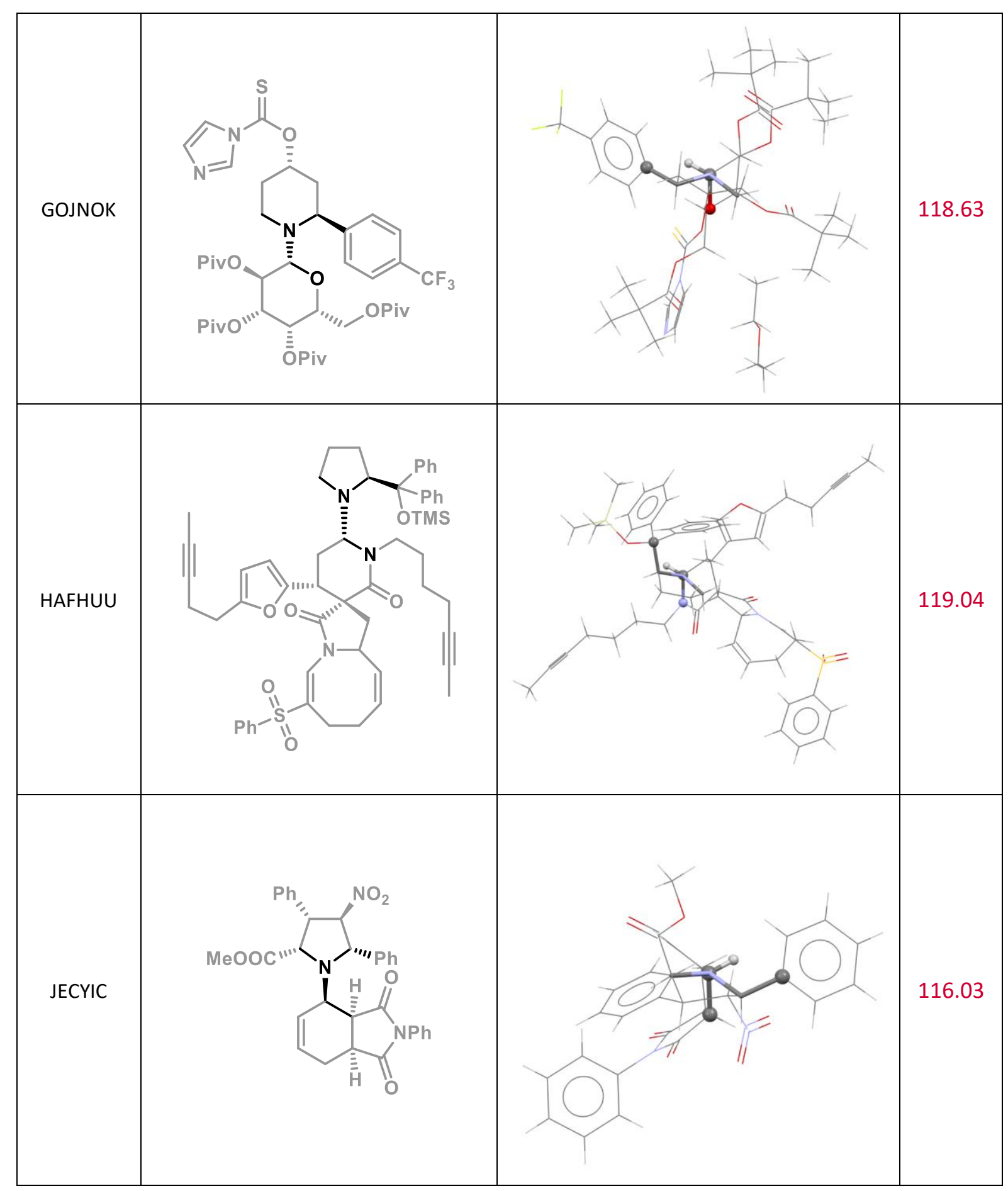




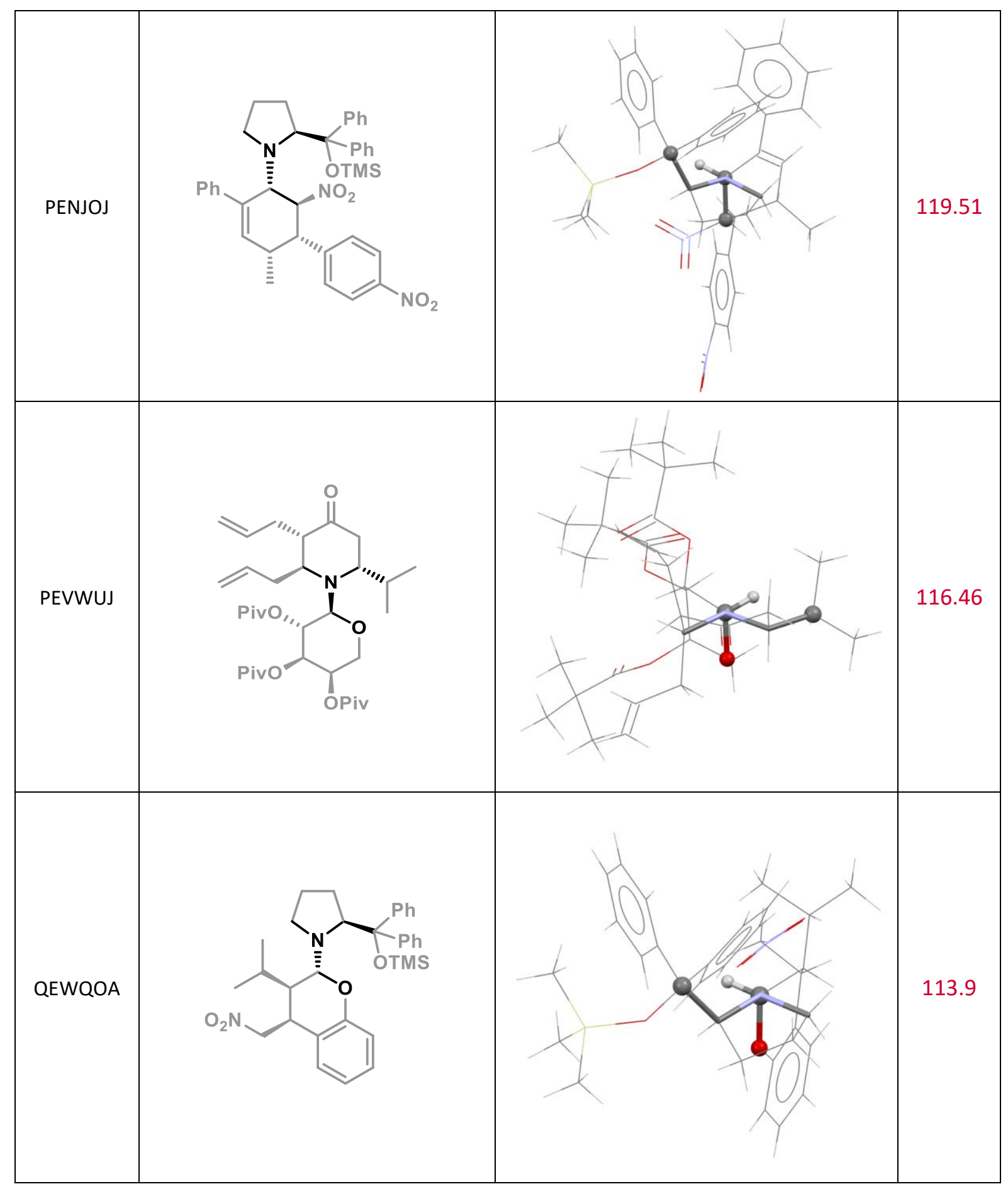




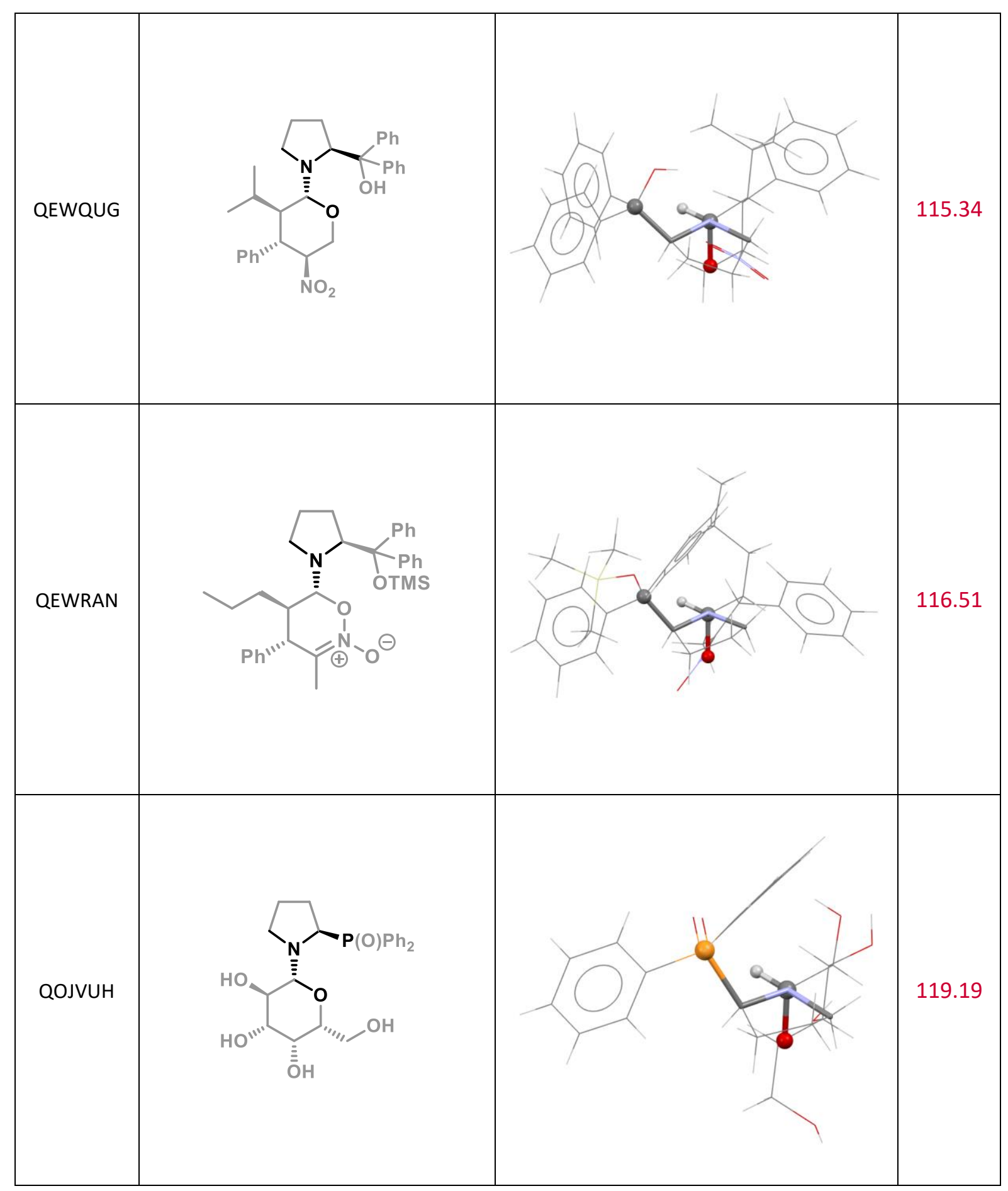




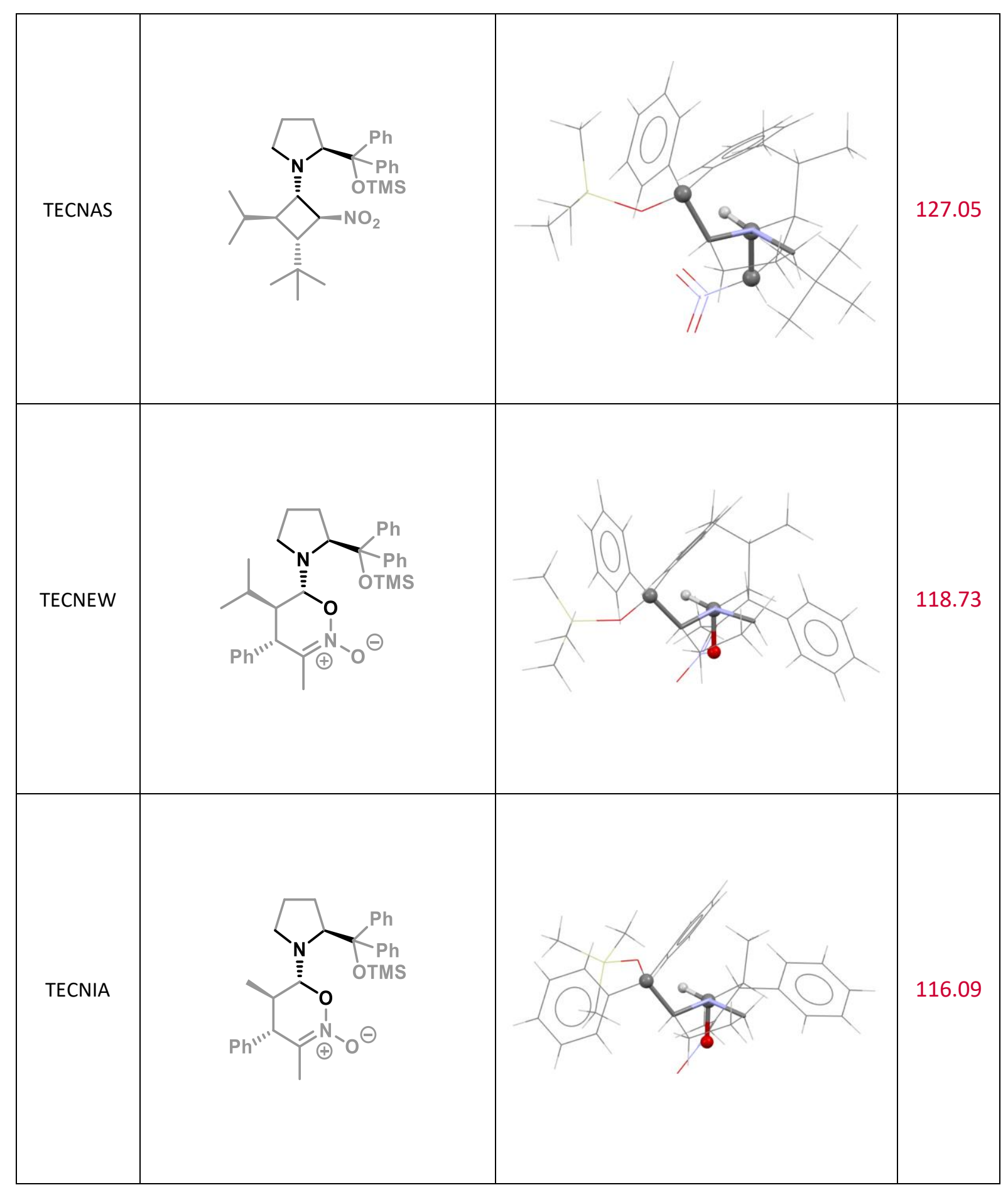




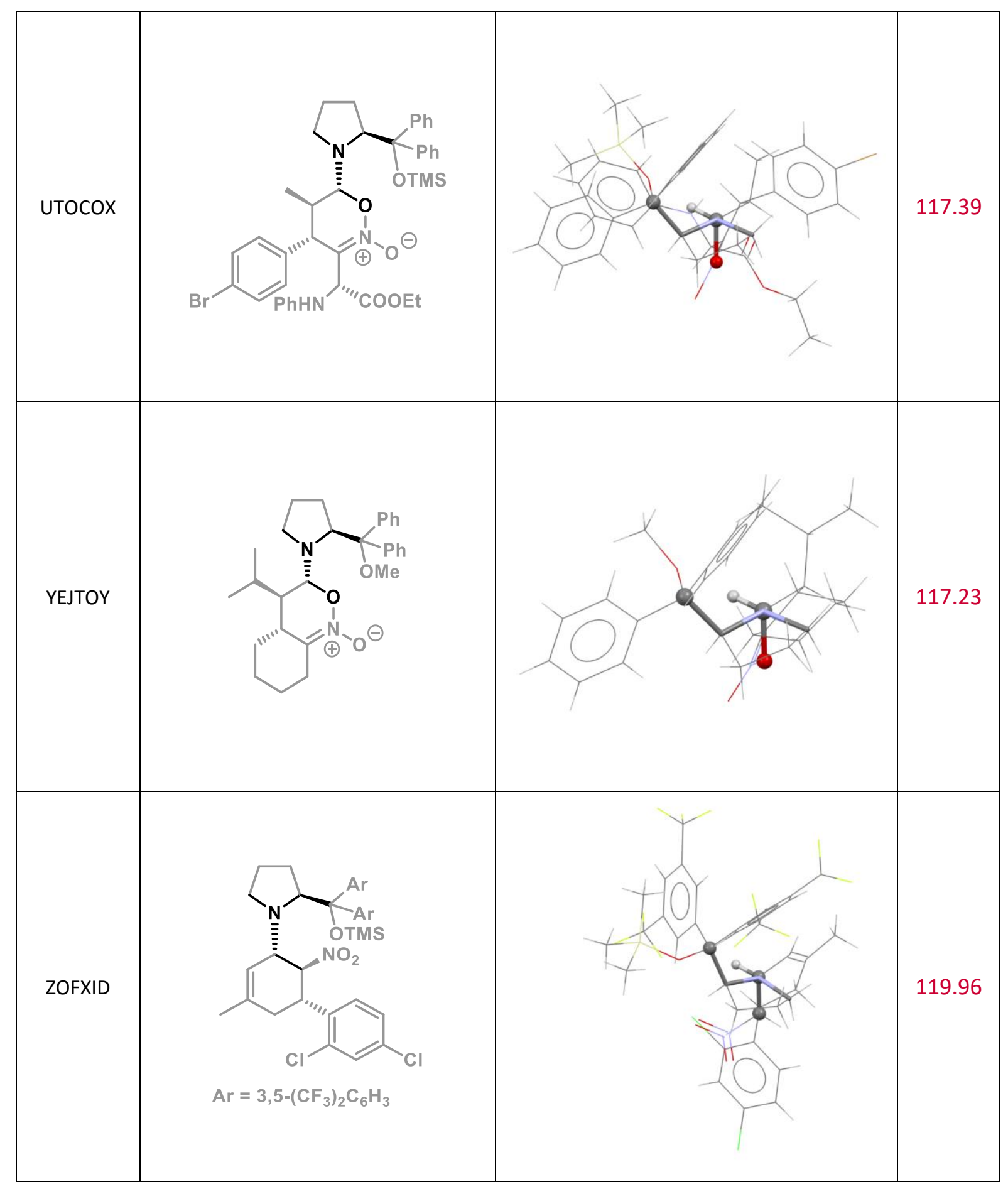




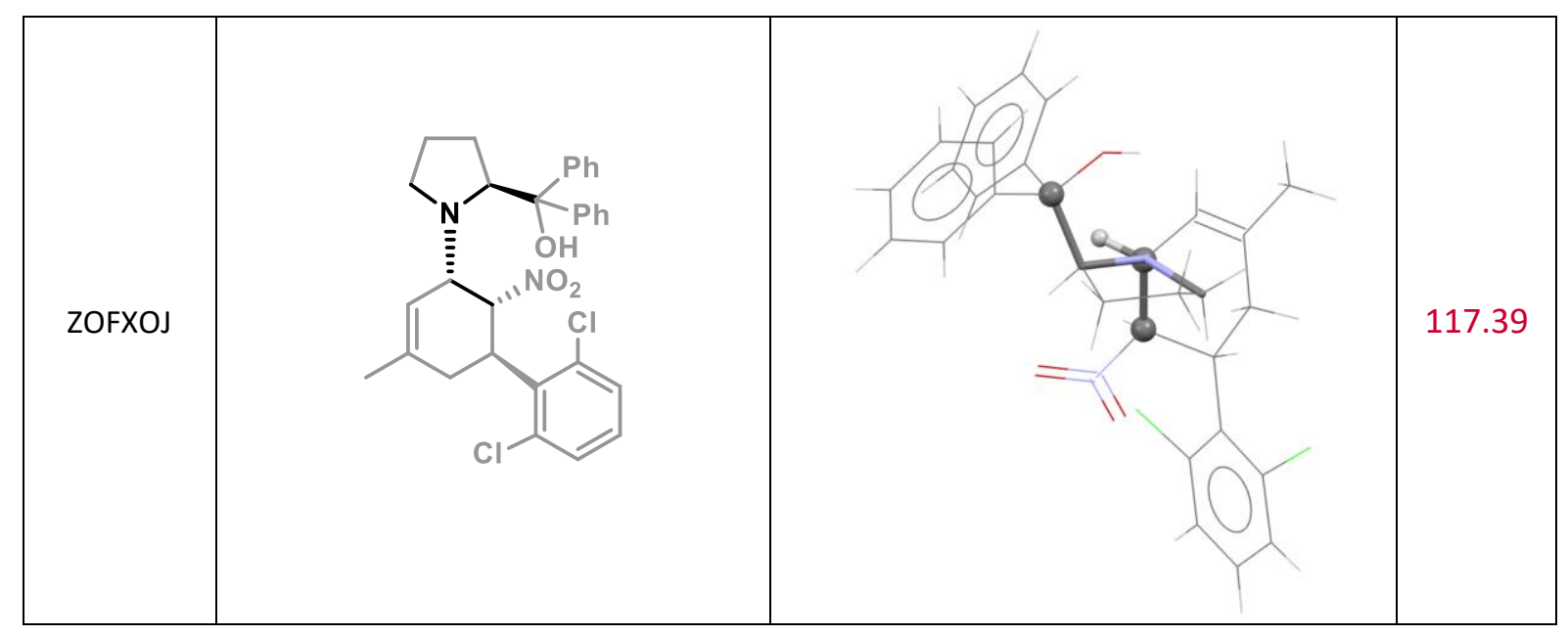




\subsection{Summary of data presented in Figure 2}

Table S4. Summary of the data presented in Figure 2 from the original publication.

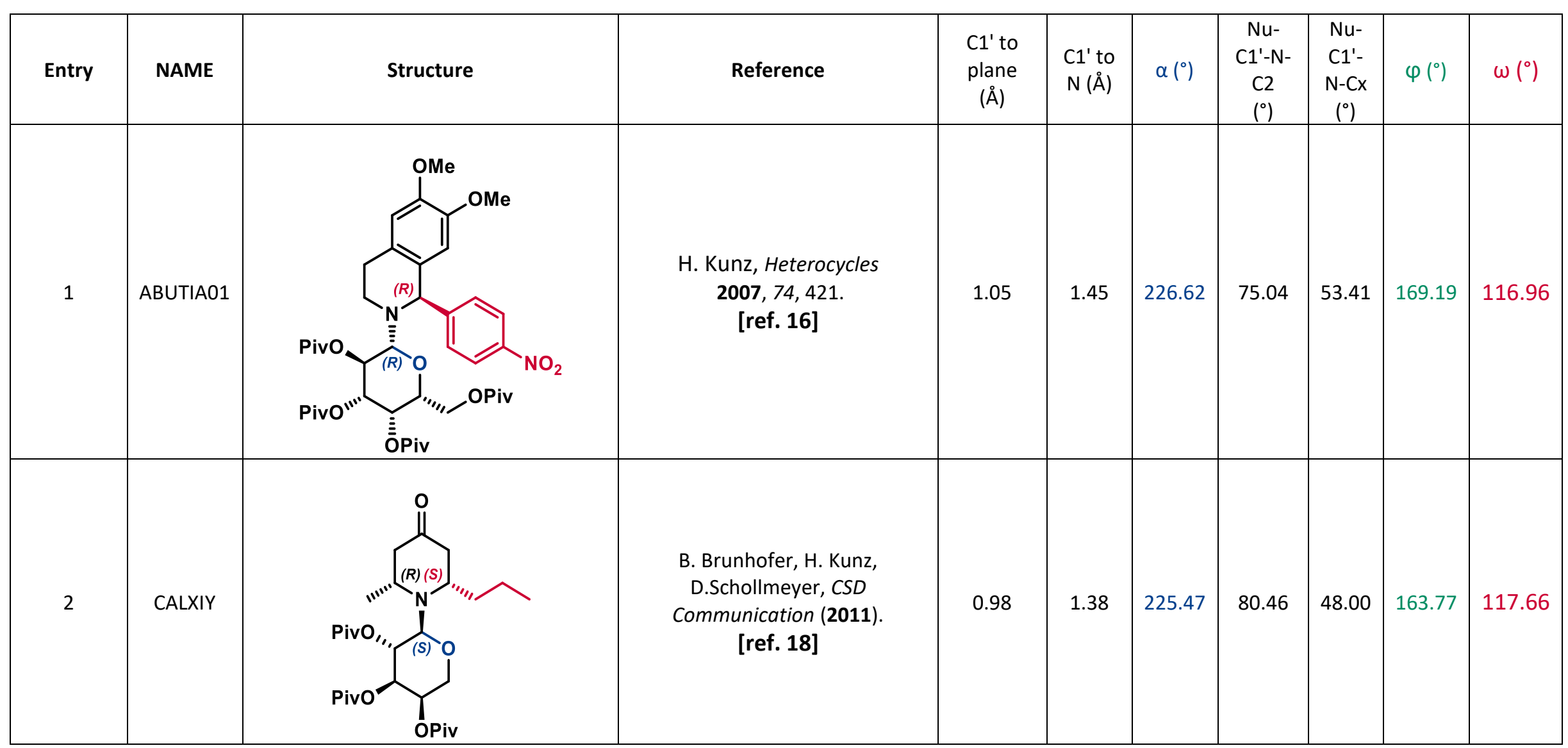




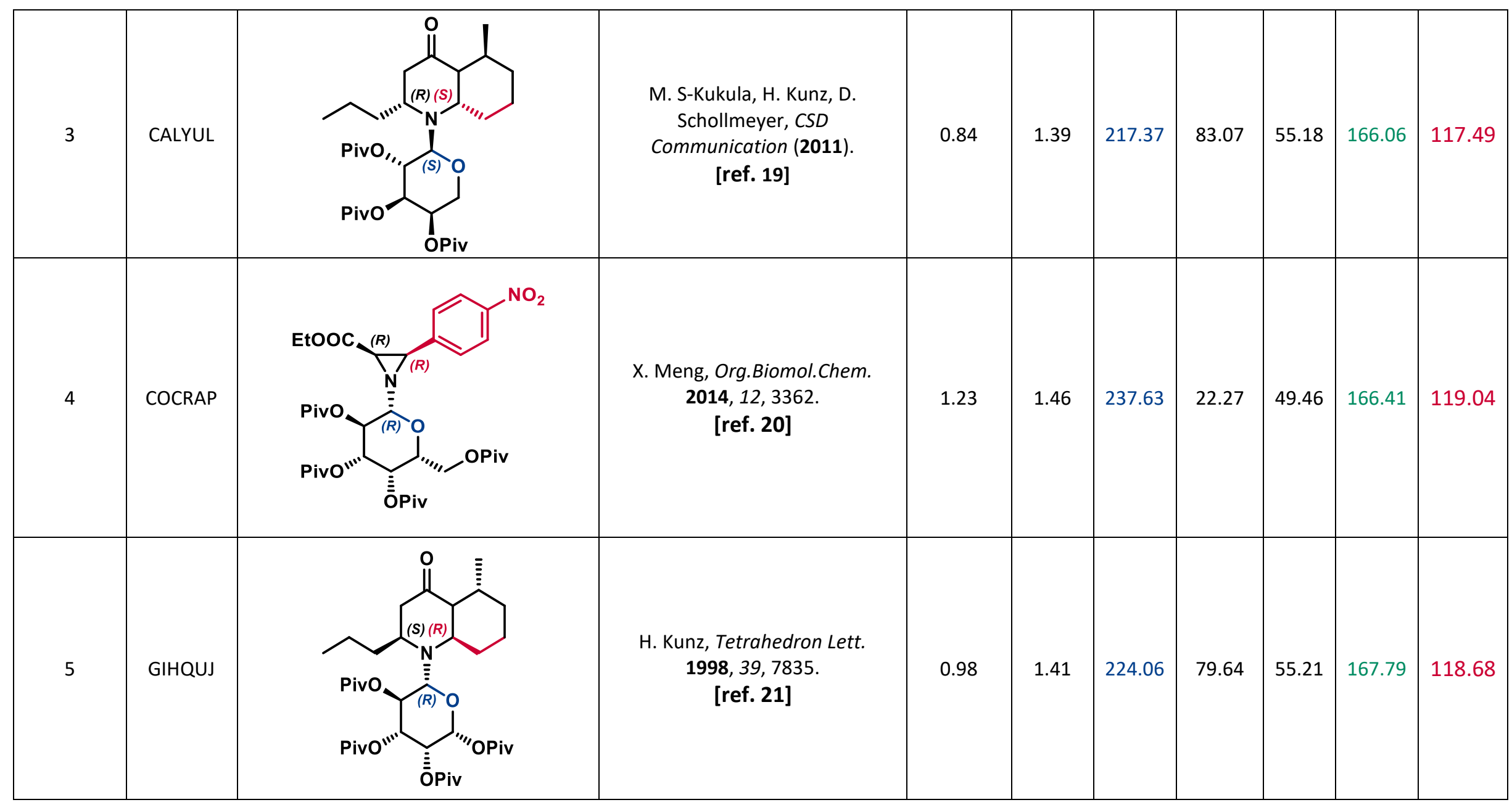




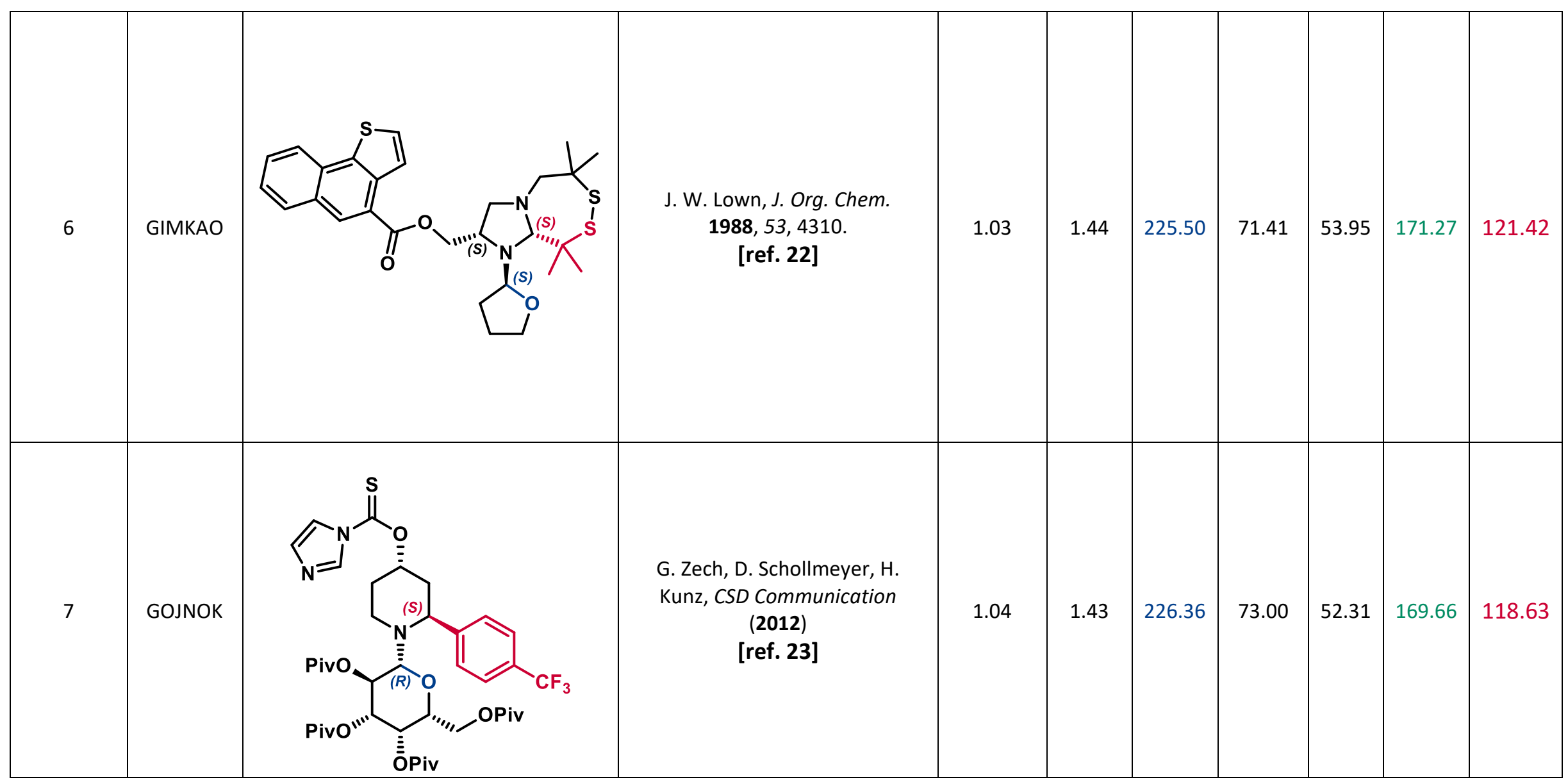




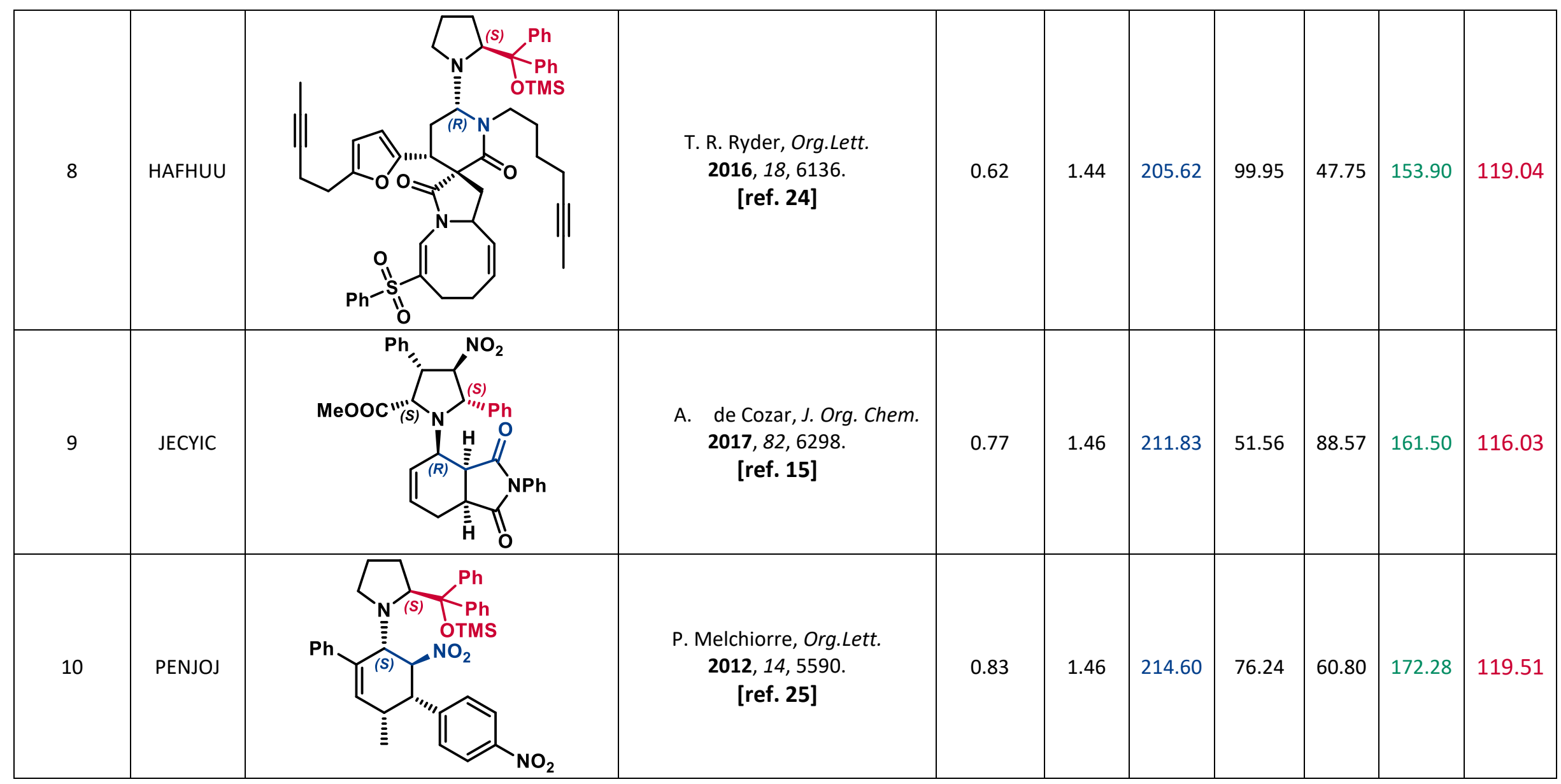




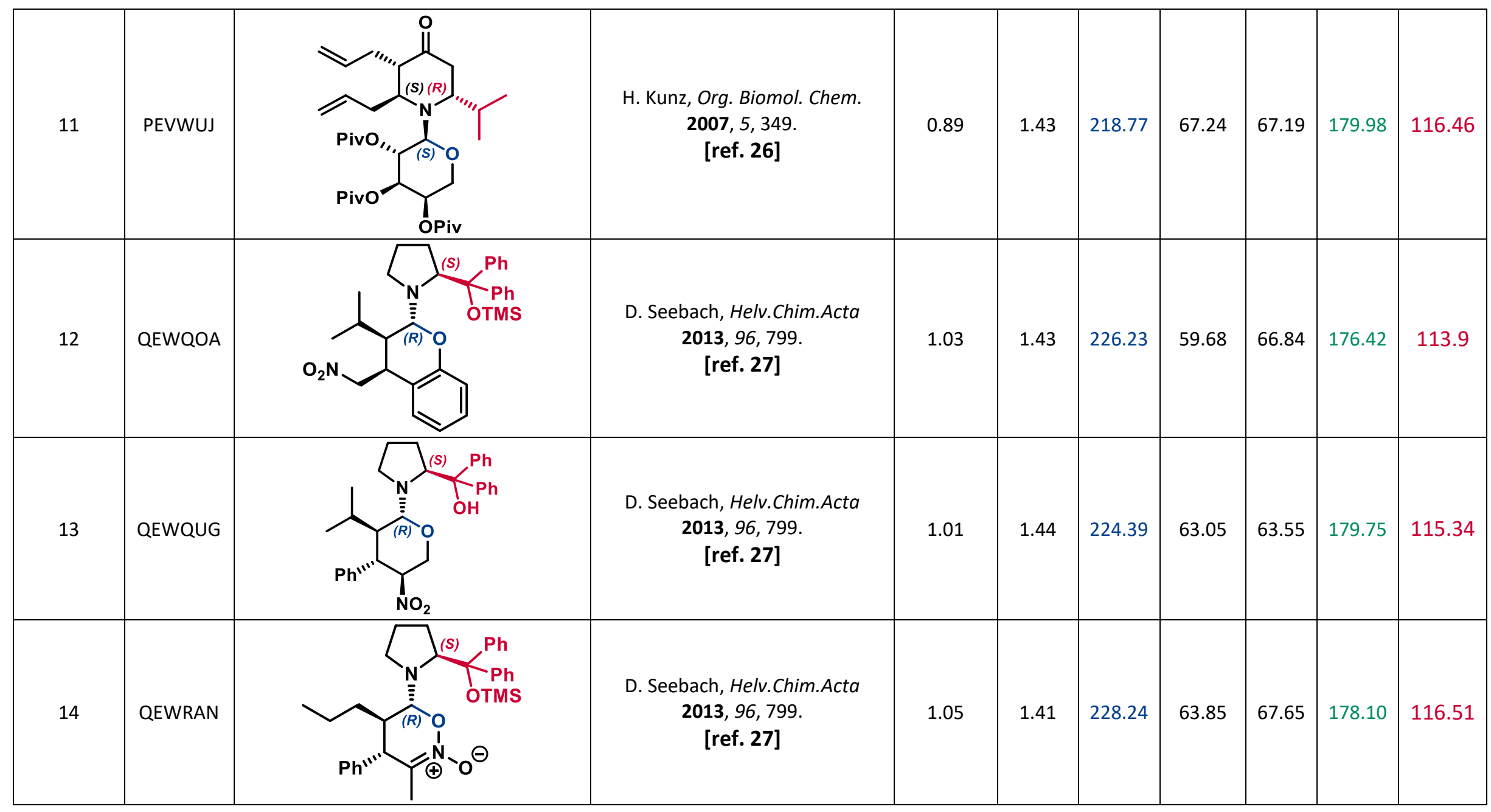




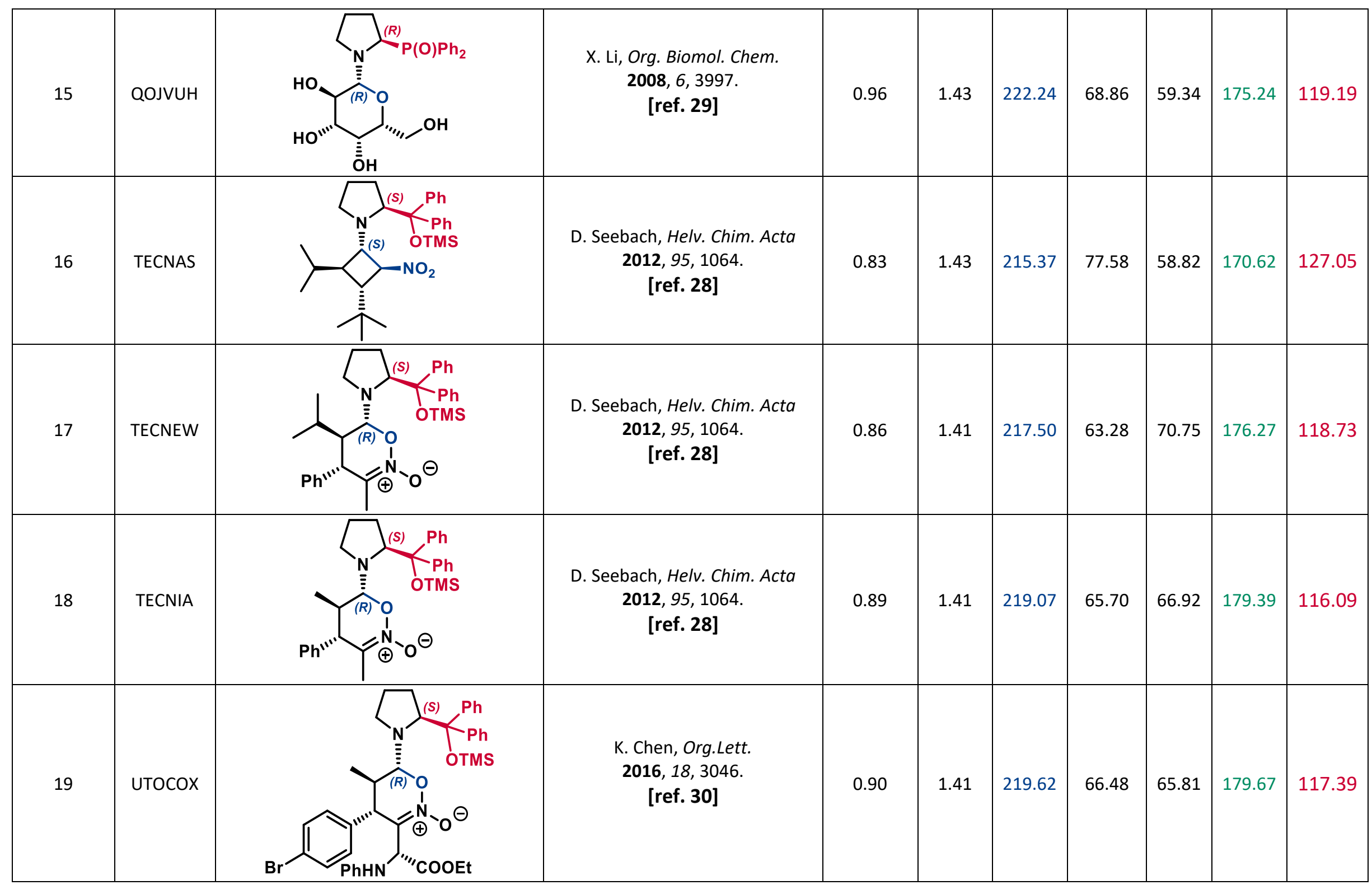




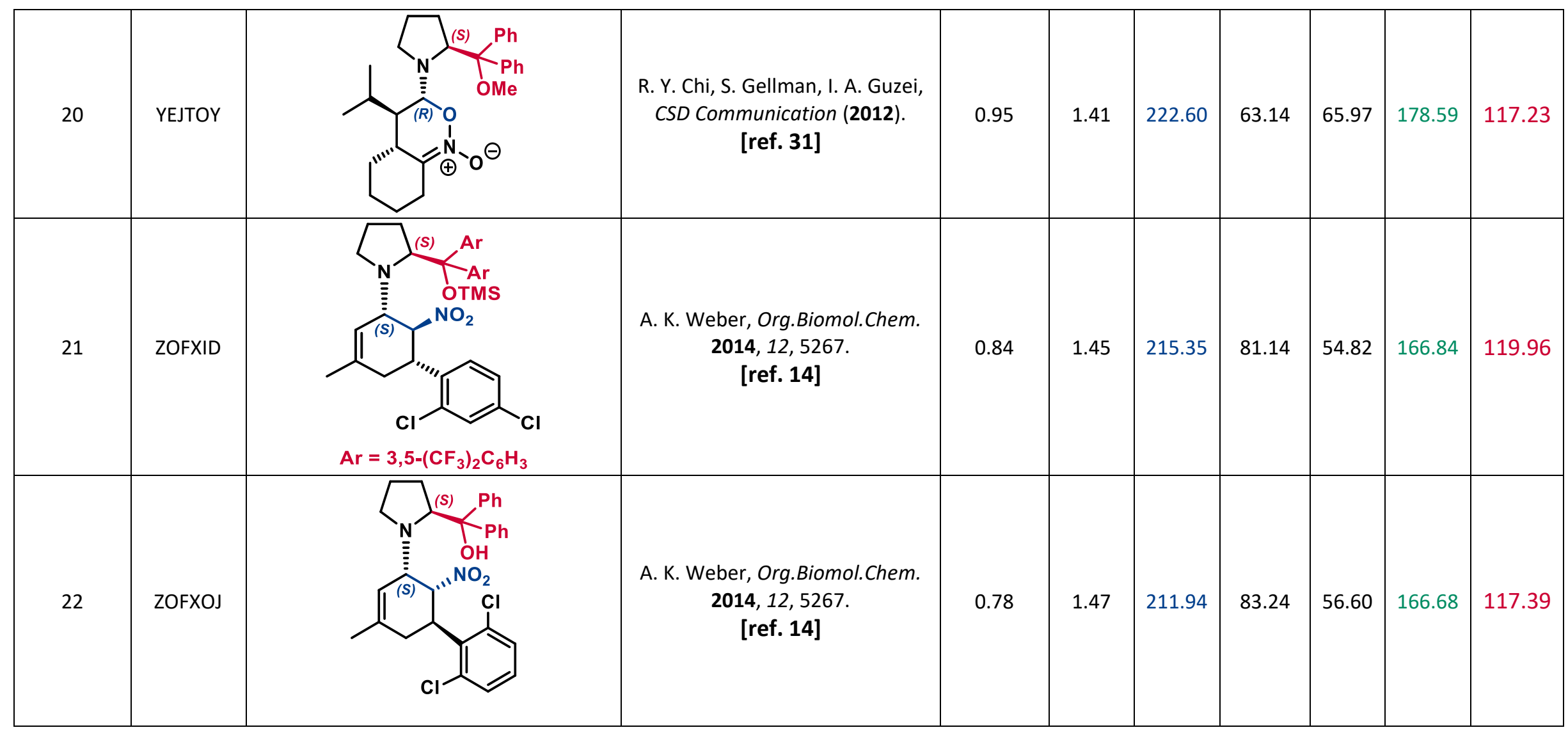




\section{General Procedures Schemes}

3.1. General Procedure 1: DIBAL-H reduction of lactones ${ }^{35}$<smiles>[R]C1CCCC(=O)O1</smiles>

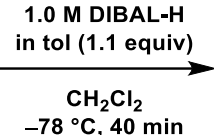<smiles>[R]C1CCC[C@@H](O)O1</smiles>

$\mathrm{R}=\mathbf{H}$ $\mathrm{R}=\mathrm{CH}_{3}$ $\mathrm{R}=\mathrm{C}_{3} \mathrm{H}_{7} \quad( \pm)-1 \mathrm{C}$ $R=\mathrm{C}_{4} \mathrm{H}_{9} \quad( \pm)-1 \mathrm{~d}$ $\mathrm{R}=\mathrm{C}_{5} \mathrm{H}_{11}( \pm)-1 \mathrm{e}$ $R=\mathrm{C}_{6} \mathrm{H}_{13}( \pm)-1 \mathrm{f}$

Scheme S1.DIBAL-H reduction of lactones.

3.2. General Procedure 2: Amine recovery by oxime formation

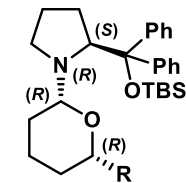

$\mathrm{R}=\mathrm{CH}_{3} \quad(R, R, R, S)-3 \mathrm{ab}$ $\mathrm{R}=\mathrm{C}_{3} \mathrm{H}_{7} \quad(R, R, R, S)-3$ ac $\mathrm{R}=\mathrm{C}_{4} \mathrm{H}_{9} \quad(R, R, R, S)-3 \mathrm{ad}$ $\mathrm{R}=\mathrm{C}_{5} \mathrm{H}_{11}(R, R, R, S)-3 \mathrm{ae}$ $\mathrm{R}=\mathrm{C}_{6} \mathrm{H}_{13}(R, R, R, S)-3 \mathrm{af}$

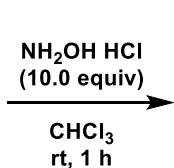

rt, $1 \mathrm{~h}$

$$
\begin{array}{ll}
\mathrm{R}=\mathrm{CH}_{3} & (R)-4 \mathrm{~b} \\
\mathrm{R}=\mathrm{C}_{3} \mathrm{H}_{7} & (R)-4 \mathrm{c} \\
\mathrm{R}=\mathrm{C}_{4} \mathrm{H}_{9} & (R)-4 \mathrm{~d} \\
\mathrm{R}=\mathrm{C}_{5} \mathrm{H}_{11} & (R)-4 \mathrm{e}
\end{array}
$$$$
\mathrm{R}=\mathrm{C}_{5} \mathrm{H}_{13}(R)-4 \mathrm{f}
$$

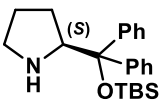

(S)-2a

Scheme S2. Amine recovery by oxime formation.

\subsection{General Procedure 3: Hydrolysis of hydroxyoxime}

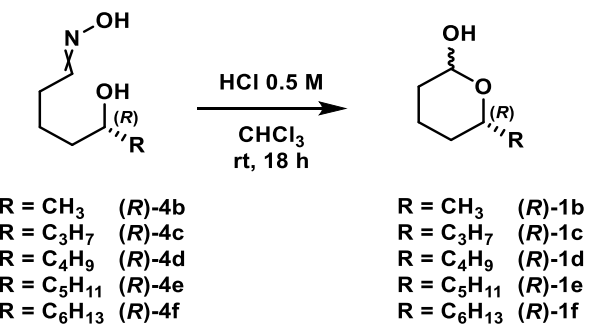

Scheme S3. Hydrolysis of hydroxyoximes $\mathbf{4 b}-\mathbf{4 f}$.

3.4. General Procedure 4: Lactol derivatization for enantioselectivity analysis by chiral HPLC

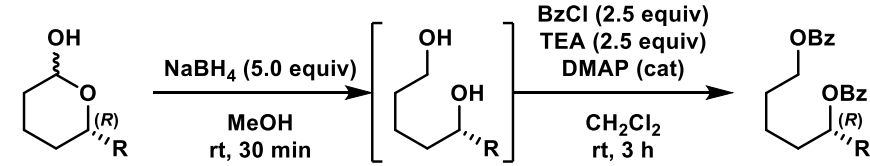

$\mathrm{R}=\mathrm{CH}_{3} \quad(R)-1 \mathrm{~b}$

$\mathrm{R}=\mathrm{C}_{3} \mathrm{H}_{7} \quad(R)-1 \mathrm{C}$

$\mathrm{R}=\mathrm{C}_{4} \mathrm{H}_{9} \quad(R)-1 \mathrm{~d}$

$\mathrm{R}=\mathrm{C}_{5} \mathrm{H}_{11}(R)-1 \mathrm{e}$

$\mathrm{R}=\mathrm{C}_{6} \mathrm{H}_{13}(R)-1 \mathrm{f}$
$\mathrm{R}=\mathrm{CH}_{3} \quad(R)-5 \mathrm{~b}$

$\mathrm{R}=\mathrm{C}_{3} \mathrm{H}_{7} \quad(R)-5 \mathrm{c}$

$\begin{array}{ll}R=\mathrm{C}_{3} \mathrm{H}_{7} & (R)-5 \mathrm{C} \\ \mathrm{R}=\mathrm{C}_{4} \mathrm{H}_{9} & (R)-5 \mathrm{~d}\end{array}$

$\mathrm{R}=\mathrm{C}_{5} \mathrm{H}_{11}(R)-5 \mathrm{e}$

$\mathrm{R}=\mathrm{C}_{6} \mathrm{H}_{13}(R)-5 \mathrm{f}$ 


\section{Resolution of racemic $\delta$-hexalactol ( \pm )-1b with different amines}

We tested the chiral resolution of lactols with several amines using racemic $\delta$-hexalactol $( \pm)-\mathbf{1 b}$. The selectivity factor $\left(K_{R, S}\right)$ is defined as the ratio between the equilibrium constants of each enantiomer, $K_{R} / K_{S}$ (Scheme S5). Using the $K_{R} / K_{S}$ equilibrium formulas, together with the conversion and the diasteromeric ratio of the hemiaminals ethers, we can define the selectivity factor $\left(K_{R, S}\right)$ as a function of lactol conversion, ratio of diatereoisomers and initial concentrations. The aim was to find the resolving agent with the highest selectivity factor $\left(K_{R, S}\right)$ for the most efficient resolution.<smiles>C[C@@H]1CCC[C@@H](O)O1</smiles>

$(R)-1 b$<smiles>[R]C=C</smiles><smiles>C[C+]1CCCN1</smiles><smiles>C=CC=C</smiles>

$(S)-1 b$<smiles>C[C@@H]1CCC[C@@H](N2CCC[C@H]2O)O1</smiles>

$(R, S)-3 \mathrm{ab}$
$\mathrm{H}_{2} \mathrm{O}$

$$
K_{R}=\frac{[(R, S) 3 a b]\left[\mathrm{H}_{2} \mathrm{O}\right]}{[(R) 1 b][\text { amine }]}
$$

Scheme S5. Equilibrium between $\delta$-hexalactol ( \pm )-1b and chiral amine with the selectivity factor equation for each enantiomer

Selectivity factor: $K_{R, S}=\frac{K_{R}}{K_{S}}$

Conversion of amine:

conv $=\frac{[(R, S) 3 a b]+[(S, S) 3 a b]}{[\text { amine }]_{0}} \quad[(R, S) 3 a b]=$ conv $\cdot[\text { amine }]_{0}-[(S, S) 3 a b]$

Diastereoselectivity: $d r=\frac{[(R, S) 3 a b]}{[(S, S) 3 a b]}$

Mass balance for the $(S)$-lactol: $[(S) 1 b]_{0}=[(S) 1 b]+[(S, S) 3 a b]$

Mass balance for the $(\boldsymbol{R})$-lactol: $[(R) 1 b]_{0}=[(R) 1 b]+[(R, S) 3 a b]$

Combining equations (4) and (5)

$$
[(S, S) 3 a b]=\frac{\operatorname{conv} \cdot[\text { amine }]_{0}}{d r+1}
$$

Combining equations (4) and (5)

$$
[(R, S) 3 a b]=d r \cdot \frac{\text { conv } \cdot[\text { amine }]_{0}}{d r+1}
$$


Combining equations (6) and (8)

$$
[(S) 1 b]=[(S) 1 b]_{0}-\frac{\operatorname{conv} \cdot[\text { amine }]_{0}}{d r+1}
$$

Combining equations (7) and (9)

$$
[(R) 1 b]=[(R) 1 b]_{0}-d r \cdot \frac{\text { conv } \cdot[\text { amine }]_{0}}{d r+1}
$$

Combining equations (1), (2), (3), (10) and (11)

$$
K_{R, S}=\frac{K_{R}}{K_{S}}=\frac{[(R, S) 3 a b] \cdot[(S) 1 b]}{[(S, S) 3 a b] \cdot[(R) 1 b]}=d r \cdot \frac{[(S) 1 b]}{[(R) 1 b]}=d r \cdot \frac{[(S) 1 b]_{0}-\frac{\text { conv } \cdot[\text { amine }]_{0}}{d r+1}}{[(R) 1 b]_{0}-d r \cdot \frac{\text { conv } \cdot[\text { amine }]_{0}}{d r+1}}
$$




\subsection{Lactol resolution with amine $(S)-2 a$}

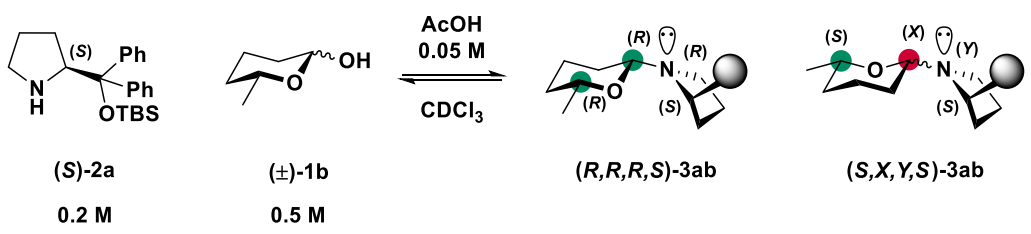

Scheme S6. Resolution of lactol ( \pm )-1b with amine (S)-2a.

An NMR tube was charged successively with (S)- $\alpha, \alpha$-diphenyl-2-pyrrolidinemethanol tertbutyldimethylsilyl ether $(S)$-2a (44.0 mg, $0.12 \mathrm{mmol}), \mathrm{CDCl}_{3}(0.6 \mathrm{~mL}$ ), racemic $\delta$-hexalactol ( \pm )-1b (34.8 $\mathrm{mg}, 0.30 \mathrm{mmol})$ and $\mathrm{AcOH}(1.7 \mu \mathrm{L}, 0.03 \mathrm{mmol})$. In order to assign all the signals of each diastereomer of the hemiaminal ethers formed, enantiopure $\delta$-hexalactol $(R)$-1b was mixed with $(R)$-enantiomer amine $(R)$-2a under the same reaction conditions.

We observed $49 \%$ conversion of amine (S)-2a by ${ }^{1} \mathrm{H}$ NMR spectroscopy by integrating the TBS peaks corresponding to the free amine (S)-2a and the TBS peaks of the hemiaminal 3ab (Figure S10).

$$
\text { conv amine }=\frac{49.04}{50.96+49.04} \cdot 100=49 \%
$$

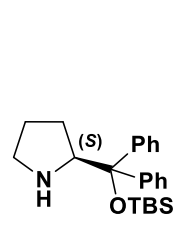

(S)-2a

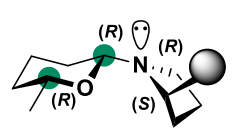

$(R, R, R, S)-3 \mathrm{ab}$

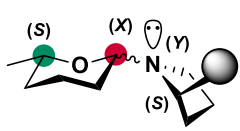

$(S, X, Y, S)-3 a b$

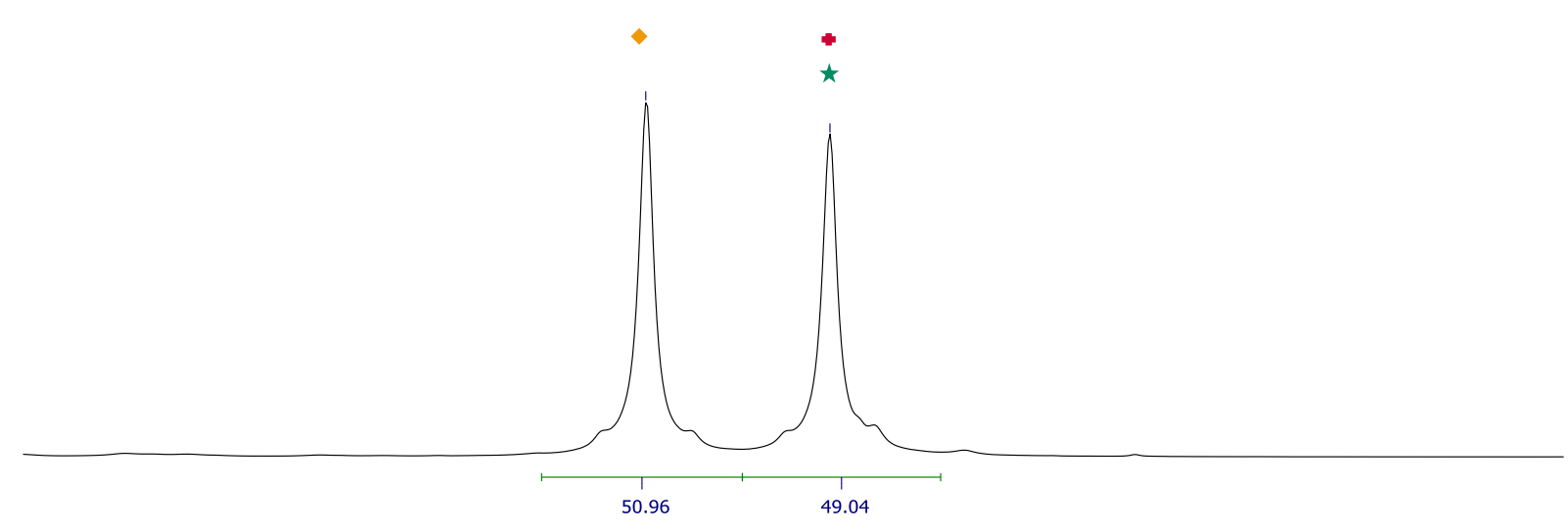

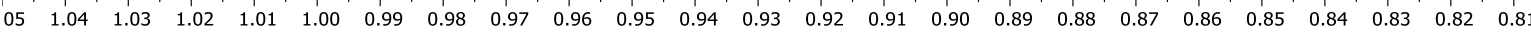
Figure S10. ${ }^{1} \mathrm{H} N \mathrm{MR}$ spectrum $\left(400 \mathrm{MHz}, \mathrm{CDCl}_{3}\right)$ to measure the conversion of amine (S)-2a. 


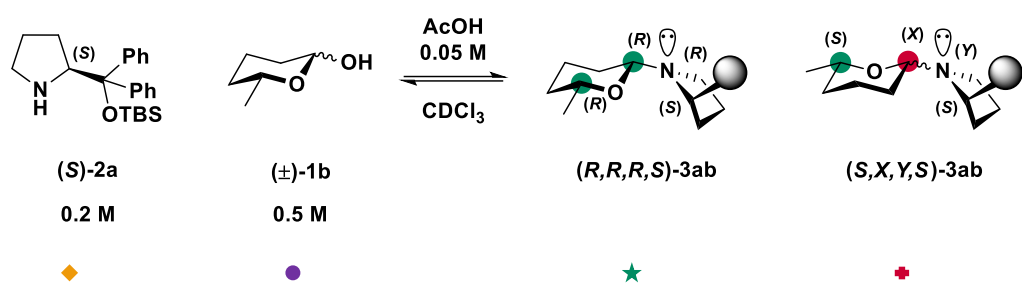

( \pm )-lactol with amine (S)-2a

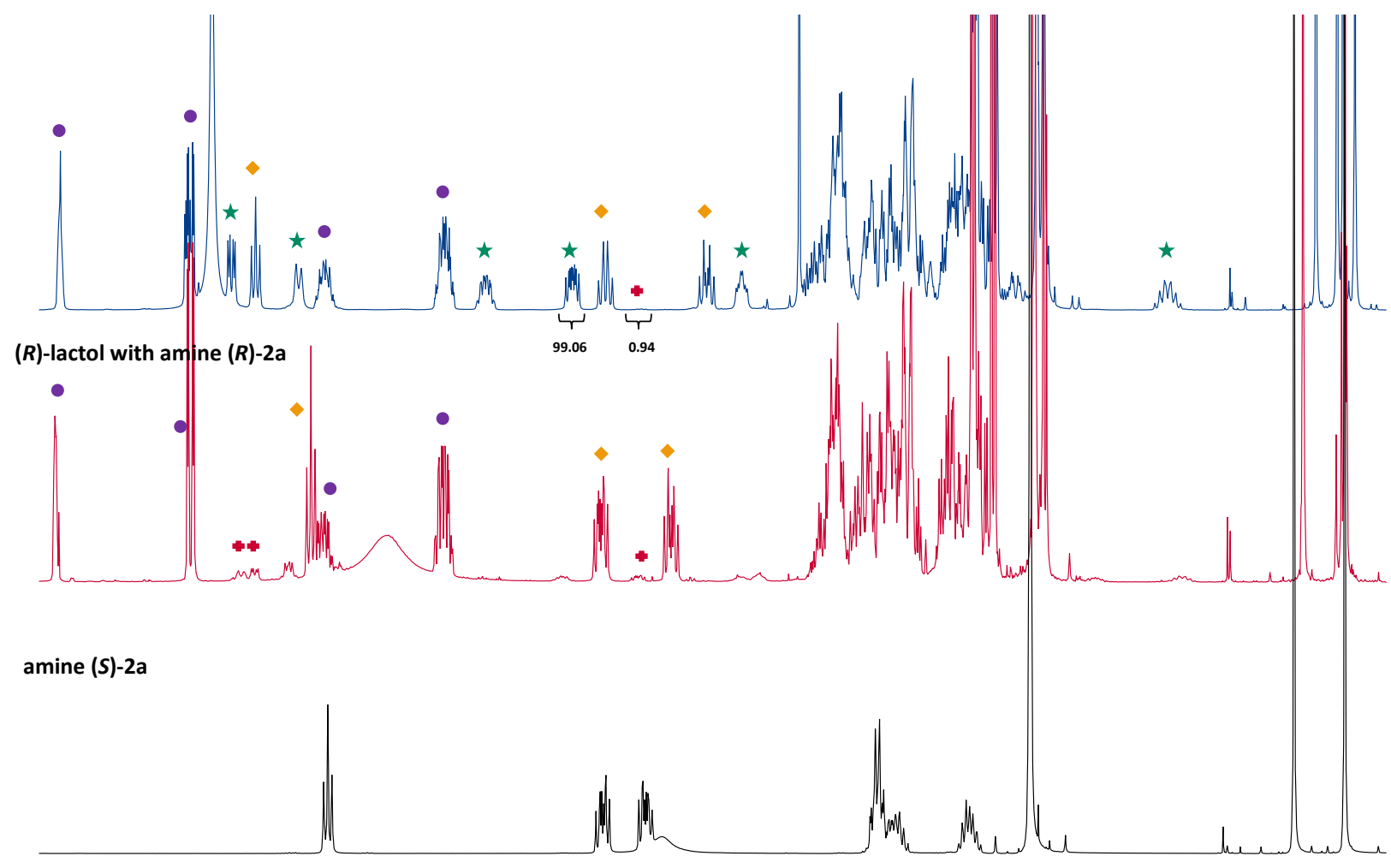

\begin{tabular}{llllllllllll}
\hline 5.0 & 4.5 & 4.0 & 3.5 & 3.0 & 2.5 & 2.0 & 1.5 & 1.0 & 0.5 & 0.0 & -0.5
\end{tabular}

Figure S11. ${ }^{1} \mathrm{H} \mathrm{NMR} \mathrm{spectrum}\left(400 \mathrm{MHz}^{\mathrm{N}} \mathrm{CDCl}_{3}\right)$ in order to assign all the signals of each diastereomer of the hemiaminal ethers formed.

$$
\begin{aligned}
& d r=\frac{[(R, R, R, S) 3 a b]}{[(S, X, Y, S) 3 a b]}=\frac{99.06}{0.94}=105.38 \\
& K_{R, S}=d r \cdot \frac{[(S) 1 \mathrm{~b}]_{0}-\frac{\operatorname{conv} \cdot[\text { amine }]_{0}}{d r+1}}{[(R) 1 \mathrm{~b}]_{0}-d r \cdot \frac{\operatorname{conv} \cdot[\text { amine }]_{0}}{d r+1}}=105.38 \cdot \frac{0.25-\frac{0.49 \cdot 0.20}{105.38+1.00}}{0.25-105.38 \cdot \frac{0.49 \cdot 0.20}{105.38+1.00}}=\mathbf{1 7 3 . 4 8}
\end{aligned}
$$




\subsection{Lactol resolution with amine $(S)-2 b$}

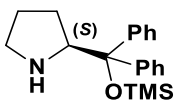

(S)-2b

$0.2 \mathrm{M}$

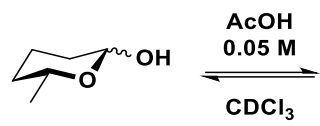

( \pm )-1b

$0.5 \mathrm{M}$

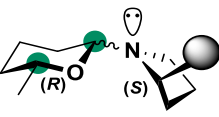

$(R, S)-3 b b$

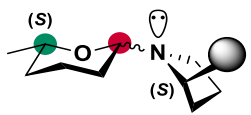

$(S, S)-3 b b$

Scheme S7. Resolution of lactol ( \pm )-1 $\mathbf{1 b}$ with amine $(S)-\mathbf{2 b}$.

An NMR tube was charged successively with $(S)$ - $\alpha, \alpha$-diphenylpyrrolidinemethanol trimethylsilyl ether $(S)-2 b$ (39.0 mg, $0.12 \mathrm{mmol}), \mathrm{CDCl}_{3}(0.6 \mathrm{~mL})$, racemic $\delta$-hexalactol $( \pm)-\mathbf{1 b}(34.8 \mathrm{mg}, 0.30 \mathrm{mmol})$ and $\mathrm{AcOH}(1.7 \mu \mathrm{L}, 0.03 \mathrm{mmol})$. In order to assign all the signals of each diastereomer of the hemiaminal ethers formed, two reactions with the enantiopure $\delta$-hexalactol $(R)$-1b were set up, one with the $(S)$ enantiomer amine $(S)$-2 $\mathbf{b}$ and the other one with the $(R)$-enantiomer amine $(R)-\mathbf{2} \mathbf{b}$.

We observed $57 \%$ conversion of amine (S)-2b by ${ }^{1} \mathrm{H}$ NMR spectroscopy by integrating the TMS peaks corresponding to the free amine (S)-2b and the TMS peaks of the hemiaminal $\mathbf{3 b b}$ (Figure S12).

$$
\text { conv amine }=\frac{56.96}{43.04+56.96} \cdot 100=57 \%
$$

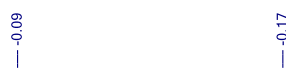

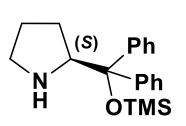

(S)-2b

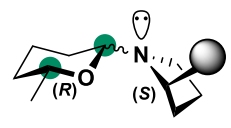

$(R, S)-3 \mathrm{bb}$

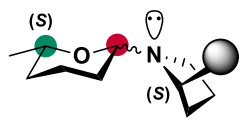

$(S, S)-3 b b$

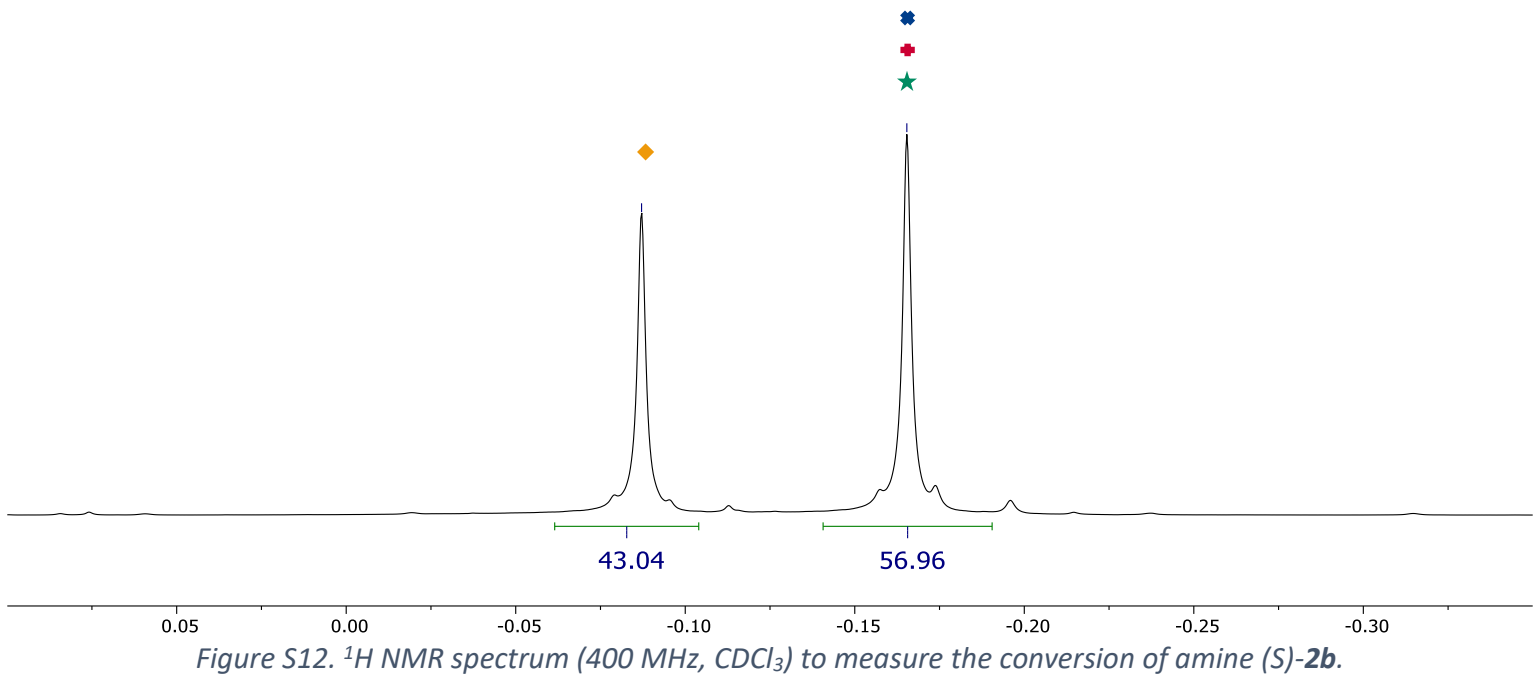




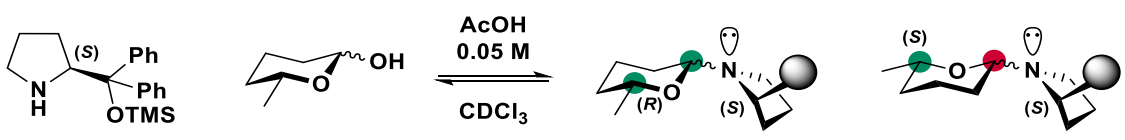

$\begin{array}{llll}(S)-2 \mathrm{~b} & ( \pm)-1 \mathrm{~b} & (R, S)-3 \mathrm{bb} & (S, S)-3 \mathrm{bb}\end{array}$

$0.2 \mathrm{M} \quad 0.5 \mathrm{M}$

$\star$

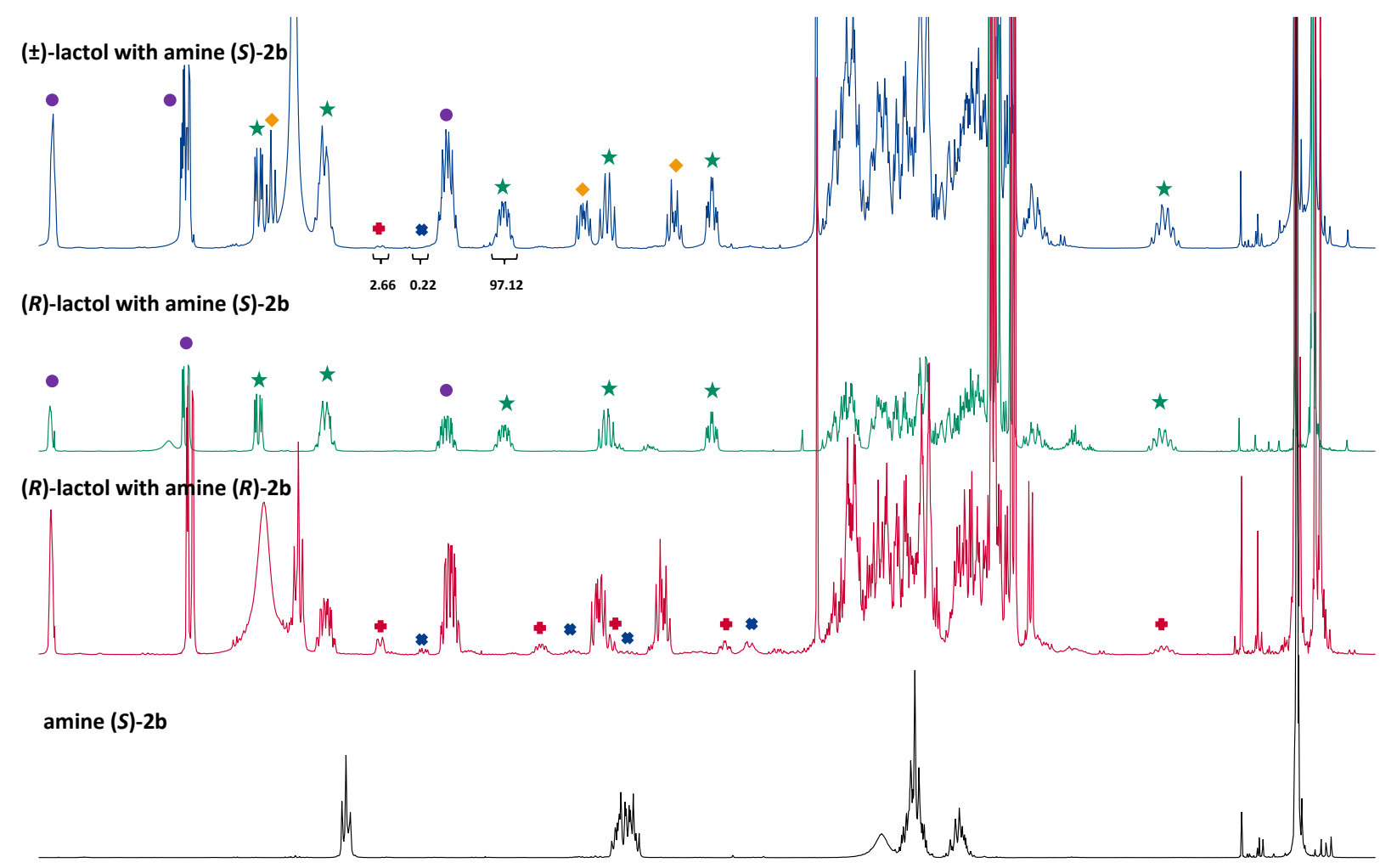

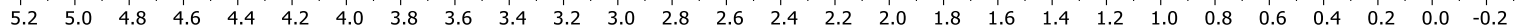
Figure S13. ${ }^{1} \mathrm{H} \mathrm{NMR} \mathrm{spectrum}\left(400 \mathrm{MHz}, \mathrm{CDCl}_{3}\right)$ in order to assign all the signals of each diastereomer of the hemiaminal ethers formed.

$d r=\frac{[(R, S) 3 b b]}{[(S, S) 3 b b]}=\frac{97.12}{(2.66+0.22)}=33.72$

$K_{R, S}=d r \cdot \frac{[(S) 1 \mathrm{~b}]_{0}-\frac{\operatorname{conv} \cdot[\text { amine }]_{0}}{d r+1}}{[(R) 1 \mathrm{~b}]_{0}-d r \cdot \frac{\operatorname{conv} \cdot[\text { amine }]_{0}}{d r+1}}=33.72 \cdot \frac{0.25-\frac{0.57 \cdot 0.20}{33.72+1.00}}{0.25-33.72 \cdot \frac{0.57 \cdot 0.20}{33.72+1.00}}=\mathbf{6 0}$ 


\subsection{Lactol resolution with amine $(S)-2 c$}

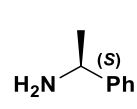

(S)-2c

$0.2 \mathrm{M}$

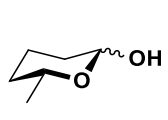

$( \pm)-1 b$

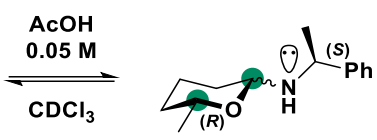

$(R, S)-3 \mathrm{cb}$

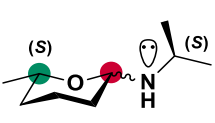

$(S, S)-3 c b$

Scheme S8. Resolution of lactol ( \pm )-1 b with amine (S)-2c.

An NMR tube was charged successively (S)-1-phenylethylamine $(S)$-2c (15.0 mg, $0.12 \mathrm{mmol}), \mathrm{CDCl}_{3}(0.6$ $\mathrm{mL})$, racemic $\delta$-hexalactol ( \pm )-1b $(34.8 \mathrm{mg}, 0.30 \mathrm{mmol}$ ) and $\mathrm{AcOH}(1.7 \mu \mathrm{L}, 0.03 \mathrm{mmol})$. In order to assign all the signals of each diastereomer of the hemiaminal ethers formed, two reactions with the enantiopure $\delta$-hexalactol $(R)$-1 $\mathbf{b}$ were set up, one with the $(S)$-enantiomer amine $(S)$ - $\mathbf{2} \mathbf{c}$ and the other one with the $(R)$-enantiomer amine $(R)-\mathbf{2 c}$.

We observed $40 \%$ conversion of lactol $( \pm)$ - $\mathbf{1 b}$ by ${ }^{1} \mathrm{H}$ NMR spectroscopy by integrating the hemiacetal peaks corresponding to the lactol $( \pm)-\mathbf{1 b}$ and the hemiaminal peaks $\mathbf{3} \mathbf{c b}$. Therefore, we observe $99 \%$ conversion of amine (S)-2c (Figure S14).

$$
\begin{gathered}
\text { conv lactol }=\frac{0.74+(1-0.60)}{0.60+1.13+(1-0.60)+0.74} \cdot 100=40 \% \\
\text { conv amine }=\frac{0.4 \cdot 0.5}{0.2} \cdot 100=99 \%
\end{gathered}
$$

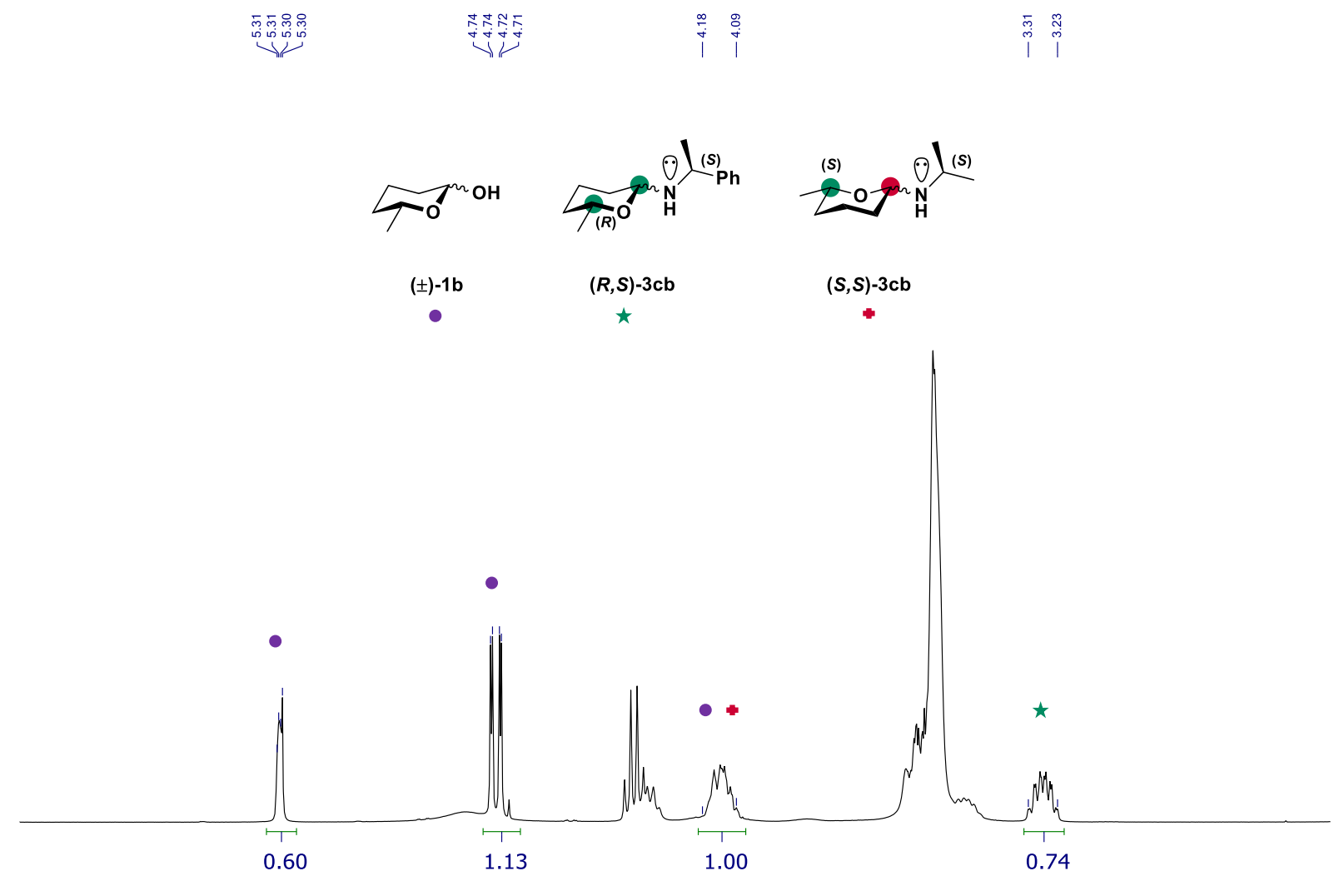

$\begin{array}{llllllllllllllllllllllllllllllllllllllllll}.0 & 5.9 & 5.8 & 5.7 & 5.6 & 5.5 & 5.4 & 5.3 & 5.2 & 5.1 & 5.0 & 4.9 & 4.8 & 4.7 & 4.6 & 4.5 & 4.4 & 4.3 & 4.2 & 4.1 & 4.0 & 3.9 & 3.8 & 3.7 & 3.6 & 3.5 & 3.4 & 3.3 & 3.2 & 3.1 & 3.0 & 2.9 & 2.8 & 2.7 & 2.6 & 2\end{array}$ Figure S14. ${ }^{1} \mathrm{H} N \mathrm{NR}$ spectrum $\left(400 \mathrm{MHz}, \mathrm{CDCl}_{3}\right)$ to measure the conversion of amine (S)-2c. 


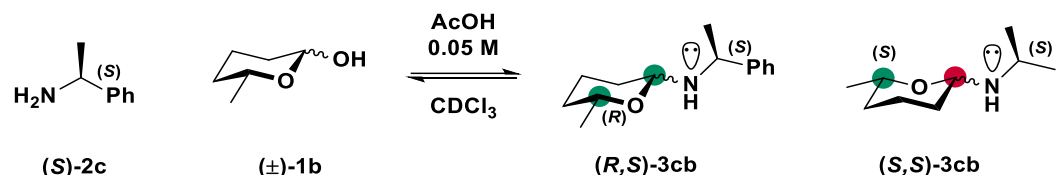

$\begin{array}{ll}(S)-2 \mathrm{C} & ( \pm)-1 \mathrm{~b} \\ 0.2 \mathrm{M} & 0.5 \mathrm{M}\end{array}$

( \pm )-lactol with amine $(S)-2 c$

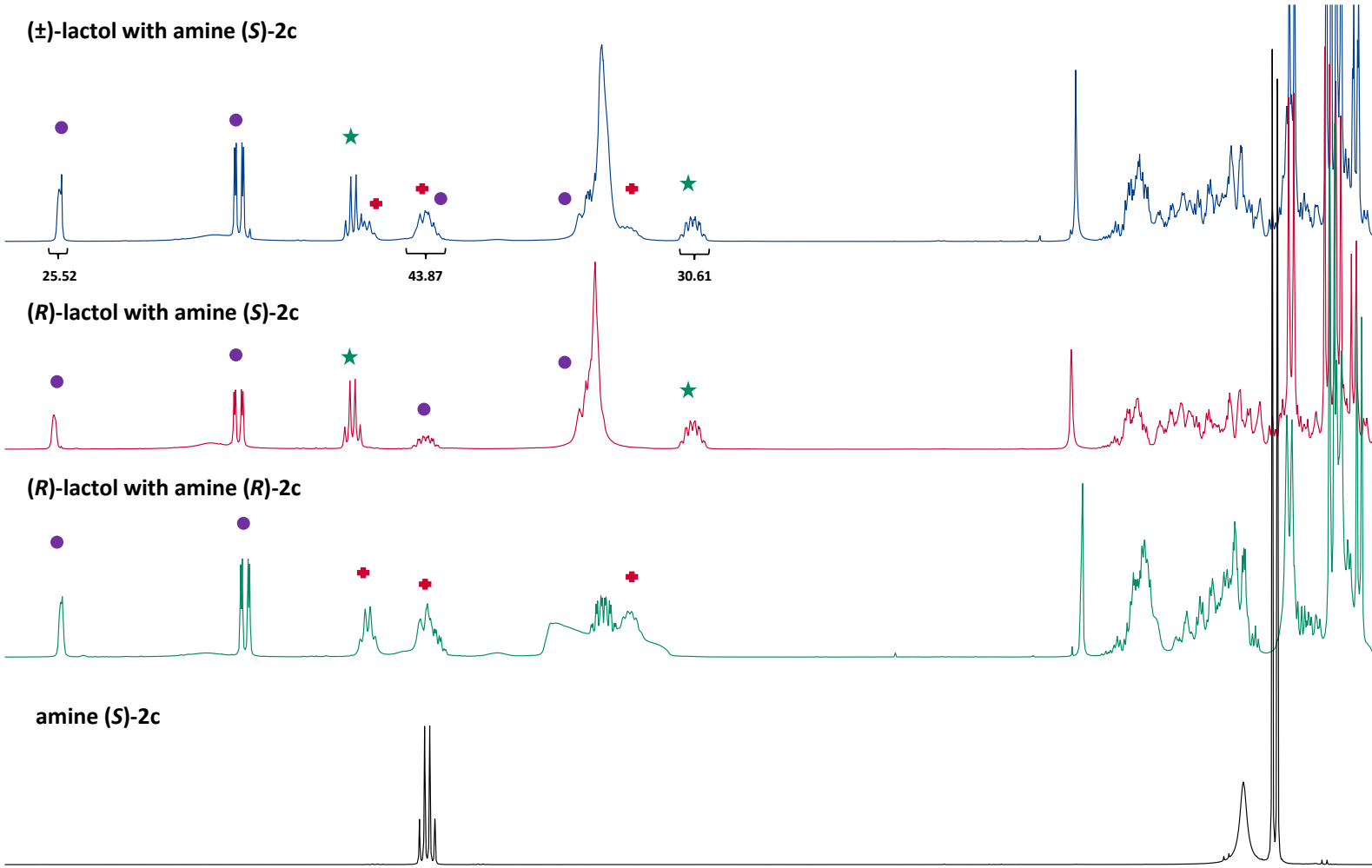

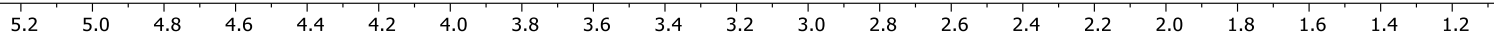
Figure S15. ${ }^{1} \mathrm{H} N \mathrm{NMR}$ spectrum $\left(400 \mathrm{MHz}, \mathrm{CDCl}_{3}\right)$ in order to assign all the signals of each diastereomer of the hemiaminal ethers formed.

$d r=\frac{[(R, S) 3 c b]}{[(S, S) 3 c b]}=\frac{30.61}{(43.87-25.52)}=1.67$

$K_{R, S}=d r \cdot \frac{[(S) 1 \mathrm{~b}]_{0}-\frac{\operatorname{conv} \cdot[\text { amine }]_{0}}{d r+1}}{[(R) 1 \mathrm{~b}]_{0}-d r \cdot \frac{\operatorname{conv} \cdot[\text { amine }]_{0}}{d r+1}}=1.67 \cdot \frac{0.25-\frac{0.99 \cdot 0.20}{1.67+1.00}}{0.25-1.67 \cdot \frac{0.99 \cdot 0.20}{1.67+1.00}}=\mathbf{2 . 3}$ 


\subsection{Lactol resolution with amine $(S)-2 d$}

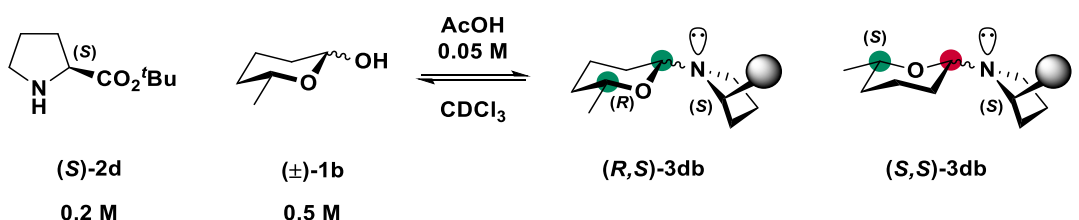

Scheme S9. Resolution of lactol ( \pm )-1b with amine (S)-2d.

An NMR tube was charged successively with L-proline tert-butyl ester $(S)-\mathbf{2 d}(21.0 \mathrm{mg}, 0.12 \mathrm{mmol})$, $\mathrm{CDCl}_{3}(0.6 \mathrm{~mL})$, racemic $\delta$-hexalactol $( \pm)-\mathbf{1 b}(34.8 \mathrm{mg}, 0.30 \mathrm{mmol})$ and $\mathrm{AcOH}(1.7 \mu \mathrm{L}, 0.03 \mathrm{mmol}) . \mathrm{In}$ order to assign all the signals of each diastereomer of the hemiaminal ethers formed, enantiopure $\delta$-hexalactol $(R)$-1 b was mixed with $(S)$-enantiomer amine $(S)$-2d under the same reaction conditions.

We observed $96 \%$ conversion of amine (S)-2d by ${ }^{1} \mathrm{H}$ NMR spectroscopy by integrating the ${ }^{t} \mathrm{Bu}$ peaks corresponding to the free amine (S)-2d and the ${ }^{t}$ Bu peaks of the hemiaminal $\mathbf{3} \mathbf{d b}$ (Figure S16).

$$
\text { conv amine }=\frac{96.29}{3.71+96.29} \cdot 100=96 \%
$$

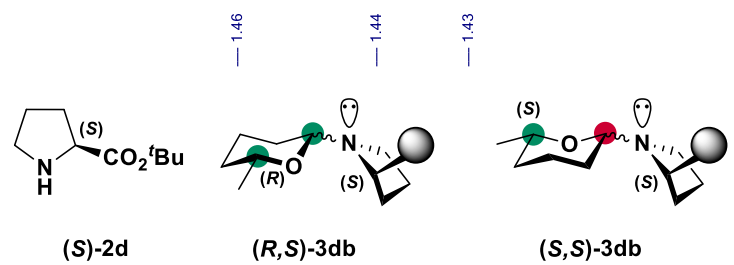

(S)-2d

$(R, S)-3 \mathrm{db}$

$(S, S)-3 \mathrm{~d}$

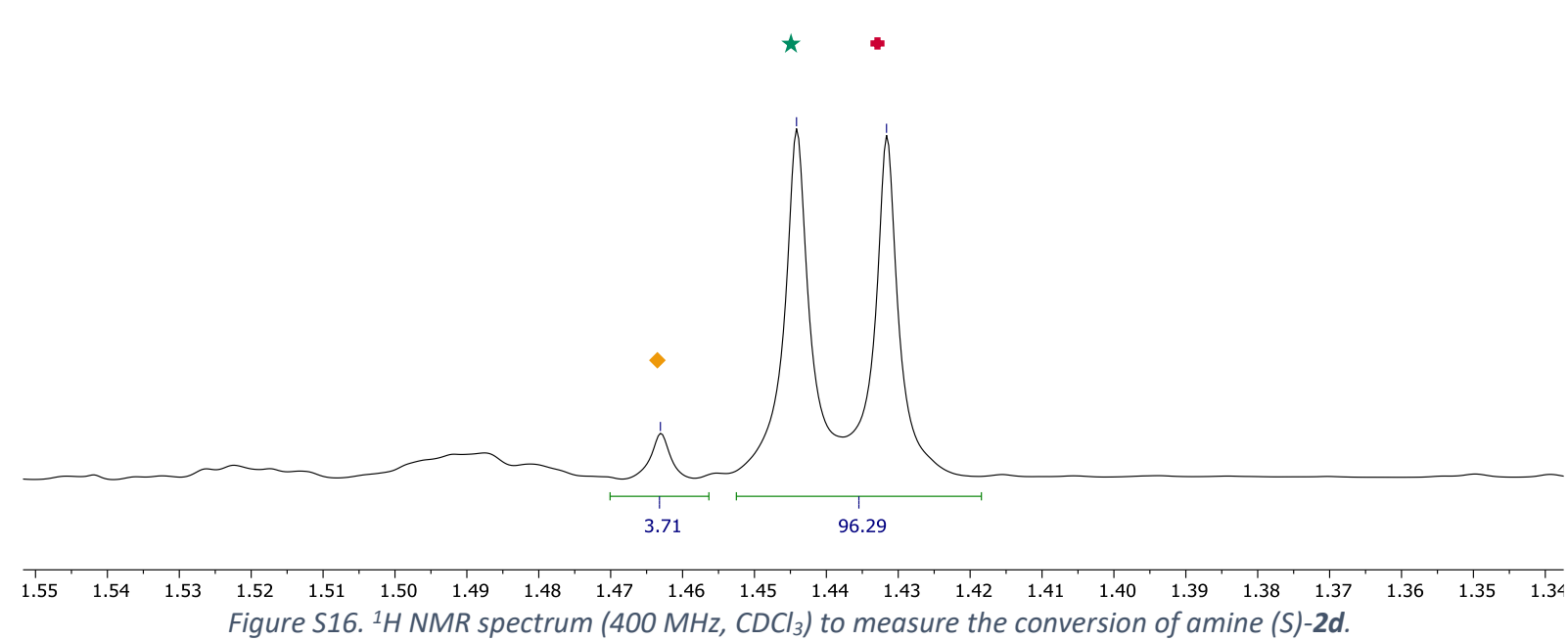




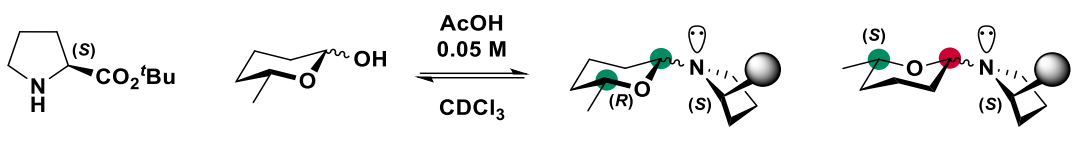

$\begin{array}{llll}(S)-2 \mathrm{~d} & ( \pm)-1 \mathrm{~b} & (R, S)-3 \mathrm{db} & (S, S)-3 \mathrm{db}\end{array}$

$0.2 \mathrm{M} \quad 0.5 \mathrm{M}$

( \pm )-lactol with amine $(S)-2 d$

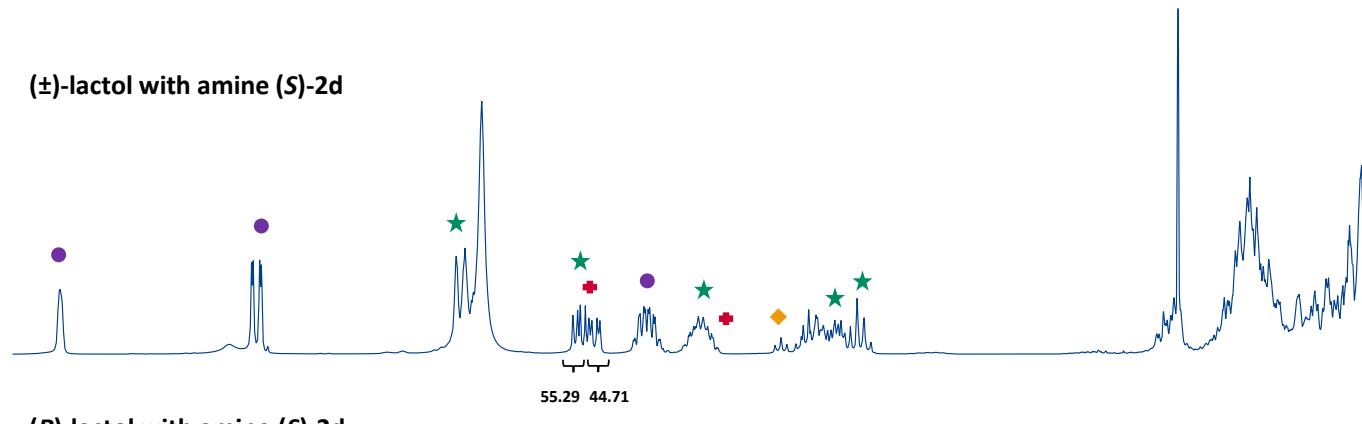

$(R)$-lactol with amine (S)-2d
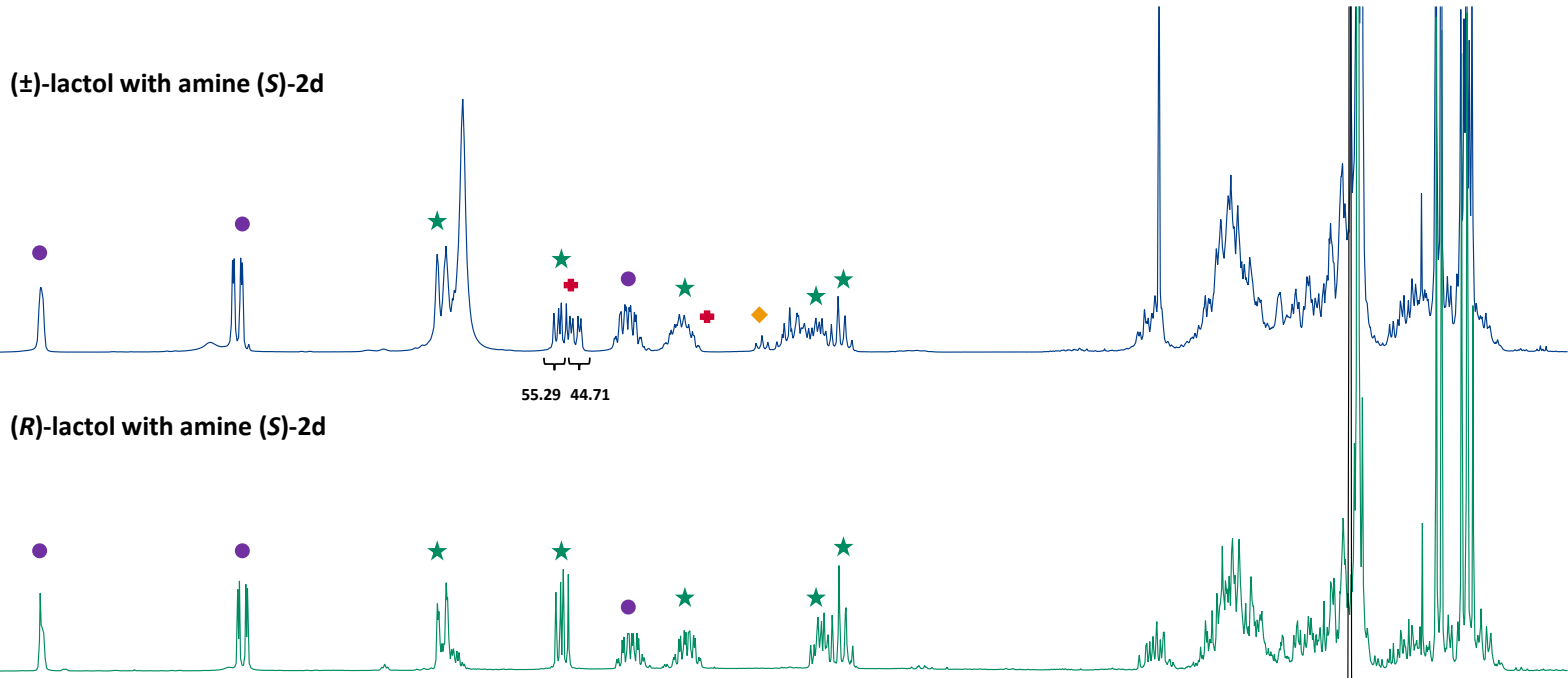

amine (S)-2d

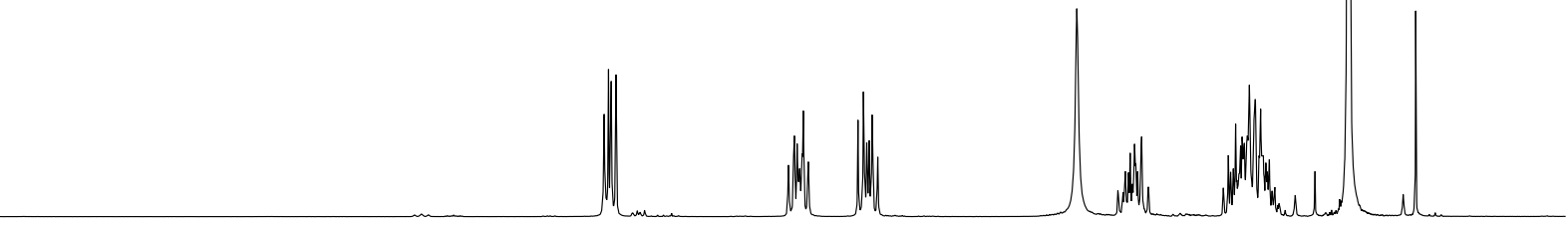

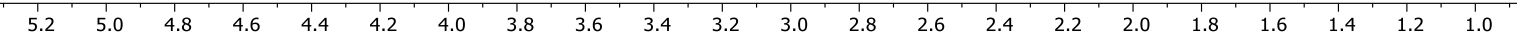
Figure S17. ${ }^{1} \mathrm{H} \mathrm{NMR}$ spectrum $\left(400 \mathrm{MHz}, \mathrm{CDCl}_{3}\right)$ in order to assign all the signals of each diastereomer of the hemiaminal ethers formed.

$d r=\frac{[(R, S) 3 d b]}{[(S, S) 3 d b]}=\frac{55.29}{44.71}=1.24$

$K_{R, S}=d r \cdot \frac{[(S) 1 \mathrm{~b}]_{0}-\frac{\operatorname{conv} \cdot[\text { amine }]_{0}}{d r+1}}{[(R) 1 \mathrm{~b}]_{0}-d r \cdot \frac{\operatorname{conv} \cdot[\text { amine }]_{0}}{d r+1}}=1.24 \cdot \frac{0.25-\frac{0.96 \cdot 0.20}{1.24+1.00}}{0.25-1.24 \cdot \frac{0.96 \cdot 0.20}{1.24+1.00}}=\mathbf{1 . 4}$ 


\subsection{Lactol resolution with amine $(S)-2 \mathrm{e}$}

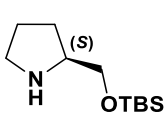

(S)-2e

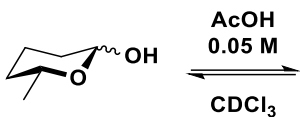

$( \pm)-1 b$

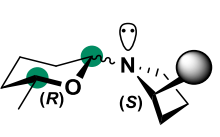

$(R, S)-3 e b$

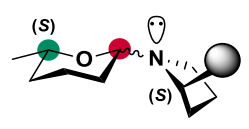

$(S, S)-3 e b$

$0.2 \mathrm{M}$

$0.5 \mathrm{M}$

Scheme S10. Resolution of lactol ( \pm )-1 $\mathbf{b}$ with amine (S)-2e.

An NMR tube was charged successively with (S)-prolinemethanol tert-butyldiphenyl ether (S)-2e (41.0 mg, $0.12 \mathrm{mmol}), \mathrm{CDCl}_{3}(0.6 \mathrm{~mL})$, racemic $\delta$-hexalactol $( \pm)$-1b $(34.8 \mathrm{mg}, 0.30 \mathrm{mmol})$ and $\mathrm{AcOH}(1.7$ $\mu \mathrm{L}, 0.03 \mathrm{mmol})$. In order to assign all the signals of each diastereomer of the hemiaminal ethers formed, enantiopure $\delta$-hexalactol $(R)$-1 $\mathbf{b}$ was mixed with $(S)$-enantiomer amine $(S)$-2e under the same reaction conditions.

We observed $90 \%$ conversion of amine (S)-2e by ${ }^{1} \mathrm{H}$ NMR spectroscopy by integrating the TBS peaks corresponding to the free amine (S)-2e and the TBS peaks of the hemiaminal 3eb (Figure S18).

$$
\text { conv amine }=\frac{90.34}{9.66+90.34} \cdot 100=90 \%
$$

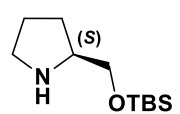

(S)-2e

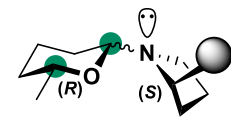

$(R, S)-3 \mathrm{eb}$

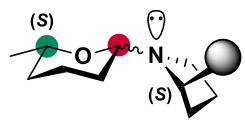

$(S, S)-3 \mathrm{eb}$

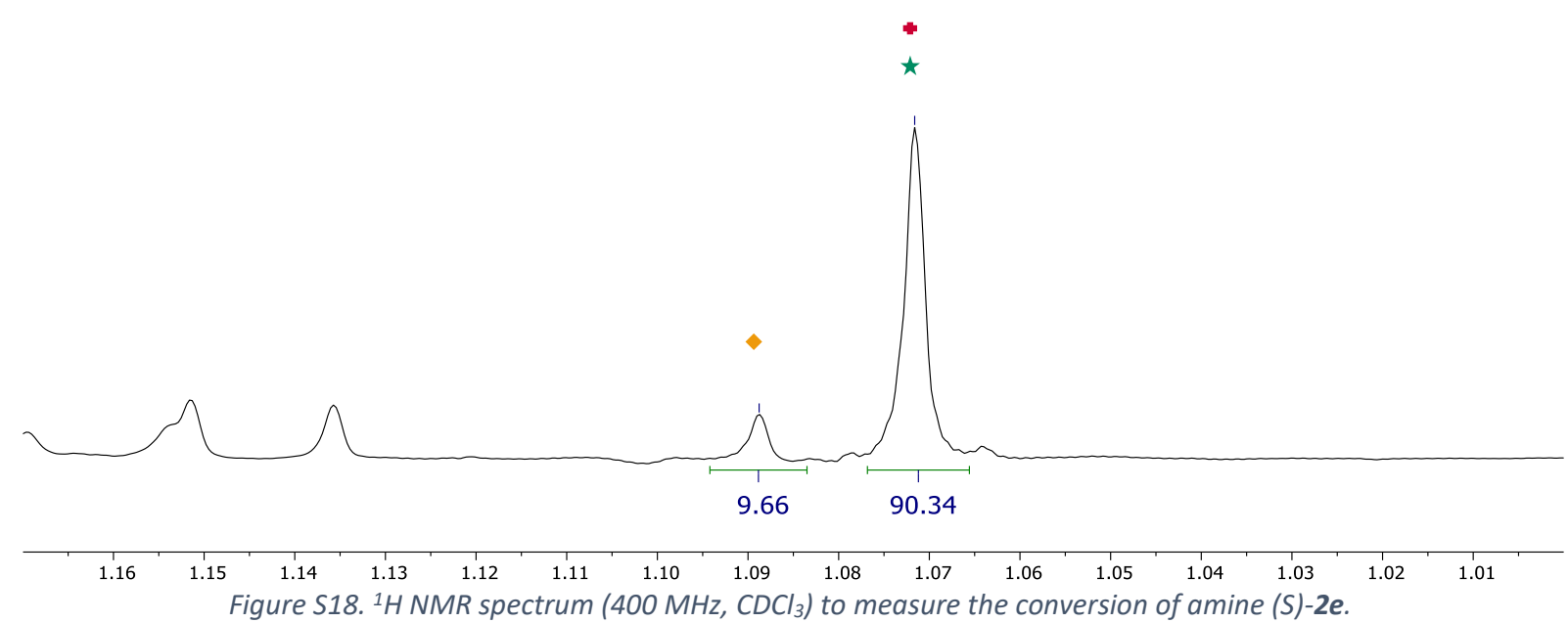



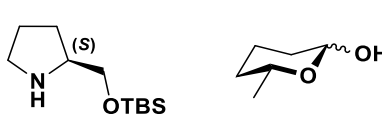

( \pm )-1b

(S)-2e

$0.2 \mathrm{M}$

$$
0.5 \mathrm{M}
$$

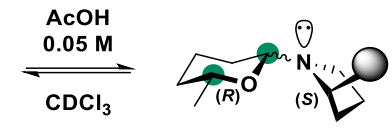

$(R, S)-3 e b$

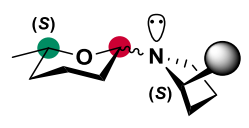

$(S, S)-3 e b$

( \pm )-lactol with amine (S)-2e

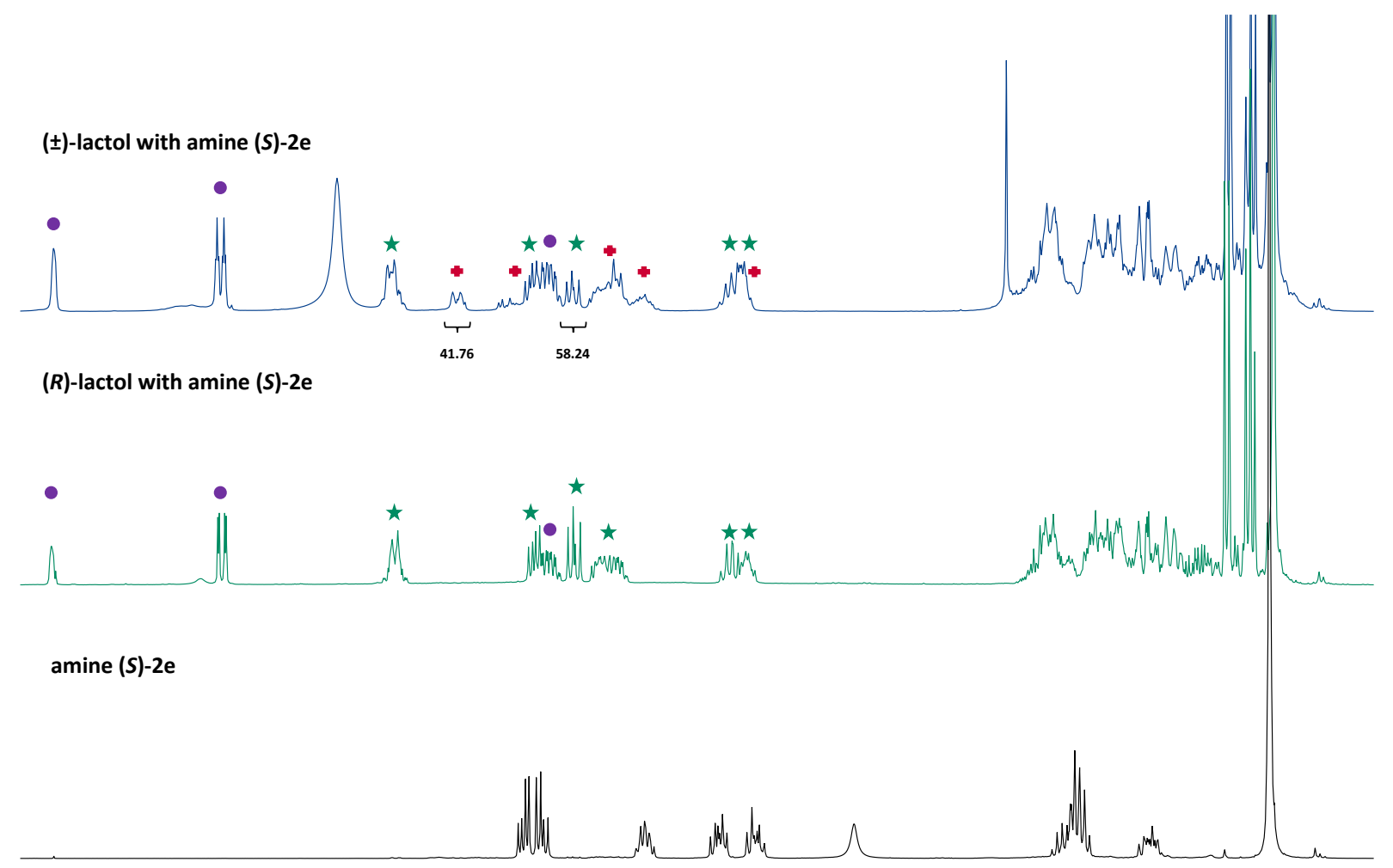

$(R)$-lactol with amine (S)-2e

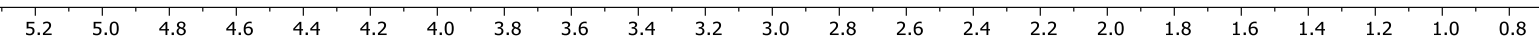
Figure S19. ${ }^{1} \mathrm{H} \mathrm{NMR}$ spectrum $\left(400 \mathrm{MHz}, \mathrm{CDCl}_{3}\right)$ in order to assign all the signals of each diastereomer of the hemiaminal ethers formed.

$$
\begin{aligned}
& d r=\frac{[(R, S) 3 e b]}{[(S, S) 3 e b]}=\frac{58.24}{41.76}=1.39 \\
& K_{R, S}=d r \cdot \frac{[(S) 1 \mathrm{~b}]_{0}-\frac{\operatorname{conv} \cdot[\text { amine }]_{0}}{d r+1}}{[(R) 1 \mathrm{~b}]_{0}-d r \cdot \frac{\operatorname{conv} \cdot[\text { amine }]_{0}}{d r+1}}=1.39 \cdot \frac{0.25-\frac{0.90 \cdot 0.20}{1.39+1.00}}{0.25-1.39 \cdot \frac{0.90 \cdot 0.20}{1.39+1.00}}=\mathbf{1 . 7}
\end{aligned}
$$




\subsection{Lactol resolution with amine $(S)-2 f$}

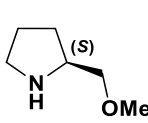

(S)-2f

$0.2 \mathrm{M}$

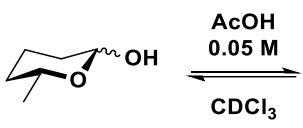

( \pm -1b

0.5 M

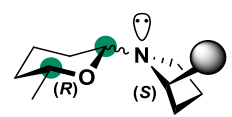

$(R, S)-3 \mathrm{fb}$

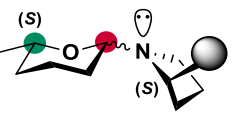

$(S, S)-3 f b$

Scheme S11. Resolution of lactol ( \pm )-1b with amine (S)-2f.

An NMR tube was charged successively with $(S)$-prolinol methyl ether $(S)-2 f(14.0 \mathrm{mg}, 0.12 \mathrm{mmol})$, $\mathrm{CDCl}_{3}(0.6 \mathrm{~mL})$, racemic $\delta$-hexalactol $( \pm)-\mathbf{1 b}(34.8 \mathrm{mg}, 0.30 \mathrm{mmol})$ and $\mathrm{AcOH}(1.7 \mu \mathrm{L}, 0.03 \mathrm{mmol})$. In order to assign all the signals of each diastereomer of the hemiaminal ethers formed, enantiopure $\delta$-hexalactol $(R)$-1 $\mathbf{b}$ was mixed with $(R)$-enantiomer amine $(R)$-2f under the same reaction conditions.

We observed $94 \%$ conversion of amine $(S)$-2f by ${ }^{1} \mathrm{H}$ NMR spectroscopy by integrating the methyl peak corresponding to the free amine (S)-2f and the methyl peaks of the hemiaminal $\mathbf{3} \mathbf{f b}$ (Figure S20).

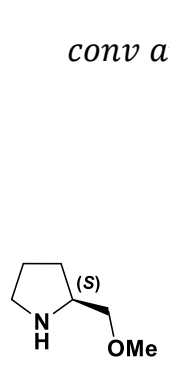

(S)-2f

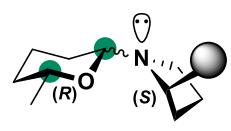

(R,S)-3fb

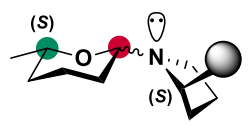

$(S, S)-3 \mathrm{fb}$

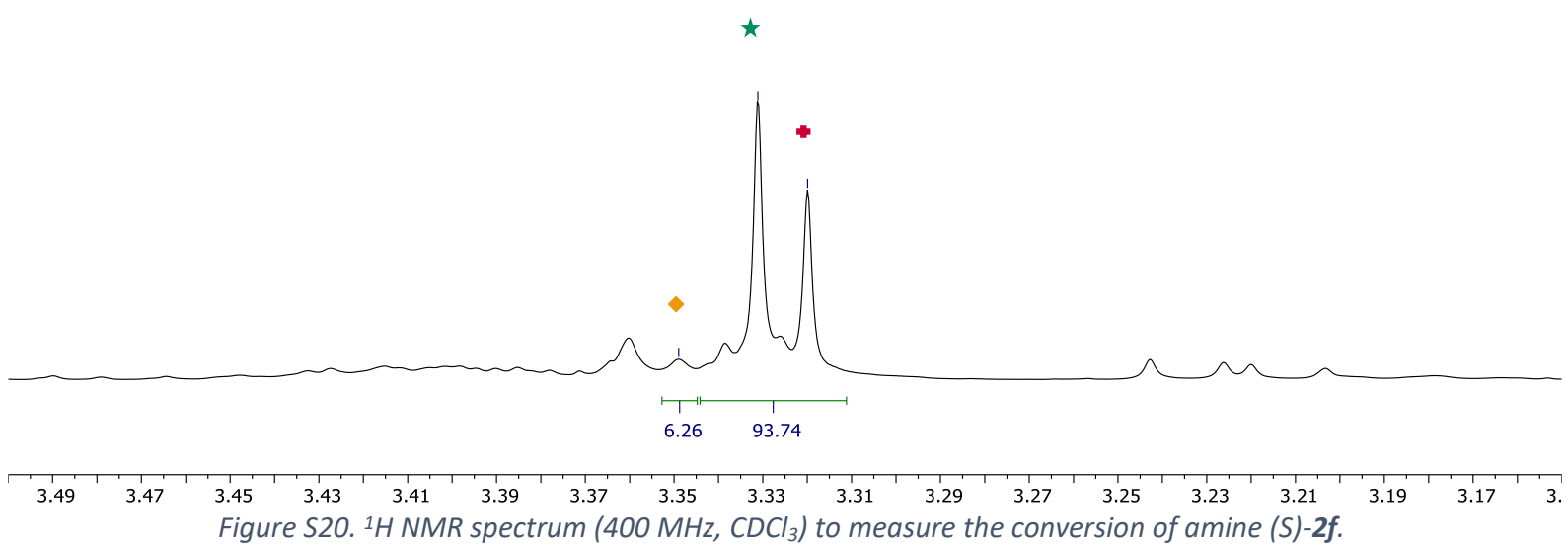




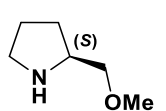

(S)-2f

$0.2 \mathrm{M}$

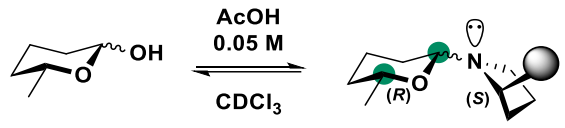

( \pm )-1b

$0.5 \mathrm{M}$

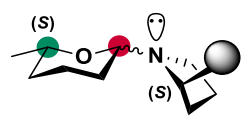

$(s, s)-3 \mathrm{fb}$

( \pm )-lactol with amine (S)-2f

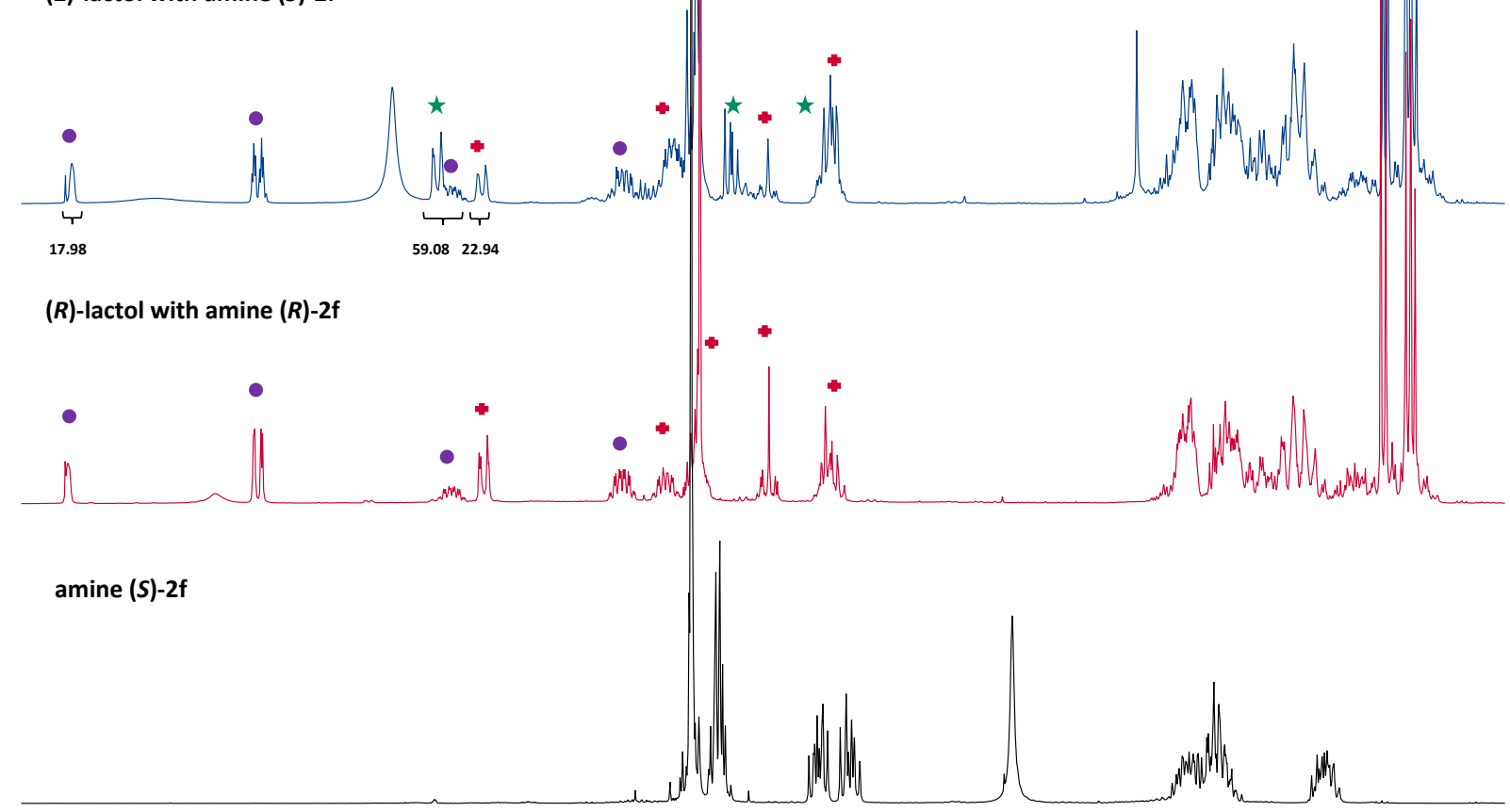

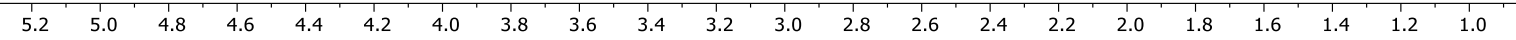
Figure S21. ${ }^{1} \mathrm{H} \mathrm{NMR}$ spectrum $\left(400 \mathrm{MHz}^{\mathrm{C}} \mathrm{CDCl}_{3}\right)$ in order to assign all the signals of each diastereomer of the hemiaminal ethers formed.

$d r=\frac{[(R, S) 3 f b]}{[(S, S) 3 f b]}=\frac{(59.08-17.98)}{22.94}=1.79$

$K_{R, S}=d r \cdot \frac{[(S) 1 \mathrm{~b}]_{0}-\frac{\operatorname{conv} \cdot[\text { amine }]_{0}}{d r+1}}{[(R) 1 \mathrm{~b}]_{0}-d r \cdot \frac{\operatorname{conv} \cdot[\text { amine }]_{0}}{d r+1}}=1.79 \cdot \frac{0.25-\frac{0.94 \cdot 0.20}{1.79+1.00}}{0.25-1.79 \cdot \frac{0.94 \cdot 0.20}{1.79+1.00}}=\mathbf{2 . 5}$ 


\subsection{Lactol resolution with amine $(S)-2 \mathrm{~g}$}

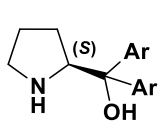

(S)-2g

$0.2 \mathrm{M}$

$\mathrm{Ar}=3,5-\mathrm{CF}_{3} \mathrm{Ph}$

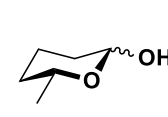

$( \pm)-1 b$

$0.5 \mathrm{M}$

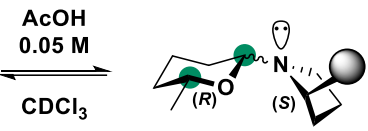

$(R, S)-3 \mathrm{gb}$

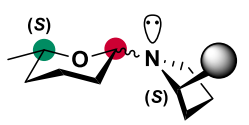

$(S, S)-3 g b$

Scheme S12. Resolution of lactol ( \pm )-1b with amine (S)-2g.

An NMR tube was charged successively with (S)- $\alpha, \alpha$-bis[3,5-bis(trifluoromethyl)phenyl]-2pyrrolidinmethanol $(S)-2 \mathrm{~g}(63.0 \mathrm{mg}, 0.12 \mathrm{mmol}), \mathrm{CDCl}_{3}(0.6 \mathrm{~mL})$, racemic $\delta$-hexalactol $( \pm)-\mathbf{1 b}(34.8 \mathrm{mg}$, $0.30 \mathrm{mmol})$ and $\mathrm{AcOH}(1.7 \mu \mathrm{L}, 0.03 \mathrm{mmol})$. In order to assign all the signals of each diastereomer of the hemiaminal ethers formed, enantiopure $\delta$-hexalactol $(R)$-1 $\mathbf{1 b}$ was mixed with $(S)$-enantiomer amine (S)-2g under the same reaction conditions.

We observed $34 \%$ conversion of lactol $( \pm)-\mathbf{1 b}$ by ${ }^{1} \mathrm{H}$ NMR spectroscopy by integrating the hemiacetal peaks corresponding to the lactol ( \pm )-1 $\mathbf{b}$ and the hemiaminal $\mathbf{3 g b}$ peaks. Therefore, we observe $85 \%$ conversion of amine (S)-2g (Figure S22).

$$
\begin{gathered}
\text { conv lactol }=\frac{1+0.30}{0.76+1.77+1+0.30} \cdot 100=34 \% \\
\text { conv amine }=\frac{0.34 \cdot 0.5}{0.2} \cdot 100=85 \%
\end{gathered}
$$

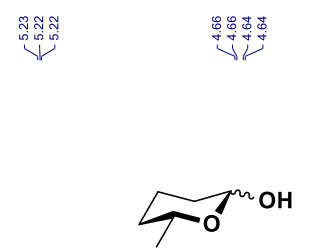

$( \pm)-1 b$

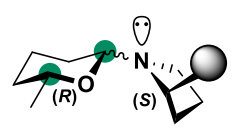

$(R, S)-3 g b$

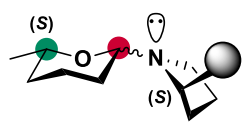

$(S, S)-3 g b$

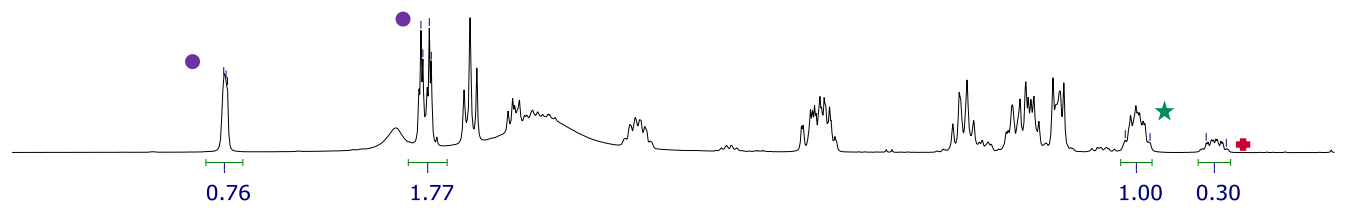

$\begin{array}{llllllllllllllllllllllllllllllllllllll}5.8 & 5.7 & 5.6 & 5.5 & 5.4 & 5.3 & 5.2 & 5.1 & 5.0 & 4.9 & 4.8 & 4.7 & 4.6 & 4.5 & 4.4 & 4.3 & 4.2 & 4.1 & 4.0 & 3.9 & 3.8 & 3.7 & 3.6 & 3.5 & 3.4 & 3.3 & 3.2 & 3.1 & 3.0 & 2.9 & 2.8 & 2.7 & 2.6 & 2.5 & 2.4 & 2.3 & 2.2 & 2.1\end{array}$

Figure S22. ${ }^{1} \mathrm{H} \mathrm{NMR} \mathrm{spectrum}\left(400 \mathrm{MHz}, \mathrm{CDCl}_{3}\right)$ to measure the conversion of amine (S)-2g. 


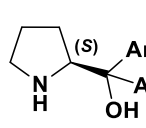

(S)-2g

$0.2 \mathrm{M}$

$\mathrm{Ar}=3,5-\mathrm{CF}_{3} \mathrm{Ph}$

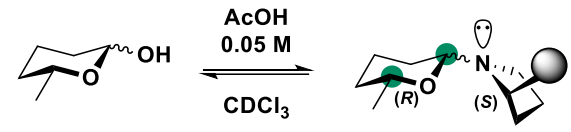

(R,S)-3gb

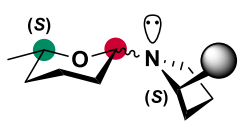

$(S, S)-3 g b$

$0.5 \mathrm{M}$

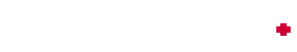

( \pm )-lactol with amine (S)-2g

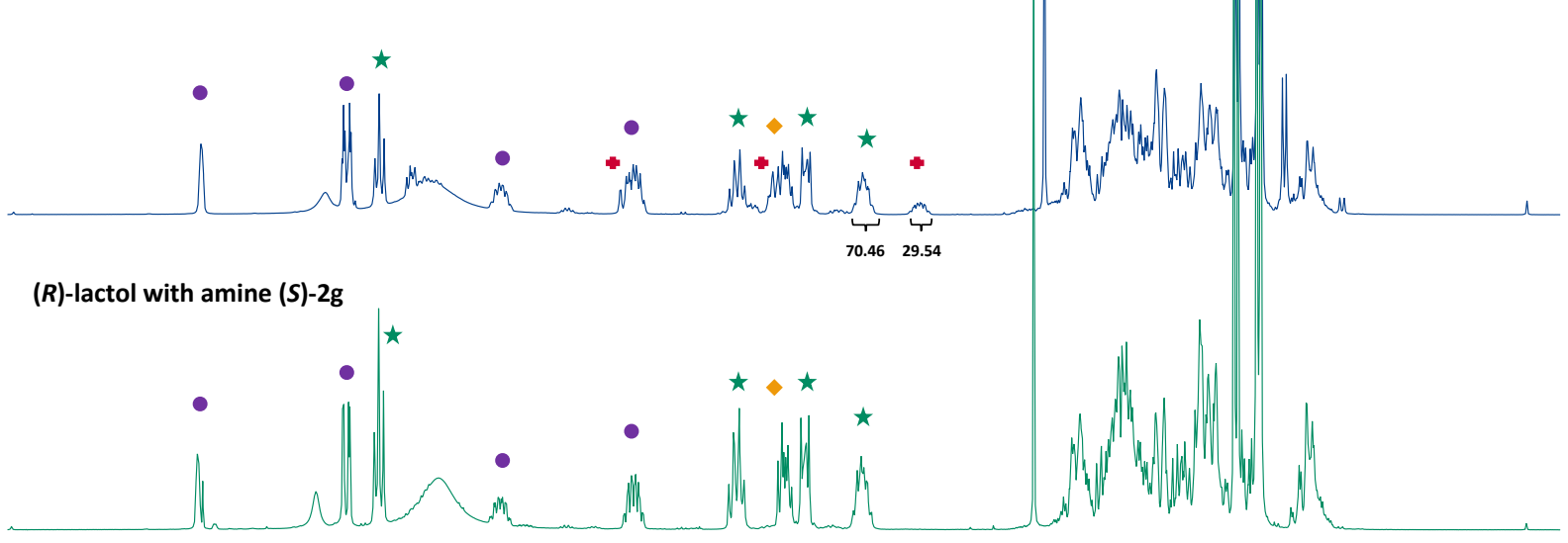

amine (S)-2g

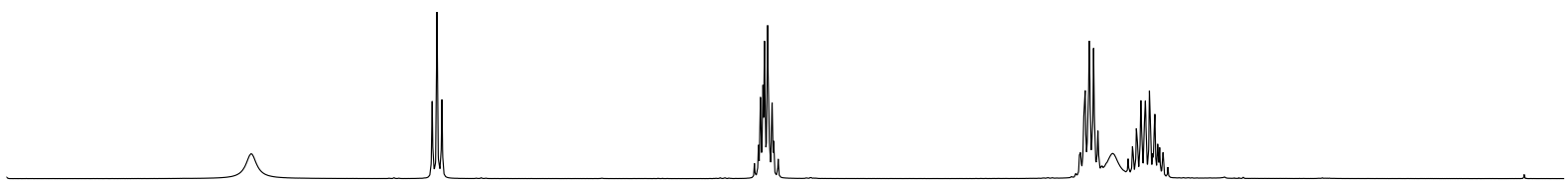

$\begin{array}{llllllllllllllllllllllllllllllllllllllllll}6.0 & 5.8 & 5.6 & 5.4 & 5.2 & 5.0 & 4.8 & 4.6 & 4.4 & 4.2 & 4.0 & 3.8 & 3.6 & 3.4 & 3.2 & 3.0 & 2.8 & 2.6 & 2.4 & 2.2 & 2.0 & 1.8 & 1.6 & 1.4 & 1.2 & 1.0 & 0.8 & 0.6 & 0.4 & 0.2 & 0.0\end{array}$ Figure S23. ${ }^{1} \mathrm{H} \mathrm{NMR} \mathrm{spectrum}\left(400 \mathrm{MHz}, \mathrm{CDCl}_{3}\right)$ in order to assign all the signals of each diastereomer of the hemiaminal ethers formed.

$d r=\frac{[(R, S) 3 g b]}{[(S, S) 3 g b]}=\frac{70.46}{29.54}=2.38$

$K_{R, S}=d r \cdot \frac{[(S) 1 \mathrm{~b}]_{0}-\frac{\operatorname{conv} \cdot[\text { amine }]_{0}}{d r+1}}{[(R) 1 \mathrm{~b}]_{0}-d r \cdot \frac{\operatorname{conv} \cdot[\text { amine }]_{0}}{d r+1}}=2.38 \cdot \frac{0.25-\frac{0.85 \cdot 0.20}{2.38+1.00}}{0.25-2.38 \cdot \frac{0.85 \cdot 0.20}{2.38+1.00}}=\mathbf{3 . 6}$ 


\subsection{Lactol resolution with amine $(S)-2 \mathrm{~h}$}

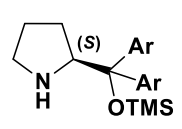

(S)-2h

$0.2 \mathrm{M}$ $\mathrm{Ar}=3,5-\mathrm{CF}_{3} \mathrm{Ph}$

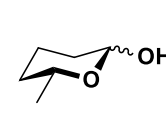

$( \pm)-1 b$

$0.5 \mathrm{M}$

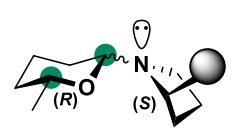

$(R, S)-3 \mathrm{hb}$

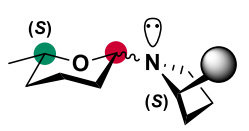

$(S, S)-3 \mathrm{hb}$

Scheme S13. Resolution of lactol ( \pm )-1b with amine (S)-2h.

An NMR tube was charged successively with $(S)$ - $\alpha, \alpha$-bis[3,5-(trifluoromethyl)phenyl]-2-pyrrolidinemethanol trimethylsilyl ether $(S)$ - $\mathbf{2 h}(72.0 \mathrm{mg}, 0.12 \mathrm{mmol}), \mathrm{CDCl}_{3}(0.6 \mathrm{~mL})$, racemic $\delta$-hexalactol $( \pm)-\mathbf{1 b}$ (34.8 $\mathrm{mg}, 0.30 \mathrm{mmol})$ and $\mathrm{AcOH}(1.7 \mu \mathrm{L}, 0.03 \mathrm{mmol})$. In order to assign all the signals of each diastereomer of the hemiaminal ethers formed, two reactions with the enantiopure $\delta$-hexalactol $(R)$ $\mathbf{1 b}$ were set up, one with the $(S)$-enantiomer amine $(S)$ - $\mathbf{2 h}$ and the other one with the $(R)$-enantiomer amine $(R)-\mathbf{2 h}$.

We observed $89 \%$ conversion of amine (S)-2h by ${ }^{1} \mathrm{H}$ NMR spectroscopy by integrating the TMS peaks corresponding to the free amine (S)-2h and the TMS peaks of the hemiaminal $3 \mathbf{h b}$ (Figure S24).

$$
\text { conv amine }=\frac{89.51}{89.51+10.49} \cdot 100=89 \%
$$

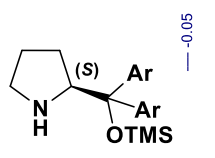

(S)-2h

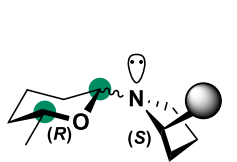

$(R, S)-3 h b$

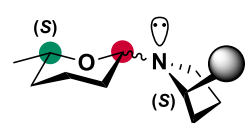

$(S, S)-3 h b$

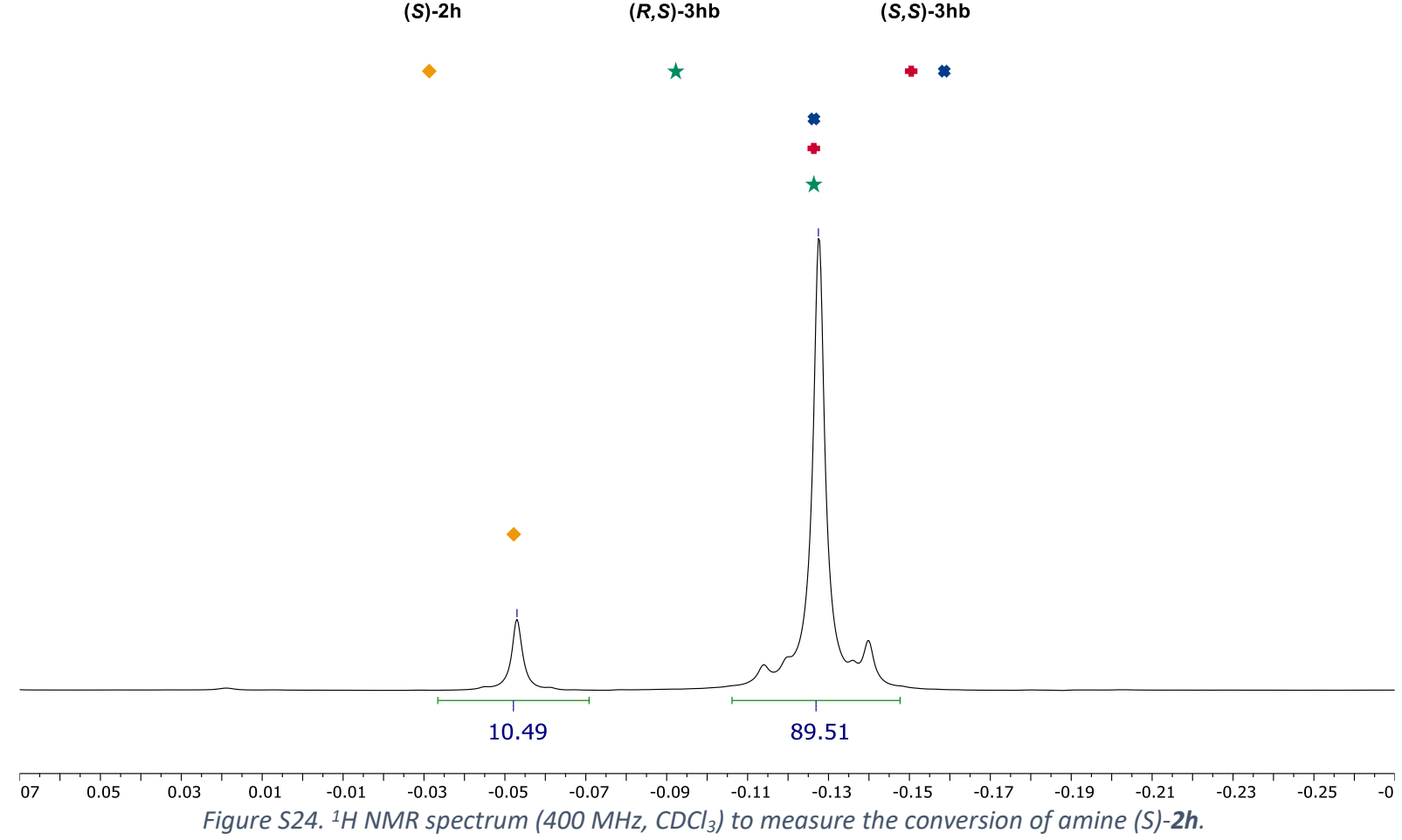




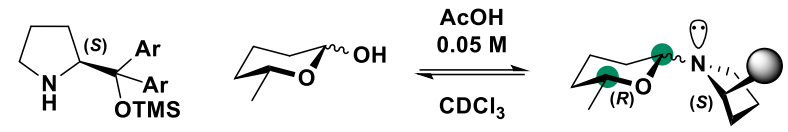

(S)-2h

( \pm )-1b

$0.2 \mathrm{M}$

$\mathrm{Ar}=3,5-\mathrm{CF}_{3} \mathrm{Ph}$

$0.5 \mathrm{M}$

(R,S)-3hb

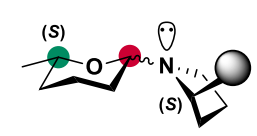

(S,S)-3hb

( \pm )-lactol with amine (S)-2h

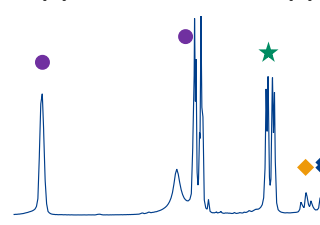

$(R)$-lactol with amine (S)-2h
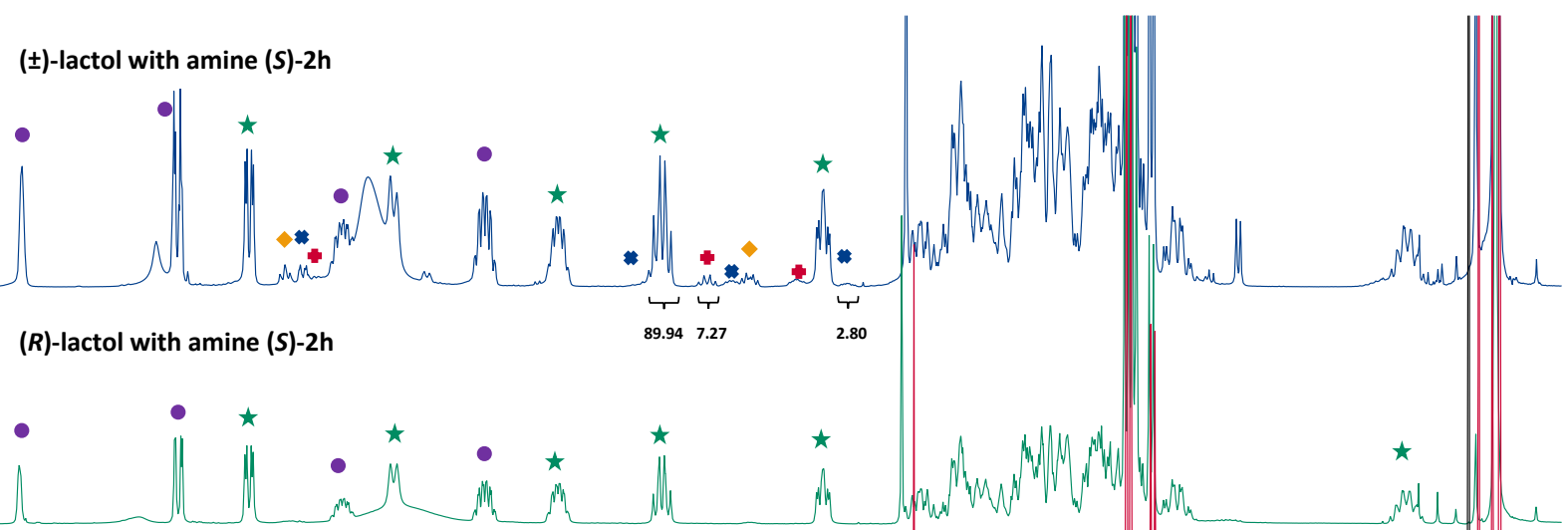

(R)-lactol with amine (R)-2h
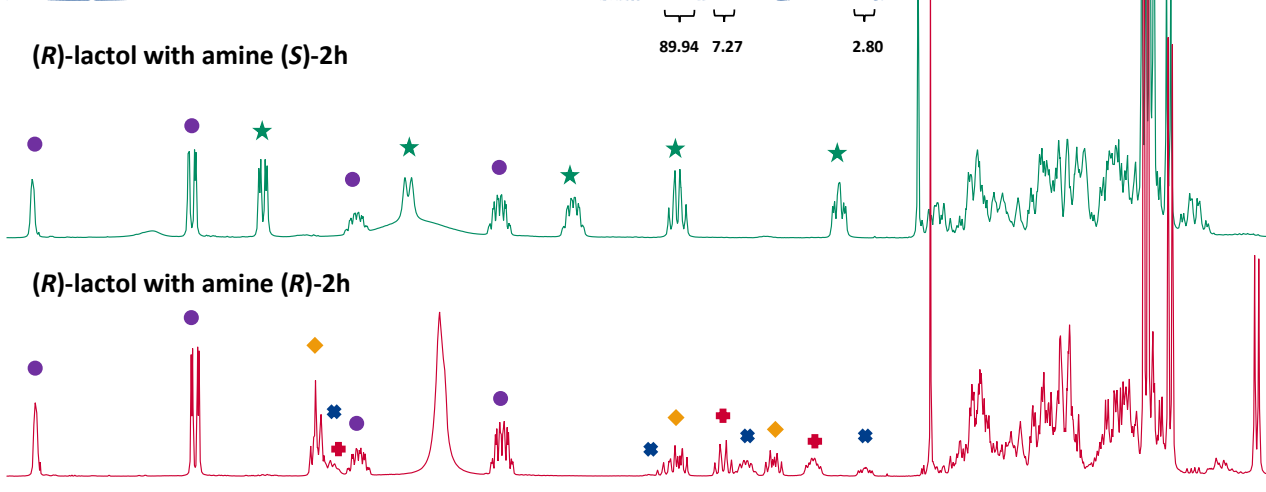

amine (S)-2h

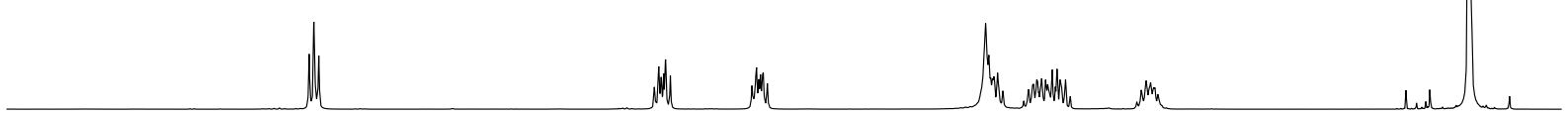

$\begin{array}{llllllllllllllllllllllllllllllll}5.2 & 5.0 & 4.8 & 4.6 & 4.4 & 4.2 & 4.0 & 3.8 & 3.6 & 3.4 & 3.2 & 3.0 & 2.8 & 2.6 & 2.4 & 2.2 & 2.0 & 1.8 & 1.6 & 1.4 & 1.2 & 1.0 & 0.8 & 0.6 & 0.4 & 0.2 & 0.0 & -0.2\end{array}$ Figure S25. ${ }^{1} \mathrm{H} N M R$ spectrum $\left(400 \mathrm{MHz} \mathrm{CDCl}_{3}\right)$ in order to assign all the signals of each diastereomer of the hemiaminal ethers formed.

$$
\begin{aligned}
& d r=\frac{[(R, S) 3 h b]}{[(S, S) 3 h b]}=\frac{89.94}{(7.27+2.8)}=8.93 \\
& K_{R, S}=d r \cdot \frac{[(S) 1 \mathrm{~b}]_{0}-\frac{\text { conv } \cdot[\text { amine }]_{0}}{d r+1}}{[(R) 1 \mathrm{~b}]_{0}-d r \cdot \frac{\operatorname{conv} \cdot[\text { amine }]_{0}}{d r+1}}=8.93 \cdot \frac{0.25-\frac{0.89 \cdot 0.20}{8.93+1.00}}{0.25-8.93 \cdot \frac{0.89 \cdot 0.20}{8.93+1.00}}=\mathbf{2 3}
\end{aligned}
$$




\subsection{Lactol resolution with amine $(S)-2 i$}

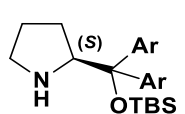

(S)-2i

$0.25 \mathrm{M}$ $\mathrm{Ar}=3,5-\mathrm{CF}_{3} \mathrm{Ph}$

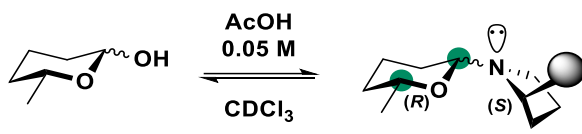

$(R, S)-3 i b$

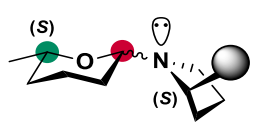

$(S, S)-3 i b$

$0.5 \mathrm{M}$

Scheme S14. Resolution of lactol ( \pm )-1b with amine (S)-2i.

An NMR tube was charged successively with (S)- $\alpha, \alpha$-bis[3,5-bis(trifluoromethyl)phenyl]-2pyrrolidinemethanol tert-butyldimethylsilyl ether $(S)-2 \mathbf{i}(93.7 \mathrm{mg}, 0.12 \mathrm{mmol}), \mathrm{CDCl}_{3}(0.6 \mathrm{~mL})$, racemic $\delta$-hexalactol ( \pm )-1b (34.8 mg, $0.30 \mathrm{mmol})$ and $\mathrm{AcOH}(1.7 \mu \mathrm{L}, 0.03 \mathrm{mmol})$.

We observed $42 \%$ conversion of lactol $( \pm)-\mathbf{1 b}$ by ${ }^{1} \mathrm{H}$ NMR spectroscopy by integrating the hemiacetal peaks corresponding to the lactol $( \pm)-\mathbf{1 b}$ and the hemiaminal 3ib peaks. Therefore, we observe $85 \%$ conversion of amine (S)-2i (Figure S26).

$$
\begin{gathered}
\text { conv lactol }=\frac{1.01+0.11}{0.55+0.95+1.01+0.11} \cdot 100=42 \% \\
\text { conv amine }=\frac{0.34 \cdot 0.5}{0.25} \cdot 100=85 \%
\end{gathered}
$$

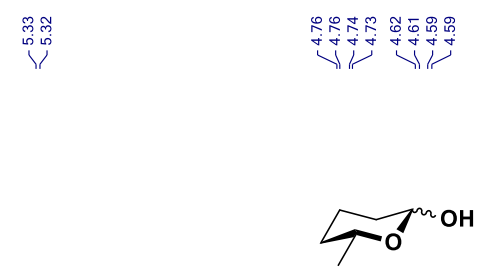

$( \pm)-1 b$

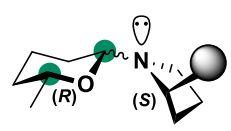

$(R, S)-3 i b$

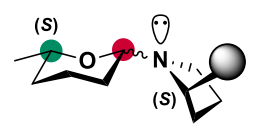

$(S, S)-3 i b$

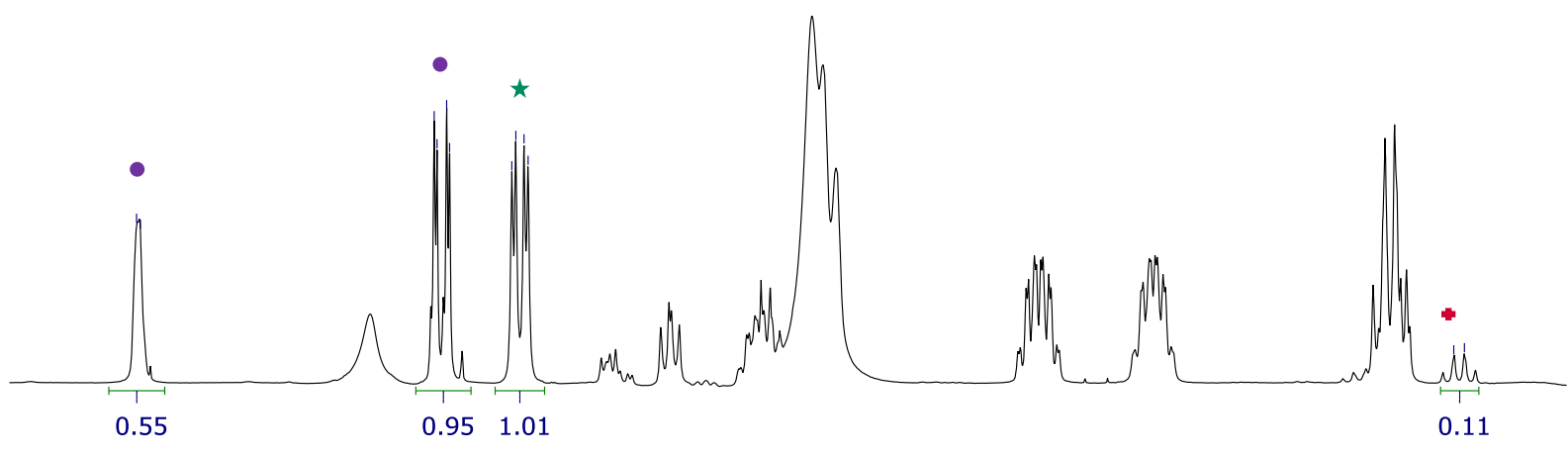

$\begin{array}{lllllllllllllllllllllllllllllllll}5.5 & 5.4 & 5.3 & 5.2 & 5.1 & 5.0 & 4.9 & 4.8 & 4.7 & 4.6 & 4.5 & 4.4 & 4.3 & 4.2 & 4.1 & 4.0 & 3.9 & 3.8 & 3.7 & 3.6 & 3.5 & 3.4 & 3.3 & 3.2 & 3.1 & 3.0 & 2.9 & 2.8 & 2.7 & \end{array}$ Figure S26. ${ }^{1} \mathrm{H} N \mathrm{NR}$ spectrum $\left(400 \mathrm{MHz}, \mathrm{CDCl}_{3}\right)$ to measure the conversion of amine (S)-2i. 


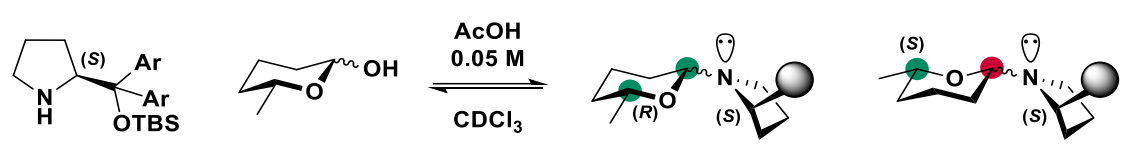
(S)-2i
( \pm )-1b
(R,S)-3ib
$(S, S)-3 i b$

$0.25 \mathrm{M}$

$0.5 \mathrm{M}$

$\mathrm{Ar}=3,5-\mathrm{CF}_{3} \mathrm{Ph}$

( \pm )-lactol with amine (S)-2i

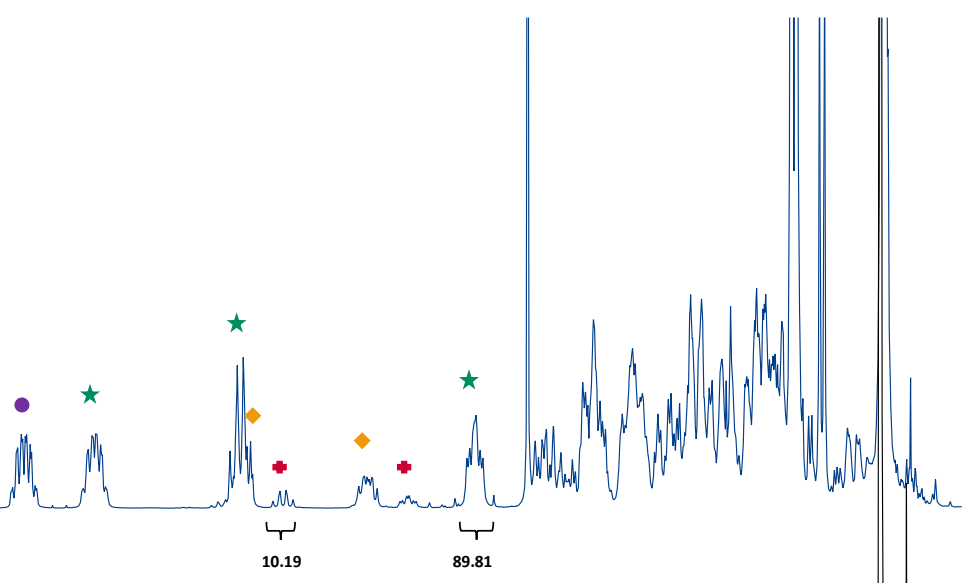

amine (S)-2i

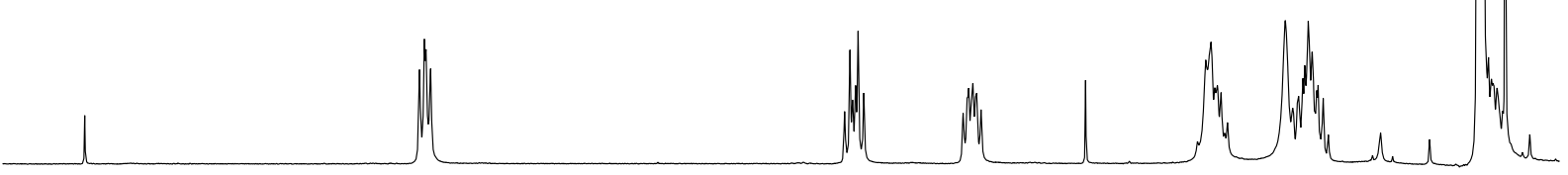

Figure S27. ${ }^{1} \mathrm{H} N M R$ spectrum $\left(400 \mathrm{MHz}, \mathrm{CDCl}_{3}\right)$ compared to amine (S)-2i.

$$
\begin{aligned}
& d r=\frac{[(R, S) 3 i b]}{[(S, S) 3 i b]}=\frac{89.91}{10.19}=8.8 \\
& K_{R, S}=d r \cdot \frac{[(S) 1 \mathrm{~b}]_{0}-\frac{\operatorname{conv} \cdot[\text { amine }]_{0}}{d r+1}}{[(R) 1 \mathrm{~b}]_{0}-d r \cdot \frac{\operatorname{conv} \cdot[\text { amine }]_{0}}{d r+1}}=8.8 \cdot \frac{0.25-\frac{0.85 \cdot 0.25}{8.8+1.00}}{0.25-8.8 \cdot \frac{0.85 \cdot 0.25}{8.8+1.00}}=\mathbf{3 4}
\end{aligned}
$$




\section{Formation of a single diastereoisomer of the hemiaminal ether $(S, R, R)$-3aa}

Having successfully found a highly selective resolution agent, we wanted to evaluate its control on the hemiaminal carbon in the absence of substituents in the lactol. To do so, amine (S)-2a (44.0 mg, $0.12 \mathrm{mmol}$ ) was added to a solution of $\delta$-valerolactol $1 \mathrm{a}(30.6 \mathrm{mg}, 0.30 \mathrm{mmol})$ in $\mathrm{CDCl}_{3}(0.6 \mathrm{~mL})$ and placed into an NMR tube followed by the addition of AcOH $(1.8 \mathrm{mg}, 0.03 \mathrm{mmol})$ to accelerate the equilibration. We immediately observed $60 \%$ conversion of the amine $(S)-2 a$, and the formation of a single diastereoisomeric hemiaminal $(S, R, R)$-3aa by ${ }^{1} \mathrm{H}$ and ${ }^{13} \mathrm{C}\{1 \mathrm{H}\}$ NMR spectroscopy (Figure S28).

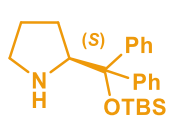

(S)-2a

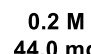

$0.12 \mathrm{mmo}$

$\Delta$

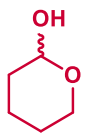

$1 \mathrm{a}$

$0.5 \mathrm{M}$

$30.6 \mathrm{mg}$

$0.30 \mathrm{mmol}$

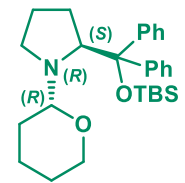

$(S, R, R)-3$ aa

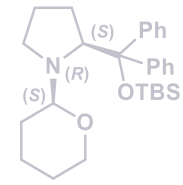

$(S, R, S)-3$ aa

$60 \%$ conv amine

single diastereoisomer

not observed

\section{${ }^{1} \mathrm{H} \mathrm{NMR}, 400 \mathrm{MHz}, \mathrm{CDCl}_{3}$}

crude after mixing (S)-2a and 1a
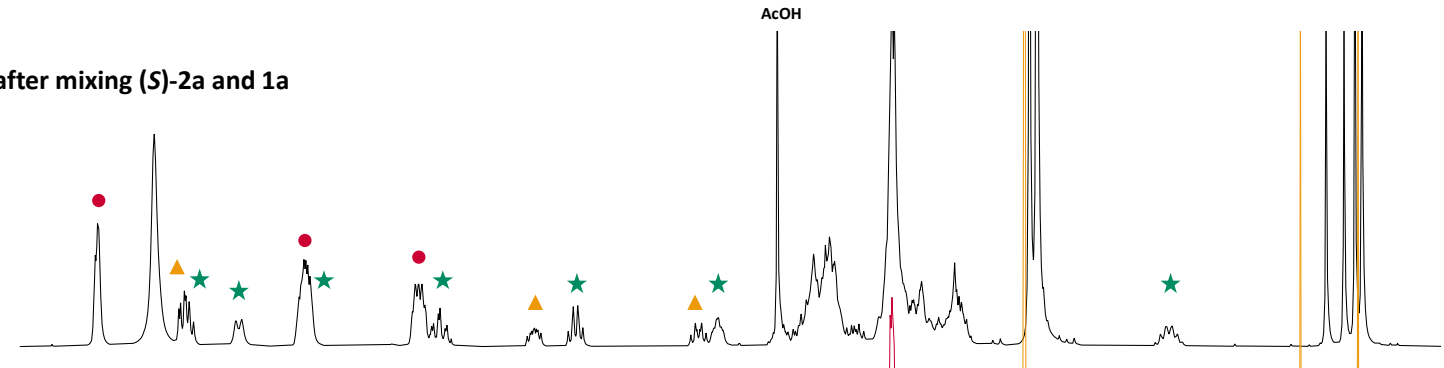
$M N$<smiles>O[C@H]1CCCCO1</smiles>

$1 \mathrm{a}$
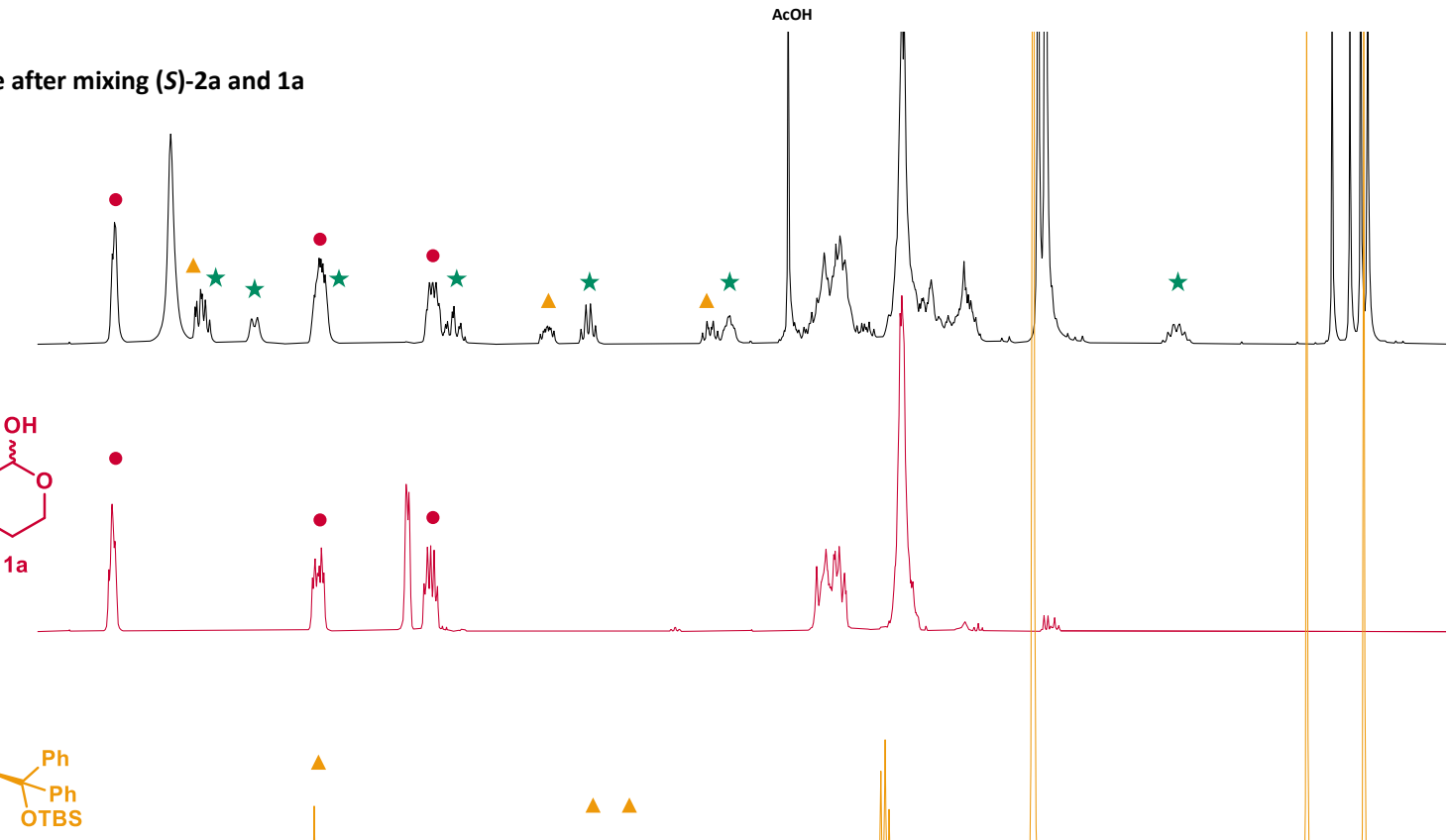

$(S)-2 a$

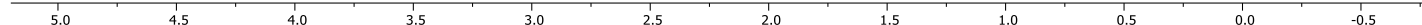

Figure S28. ${ }^{1} \mathrm{H} N \mathrm{NR}$ spectrum $\left(400 \mathrm{MHz}, \mathrm{CDCl}_{3}\right)$ compared to lactol 1a and amine (S)-2a.

For the assignment of the peaks see page S-63. 

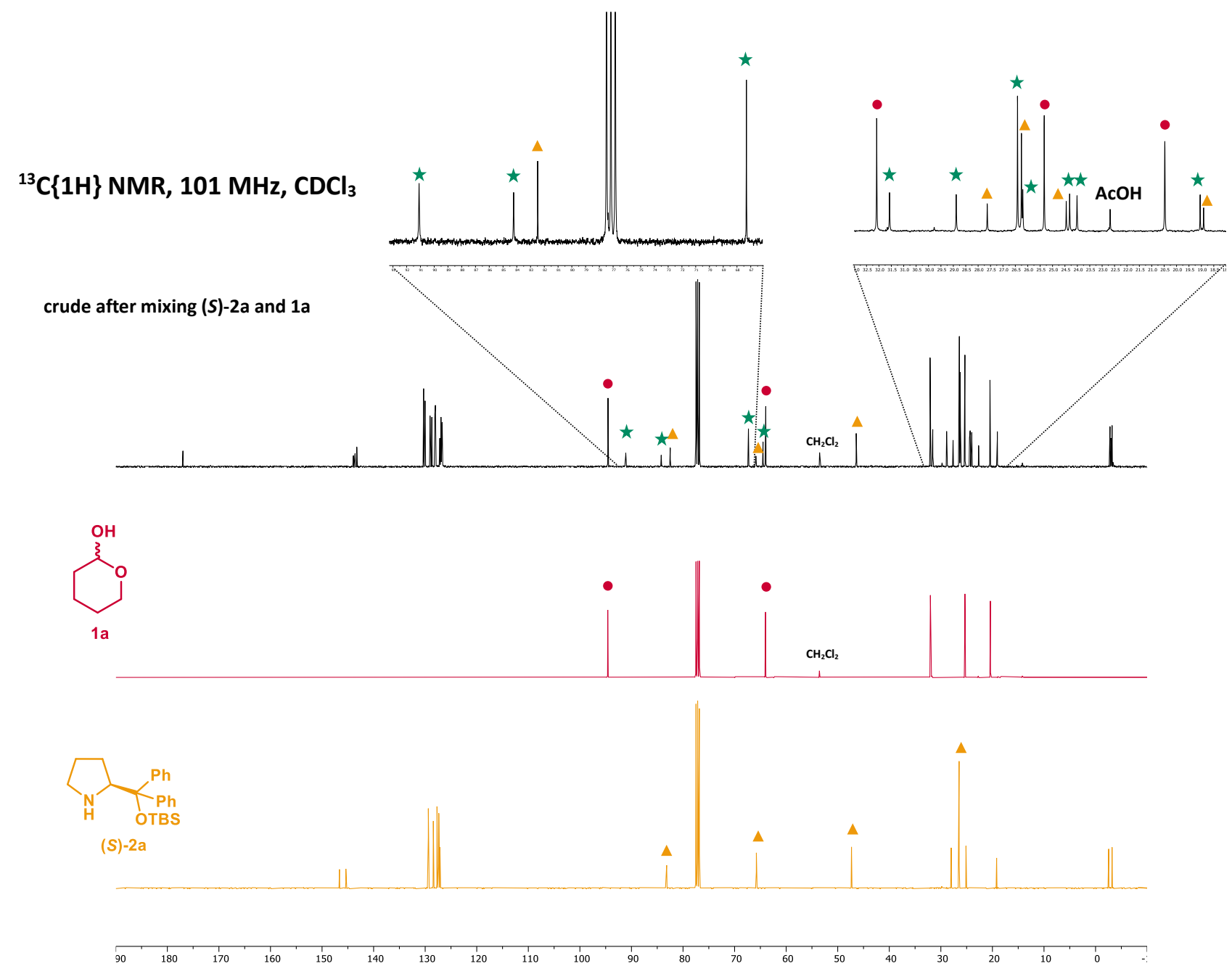

Figure S29. ${ }^{13} \mathrm{C}\{\mathrm{H}\} \mathrm{NMR}$ spectrum $\left(101 \mathrm{MHz}, \mathrm{CDCl}_{3}\right)$ compared to lactol $1 \mathrm{a}$ and amine (S)-2a. 


\section{Characterization of hemiaminal ether $(S, R, R)$-3aa}

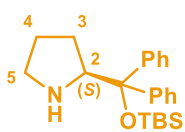

$(S)-2 a$<smiles>CC1CC2CC3CC2CC3C1O</smiles>

$1 \mathrm{a}$

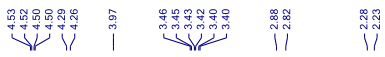

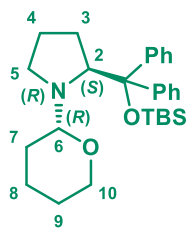

$(S, R, R)-3$ aa

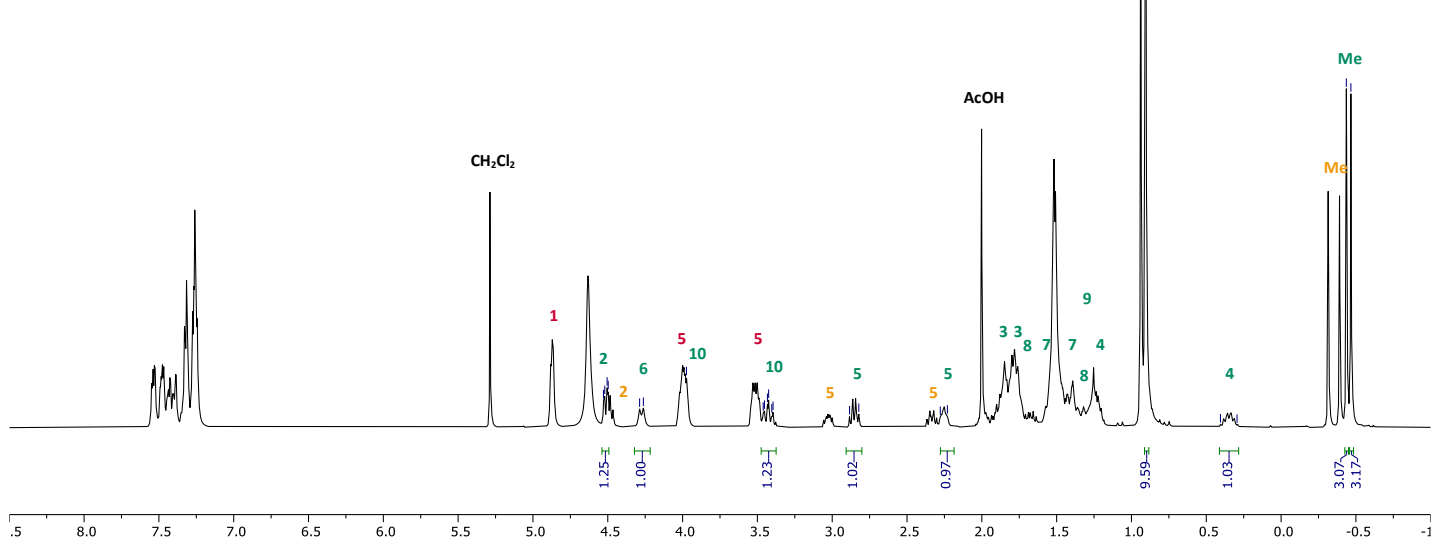

Figure S30. ${ }^{1} \mathrm{H} N M R$ spectrum $\left(400 \mathrm{MHz}, \mathrm{CDCl}_{3}\right)$ of crude hemiaminal ether $(S, R, R)-3 a a$.

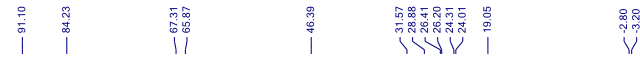

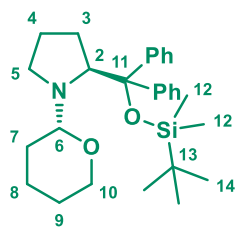

$(S, R, R)-3$ aa
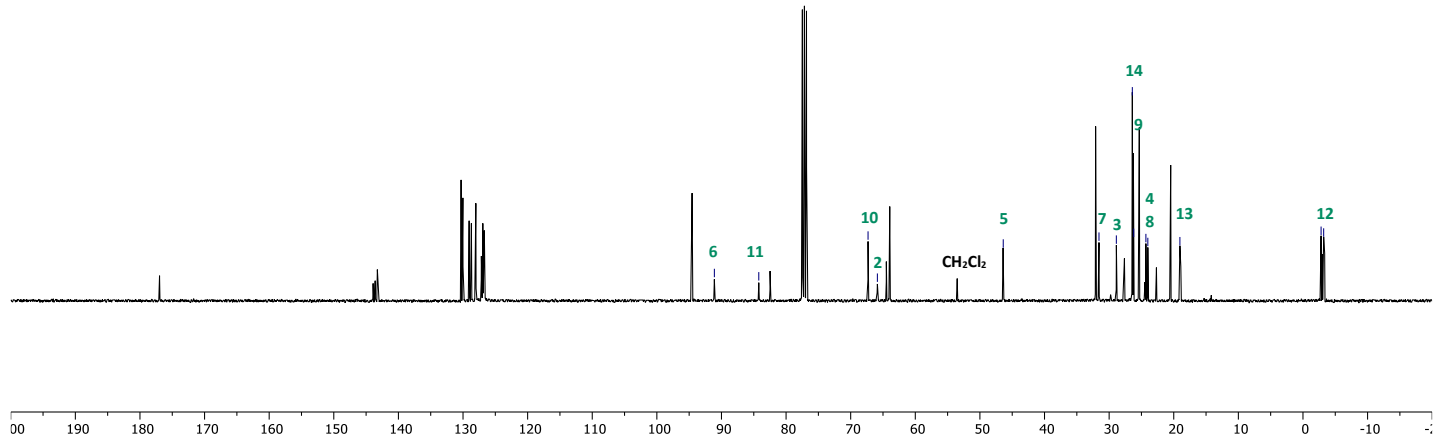

Figure $S 31 .{ }^{13} \mathrm{C}\{\mathrm{H}\} \mathrm{NMR}$ spectrum $\left(101 \mathrm{MHz}, \mathrm{CDCl}_{3}\right)$ of crude hemiaminal ether $(S, R, R)$-3aa. 


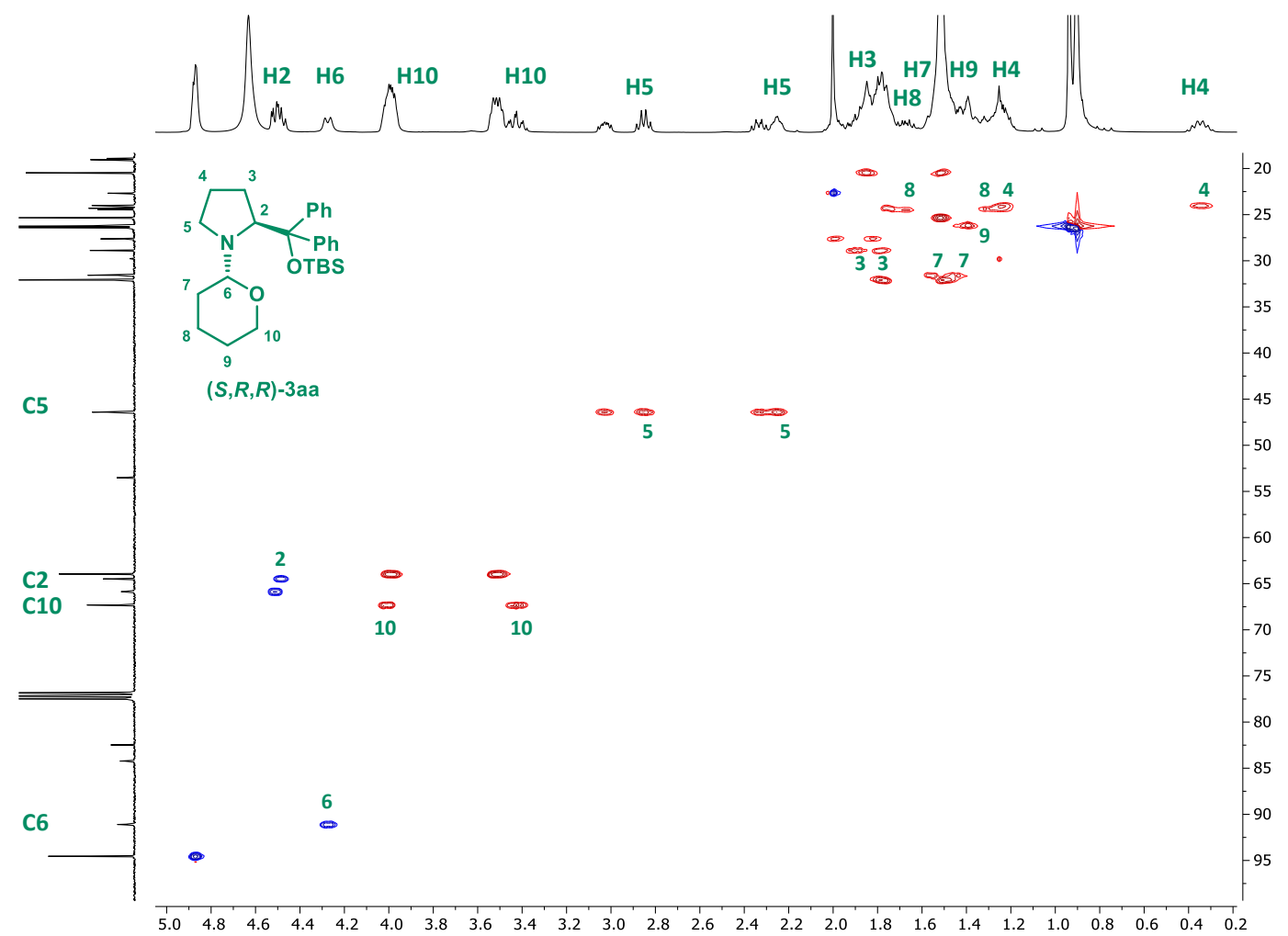

Figure S32. HSQC spectrum $\left(400 \mathrm{MHz}, \mathrm{CDCl}_{3}\right)$ of crude hemiaminal ether $(S, R, R)$-3aa.

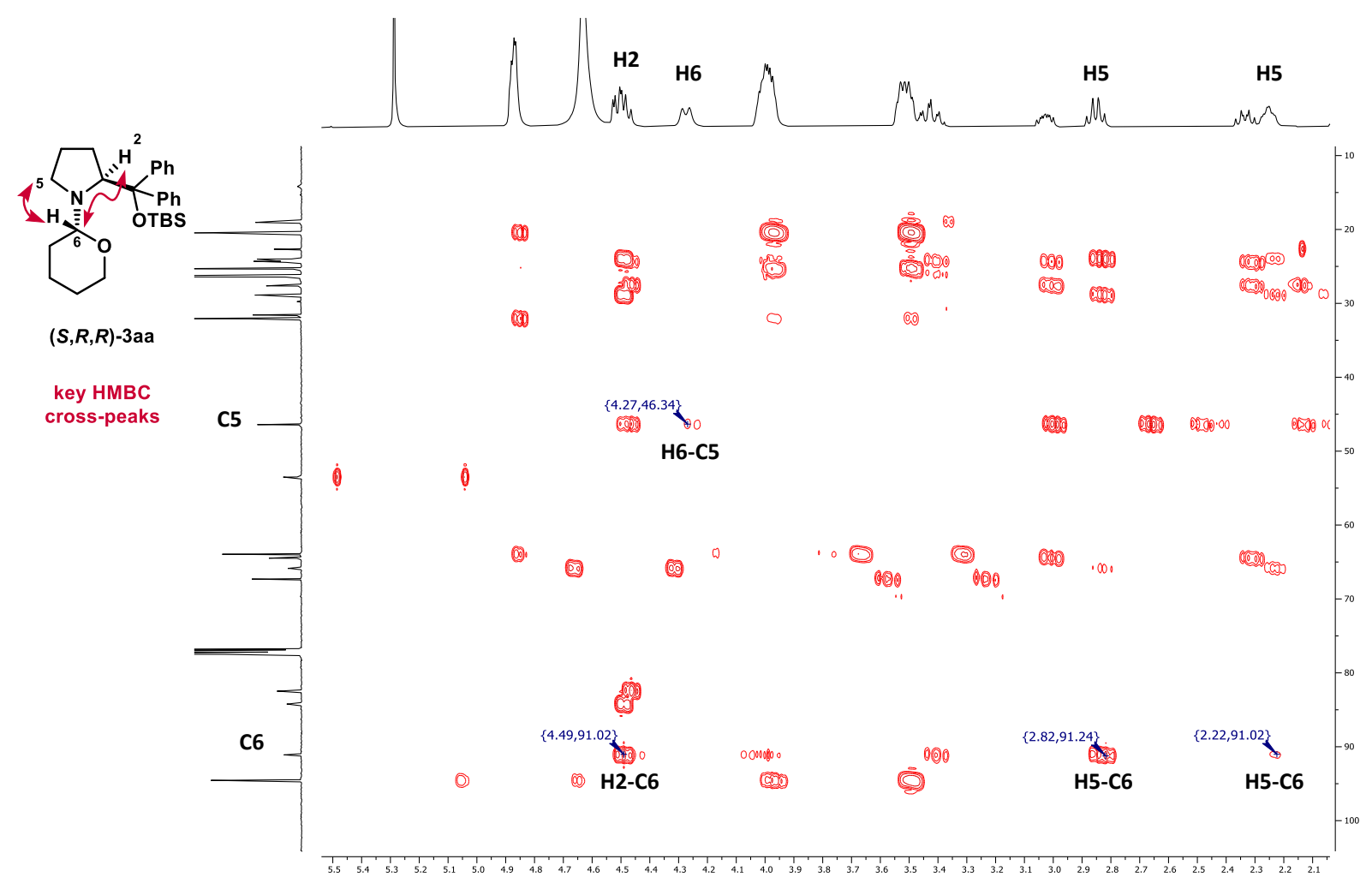

Figure S33. $\mathrm{HMBC}$ spectrum $\left(400 \mathrm{MHz}, \mathrm{CDCl}_{3}\right)$ of crude hemiaminal ether $(S, R, R)$-3aa. 


\section{Study of the reversibility of the condensation reaction of formation of hemiaminal ether}

$(S, R, R)$-3aa

After proving the formation of a single diastereoisomer when mixing amine (S)-2a and $\delta$-valerolactol 1a, we wanted to verify the reversibility of the reaction. If the formation of the hemiaminal ether $(S, R, R)$-3aa is reversible, the addition of a different amine, $(S)-\mathbf{2} \mathbf{b}$, would shift the reaction towards free amine (S)-2a and free lactol 1a, and a new hemiaminal ether $(S, R, R)$-3ba would be formed (Figure S34).

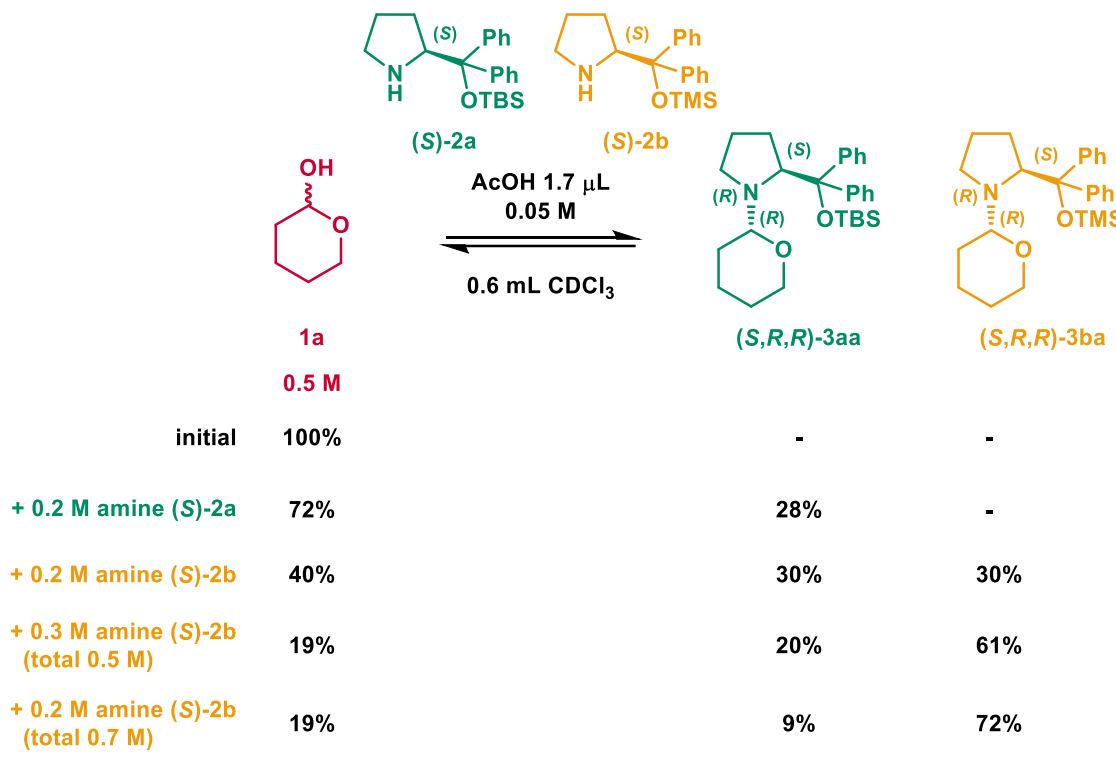

Figure S34. Reversibility of the reaction between lactol $\mathbf{1} \boldsymbol{a}$ and amine (S)-2a and (S)-2b to form hemiaminal ether (S,R,R)-3aa and hemiaminal ether $(S, R, R)-3 b a$

An NMR tube was charged successively with lactol $1 \mathrm{a}(30.6 \mathrm{mg}, 0.30 \mathrm{mmol}, 0.5 \mathrm{M}), \mathrm{CDCl}_{3}(0.6 \mathrm{~mL})$, amine $(S)-2 a(44.0 \mathrm{mg}, 0.12 \mathrm{mmol}, 0.2 \mathrm{M})$ and $\mathrm{AcOH}(1.8 \mathrm{mg}, 0.03 \mathrm{mmol})$. The reaction immediately occurred, and we observed the formation of a single diastereoisomer $(S, R, R)$-3aa by ${ }^{1} \mathrm{H} N \mathrm{NR}$ spectroscopy in a $28 \%$ conversion of the lactol 1a (Figure S34).

Once the equilibrium was reached, we added amine $(S)-2 \mathbf{b}(40.9 \mathrm{mg}, 0.12 \mathrm{mmol}, 0.2 \mathrm{M})$ into the NMR tube. We observed the formation of the new hemiaminal ether $(S, R, R)$-3ba, however the reversibility of the original reaction was not observed because the new hemiaminal $(S, R, R)$-3ba was formed from lactol 1a in excess (Figure S34) (the amount of original hemiaminal ether $(S, R, R)$-3aa was practically maintained, 30\%).

We added extra amine $(S)-2 b(54.0 \mathrm{mg}, 0.17 \mathrm{mmol}$, total $0.5 \mathrm{M})$ and we observed that the amount of original hemiaminal ether $(S, R, R)$-3aa decreased, proving that the equilibrium shifted towards free amine (S)-2a and lactol 1a, by forming more hemiaminal ether $(S, R, R)$-3ba (Figure $S 34$ ). 
To further shift the equilibrium, we added more amine (S)-2b (42.5 mg, $0.13 \mathrm{mmol}$, total $0.7 \mathrm{M})$ into the NMR tube. After the third addition, the equilibrium from the original hemiaminal ether $(S, R, R)$ 3aa is practically all shifted towards free amine (S)-2a and lactol $\mathbf{1 a}$, with only a $9 \%$ remaining of the original hemiaminal ether $(S, R, R)$-3aa and a $72 \%$ of the new hemiaminal ether $(S, R, R)$-3ba, proving the reversibility of the reaction (Figure S34).

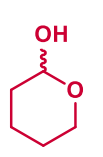

$1 a$

-

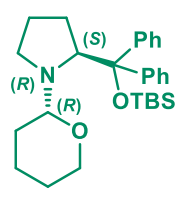

$(S, R, R)-3$ aа

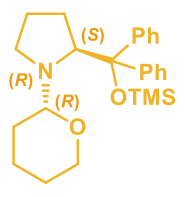

(S,R,R)-3ba

Distribution of lactol species. Stacked ${ }^{1} \mathrm{H}$ NMR spectra over the addition of amine (S)-2b

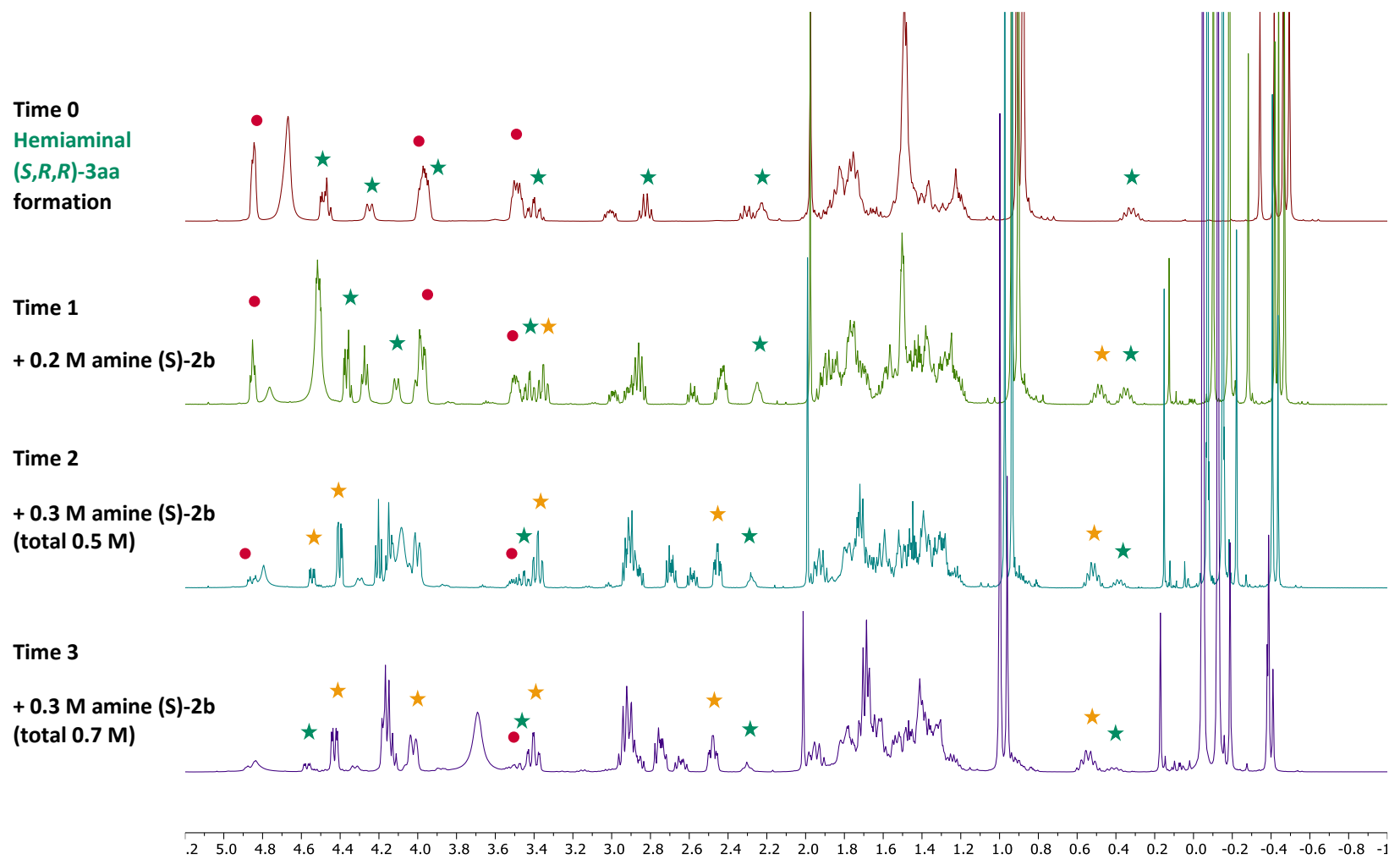

Figure S35. ${ }^{1} \mathrm{H} N \mathrm{NR}$ spectrum $\left(400 \mathrm{MHz}, \mathrm{CDCl}_{3}\right)$ in order to assign all the signals of each the hemiaminal ethers formed. 


\section{Chiral resolution of lactols to obtain high ee}

In the first protocol, we prioritized the enantiopurity of the lactol. To do so, the chiral resolution racemic $\delta$-lactols $( \pm)$-(1)-1f) involved three steps. The first step is the formation of the hemiaminal ether $(R, R, R, S)$-3ab. The second step is the partial hydrolysis of the hemiaminal ether (3ab-3af) in order to improve the diastereoselectivity of the hemiaminal ether (3ab-3af). And the third step is the

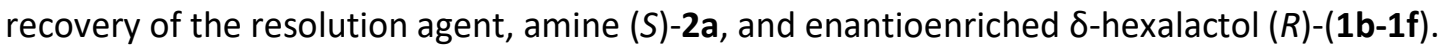

\subsection{Resolution of racemic $\delta$-hexalactol ( \pm )-1b}<smiles>CC1CCCC(O)O1</smiles>

$( \pm)-1 b$

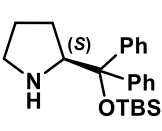

$(S)-2 a$

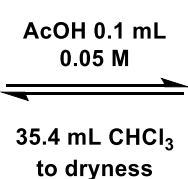

to dryness

$28 \%$ conv lactol

$0.2 \mathrm{M}$

$2.5969 \mathrm{~g}$

$7.08 \mathrm{mmol}$<smiles>C[C@@H]1CCC[C@@H](O)O1</smiles>

(S)-1b

$1.0928 \mathrm{~g}$

$9.42 \mathrm{mmol}$

$50 \%$ ee
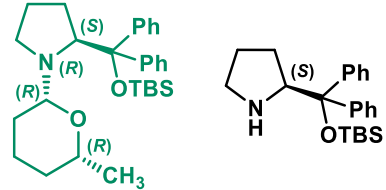

(S)-2a

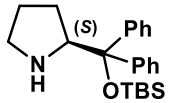

$(R, R, R, S)-3 \mathrm{ab}$

(S)-2a 
Hemiaminal ether $(R, R, R, S)$-3ab (crude mixture)

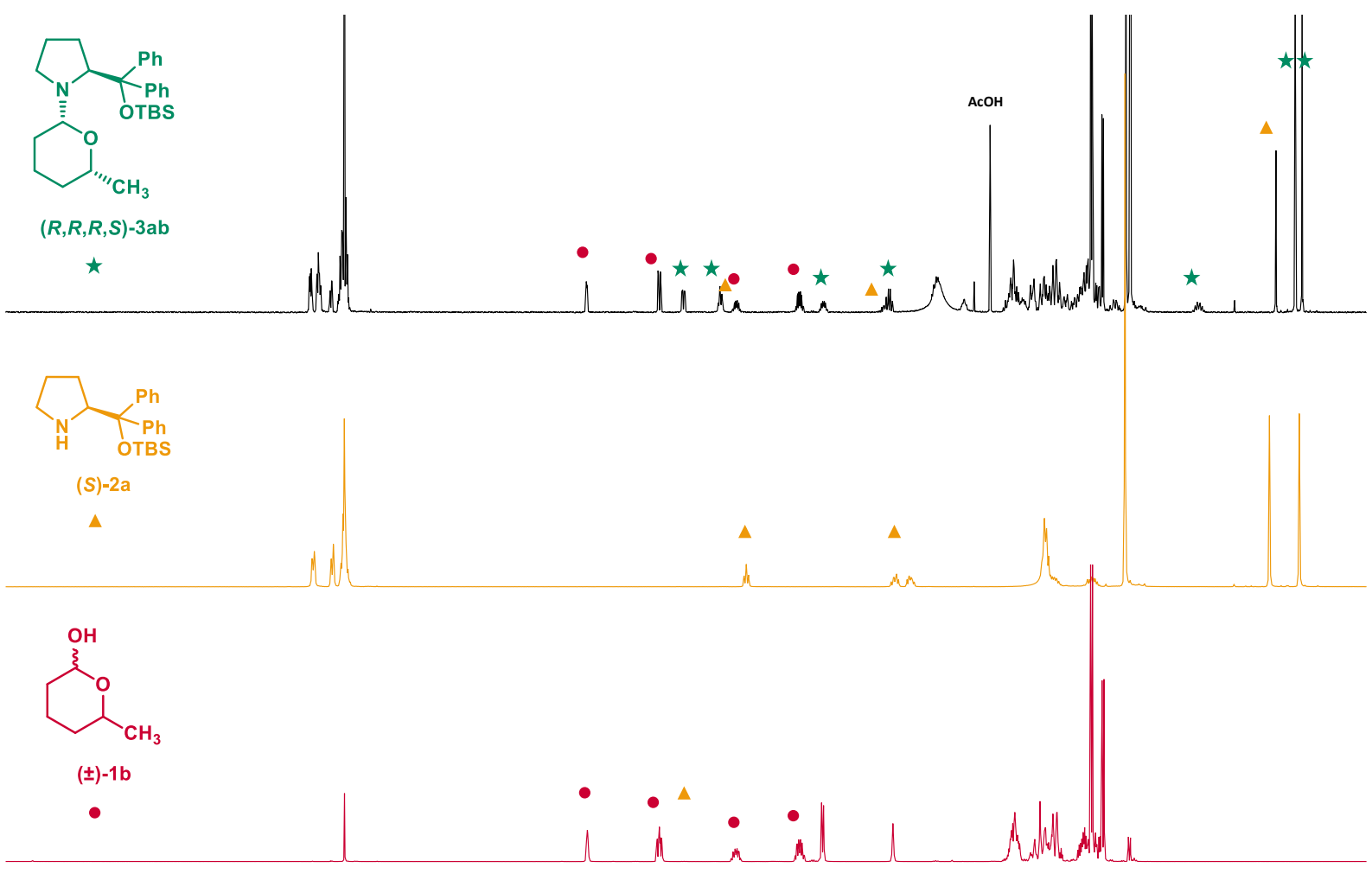

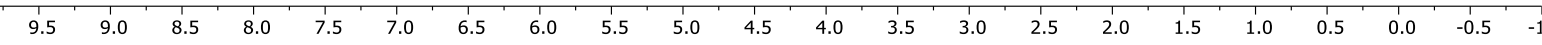
Figure S36. ${ }^{1} \mathrm{H} N \mathrm{NR}$ spectrum $\left(400 \mathrm{MHz}, \mathrm{CDCl}_{3}\right)$ to assign the signals of the hemiaminal ether formed.

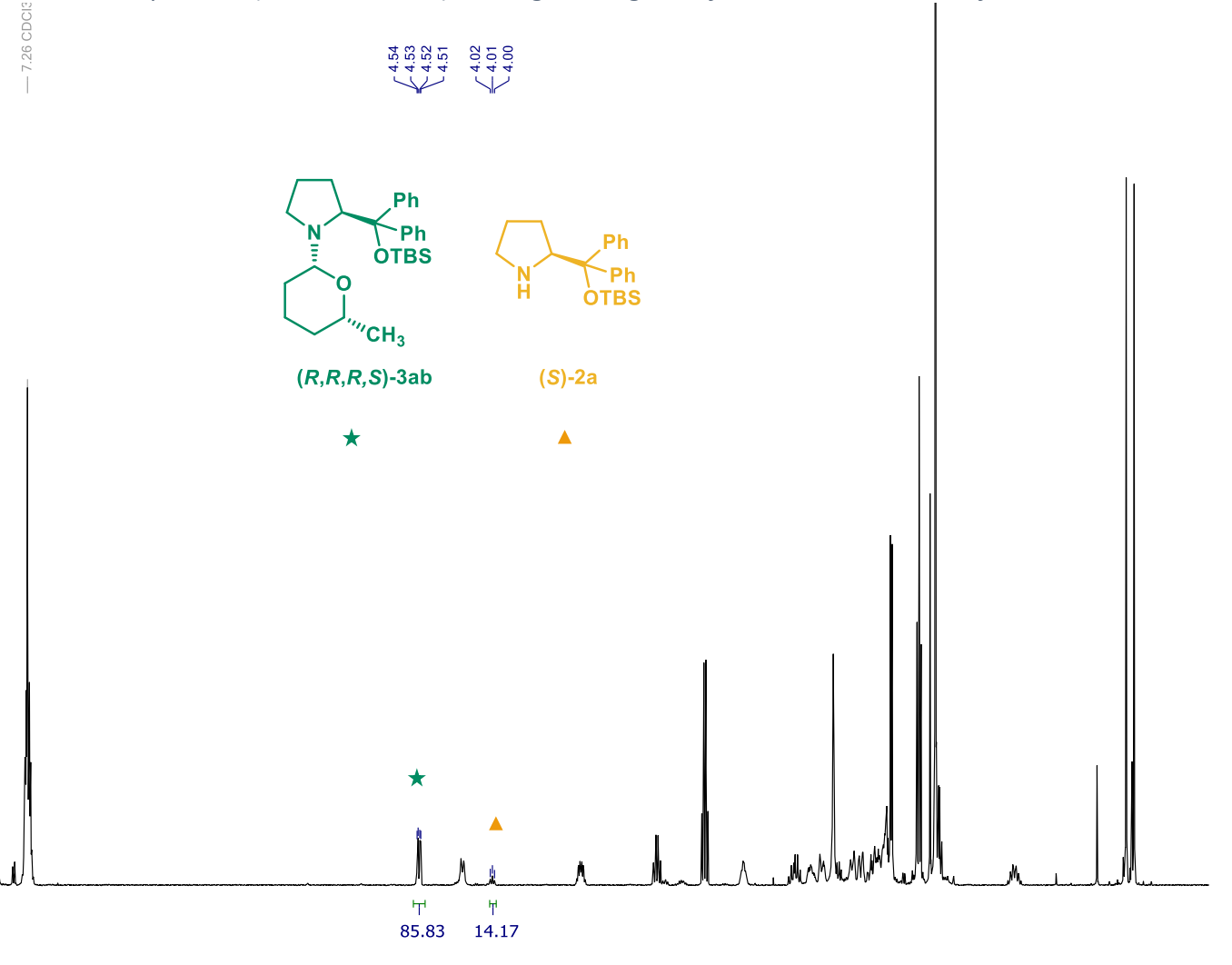

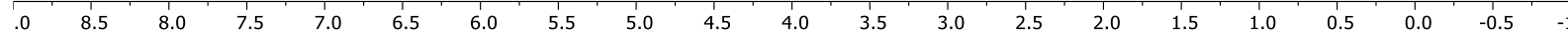
Figure S37. ${ }^{1} \mathrm{H} N \mathrm{NM}$ spectrum $\left(400 \mathrm{MHz}, \mathrm{CDCl}_{3}\right)$ of hemiaminal ether $(R, R, R, S)$-3ab after silica gel purification. 
To check the enantioselectivity of the reaction, a sample of the diastereomeric enriched hemiaminal ether 3ab was fully hydrolysed to the corresponding $\delta$-hexalactol $(R)-\mathbf{1 b}$ using $0.5 \mathrm{M} \mathrm{AcOH}$ in $\mathrm{CHCl}_{3}$ (Scheme S16). The $\delta$-hexalactol (R)-1b was derivatized following General Procedure 4 to enable the measurement of its enantiomeric excess by chiral HPLC (93\%) (Figure S96).

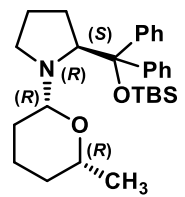

$(R, R, R, S)-3 \mathrm{ab}$

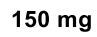

$0.32 \mathrm{mmol}$

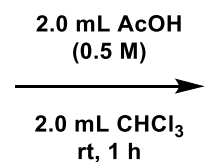

rt, $1 \mathrm{~h}$

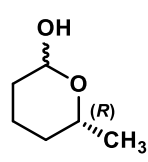

(R)-1b

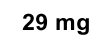

$0.25 \mathrm{mmol}$

$93 \%$ ee<smiles>CC(C)(O)C(C)(O)c1ccccc1</smiles>

(S)-2a

$0.30 \mathrm{mmol}$

Scheme S16. Fully hydrolysis of hemiaminal ether $(R, R, R, S)-\mathbf{3 a b}$ to check enantiopurity of lactol $\mathbf{1 b}$.

The $93 \%$ enantiomeric excess was further improved by selective hydrolysis of the less stable $(S, X, Y, S)$ 3ab diastereoisomers of the hemiaminal ether (Scheme S17). As shown in Scheme S17, the hemiaminal ether $(R, R, R, S)$-3ab equilibrium is shifted towards the hemiaminal, whereas the equilibrium of the hemiaminal $(S, X, Y, S)$-3ab is shifted towards the $\delta$-hexalactol $(S)$-1 $\mathbf{b}$ and free amine (S)-2a.

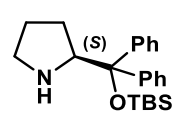

(S)-2a

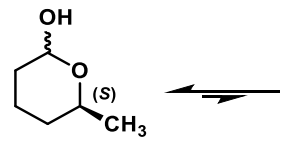

(S)-1b

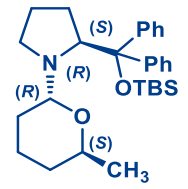

$(S, X, Y, S)-3 a b$

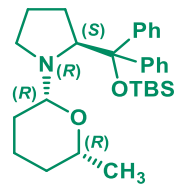

$(R, R, R, S)$-3ab

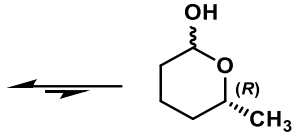

(R)-1b

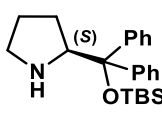

(S)-2a

Scheme S17. Selective hydrolysis of the less stable $(S, X, Y, S)$-3ab diastereoisomer of the hemiaminal ether.

\section{Partial hydrolysis of hemiaminal ether $(R, R, R, S)-3 a b$}

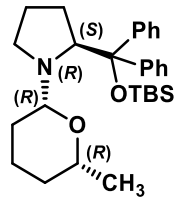

$(R, R, R, S)-3 \mathrm{ab}$

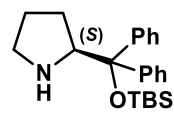

$(s)-2 a$

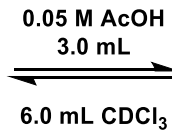

$2.5278 \mathrm{~g}$
86.14 $86: 14$ $2.1739 \mathrm{~g} \quad 0.3539 \mathrm{~g}$ $4.67 \mathrm{mmol} 0.96 \mathrm{mmol}$

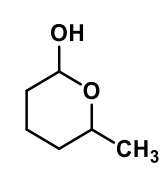

$(S)-1 b$

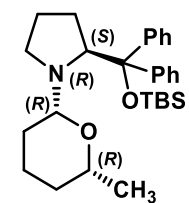

$(R, R, R, S)-3 \mathrm{ab}$

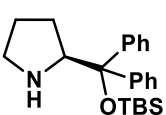

(S)-2a

$$
\begin{aligned}
& 2.3455 \mathrm{~g} \\
& 72: 28 \\
& 1.6887 \mathrm{~g} \quad 0.6537 \mathrm{~g} \\
& 3.63 \mathrm{mmol} 1.79 \mathrm{mmol}
\end{aligned}
$$



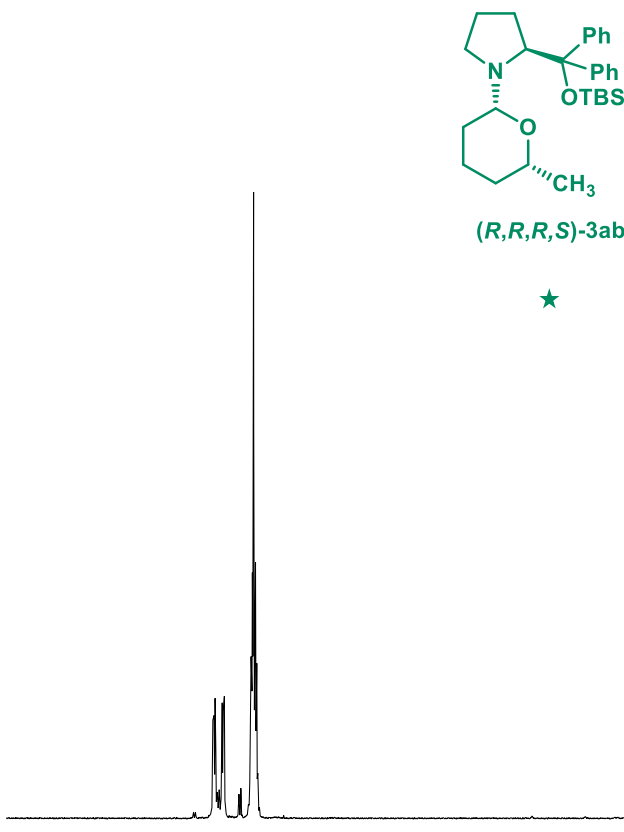

$(R, R, R, S)-3 a b$

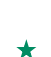

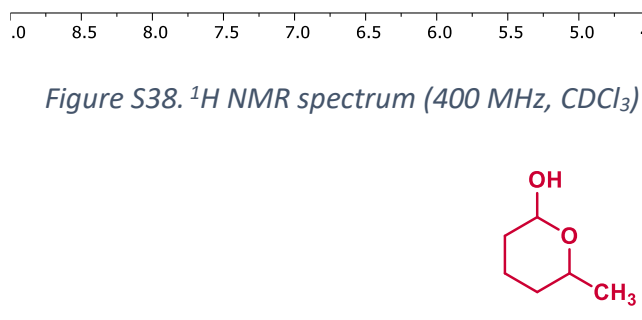

(S)-1b

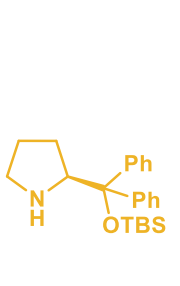

(S)-2a

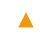

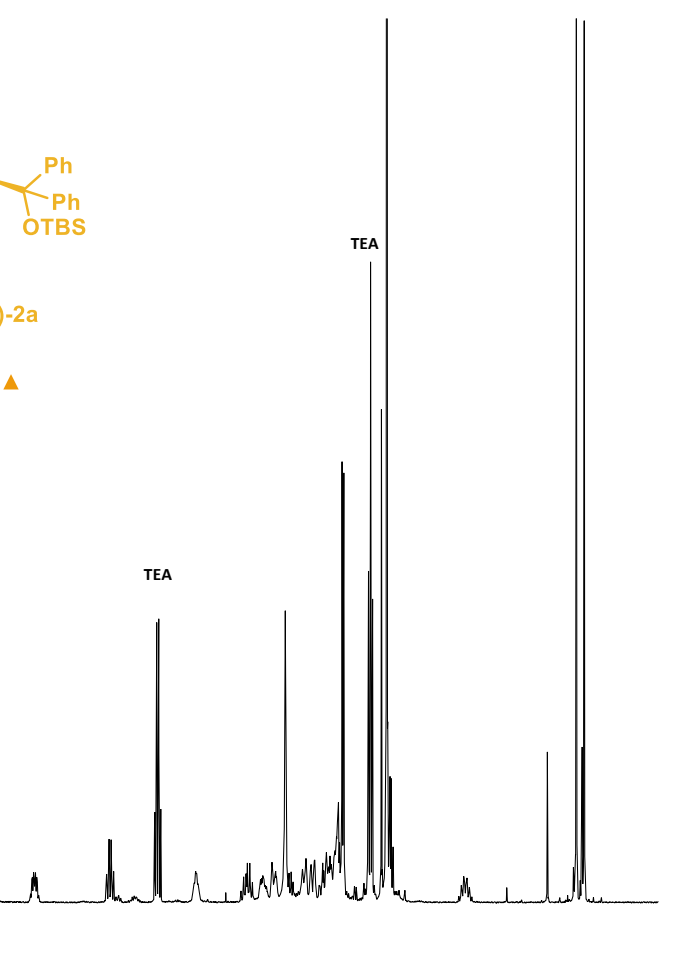

$85.97 \quad 14.03$

$4.5 \quad 4.0$ 


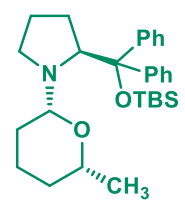

$(R, R, R, S)-3 \mathrm{ab}$
$(S)-2 a$

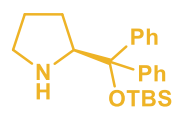

$\Delta$
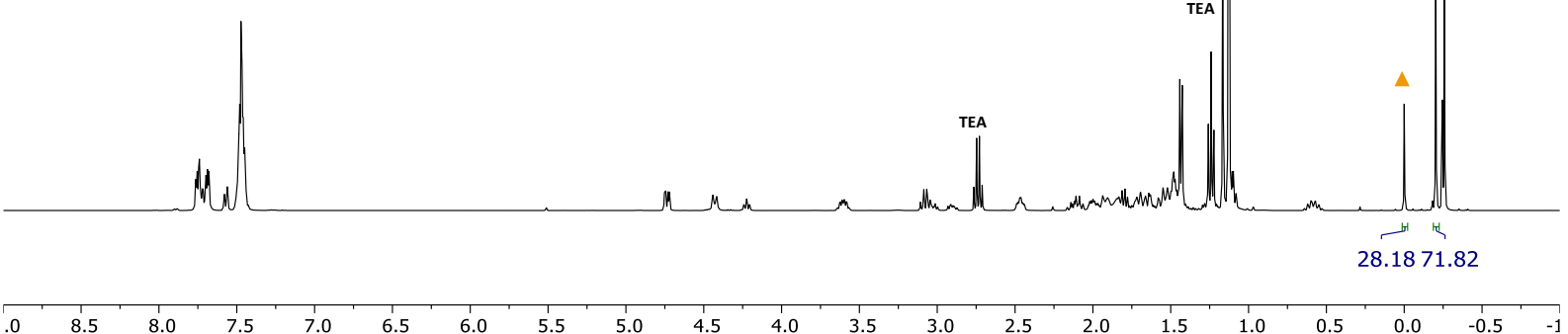

Figure $540 .{ }^{1} \mathrm{H} N \mathrm{NR}$ spectrum $\left(400 \mathrm{MHz}, C D C l_{3}\right)$ of hemiaminal ether $(R, R, R, S)$-3ab after silica gel purification.

\section{Recovery of amine (S)-2a and enantioenriched lactol $(R)-1 b$}
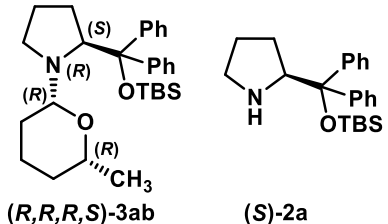

(S)-2a

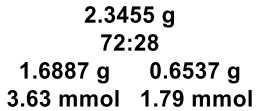

$3.63 \mathrm{mmol} 1.79 \mathrm{mmol}$
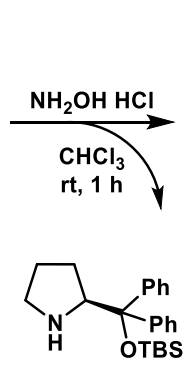

(S)-2a

$1.9700 \mathrm{~g}$

$5.36 \mathrm{mmol}$

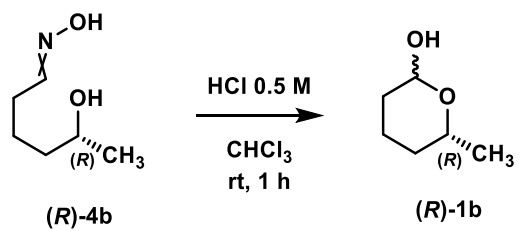

$0.4723 \mathrm{~g}$

$3.60 \mathrm{mmol}$

$0.3829 \mathrm{~g}$

$3.30 \mathrm{mmol}$

$99.2 \%$ ee

Scheme S19. Recovery of amine (S)-2a and enantioenriched lactol (R)-1b. 


\subsection{Resolution of racemic $\delta$-octalactol $( \pm)$-1c}

\section{Formation of the hemiaminal ether $(R, R, R, S)$-3ac}<smiles>O[C@H]1CCC[C@@H](S)O1</smiles>

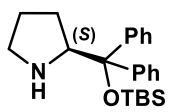

(S)-2a

(士)-1c

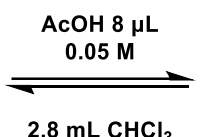

$2.8 \mathrm{~mL} \mathrm{CHCl}$
to dryness<smiles>CC[C@@H]1CCC[C@H](O)O1</smiles>

(S)-1c

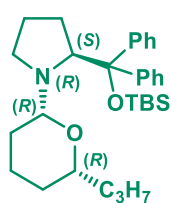

$(R, R, R, S)-3$ ac

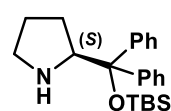

(S)-2a
$28 \%$ conv lactol

$128.2 \mathrm{mg}$

$0.89 \mathrm{mmol}$
$264.8 \mathrm{mg}$

$86: 14$ $227.7 \mathrm{mg} \quad 37.1 \mathrm{mg}$ $0.46 \mathrm{mmol} 0.10 \mathrm{mmol}$

Scheme S20. Formation of the hemiaminal ether $(R, R, R, S)-3 a c$.

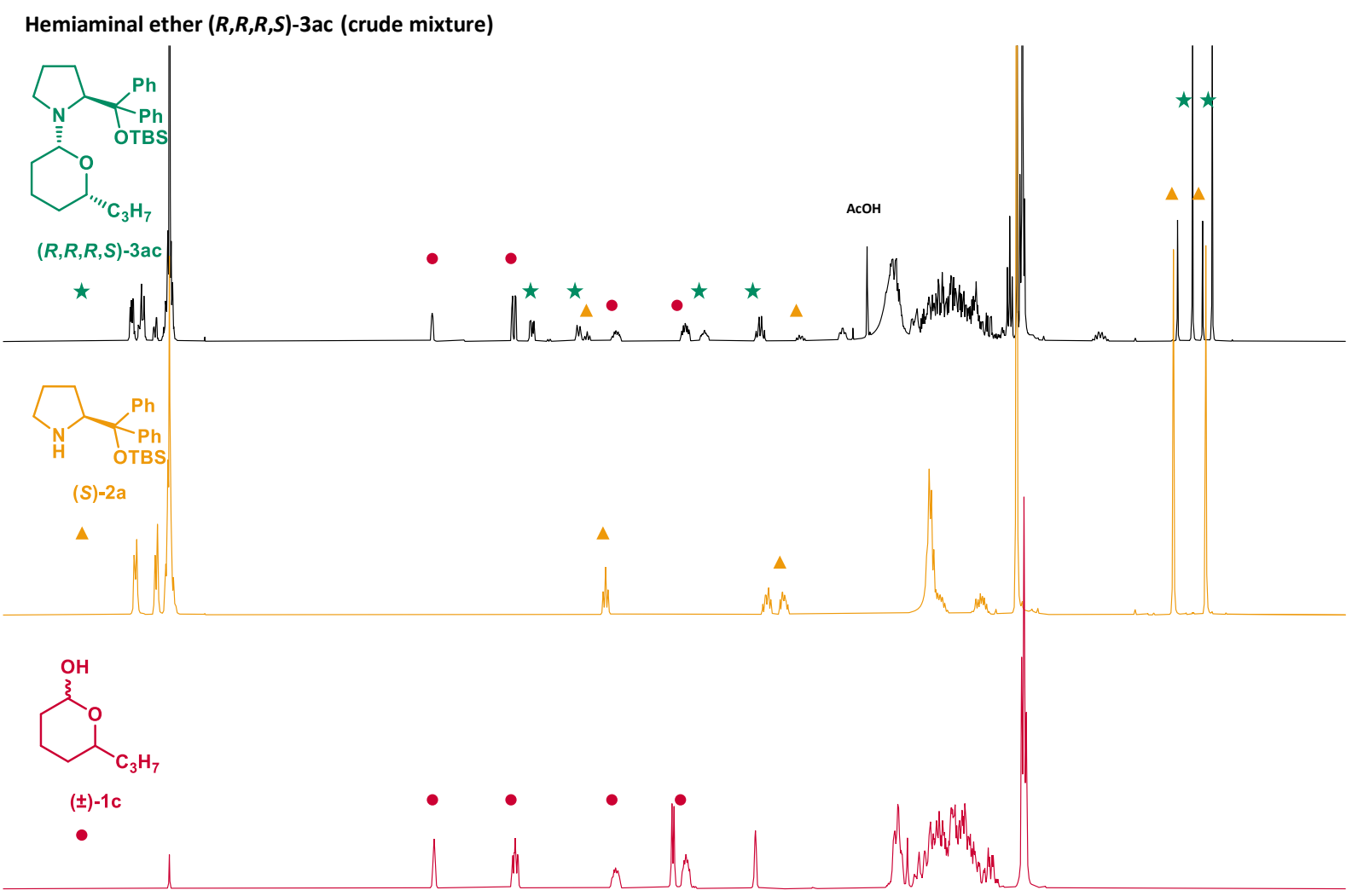

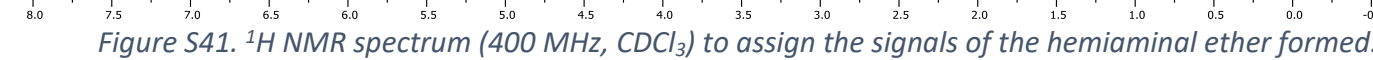




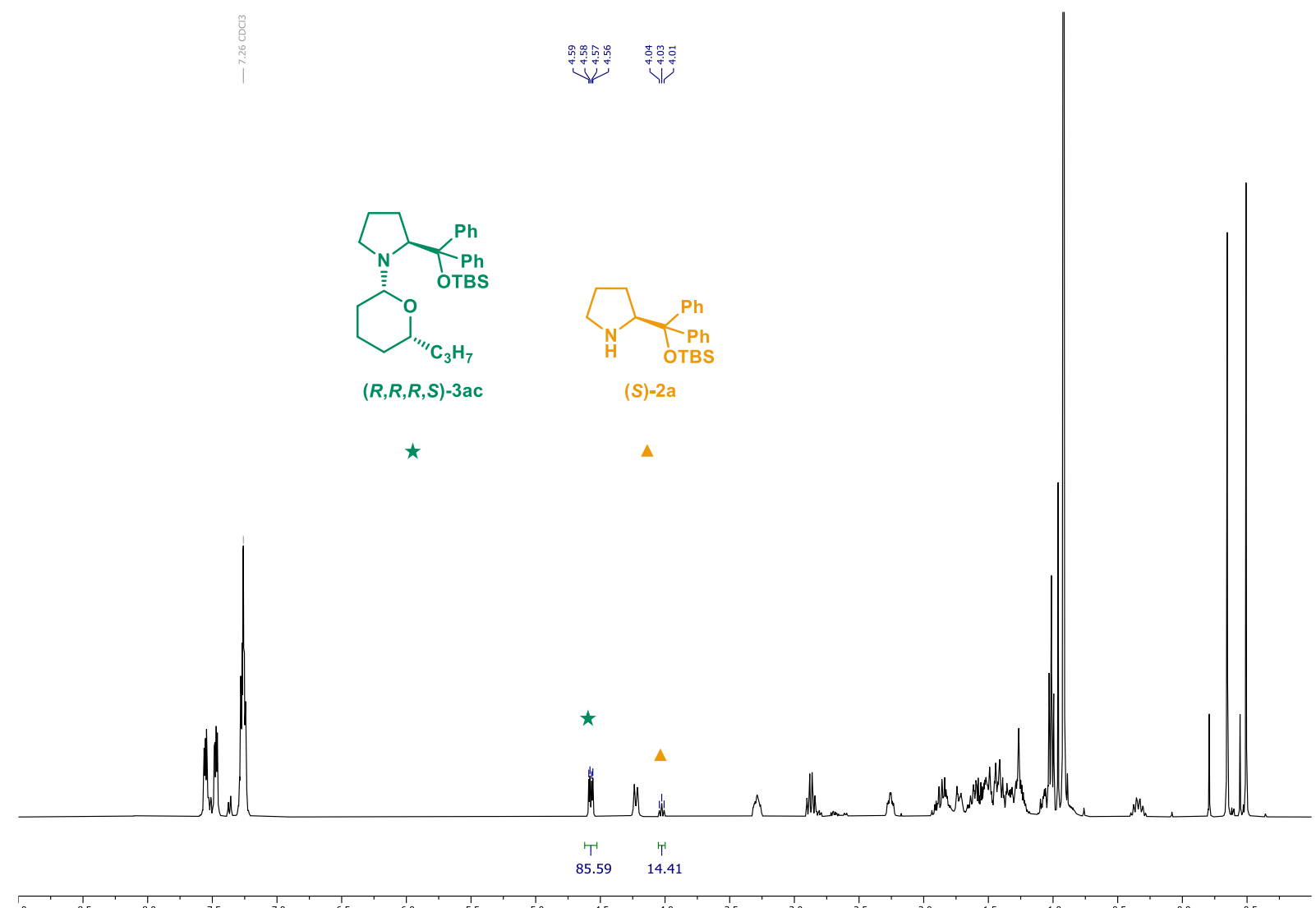

Figure $542 .{ }^{1} \mathrm{H} N \mathrm{NMR}$ spectrum $\left(400 \mathrm{MHz}, \mathrm{CDCl}_{3}\right)$ of hemiaminal ether $(R, R, R, S)$-3ac after silica gel purification.

\section{Partial hydrolysis of hemiaminal ether $(R, R, R, S)$-3ac}

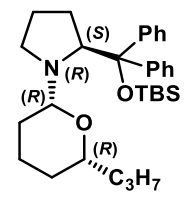

$(R, R, R, S)-3$ ac

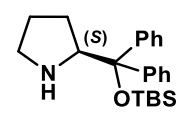

(S)-2a

$264.8 \mathrm{mg}$

$86: 14$

$227.7 \mathrm{mg} \quad 37.1 \mathrm{mg}$

$0.46 \mathrm{mmol} 0.10 \mathrm{mmol}$

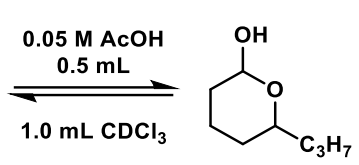

(S)-1c

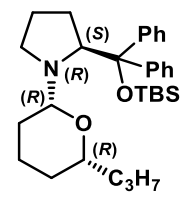

$(R, R, R, S)-3$ ac

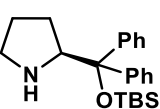

$(S)-2 a$

Scheme S21. Partial hydrolysis of hemiaminal ether $(R, R, R, S)-3 a c$. 


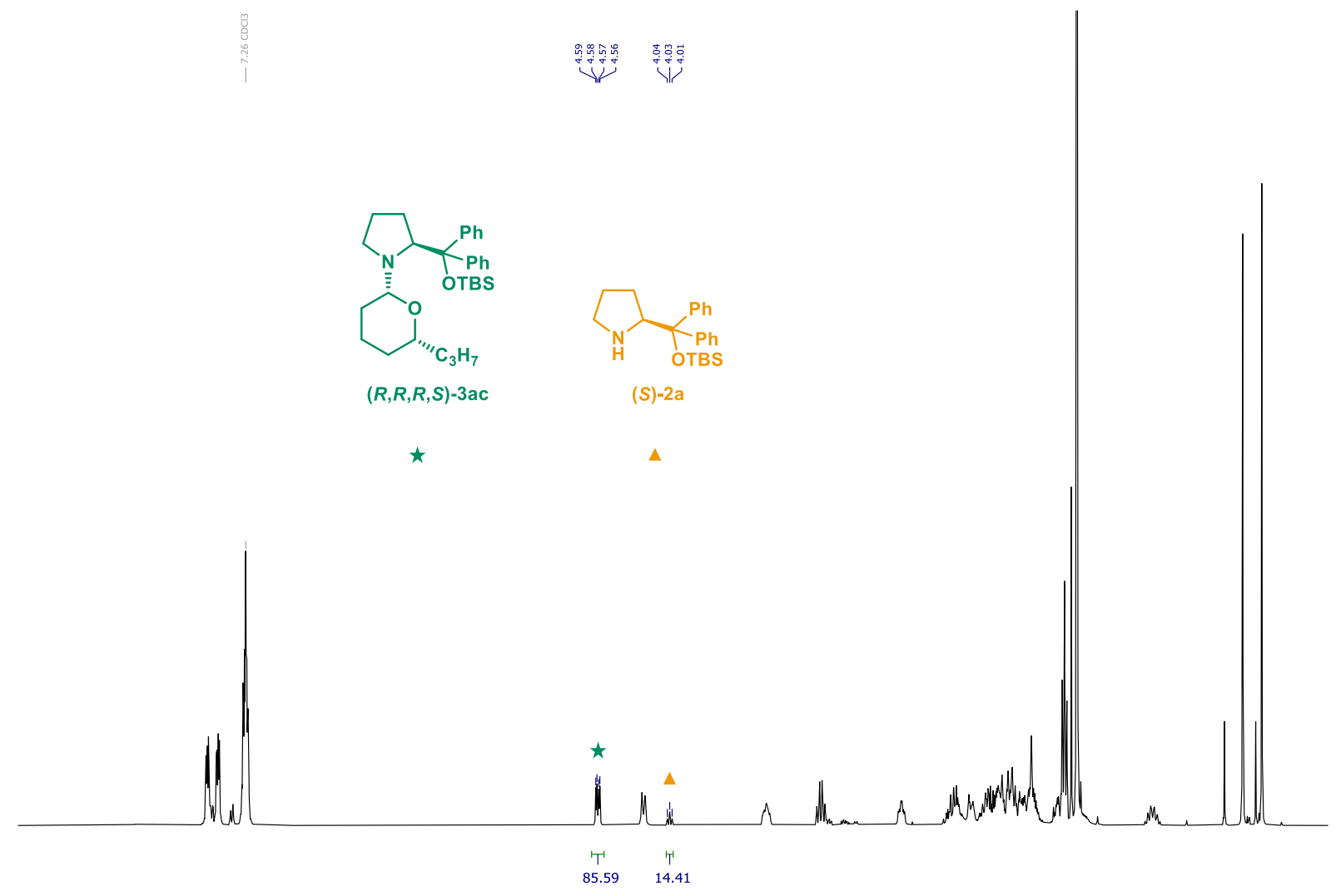

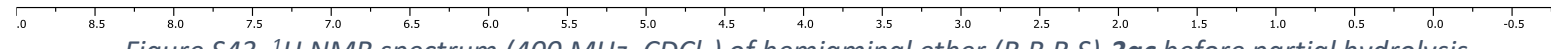
Figure S43. ${ }^{1} \mathrm{H} N \mathrm{NR}$ spectrum $(400 \mathrm{MHz}, \mathrm{CDCl}$ ) of hemiaminal ether $(R, R, R, S)$-3ac before partial hydrolysis.

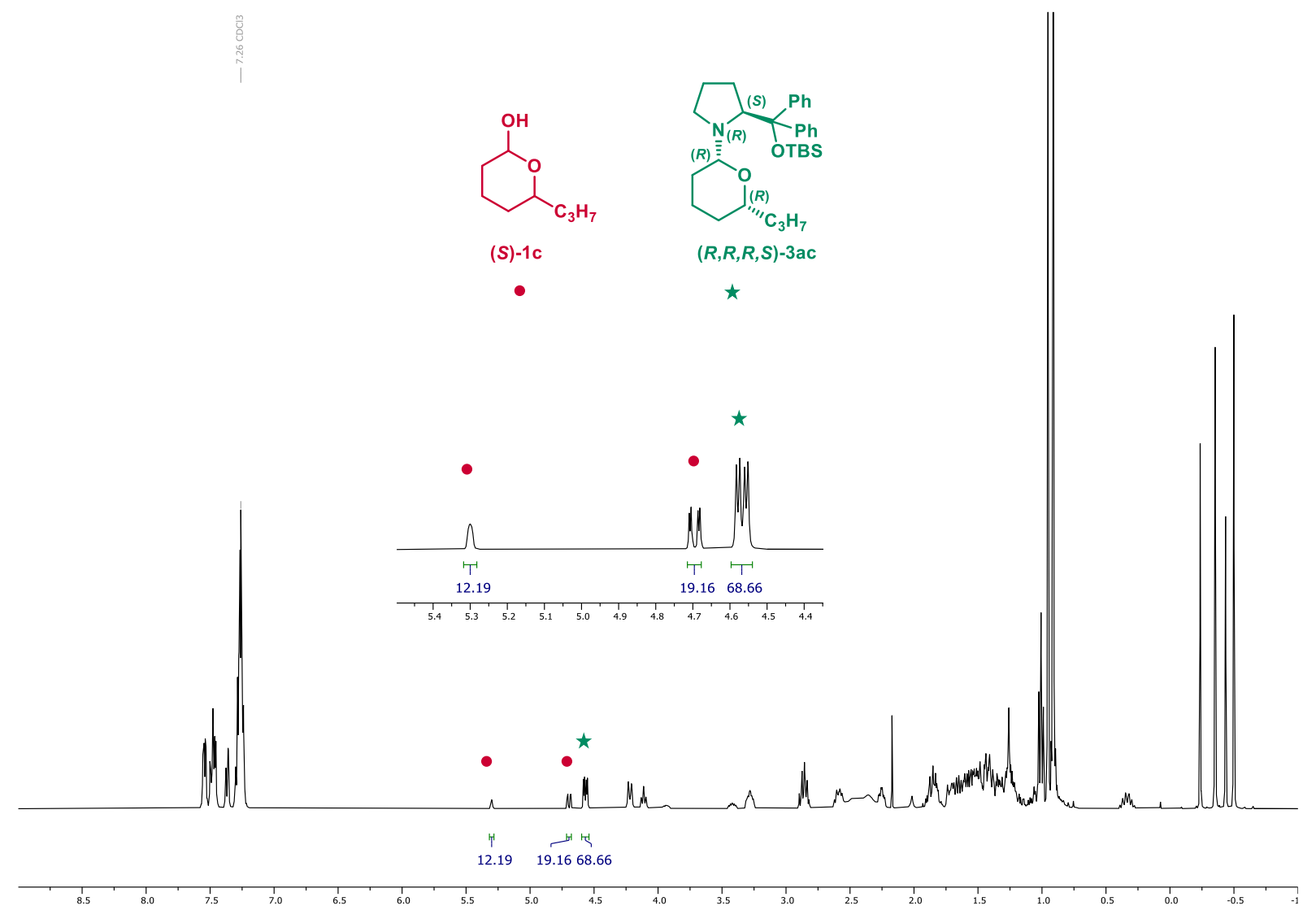

Figure $544 .{ }^{1} \mathrm{H} N \mathrm{NR}$ spectrum $\left(400 \mathrm{MHz}, \mathrm{CDCl}_{3}\right)$ of crude hemiaminal ether $(R, R, R, S)$-3ac after partial hydrolysis. 


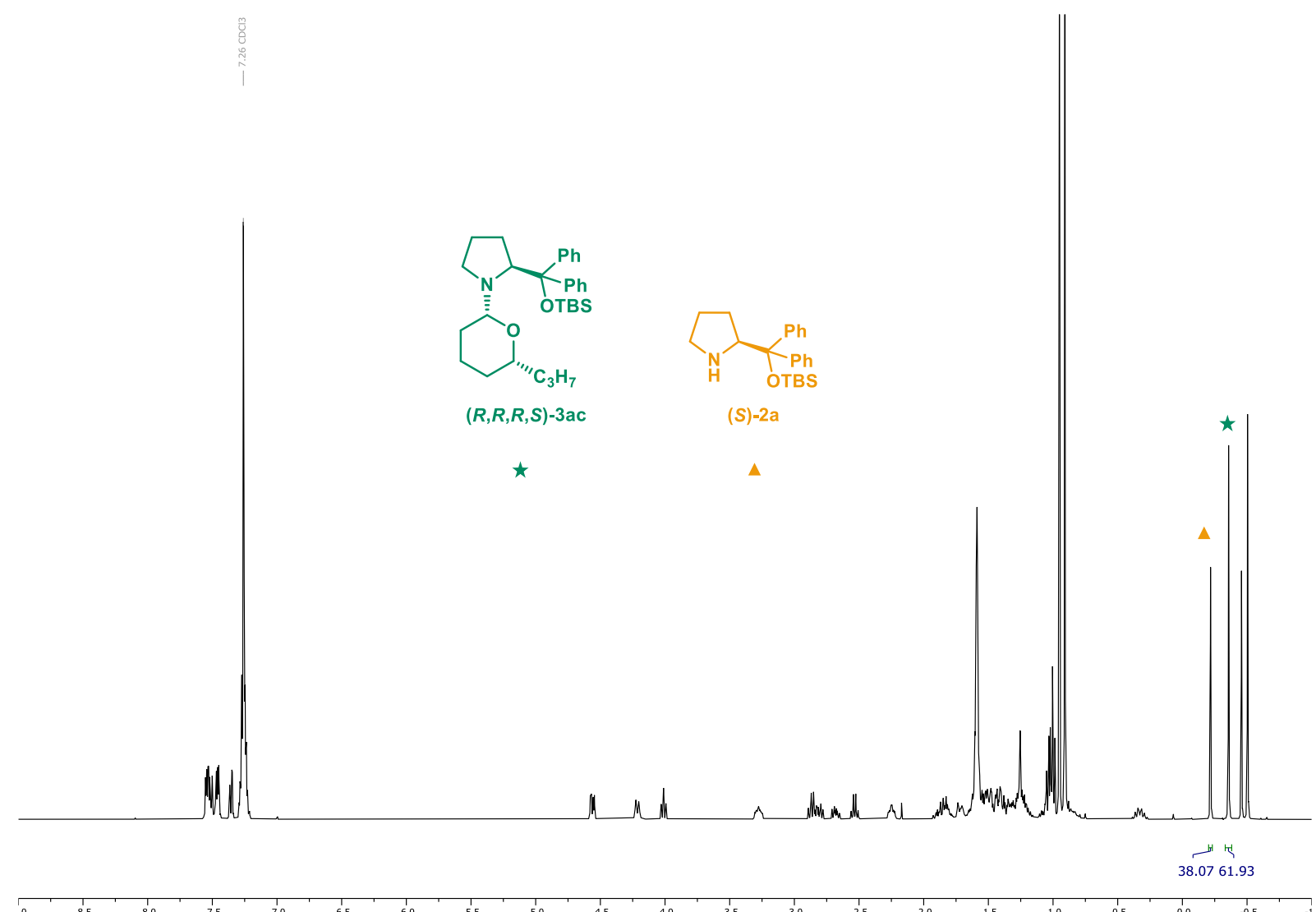

Figure S45. ${ }^{1} \mathrm{H} N \mathrm{MR}$ spectrum $\left(400 \mathrm{MHz}, \mathrm{CDCl}_{3}\right)$ of hemiaminal ether $(R, R, R, S)$-3ac after silica gel purification.

\section{Recovery of amine (S)-2a and enantioenriched lactol $(R)-1 \mathrm{c}$}

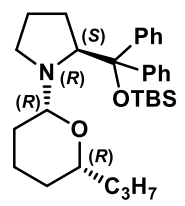

$(R, R, R, S)-3$ ac

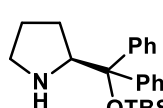

(S)-2a

$38.0 \mathrm{mg}$

62:38

$0.30 \mathrm{mmol} \quad 0.25 \mathrm{mmol}$

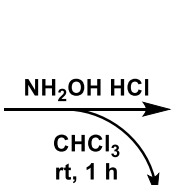

rt, $1 \mathrm{~h}$

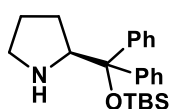

(S)-2a

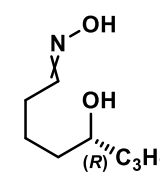

$(R)-4 c$

$40.7 \mathrm{mg}$

$0.25 \mathrm{mmol}$

$201.5 \mathrm{mg}$

$0.55 \mathrm{mmol}$

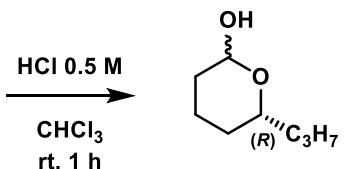

(R)-1c
$30.1 \mathrm{mg}$

$0.21 \mathrm{mmol}$

$99.1 \%$ ee

Scheme S22. Recovery of amine (S)-2a and enantioenriched lactol (R)-1c. 


\subsection{Resolution of racemic $\delta$-nonalactol $( \pm)-1 d$}

\section{Formation of the hemiaminal ether $(R, R, R, S)$-3ad}<smiles>CCCCCCCCCO</smiles>

$( \pm)-1 d$

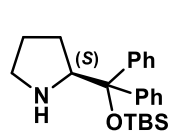

(S)-2a

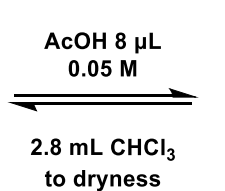

$27 \%$ conv lactol<smiles>C[C@@H]1CCC[C@@H](O)O1</smiles>

(S)-1d

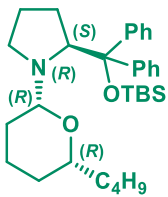

$(R, R, R, S)-3$ ad

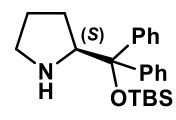

(S)-2a

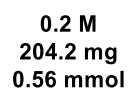

$143.1 \mathrm{mg}$

$0.92 \mathrm{mmol}$

$$
\begin{gathered}
263.9 \mathrm{mg} \\
86: 14 \\
234.9 \mathrm{mg} \quad 36.9 \mathrm{mg} \\
0.46 \mathrm{mmol} \quad 0.1 \mathrm{mmol}
\end{gathered}
$$

$39.3 \%$ ee

Scheme S23. Formation of the hemiaminal ether $(R, R, R, S)$-3ad.

Hemiaminal ether $(R, R, R, S)$-3ad (crude mixture)

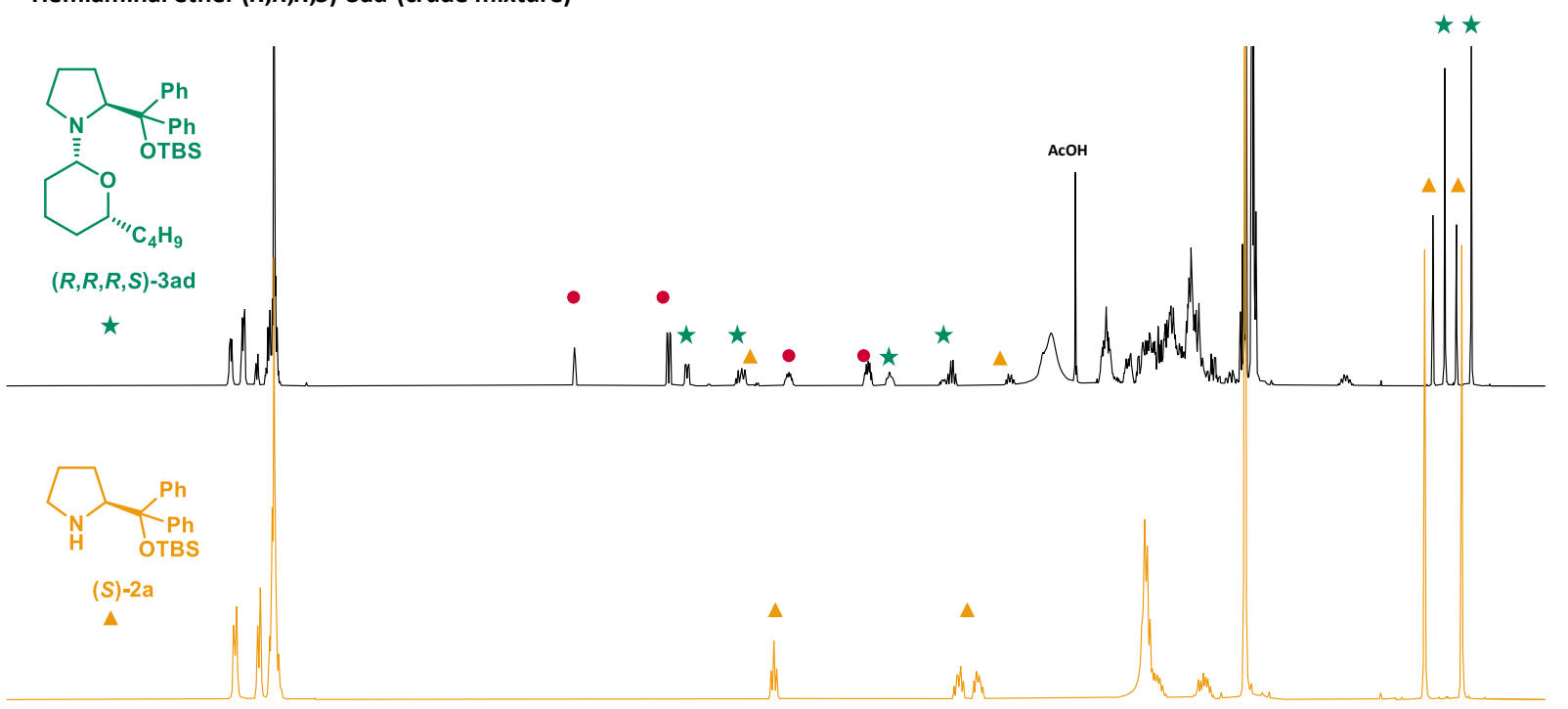<smiles>CC1CCCC(O)O1</smiles>

$( \pm)-1 d$

-

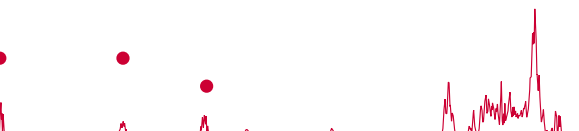

Figure S46. ${ }^{1} \mathrm{H} N \mathrm{MR}$ spectrum $\left(400 \mathrm{MHz}, \mathrm{CDCl}_{3}\right)$ to assign the signals of the hemiaminal ether formed. 


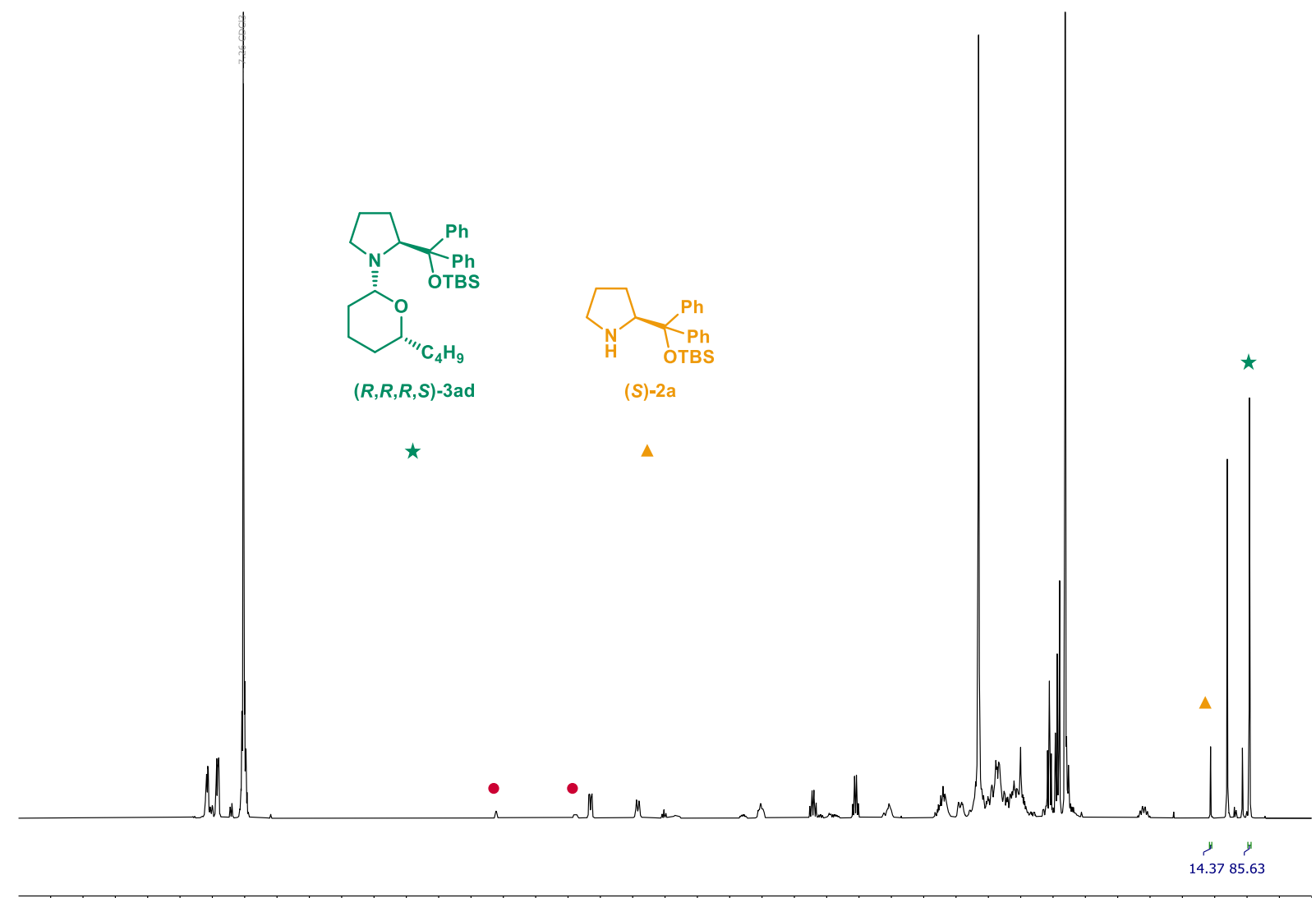

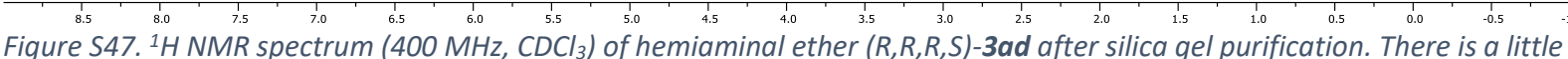
Impurified with lactol (red), but since we are purifying it after the partial hydrolysis, we used it in the next step.

\section{Partial hydrolysis of hemiaminal ether $(R, R, R, S)-3 a d$}

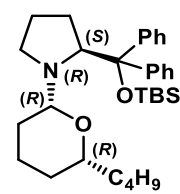

$(R, R, R, S)-3 a d$

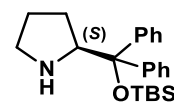

(S)-2a

$263.9 \mathrm{mg}$

$86: 14$

$234.9 \mathrm{mg} \quad 36.9 \mathrm{mg}$

$0.46 \mathrm{mmol} 0.1 \mathrm{mmol}$

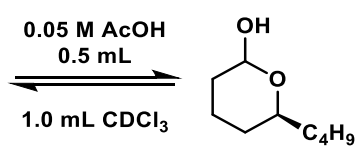

(S)-1d

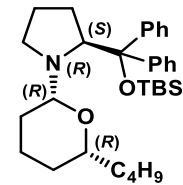

$(R, R, R, S)-3$ ad

$247.8 \mathrm{mg}$
$66: 34$

$163.5 \mathrm{mg} \quad 84.3 \mathrm{mg}$

$0.32 \mathrm{mmol} 0.23 \mathrm{mmo}$

Scheme S24. Partial hydrolysis of hemiaminal ether $(R, R, R, S)-3 a d$. 


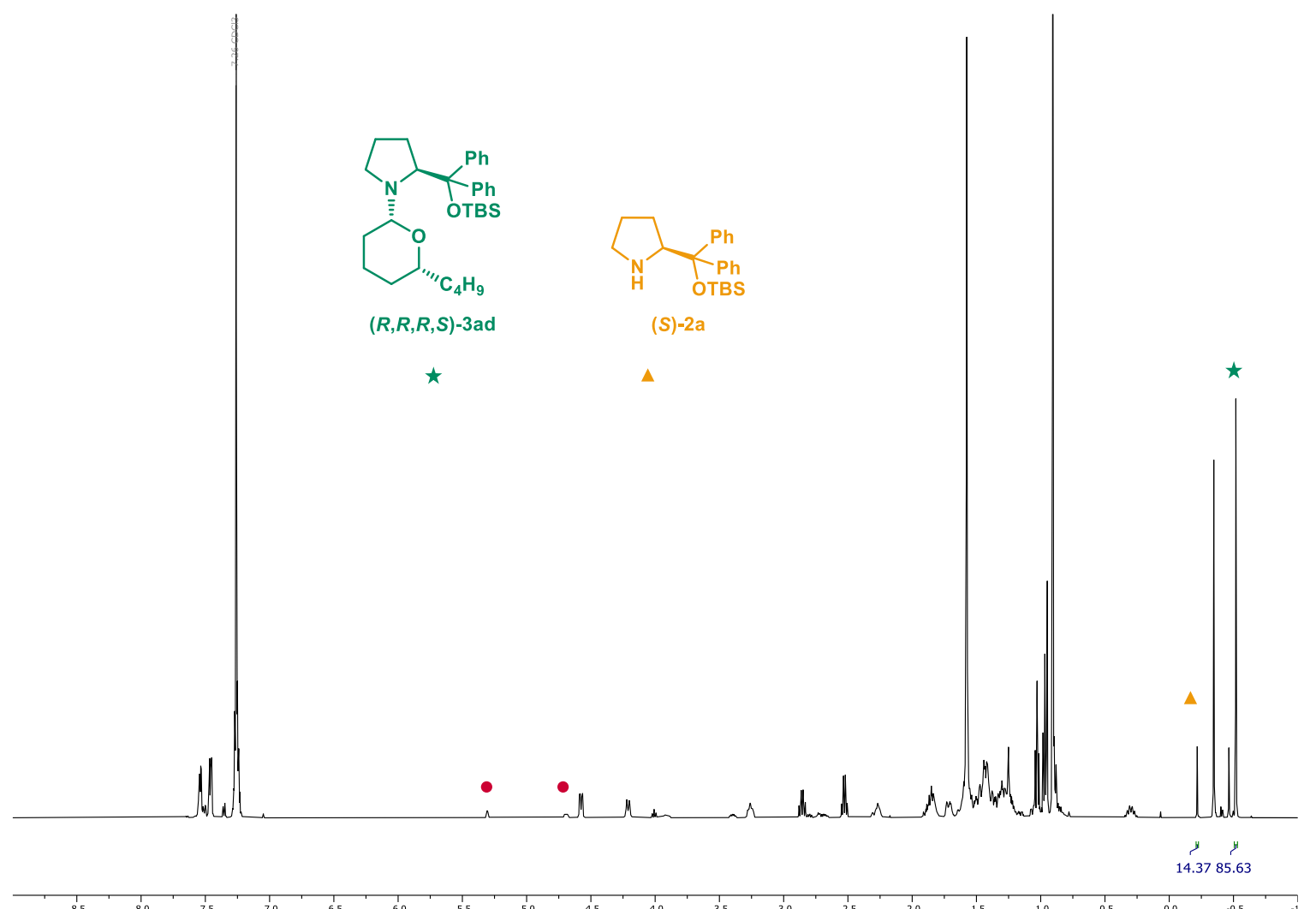

Figure $548 .{ }^{1} \mathrm{H} N M R$ spectrum $\left(400 \mathrm{MHz}, C D C l_{3}\right)$ of hemiaminal ether $(R, R, R, S)$-3ad before partial hydrolysis.

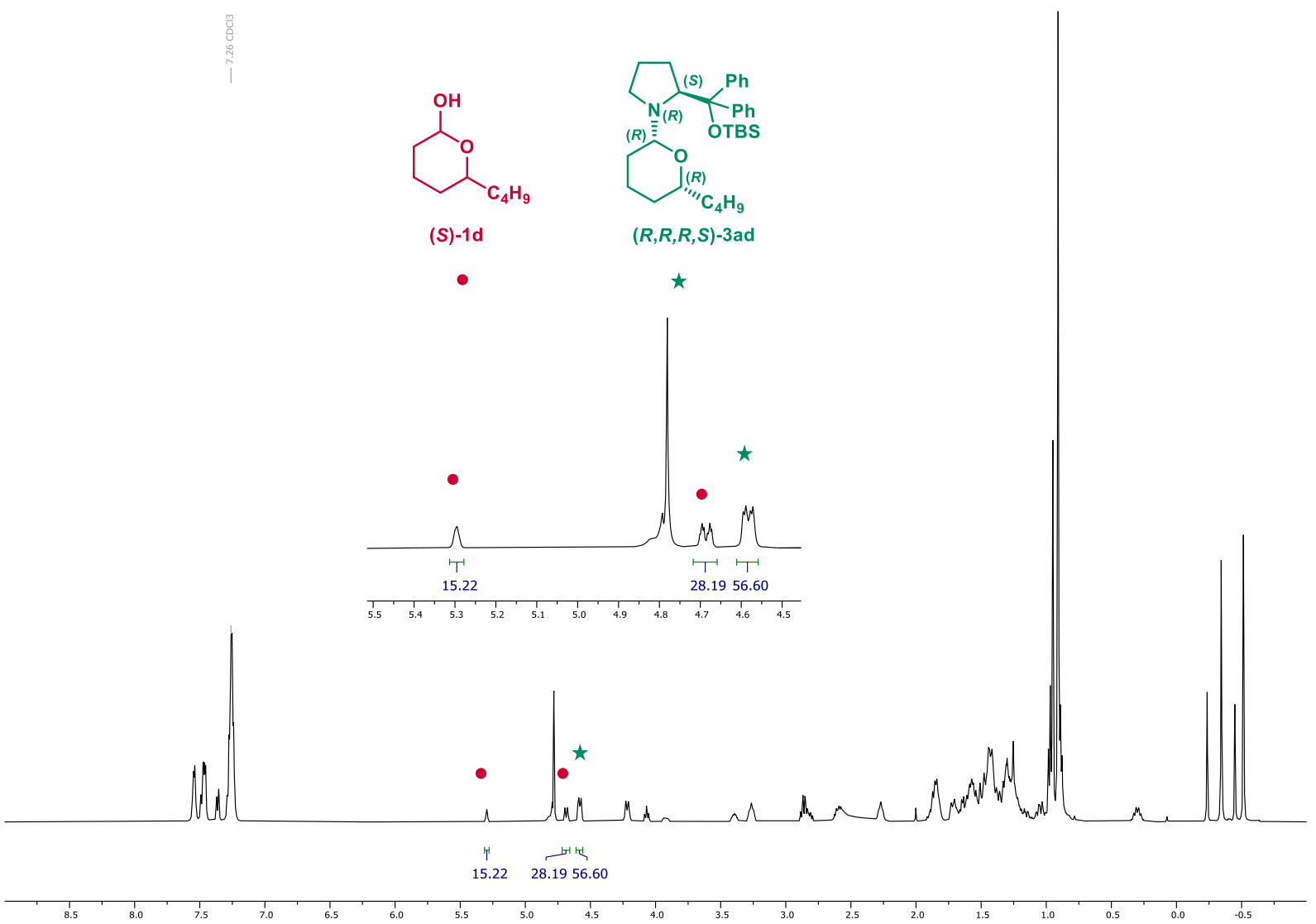

Figure S49. ${ }^{1} \mathrm{H} N \mathrm{NR}$ spectrum $\left(400 \mathrm{MHz}, \mathrm{CDCl}_{3}\right)$ of crude hemiaminal ether $(R, R, R, S)$-3ad after partial hydrolysis. 


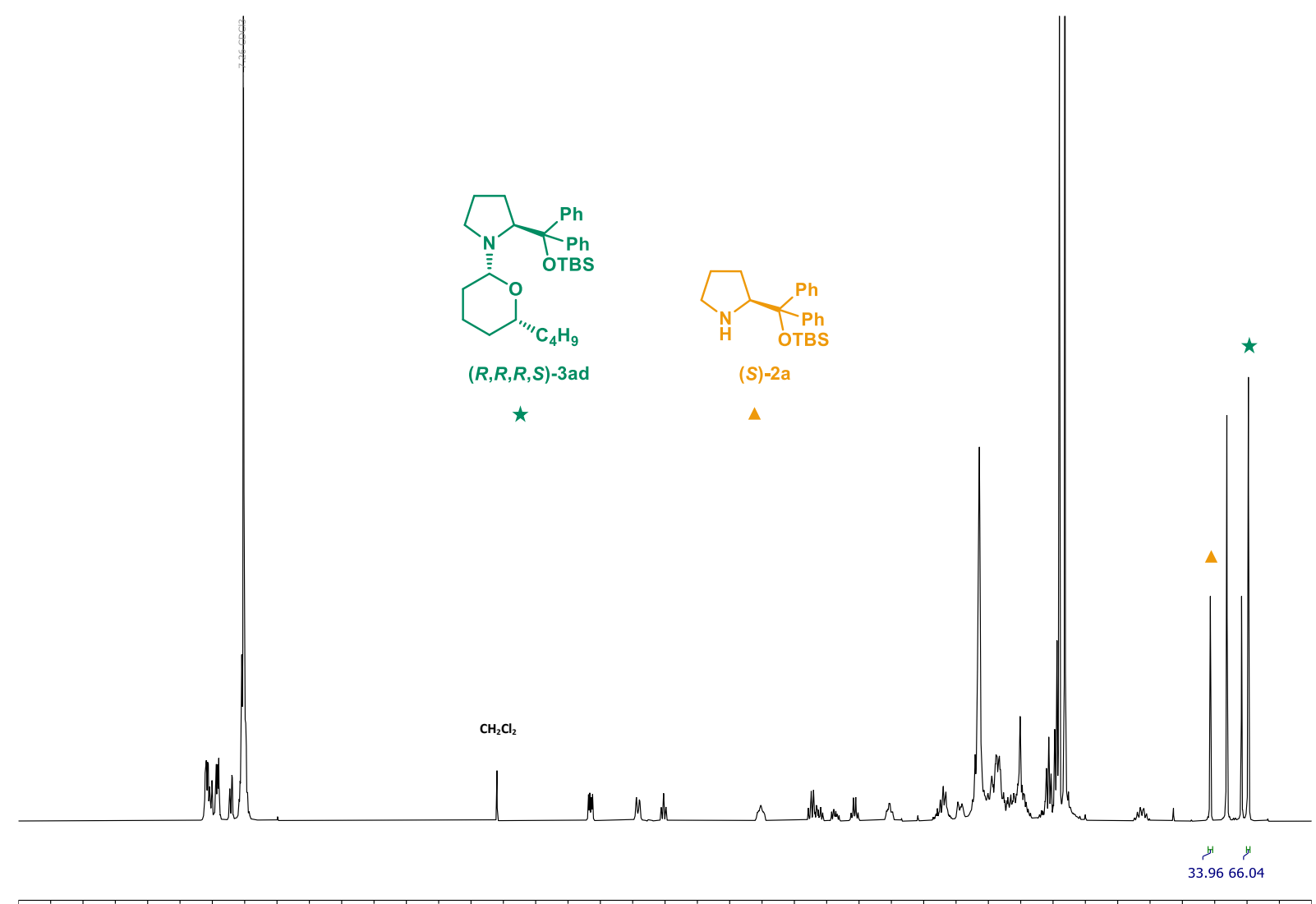

Figure $550 .{ }^{1} \mathrm{H} N M R$ spectrum $\left(400 \mathrm{MHz}, \mathrm{CDCl}_{3}\right)$ of hemiaminal ether $(R, R, R, S)$-3ad after silica gel purification.

\section{Recovery of amine (S)-2a and enantioenriched lactol (R)-1d}
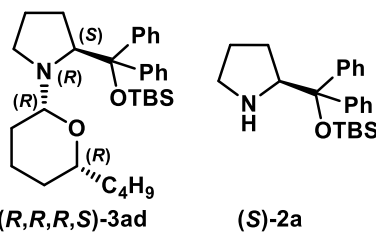

(S)-2a

$247.8 \mathrm{mg}$

$66: 34$

$163.5 \mathrm{mg} \quad 84.3 \mathrm{mg}$

$0.32 \mathrm{mmol} \quad 0.23 \mathrm{mmol}$
$\mathrm{NH}_{2} \mathrm{OH} \mathrm{HCl}$

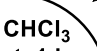

rt, $1 \mathrm{~h}$

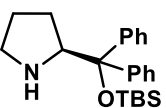

(S)-2a

$200.3 \mathrm{mg}$

$0.54 \mathrm{mmol}$

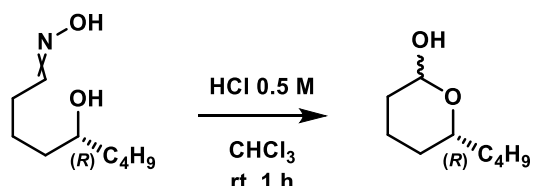

(R)-4d

$(R)-1 \mathrm{~d}$

$56.1 \mathrm{mg} \quad 48.1 \mathrm{mg}$

$0.32 \mathrm{mmol} \quad 0.31 \mathrm{mmol}$

$96.8 \%$ ee

Scheme S25. Recovery of amine (S)-2a and enantioenriched lactol (R)-1d. 


\subsection{Resolution of racemic $\delta$-decalactol $( \pm)-1 e$}

\section{Formation of the hemiaminal ether $(R, R, R, S)$-3ae}<smiles>O[C@H]1CCC[C@@H](S)O1</smiles><smiles>[2H]C(C)(Oc1ccccc1)C1CCCN1</smiles>

$(S)-2 a$

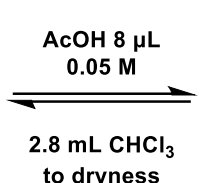

to dryness

$25 \%$ conv lactol

$239.1 \mathrm{mg}$

$1.39 \mathrm{mmol}$

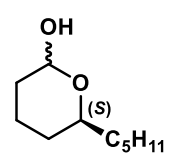

$(S)-1 e$

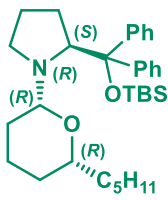

$(R, R, R, S)-3 \mathrm{ae}$

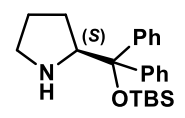

(S)-2a

$33.2 \%$ ee

Scheme S26. Formation of the hemiaminal ether $(R, R, R, S)$-3ae.

Hemiaminal ether $(R, R, R, S)-3$ ae (crude mixture)

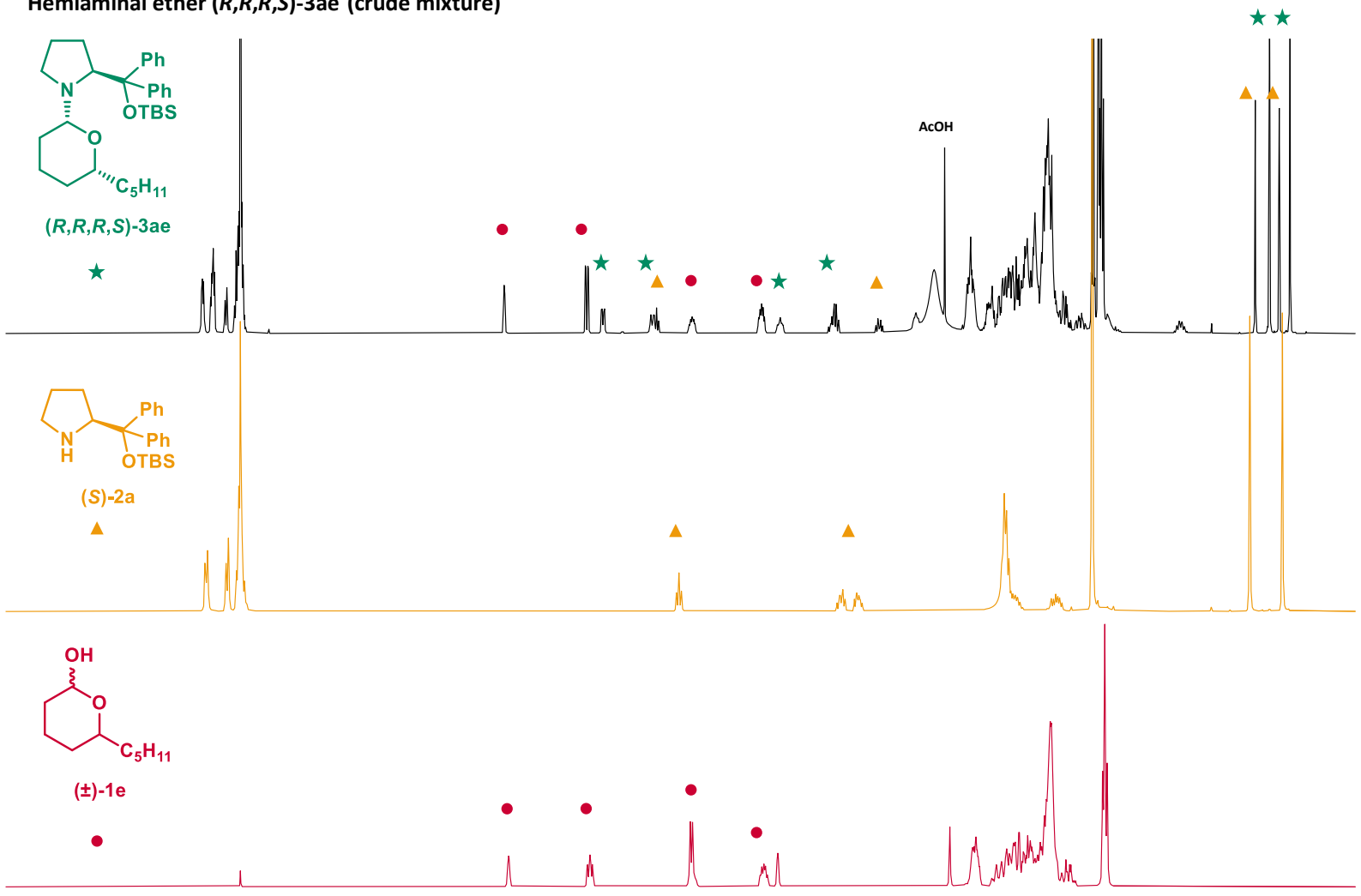

$0 \quad \frac{1}{0}$

Figure S51. ${ }^{1} \mathrm{H} N \mathrm{NR}$ spectrum $\left(400 \mathrm{MHz}, \mathrm{CDCl}_{3}\right)$ to assign the signals of the hemiaminal ether formed. 


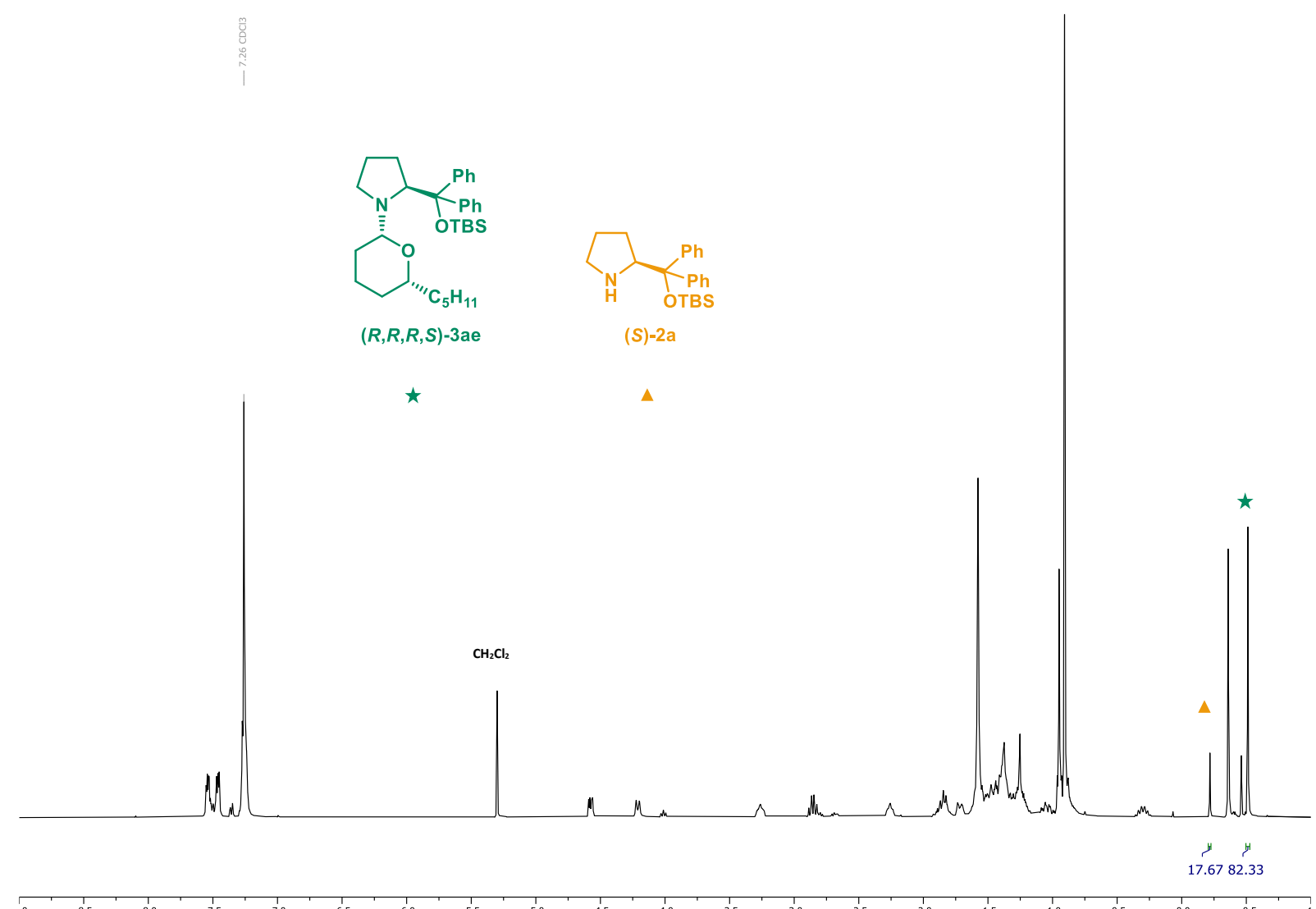

Figure $S 52 .{ }^{1} \mathrm{H} N \mathrm{NM}$ spectrum $\left(400 \mathrm{MHz}, C D C l_{3}\right)$ of hemiaminal ether $(R, R, R, S)$-3ae after silica gel purification

\section{Partial hydrolysis of hemiaminal ether $(R, R, R, S)-3$ ae}

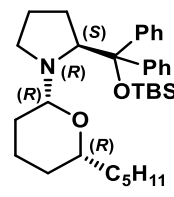

$(R, R, R, S)-3$ ae

$$
\begin{array}{cc}
226.0 \mathrm{mg} & 49.6 \mathrm{mg} \\
0.43 \mathrm{mmol} & 0.13 \mathrm{mmol}
\end{array}
$$

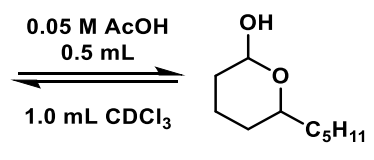

(S)-1e

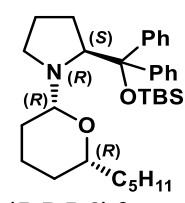

$(R, R, R, S)-3$ ae

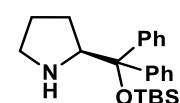

(S)-2a

Scheme S27. Partial hydrolysis of hemiaminal ether $(R, R, R, S)-3 a e$. 


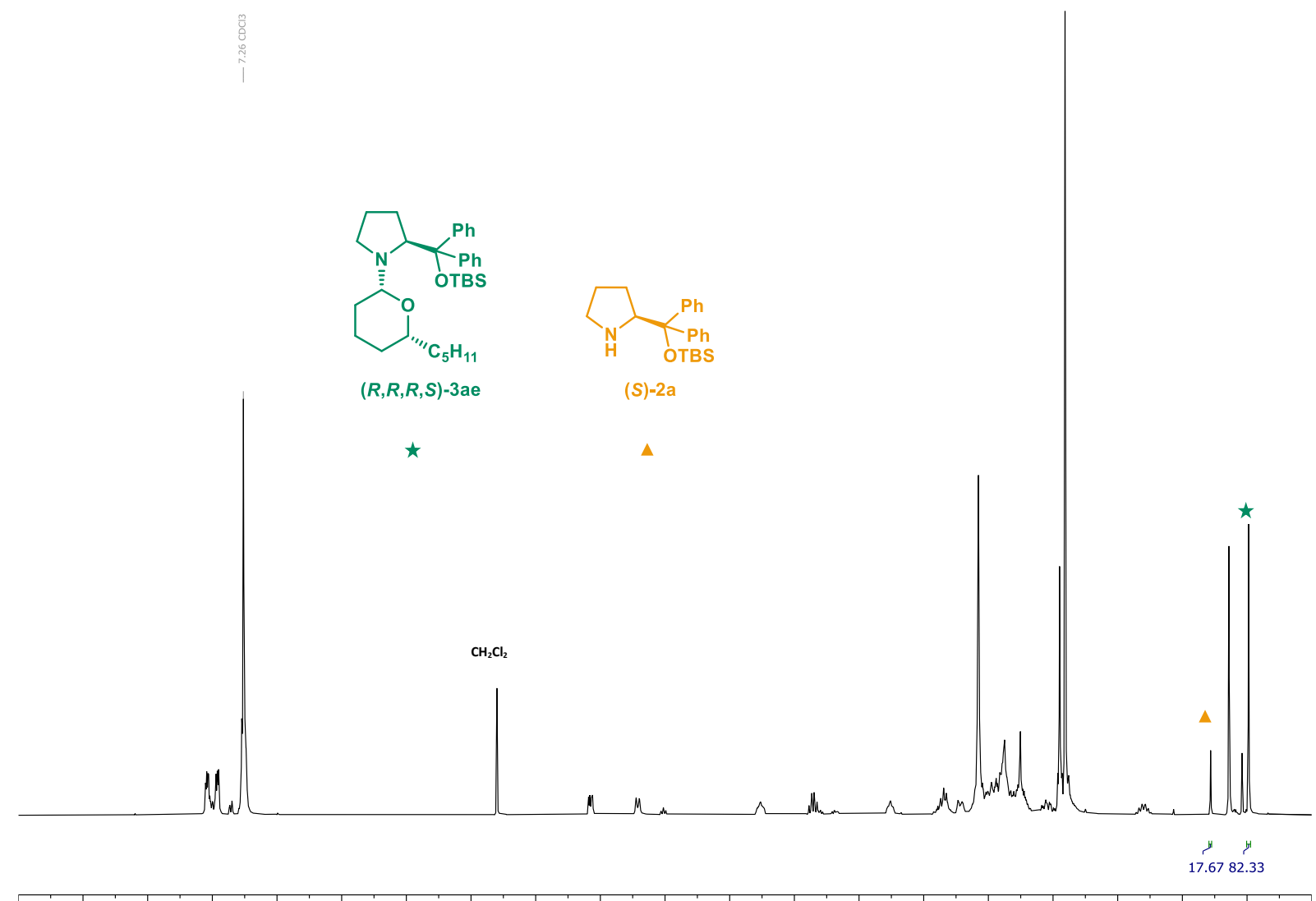

Figure S53. ${ }^{1} \mathrm{H} N \mathrm{NM}$ spectrum $\left(400 \mathrm{MHz}, \mathrm{CDCl}_{3}\right)$ of hemiaminal ether $(R, R, R, S)$-3ae before partial hydrolysis.

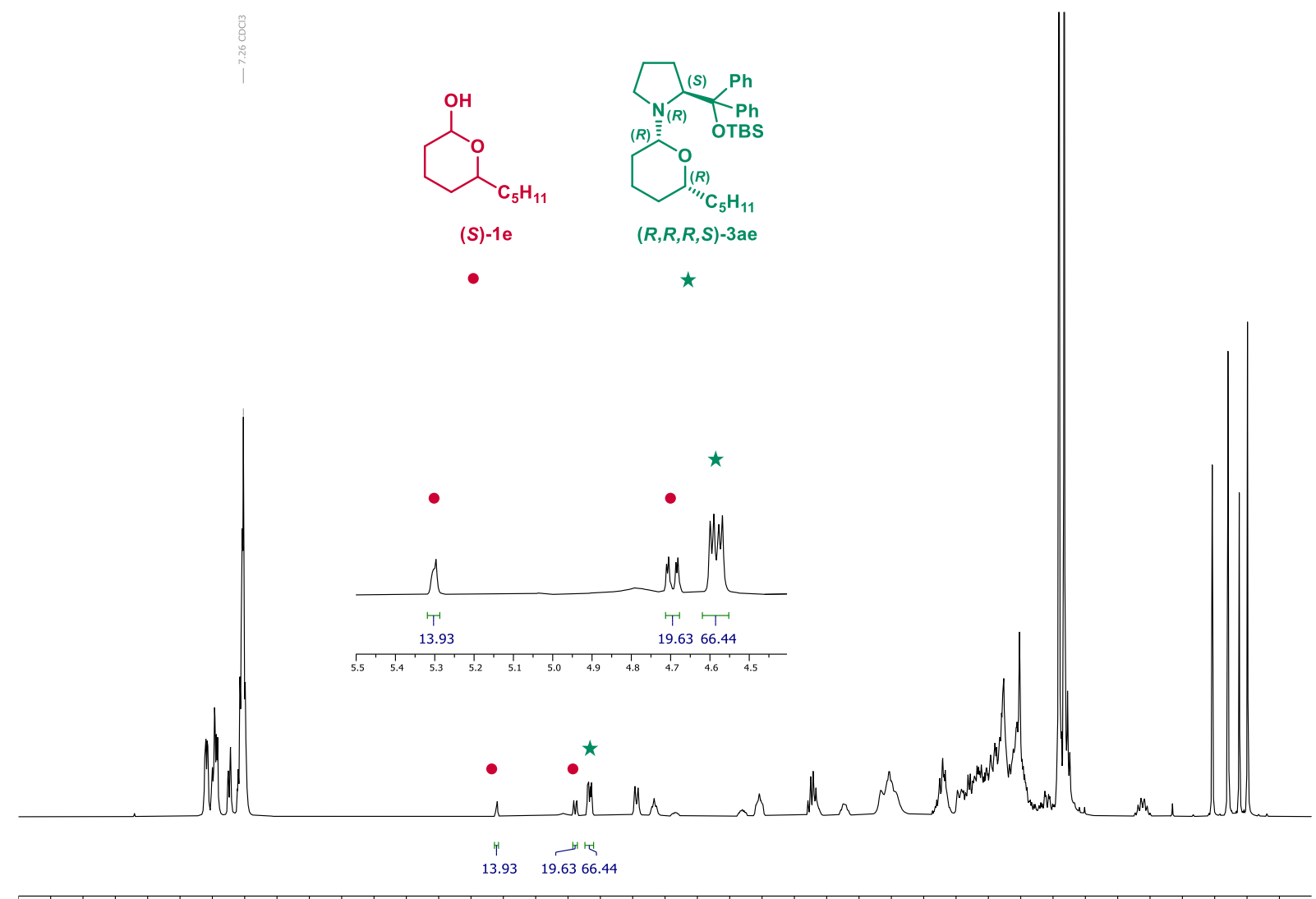

Figure S54. ${ }^{1} \mathrm{H}$ NMR spectrum ( $400 \mathrm{MHz}^{5.5}, \mathrm{CDCl}_{3}$ ) of crude hemiaminal ether $(R, R, R, S)$-3ae after partial hydrolysis. 


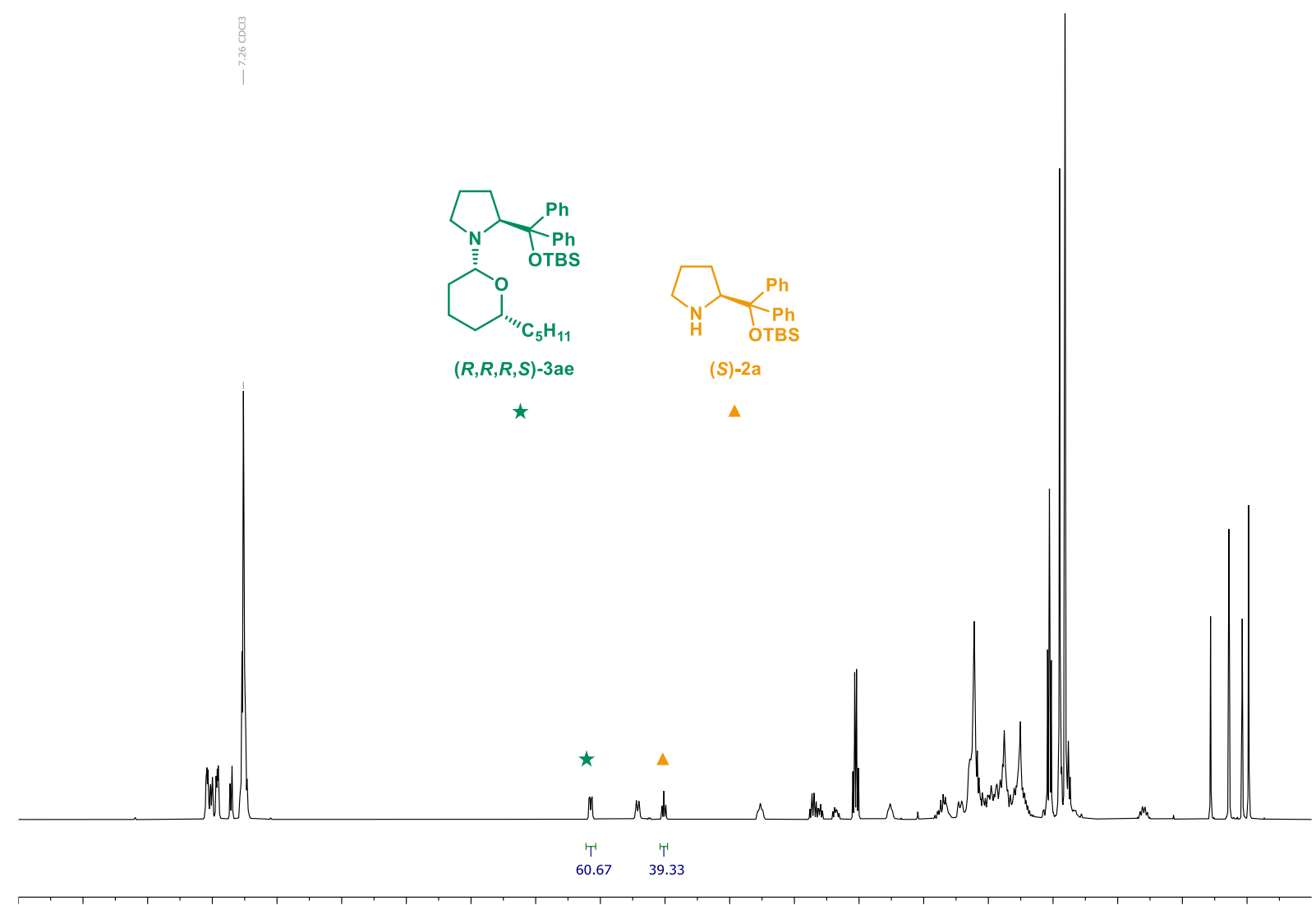

Figure $555 .{ }^{1} \mathrm{H} N \mathrm{MR}$ spectrum $\left(400 \mathrm{MHz}, \mathrm{CDCl}_{3}\right)$ of hemiaminal ether $(R, R, R, S)$-3ae after silica gel purification.

\section{Recovery of amine (S)-2a and enantioenriched lactol $(R)-1 \mathrm{e}$}

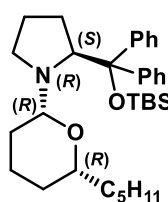
$(R, R, R, S)-3$ ae

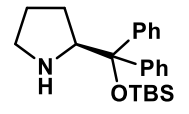

(S)-2a

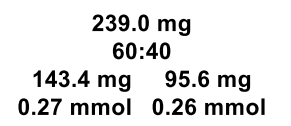
$0.27 \mathrm{mmol} \quad 0.26 \mathrm{mmol}$
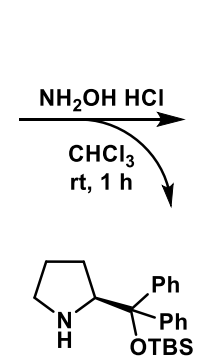

$(s)-2 a$

$193.9 \mathrm{mg}$ $0.53 \mathrm{mmol}$

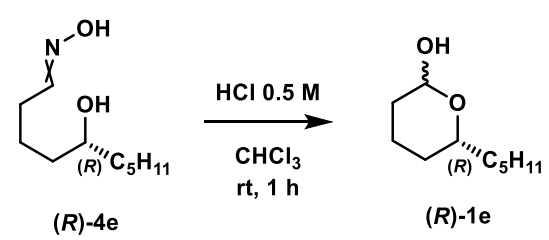

$50.1 \mathrm{mg}$

$0.26 \mathrm{mmol}$

$0.24 \mathrm{mmol}$

$98.5 \%$ ee

Scheme S28. Recovery of amine (S)-2a and enantioenriched lactol (R)-1e. 


\subsection{Resolution of racemic $\delta$-undecalactol ( \pm )-1f}

\section{Formation of the hemiaminal ether $(R, R, R, S)$-3af}

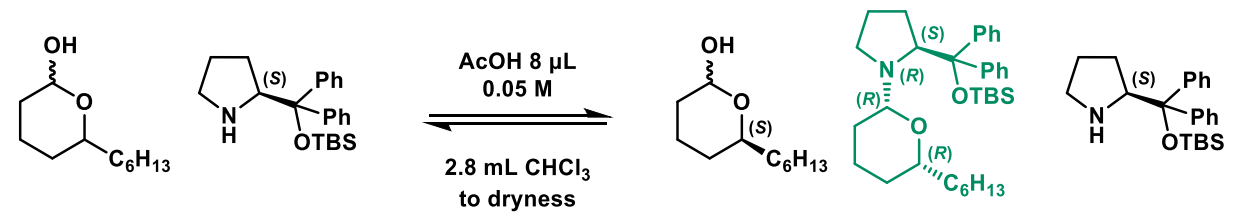

$\begin{array}{cc}( \pm)-1 \mathrm{f} & (S)-2 \mathrm{a} \\ & \\ & \\ 0.5 \mathrm{M} & 0.2 \mathrm{M} \\ 258.9 \mathrm{mg} & 204.2 \mathrm{mg} \\ .39 \mathrm{mmol} & 0.56 \mathrm{mmol}\end{array}$

(S)-1f

$(R, R, R, S)-3$ af

(S)-2a

$30 \%$ conv lacto

$$
\begin{array}{ccc} 
& \multicolumn{2}{c}{279.7 \mathrm{mg}} \\
& \multicolumn{1}{c}{91: 9} \\
174.5 \mathrm{mg} & 254.5 \mathrm{mg} & 25.2 \mathrm{mg} \\
0.92 \mathrm{mmol} & 0.48 \mathrm{mmol} & 0.07 \mathrm{mmol}
\end{array}
$$

$27.8 \%$ ee

Scheme S29. Formation of the hemiaminal ether $(R, R, R, S)-3 a f$

Hemiaminal ether $(R, R, R, S)$-3af (crude mixture)
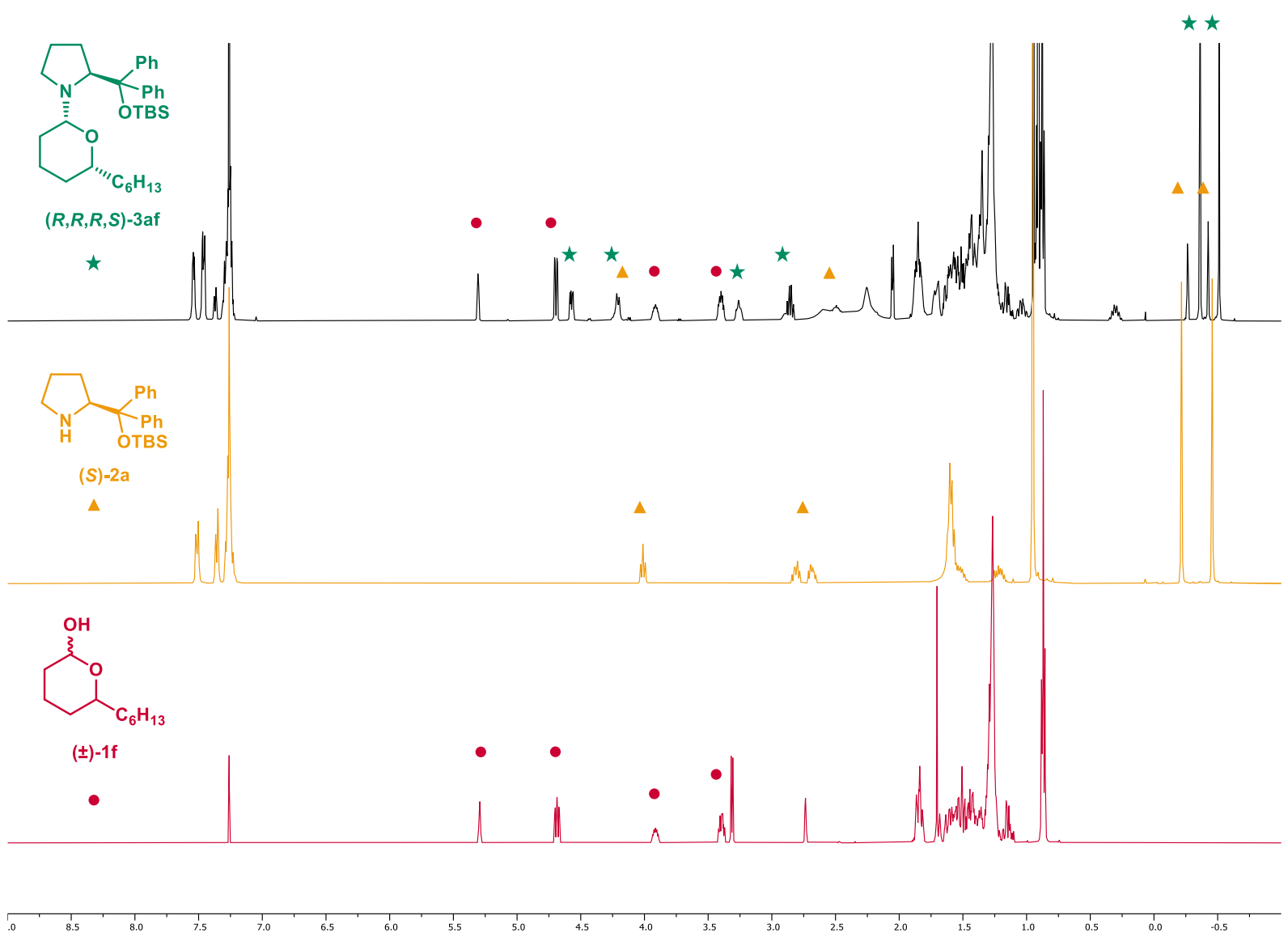

Figure S56. ${ }^{1} \mathrm{H} \mathrm{NMR}$ spectrum $\left(400 \mathrm{MHz}, \mathrm{CDCl}_{3}\right)$ to assign the signals of the hemiaminal ether formed. 


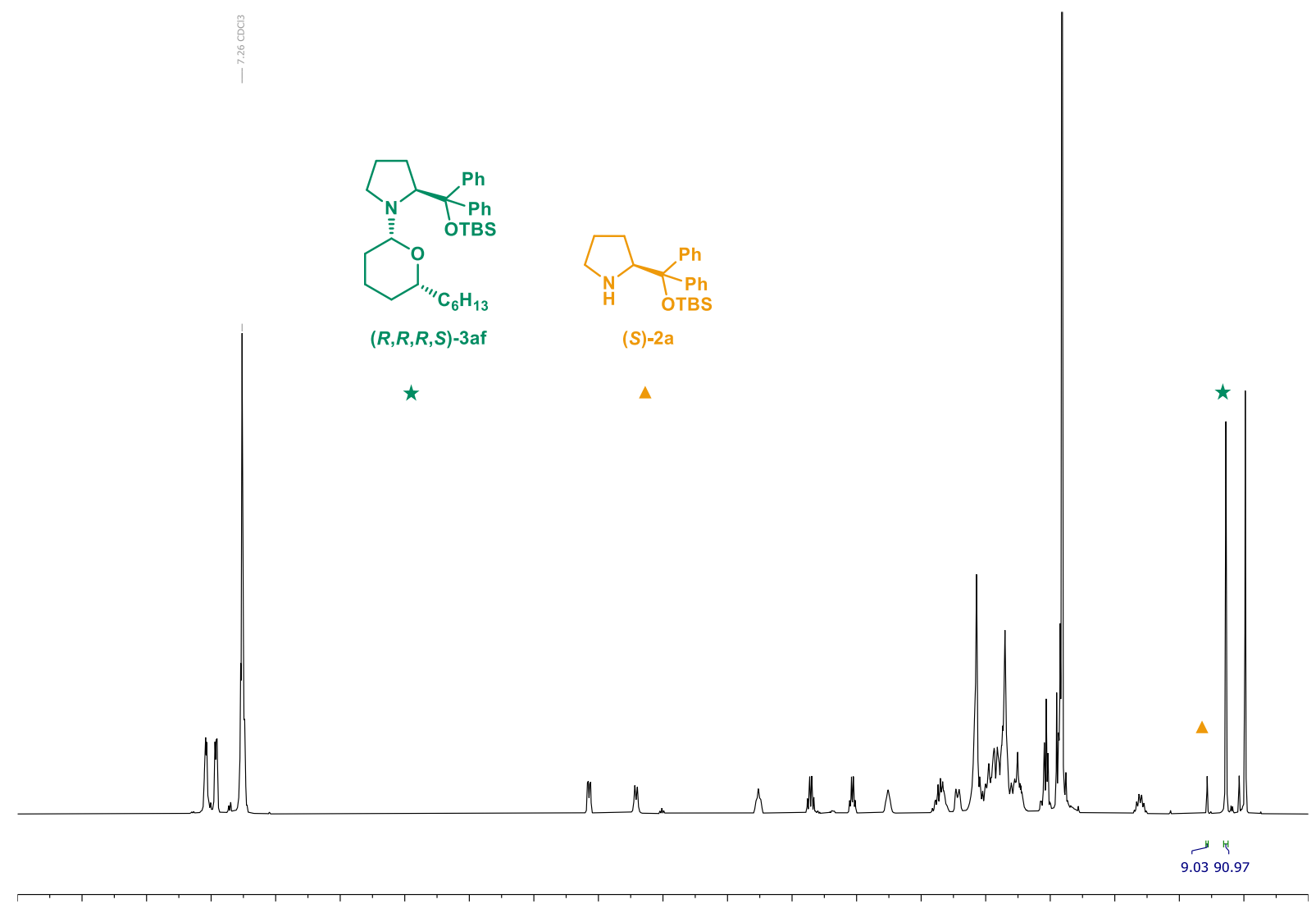

Figure S57. ${ }^{1} \mathrm{H} N M R$ spectrum $\left(400 \mathrm{MHz}, \mathrm{CDCl}_{3}\right)$ of hemiaminal ether $(R, R, R, S)$-3af after silica gel purification

\section{Partial hydrolysis of hemiaminal ether $(R, R, R, S)-3$ af}

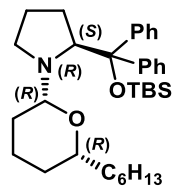

$(R, R, R, S)-3$ af

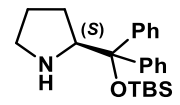

(S)-2a $279.7 \mathrm{mg}$

91:9

$254.5 \mathrm{mg} \quad 25.2 \mathrm{mg}$ $\begin{array}{cc}254.5 \mathrm{mg} & 25.2 \mathrm{mg} \\ 0.48 \mathrm{mmol} & 0.07 \mathrm{mmol}\end{array}$

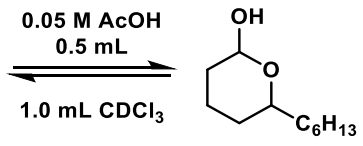

(S)-1f

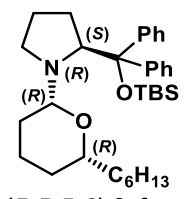

$(R, R, R, S)-3$ af

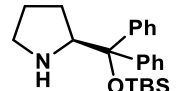

(s)-2a

\section{$145.4 \mathrm{mg}$}$$
\text { 95:5 }
$$

$138.1 \mathrm{mg} \quad 7.3 \mathrm{mg}$ $0.26 \mathrm{mmol} 0.02 \mathrm{mmol}$

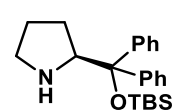

(S)-2a

$94.9 \mathrm{mg}$ $0.26 \mathrm{mmol}$

Scheme S30. Partial hydrolysis of hemiaminal ether ( $R, R, R, S)$-3af. 


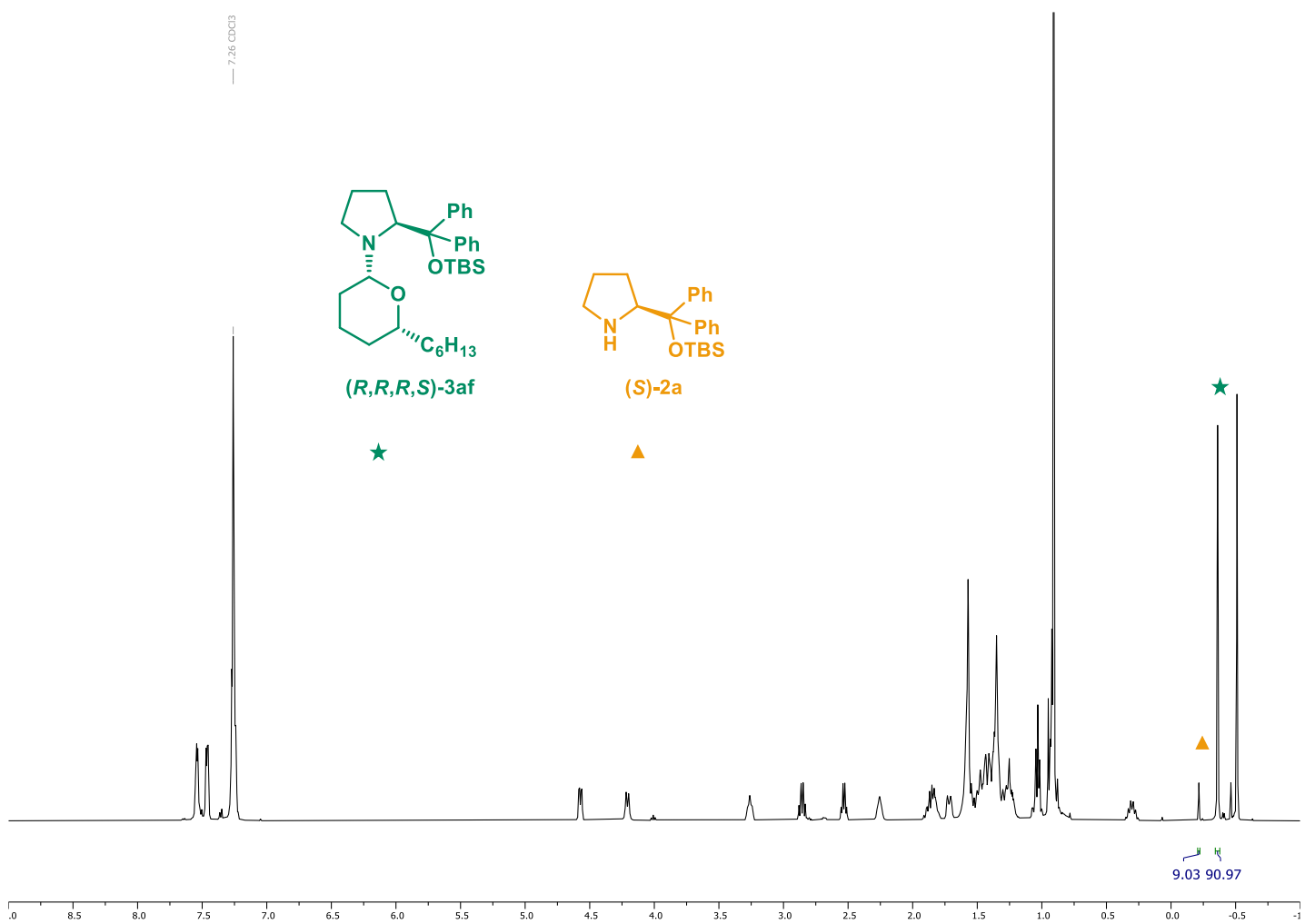

Figure S58. ${ }^{1} \mathrm{H} N \mathrm{NR}$ spectrum $\left(400 \mathrm{MHz}, \mathrm{CDCl}_{3}\right)$ of hemiaminal ether $(R, R, R, S)$-3af before partial hydrolysis.

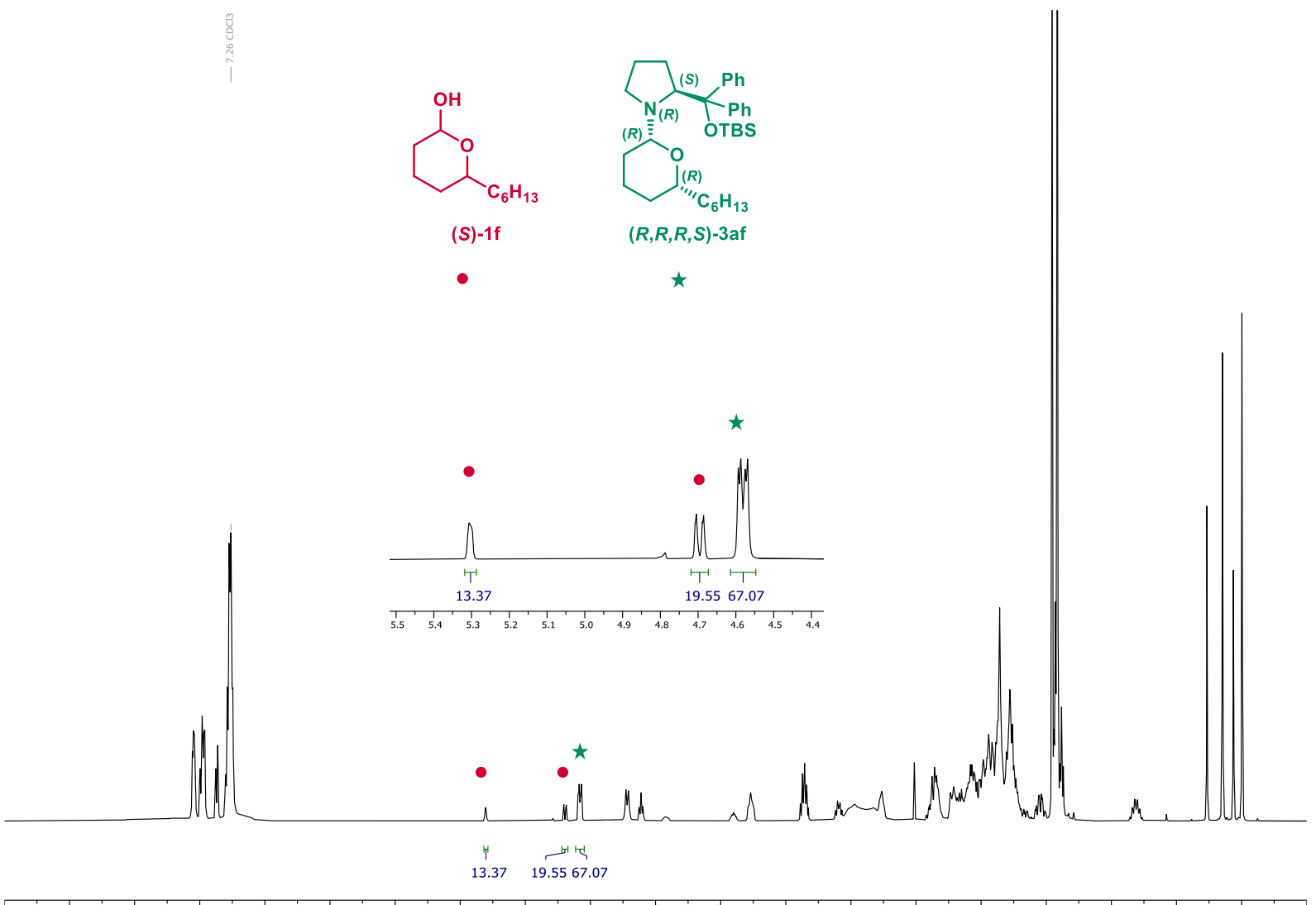

Figure S 59. ${ }^{1} \mathrm{H} N \mathrm{NMR}$ spectrum $\left(400 \mathrm{MHz}, \mathrm{CDCl}_{3}\right)$ of crude hemiaminal ether $(R, R, R, S)$-3af after partial hydrolysis. 


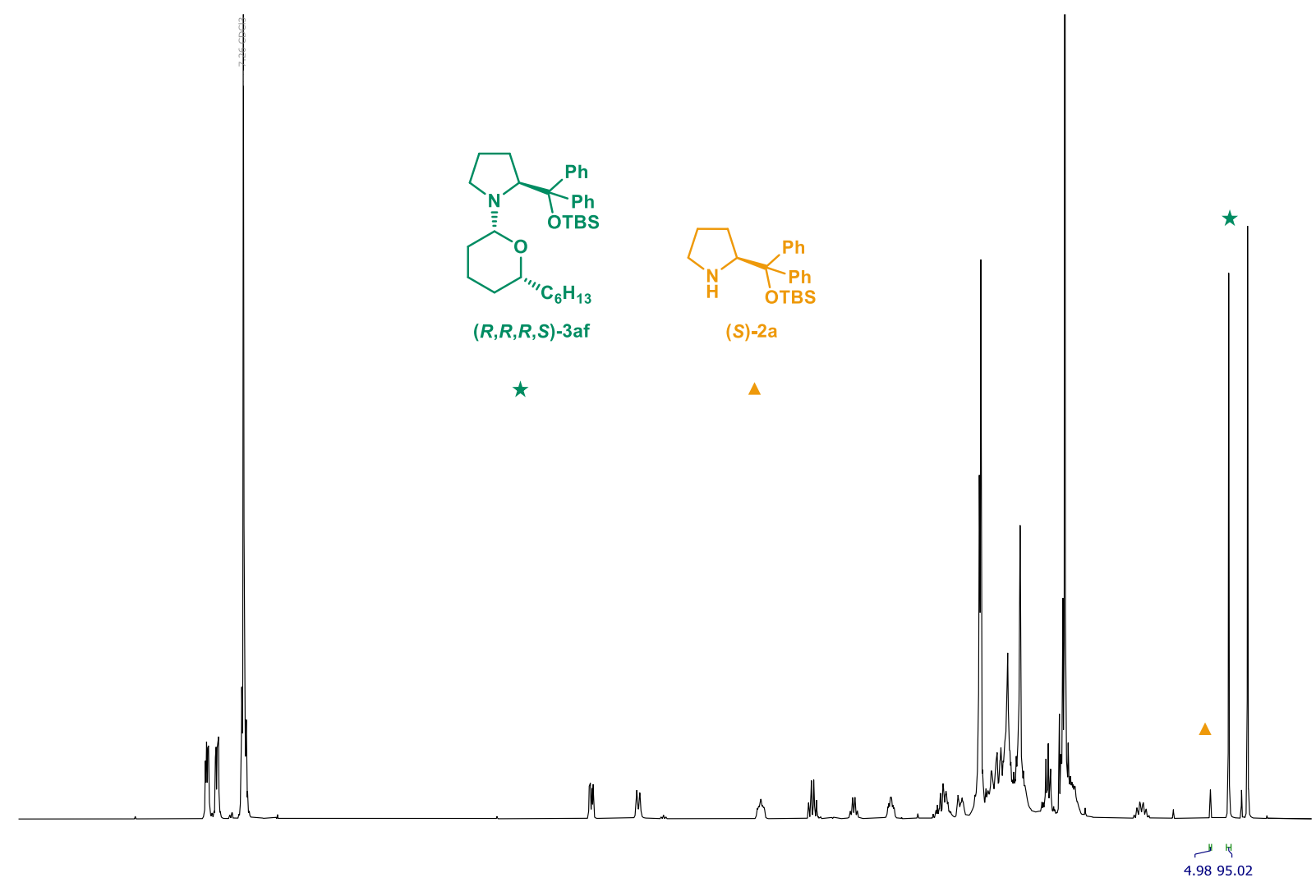

Figure $560 .{ }^{1} \mathrm{H} N \mathrm{MR}$ spectrum $\left(400 \mathrm{MHz}, \mathrm{CDCl}_{3}\right)$ of hemiaminal ether $(R, R, R, S)$-3af after silica gel purification.

Recovery of amine (S)-2a and enantioenriched lactol (R)-1f

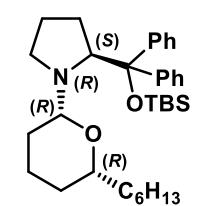

$(R, R, R, S)-3$ af

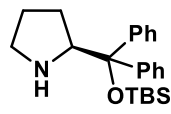

(S)-2a
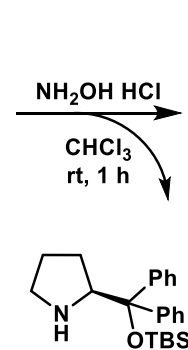

(S)-2a<smiles>CC[C@@H](O)CCC/C=N/O</smiles>

(R)-4f

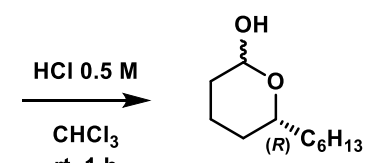

$(R)-1 f$ 


\section{Chiral resolution of lactols to obtain scalemic mixtures}

In the second protocol, we prioritized the possibility of performing the resolution in multigram scale instead of enantioselectivity because of scalemic mixtures of the corresponding $\delta$-lactones. To do so, we used $\delta$-octalactol $( \pm)$-1c and $\delta$-decalactol $( \pm)$-1e.

To do so, the chiral resolution racemic $\delta$-lactols $( \pm)-(\mathbf{1 c}, \mathbf{1 e})$ involved two steps. The first step is the formation of the hemiaminal ether $(R, R, R, S)$-3ac, 3ae. The second step is the recovery of the resolution agent, amine (S)-2a, and enantioenriched $\delta$-hexalactol $(R)$-1c, 1e.

\subsection{Resolution of racemic $\delta$-octalactol $( \pm)-1 \mathrm{c}$}

Formation of the hemiaminal ether $(R, R, R, S)$-3ac<smiles>O[C@@H]1CCC[C@@H](S)O1</smiles>

(士)-1c

$$
\begin{gathered}
1.0 \mathrm{M} \\
9.7741 \mathrm{~g}
\end{gathered}
$$
$67.89 \mathrm{mmol}$

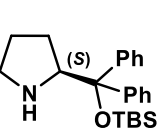

(S)-2a

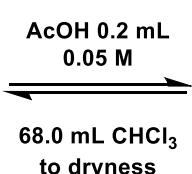

$20 \%$ conv lactol

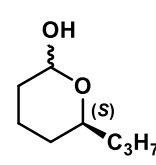

(S)-1c

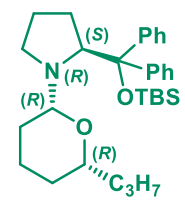

$(R, R, R, S)-3$ ac

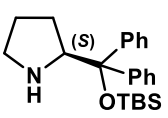

(S)-2a

$$
\begin{gathered}
6.0247 \mathrm{~g} \\
41.84 \mathrm{mmol}
\end{gathered}
$$$$
\begin{aligned}
& 6.3802 \mathrm{~g} \\
& 94: 6
\end{aligned}
$$$$
5.9974 \mathrm{~g} \quad 0.3828 \mathrm{~g}
$$$$
12.17 \mathrm{mmol} 1.04 \mathrm{mmol}
$$ 
Hemiaminal ether $(R, R, R, S)$-3ac (crude mixture)

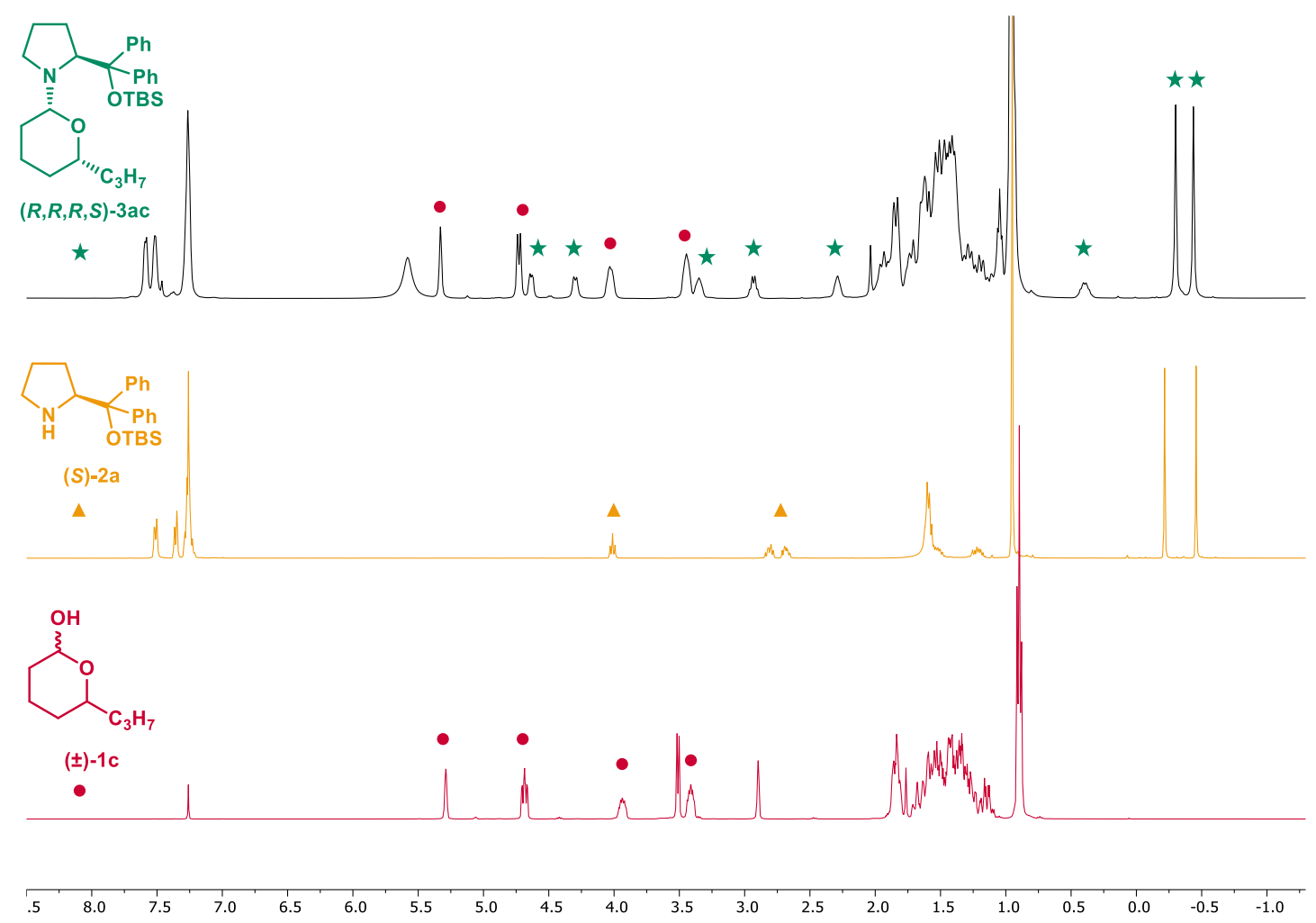

Figure $561 .{ }^{1} \mathrm{H} N M R$ spectrum $\left(400 \mathrm{MHz}, \mathrm{CDCl}_{3}\right)$ to assign the signals of the hemiaminal ether formed.

\section{Recovery of amine (S)-2a and enantioenriched lactol $(R)-1 \mathrm{c}$}

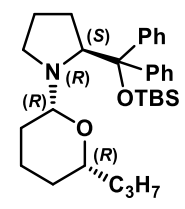

$(R, R, R, S)-3$ ac

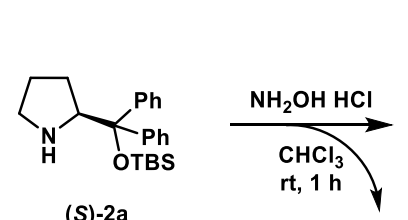

(S)-2a

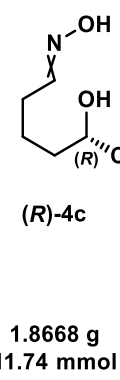

(S)-2a

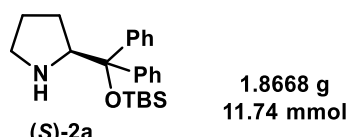

$4.8144 \mathrm{~g}$

$13.11 \mathrm{mmol}$

$97 \%$ recovered

Scheme S33. Recovery of amine (S)-2a and enantioenriched lactol (R)-1c. 


\subsection{Resolution of racemic $\delta$-decalactol $( \pm)-1 e$}

\section{Formation of the hemiaminal ether $(R, R, R, S)$-3ae}<smiles>O[C@H]1CCC[C@@H](S)O1</smiles>

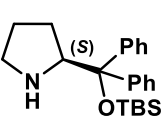

(S)-2a

$( \pm)-1 e$

$1.0 \mathrm{M}$

$10.8000 \mathrm{~g}$

$62.69 \mathrm{~mol}$

$4.6000 \mathrm{~g}$

$12.57 \mathrm{mmol}$

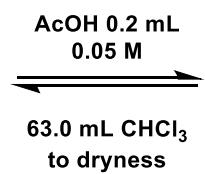

to dryness

$20 \%$ conv lactol<smiles>O[C@H]1CCC[C@@H](S)O1</smiles>

(S)-1e

$7.1420 \mathrm{~g}$

$41.46 \mathrm{~mol}$

$20 \%$ ee

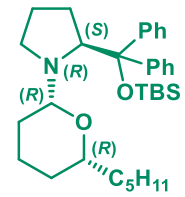

$(R, R, R, S)$-3ae

5.8620

$75: 25$

$4.3965 \mathrm{~g} 1.4655 \mathrm{~g}$

$8.43 \mathrm{mmol} 3.99 \mathrm{mmol}$

Scheme S34. Formation of the hemiaminal ether (R, R, R,S)-3ae.

Hemiaminal ether $(R, R, R, S)$-3ae (crude mixture)

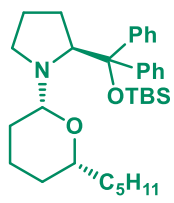

$(R, R, R, S)-3$ ae

$\star$

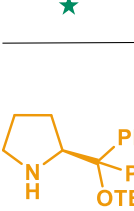

(S)-2a
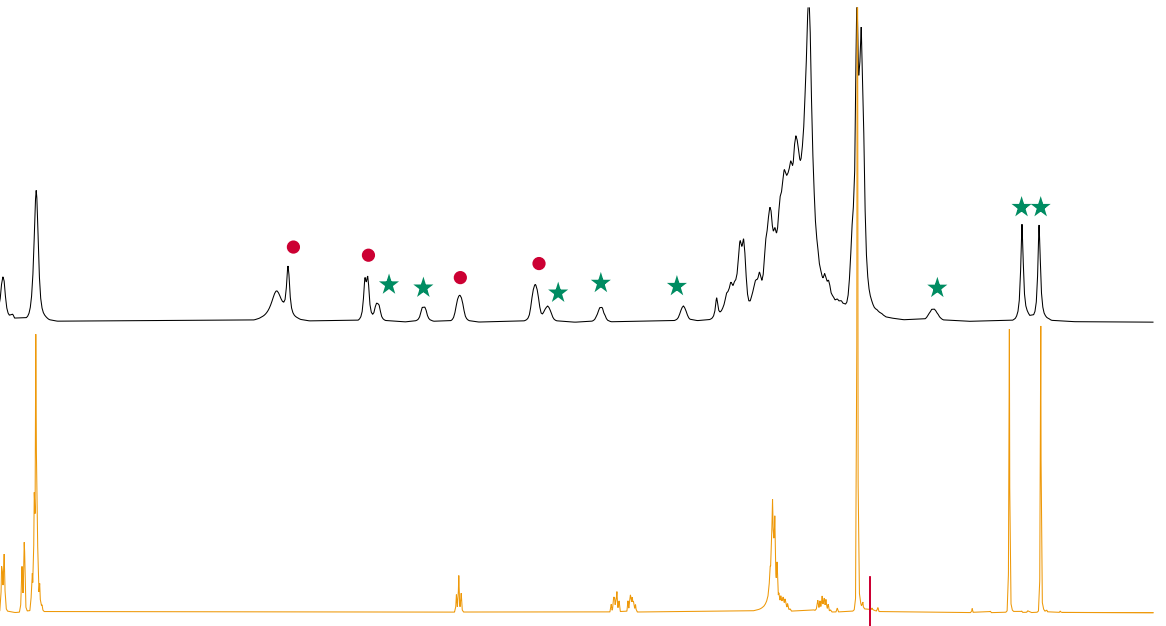

$\underbrace{\mathrm{OH}}_{\mathrm{C}_{5} \mathrm{H}_{11}}$

$( \pm)-1 e$

95
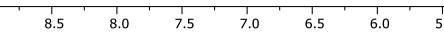

Figure S62. ${ }^{1} \mathrm{H} N \mathrm{MR}$ spectrum $\left(400 \mathrm{MHz}, \mathrm{CDCl}_{3}\right)$ to assign the signals of the hemiaminal ether formed. 
Recovery of amine (S)-2a and enantioenriched lactol (R)-1e

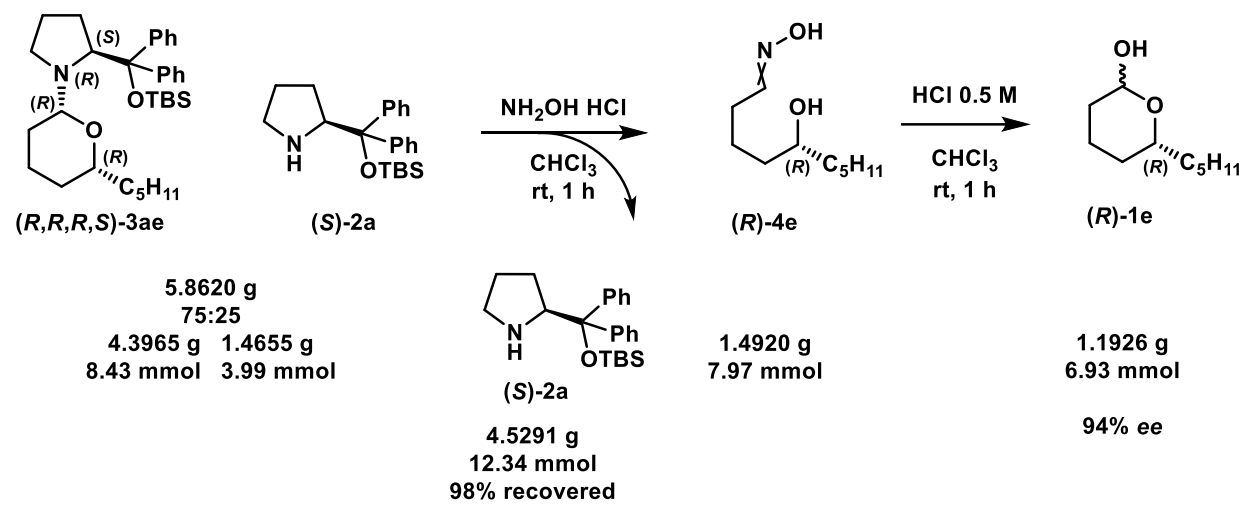

Scheme S35. Recovery of amine (S)-2a and enantioenriched lactol (R)-1e. 


\section{NMR spectra}

\section{$\delta$-Valerolactol 1a}<smiles>OC1=COCCC1</smiles>

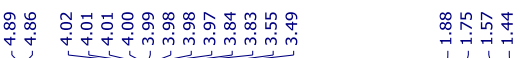

$1 \mathrm{a}$

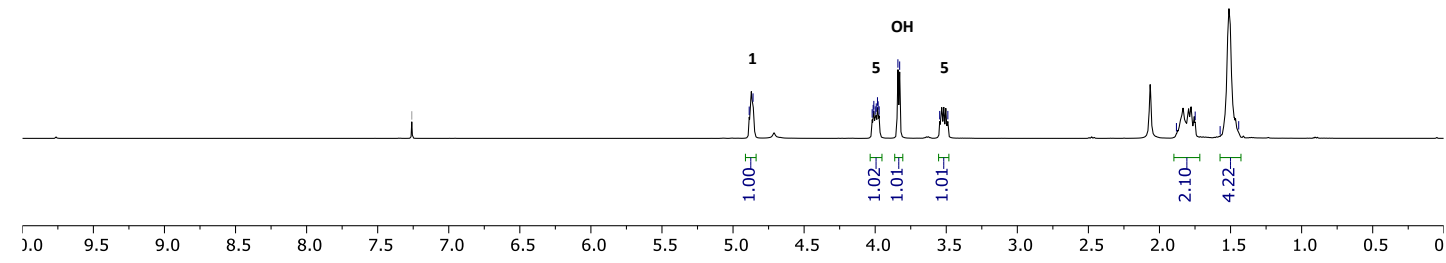<smiles>OC1CCCCO1</smiles>

1a

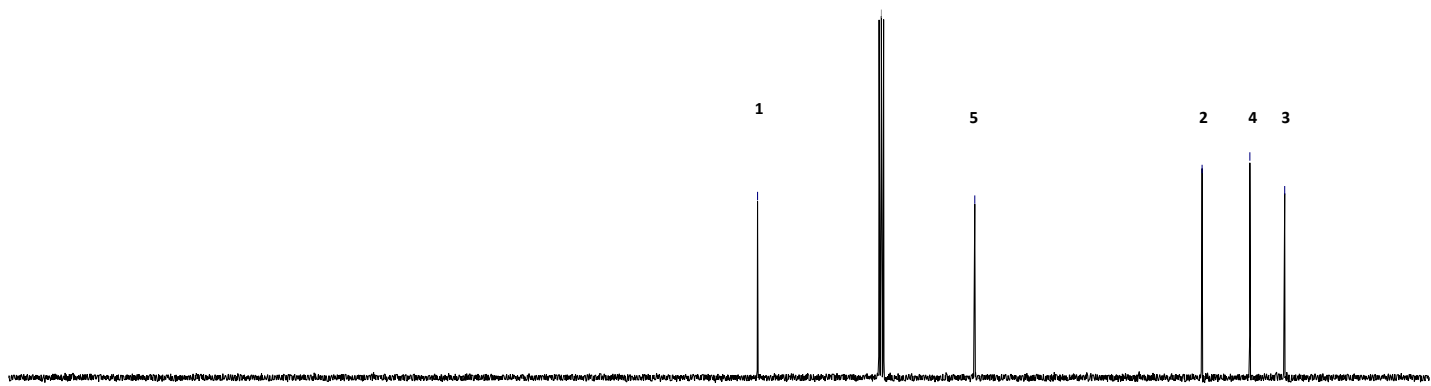

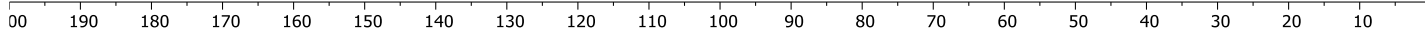

Figure S63. ${ }^{1} \mathrm{H} N \mathrm{NM}$ spectrum $\left.(400 \mathrm{MHz}, \mathrm{CDCl})_{3}\right)$ and ${ }^{13} \mathrm{C}\{1 \mathrm{H}\} \mathrm{NMR}$ spectrum $(101 \mathrm{MHz}, \mathrm{CDCl})$ of $1 \mathrm{a}$. 


\section{( \pm )- $\delta$-Hexalactol 1b}

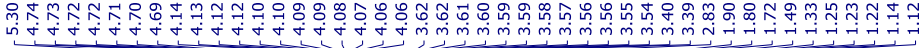<smiles>CC1CCCC(O)O1</smiles>

( \pm - $-c i s-1 \mathrm{~b}$

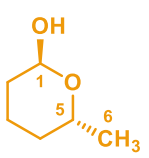

$( \pm)$-trans-1b

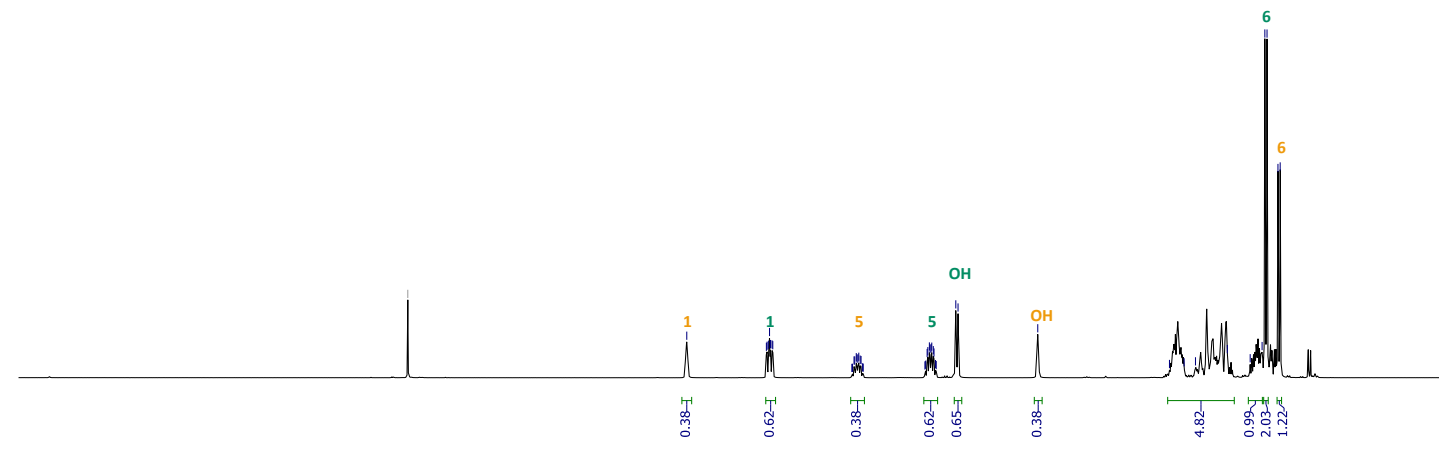

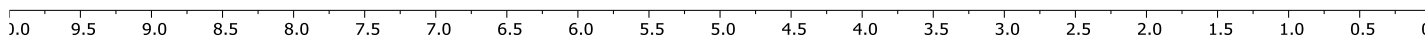<smiles>C[C@@H]1CCC[C@@H](O)O1</smiles>

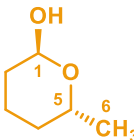

( \pm )-cis-1b

( \pm )-trans-1b

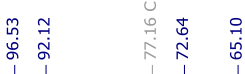

ำ

लำ

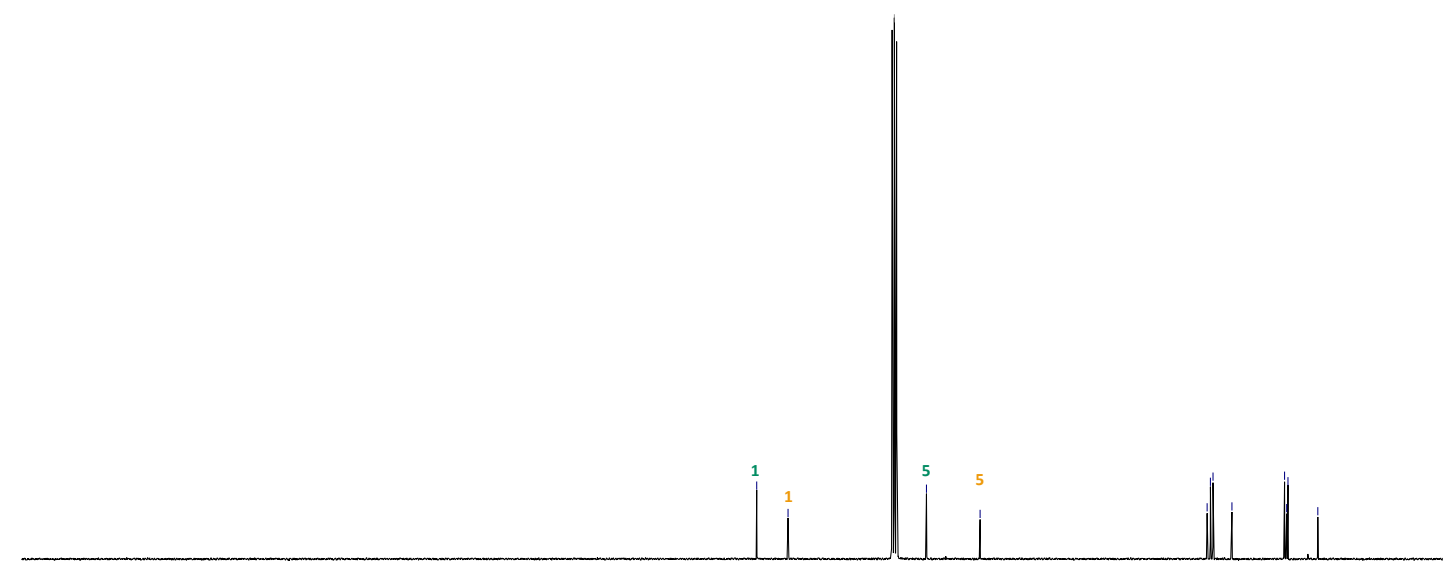

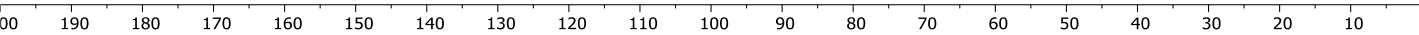

Figure S64. ${ }^{1} \mathrm{H} N M R$ spectrum $\left.(400 \mathrm{MHz}, \mathrm{CDCl})_{3}\right)$ and ${ }^{13} \mathrm{C}\{1 \mathrm{H}\} \mathrm{NMR}$ spectrum $(101 \mathrm{MHz}, \mathrm{CDCl} / 3)$ of $( \pm)-\mathbf{1 b}$. 


\section{(士)-8-Octalactol 1c}

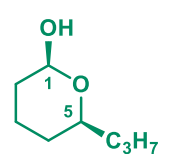

(士)-cis-1c

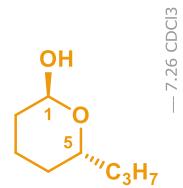

(土)-trans-1c

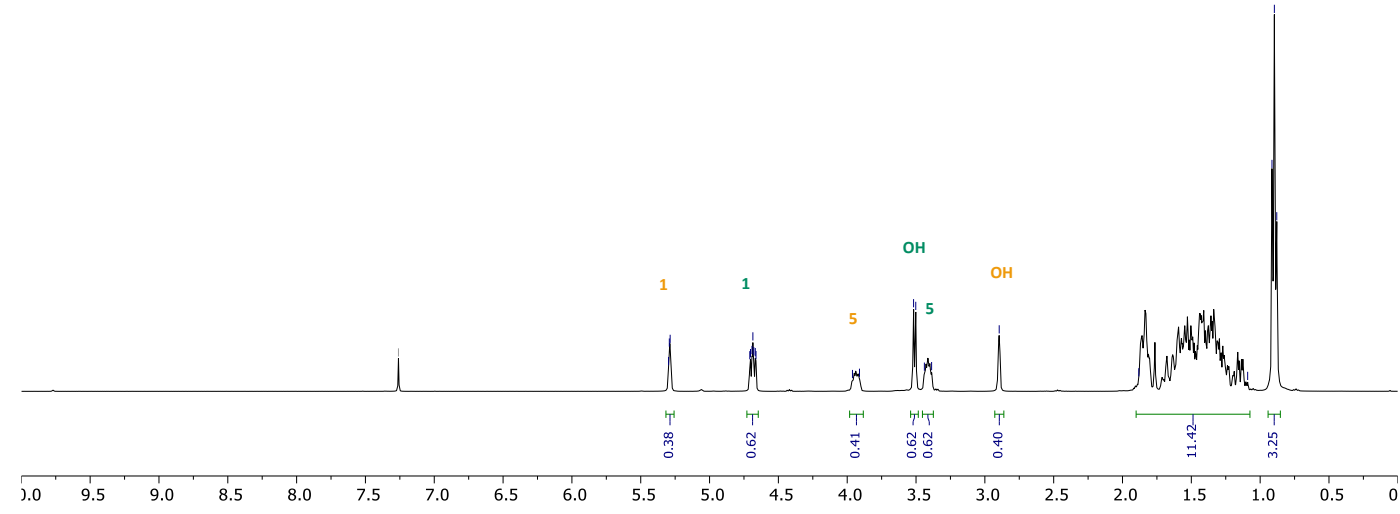

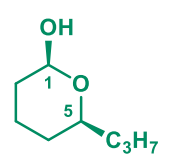

(士)-cis-1c

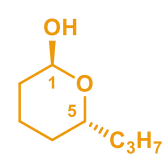

(士)-trans-1c

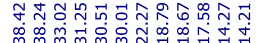

m m m

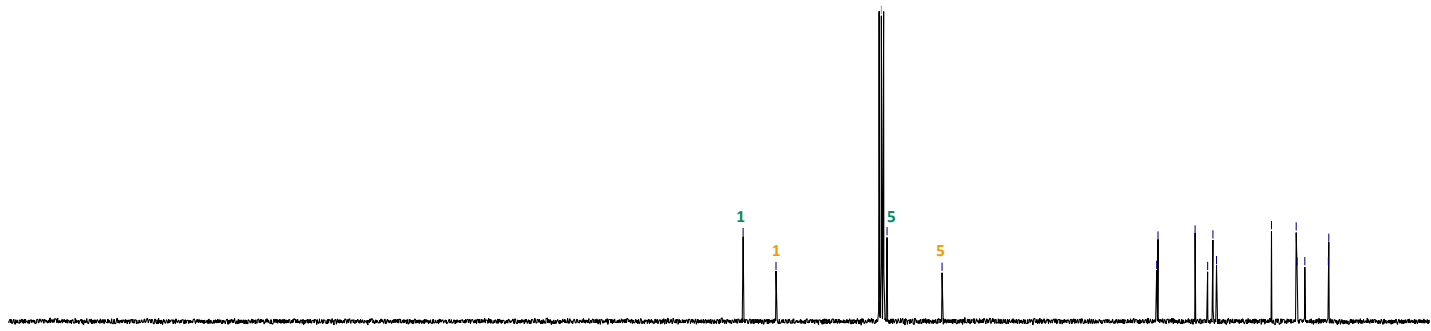

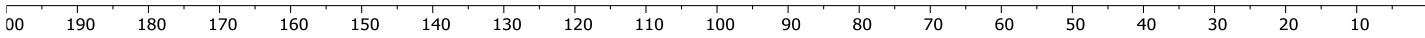

Figure S65. ${ }^{1} \mathrm{H} N \mathrm{NR}$ spectrum $(400 \mathrm{MHz}, \mathrm{CDCl} 3)$ and ${ }^{13} \mathrm{C}\{1 \mathrm{H}\} \mathrm{NMR}$ spectrum $(101 \mathrm{MHz}, \mathrm{CDCl})_{3}$ of $( \pm)-1 \mathrm{c}$. 


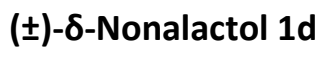

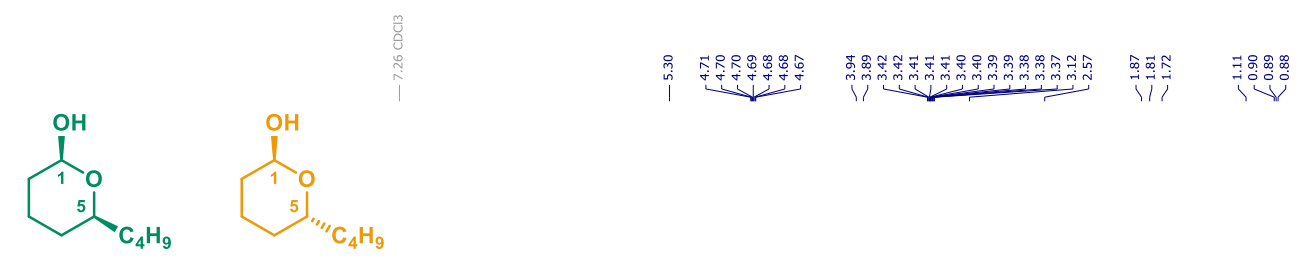

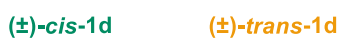

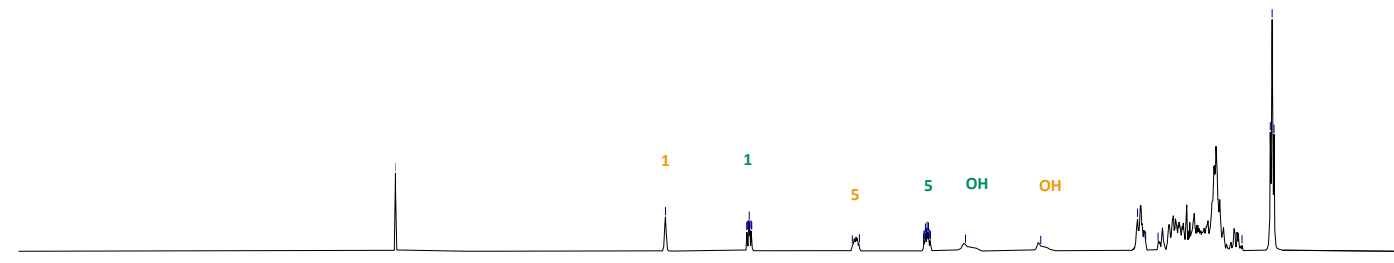

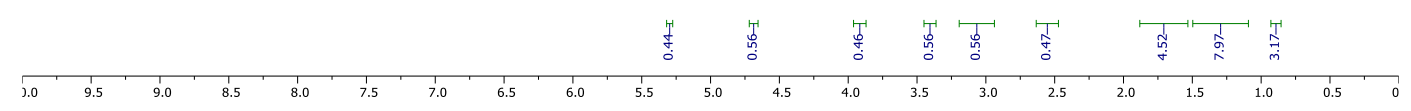

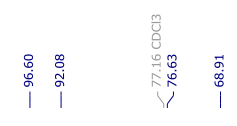

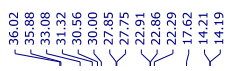

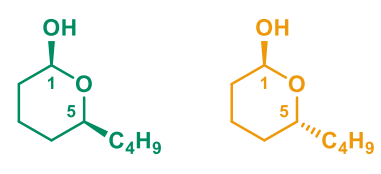

(士)-cis-1d $\quad( \pm)$-trans-1d

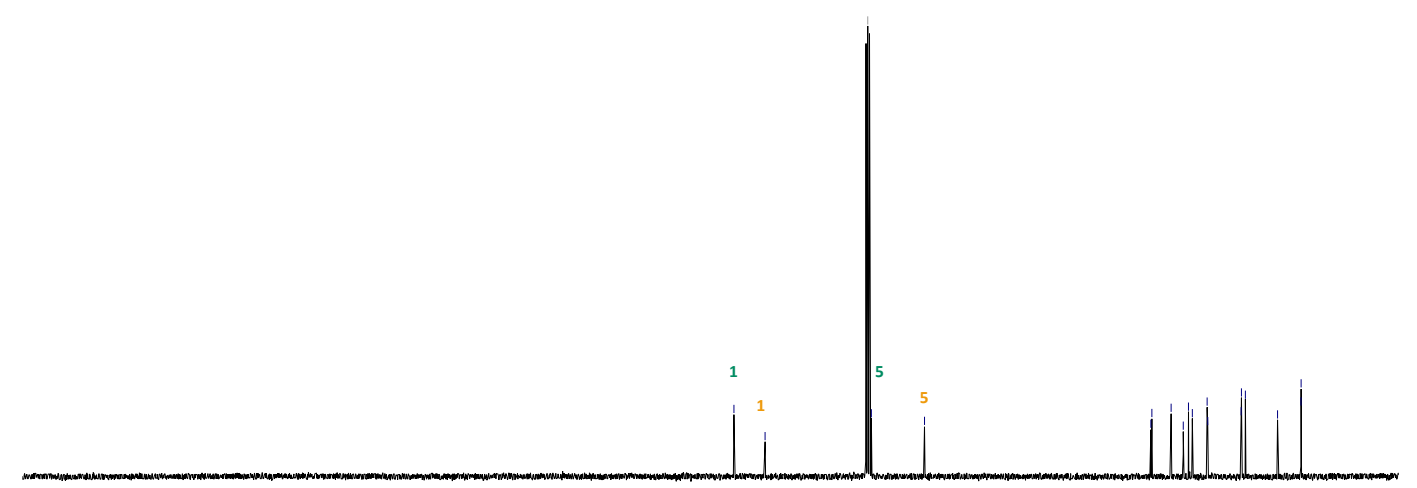

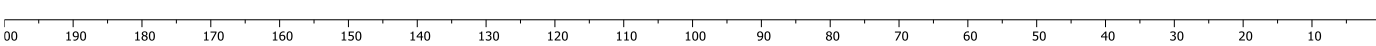

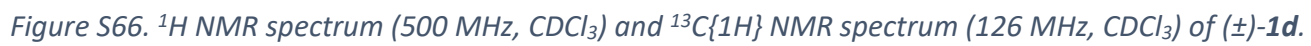




\section{( \pm )-ס-Decalactol 1e}

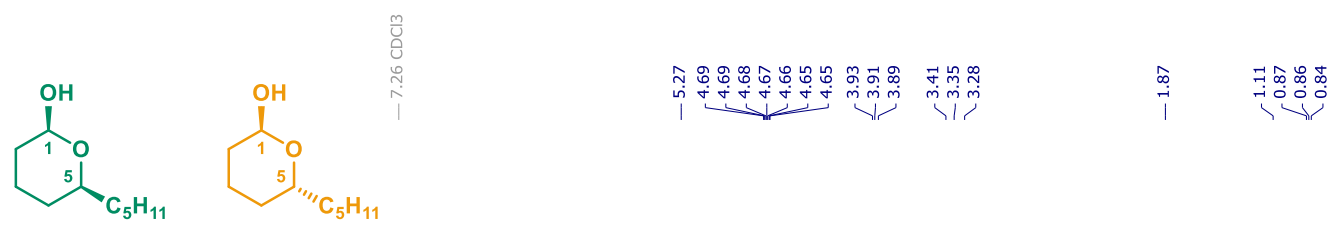

(士)-cis-1e $\quad( \pm)$-trans-1e
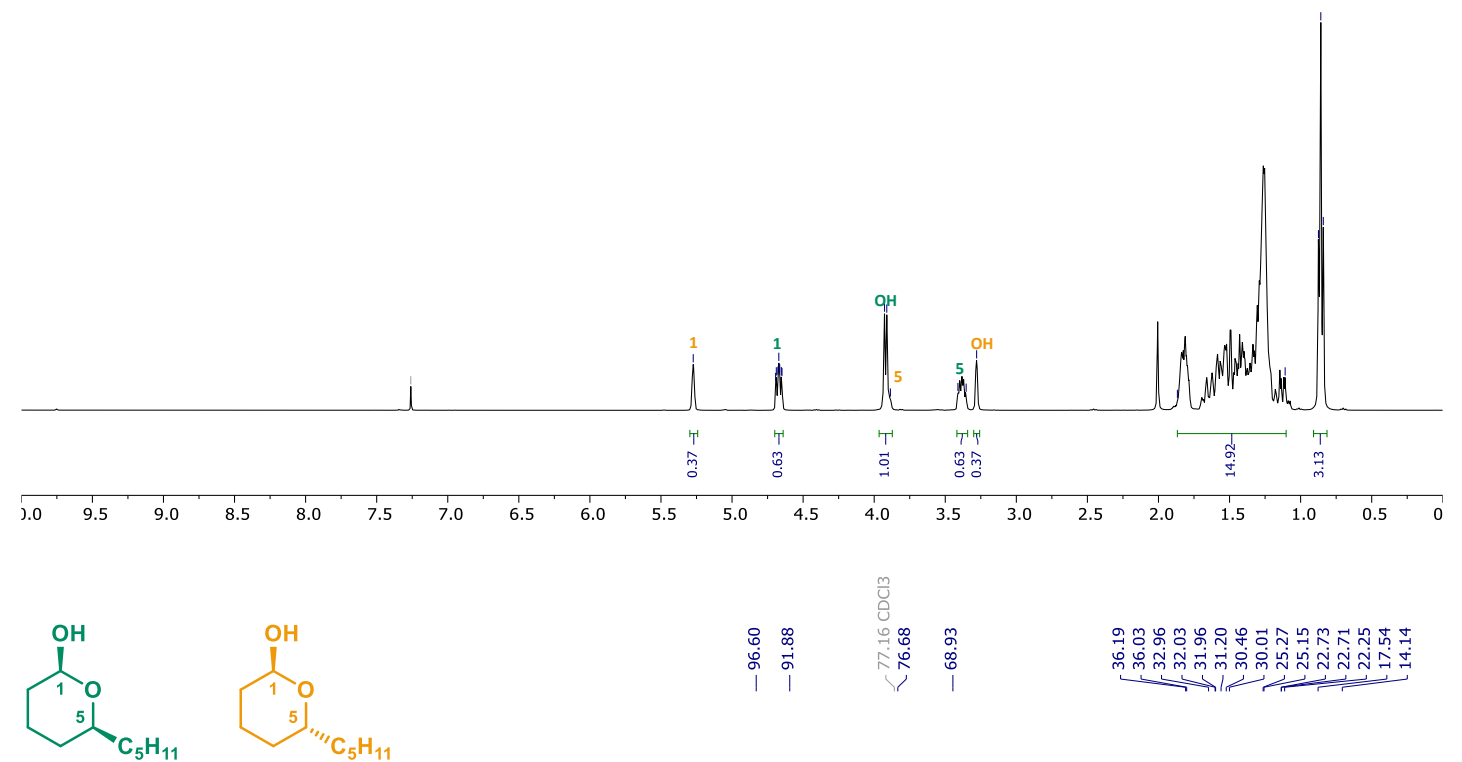

$( \pm)$-cis-1e $\quad( \pm)$-trans-1e

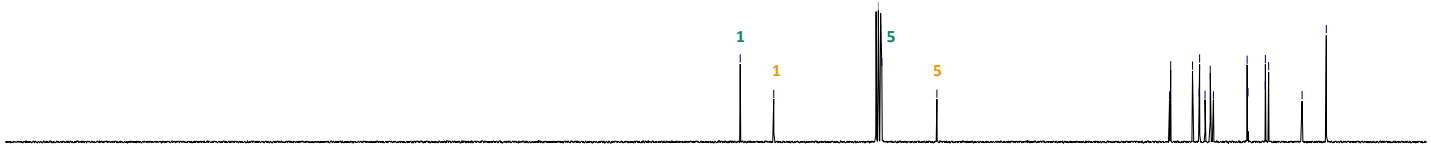

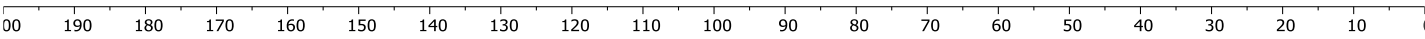

Figure S67. ${ }^{1} \mathrm{H} N \mathrm{NR}$ spectrum $(400 \mathrm{MHz}, \mathrm{CDCl} 3)$ and ${ }^{13} \mathrm{C}\{1 \mathrm{H}\} \mathrm{NMR}$ spectrum $(101 \mathrm{MHz}, \mathrm{CDCl} / 3)$ of $( \pm)-1 e$. 


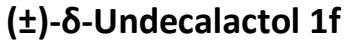<smiles>CC1CCCC(O)O1</smiles>

(士)-cis-1f

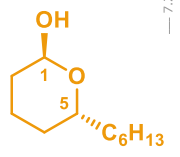

( \pm )-trans-1f

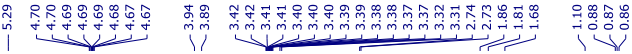

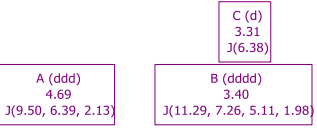

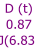

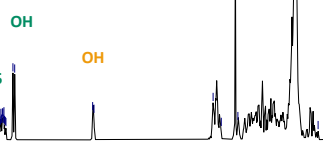

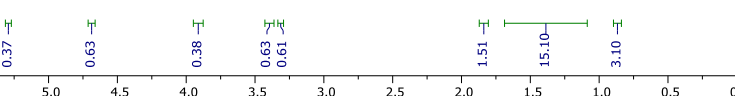

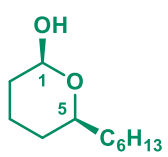

(士)-cis-1f

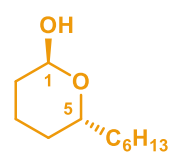

$( \pm)$-trans-1f

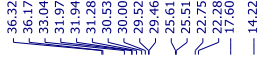

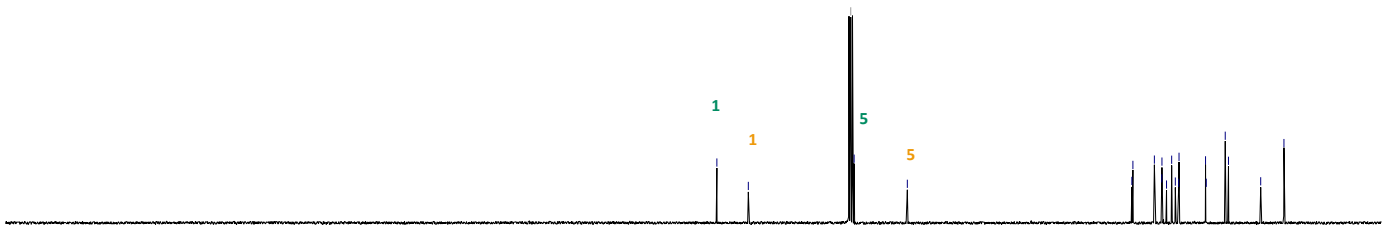

Figure S68. ${ }^{1} \mathrm{H} N \mathrm{NMR}$ spectrum $\left(500 \mathrm{MHz}, \mathrm{CDCl}_{3}\right)$ and ${ }^{13} \mathrm{C}\{1 \mathrm{H}\} \mathrm{NMR}$ spectrum $\left(126 \mathrm{MHz}, \mathrm{CDCl}_{3}\right)$ of $( \pm)-1 f$. 
(2S)-2-(((tert-Butyldimethylsilyl)oxy(diphenylmethyl)-1-((2R,6R)-6-methyltetrahydro-2H-pyran-2yl)pyrrolidine 3ab
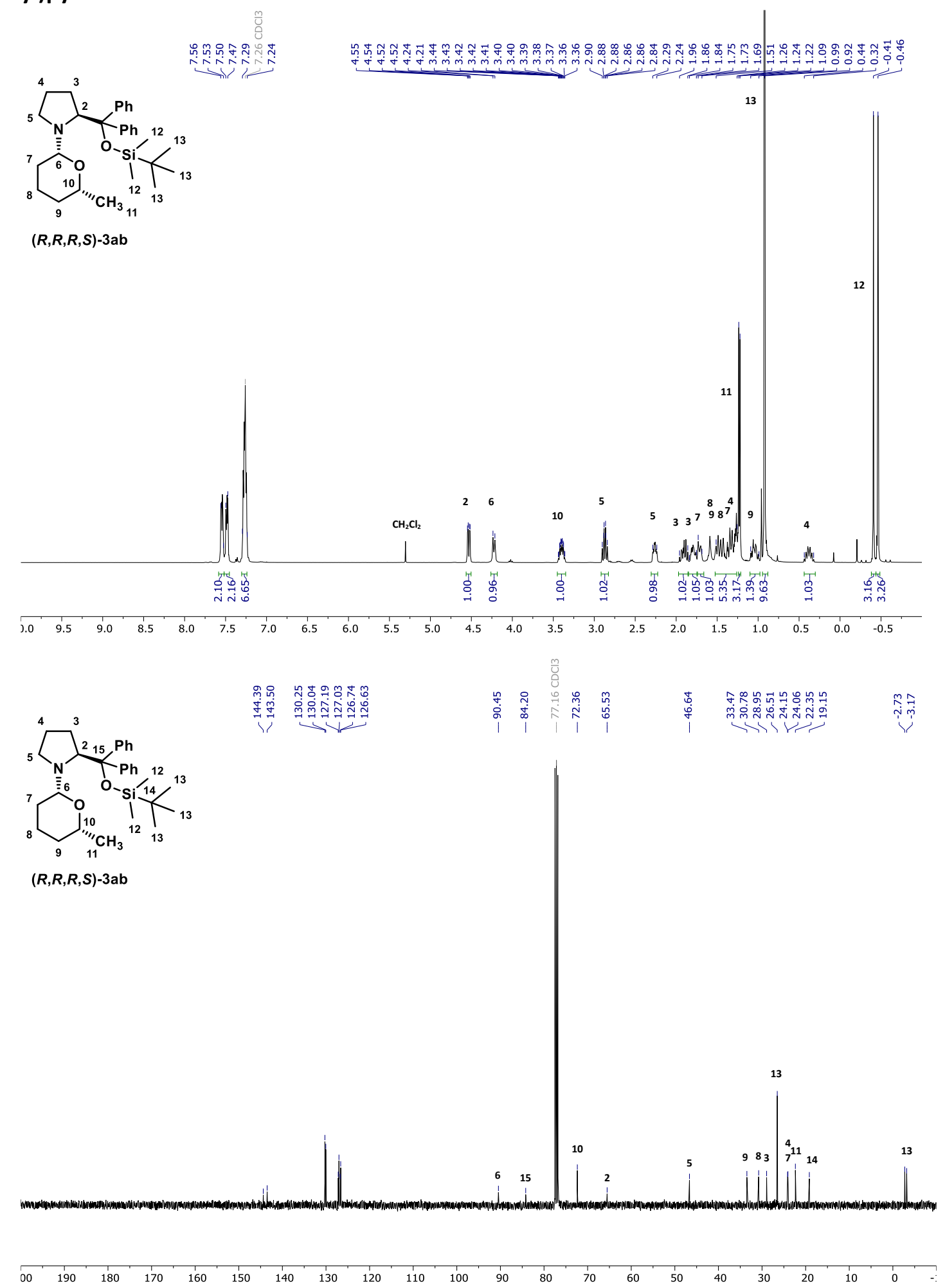

Figure S69. ${ }^{1} \mathrm{H} N \mathrm{NR}$ spectrum $\left(400 \mathrm{MHz}, \mathrm{CDCl}_{3}\right)$ and ${ }^{13} \mathrm{C}\{1 \mathrm{H}\} \mathrm{NMR}$ spectrum $\left(101 \mathrm{MHz}, \mathrm{CDCl}_{3}\right)$ of $(R, R, R, S)-3 a b$. 
(2S)-2-((tert-Butyldimethylsilyl)oxy(diphenylmethyl)-1-((2R,6R)-6-methyltetrahydro-2H-pyran-2yl)pyrrolidine 3ab

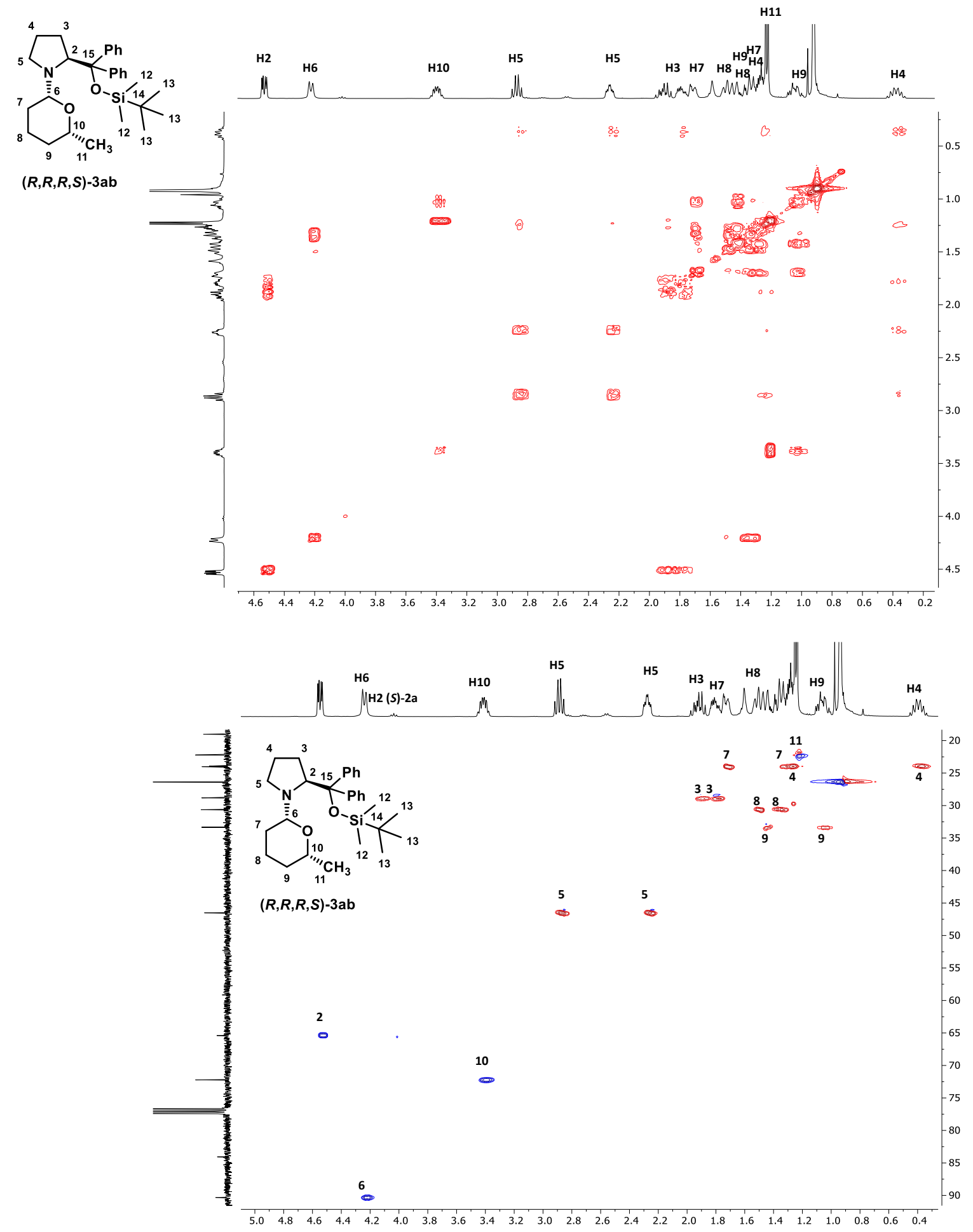

Figure S70. COSY spectrum (400 MHz, CDCl$)_{3}$ ) and HSQC spectrum (400 MHz, CDCl 3 ) of (R,R,R,S)-3ab. 
(2S)-2-((tert-Butyldimethylsilyl)oxy(diphenylmethyl)-1-((2R,6R)-6-methyltetrahydro-2H-pyran-2yl)pyrrolidine 3ab

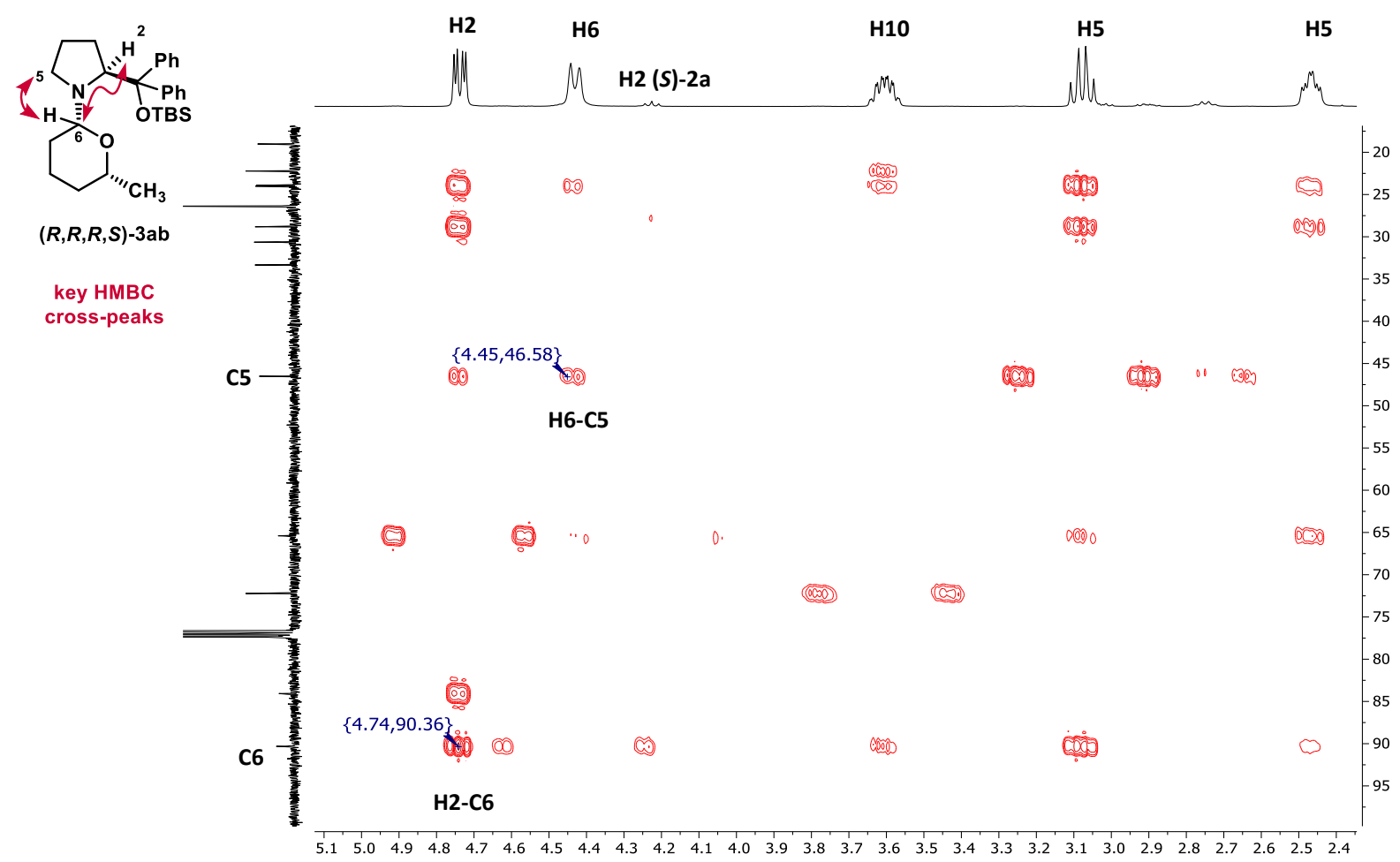

Figure S71. $\mathrm{HMBC}$ spectrum (400 MHz, $\left.\mathrm{CDCl}_{3}\right)$ of $(R, R, R, S)$-3ab. 
(2S)-2-((tert-Butyldimethylsilyl)oxy(diphenylmethyl)-1-((2R,6R)-6-propyltetrahydro-2H-pyran-2yl)pyrrolidine $3 a c$
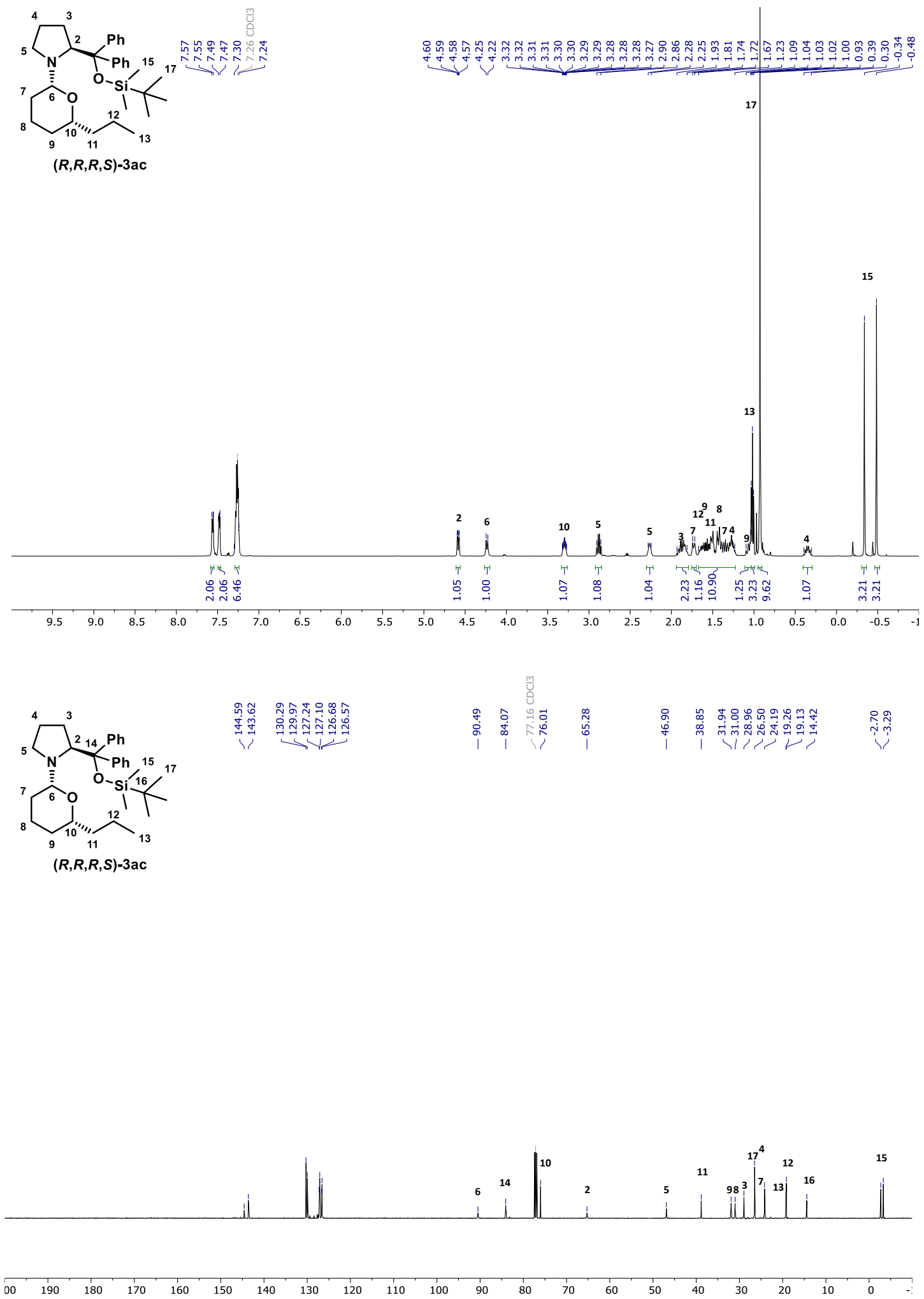

Figure S72. ${ }^{1} \mathrm{H} N \mathrm{NM}$ spectrum $(500 \mathrm{MHz}, \mathrm{CDCl} 3)$ and ${ }^{13} \mathrm{C}\{1 \mathrm{H}\} \mathrm{NMR}$ spectrum $(126 \mathrm{MHz}, \mathrm{CDCl}$ ) of $(R, R, R, S)-3 a c$. 
(2S)-2-((tert-Butyldimethylsilyl)oxy(diphenylmethyl)-1-((2R,6R)-6-propyltetrahydro-2H-pyran-2yl)pyrrolidine 3ac
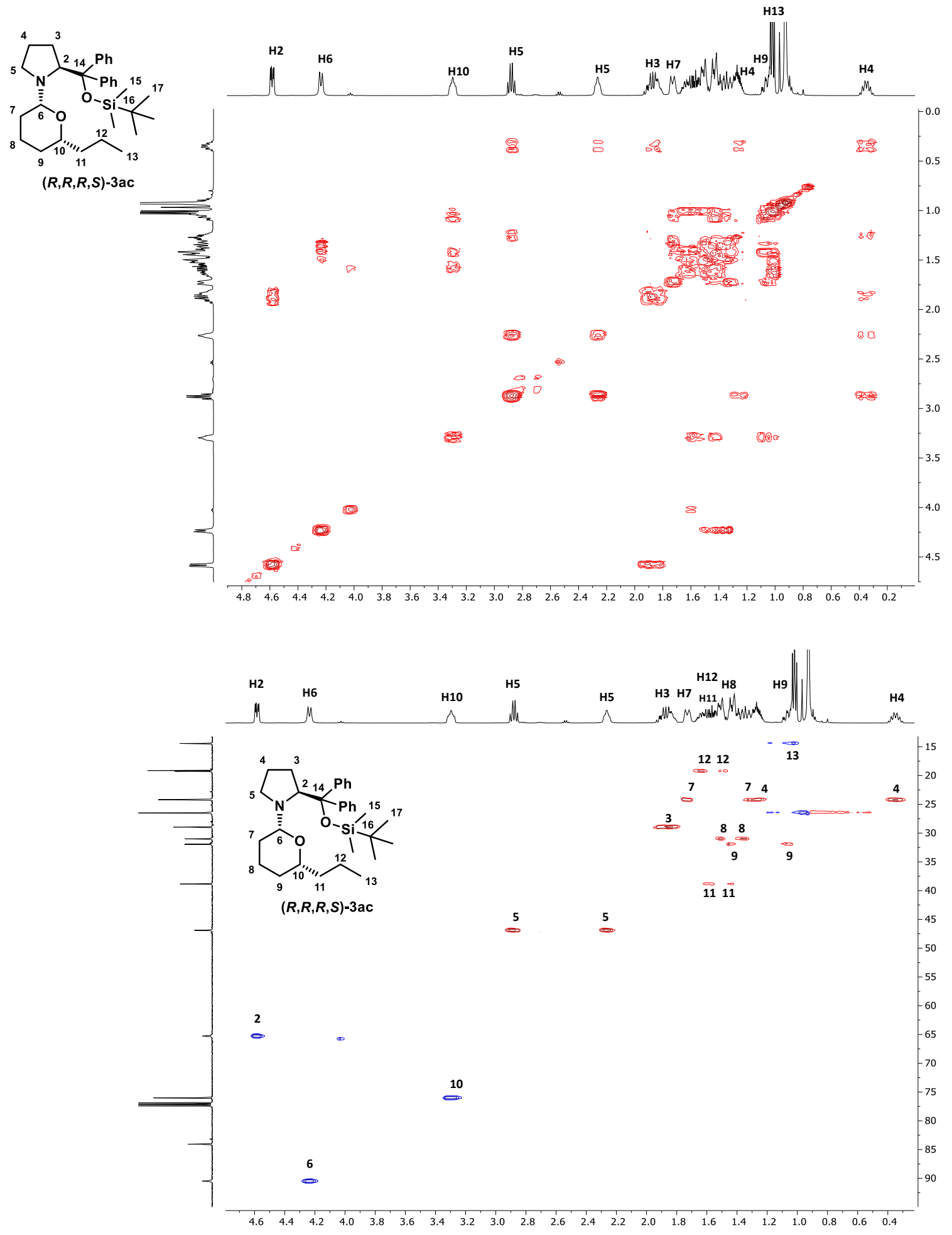

Figure S73. COSY spectrum (400 MHz, CDCl $)$ and HSQC spectrum (400 MHz, CDCl $)$ of $(R, R, R, S)-3 a c$. 
(2S)-2-(((tert-Butyldimethylsilyl)oxy(diphenylmethyl)-1-((2R,6R)-6-propyltetrahydro-2H-pyran-2yl)pyrrolidine 3ac, $\mathrm{HMBC} \mathrm{NMR}, 400 \mathrm{MHz}, \mathrm{CDCl}_{3}$

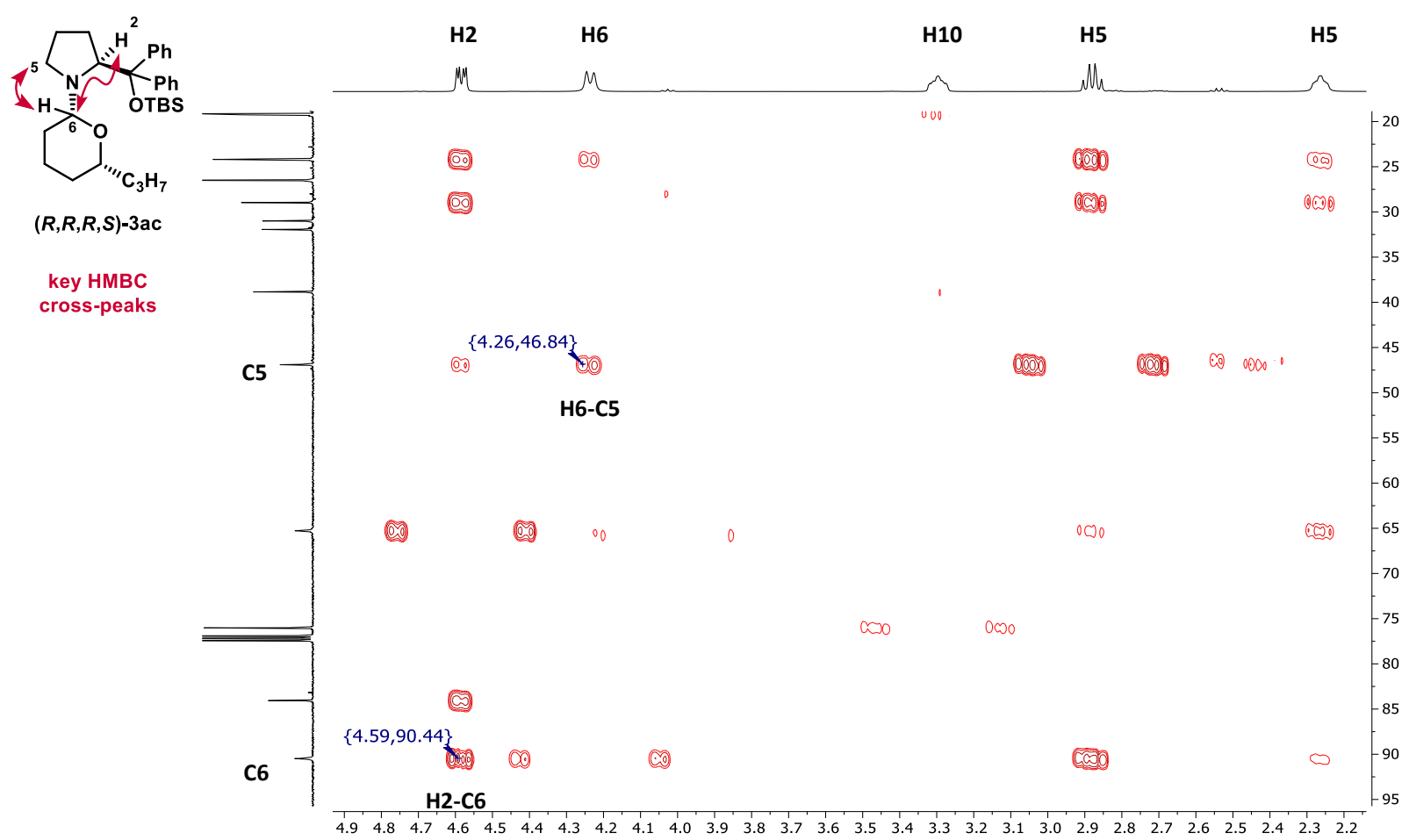

Figure S74. $\mathrm{HMBC}$ spectrum (400 MHz, $\left.C D C C_{3}\right)$ of $(R, R, R, S)-3 a c$. 
(2S)-2-((tert-Butyldimethylsilyl)oxy)diphenylmethyl)-1-((2R,6R)-6-butyltetrahydro-2H-pyran-2yl)pyrrolidine 3ad

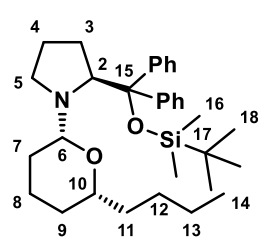

$(R, R, R, S)$-3ad
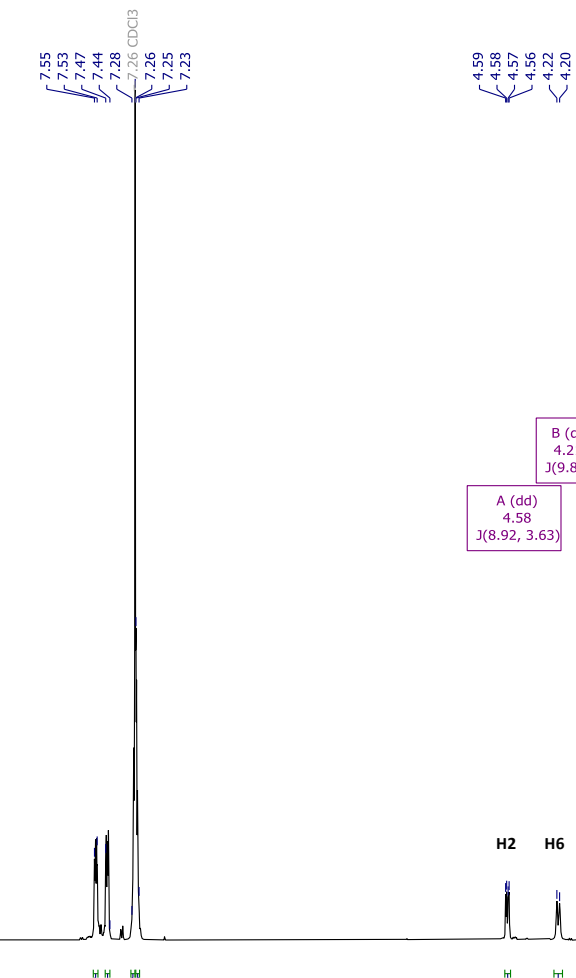

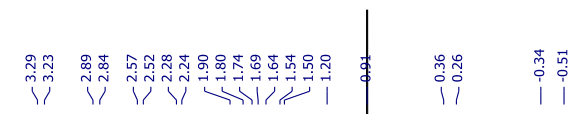
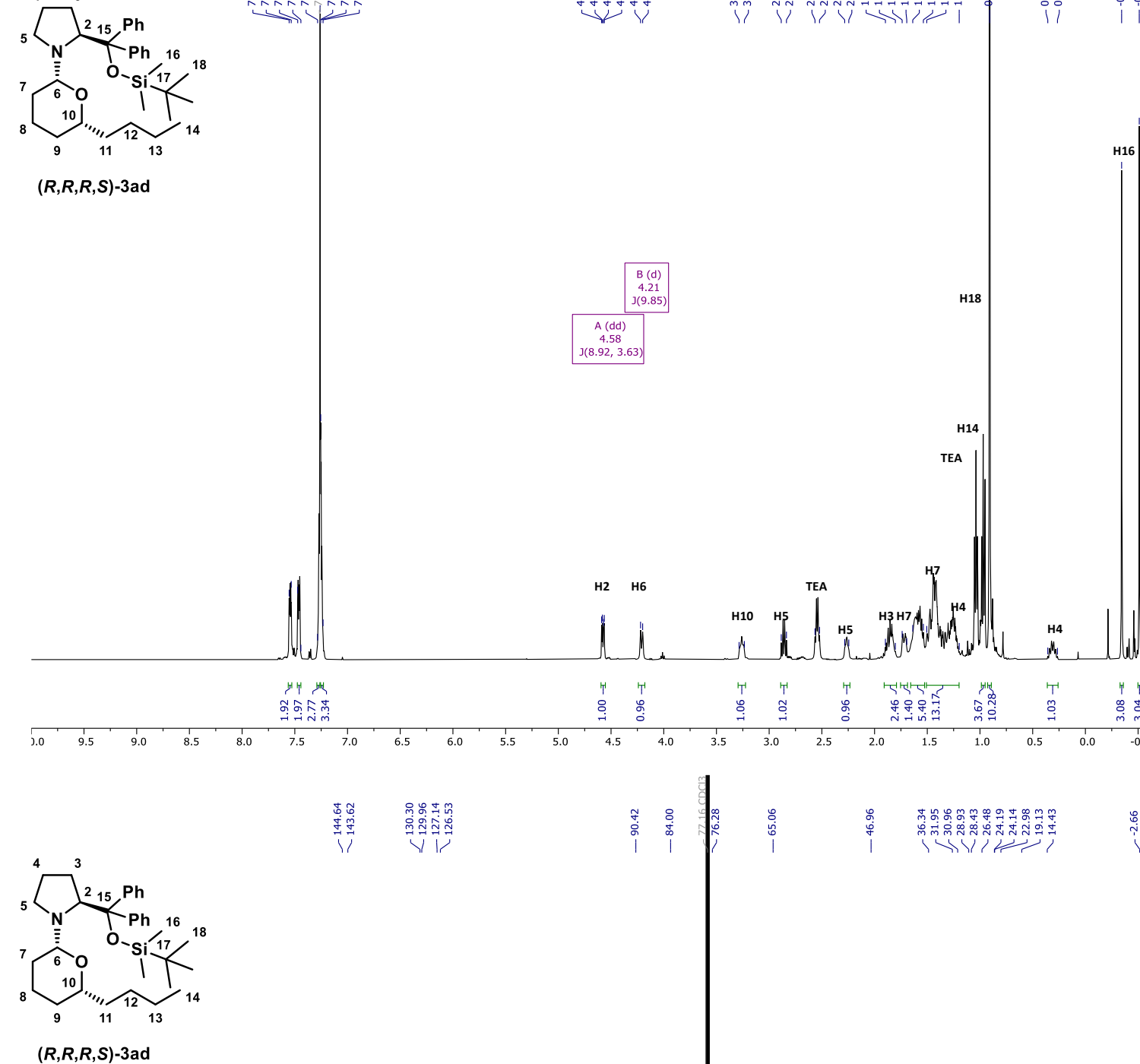

$(R, R, R, S)-3$ ad

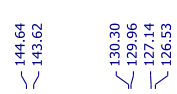
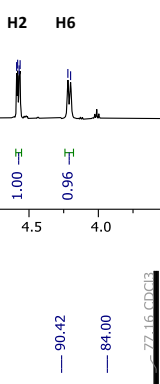

12
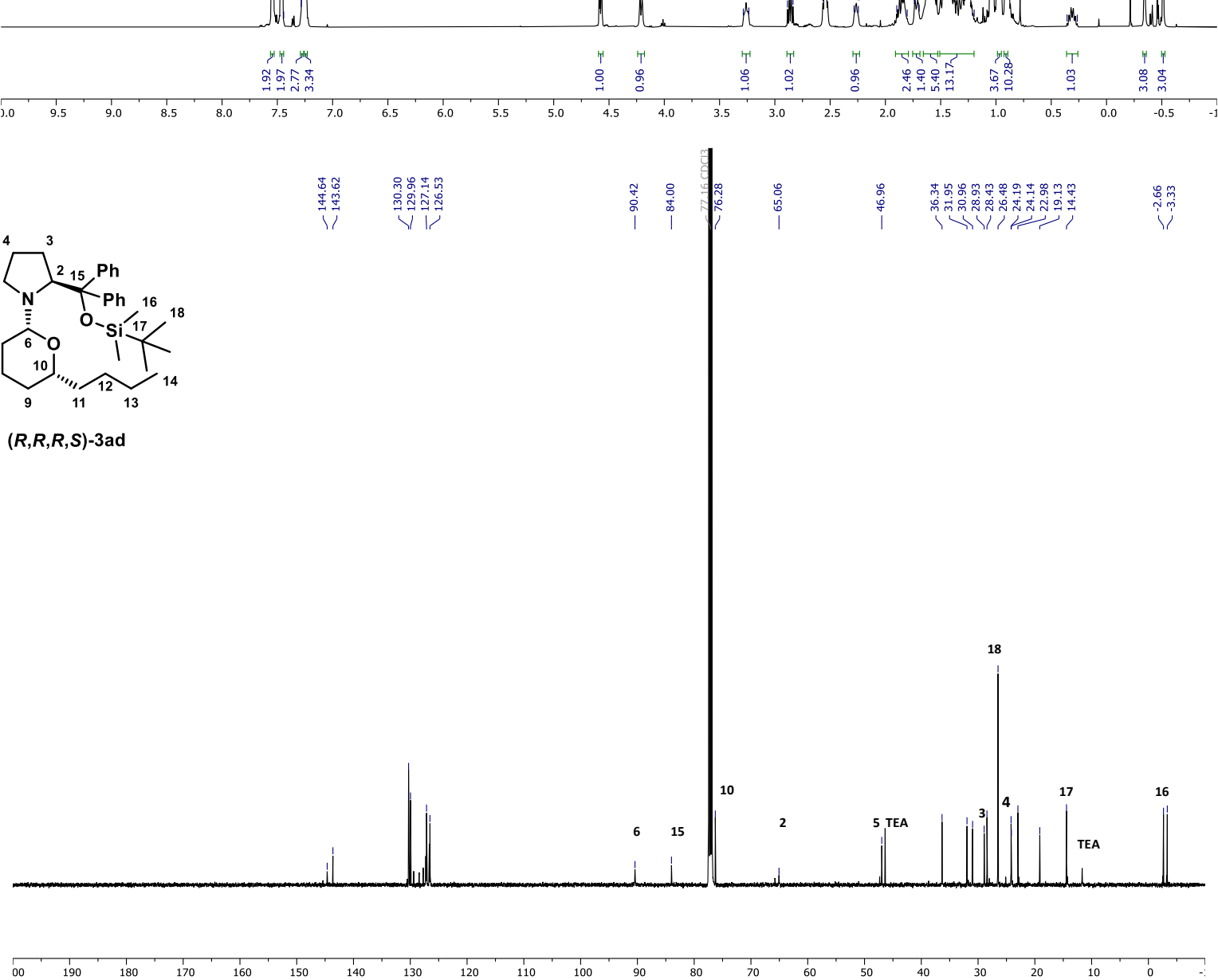

Figure S75. ${ }^{1} \mathrm{H}$ NMR spectrum $\left(500 \mathrm{MHz}, C D C l_{3}\right)$ and ${ }^{13} \mathrm{C}\{1 \mathrm{H}\} \mathrm{NMR}$ spectrum $\left(126 \mathrm{MHz}, \mathrm{CDCl}_{3}\right)$ of $(R, R, R, S)$-3ad. 
(2S)-2-(((tert-Butyldimethylsilyl)oxy(diphenylmethyl)-1-((2R,6R)-6-butyltetrahydro-2H-pyran-2yl)pyrrolidine 3ad, COSY NMR, $500 \mathrm{MHz}, \mathrm{CDCl}_{3}$
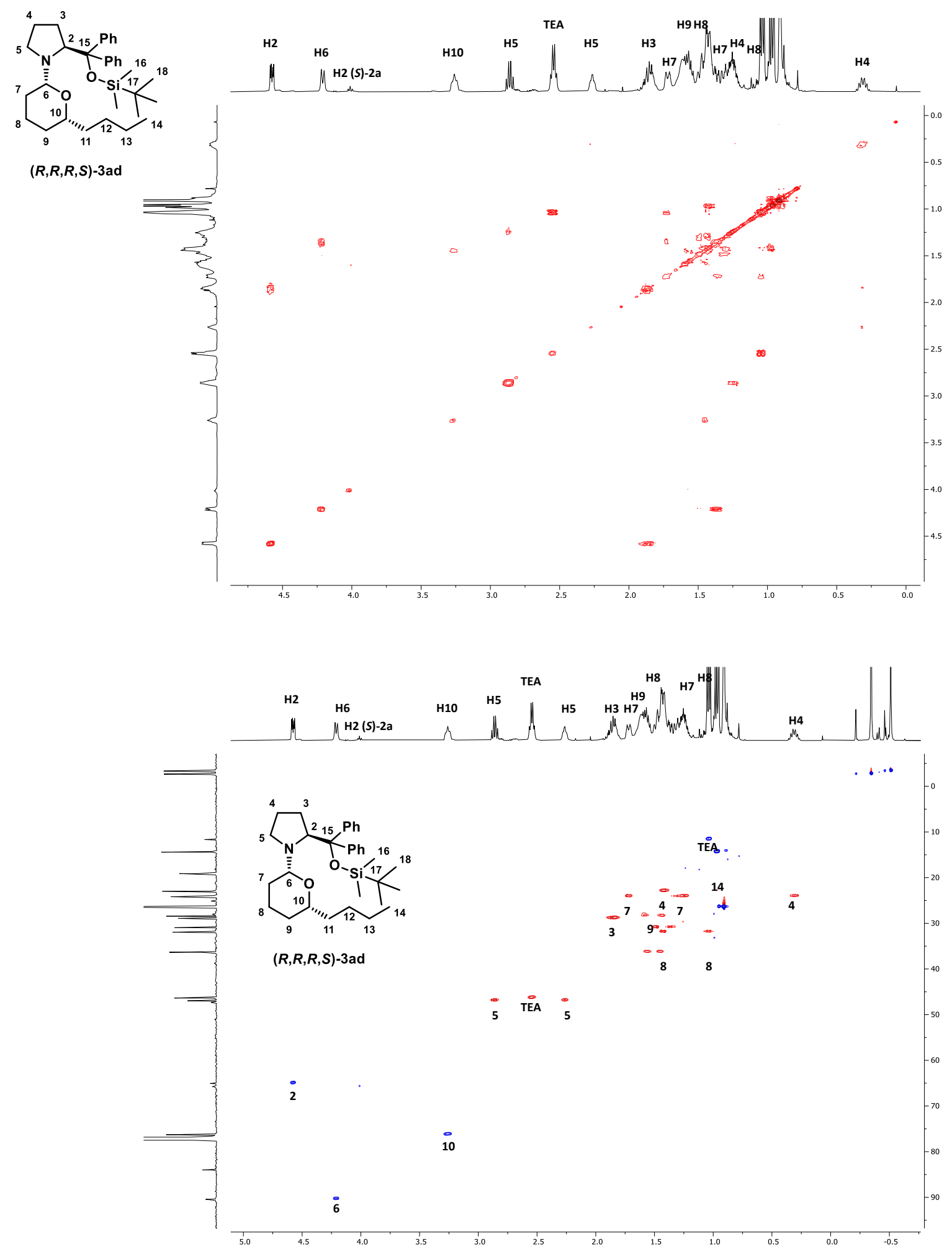

Figure S76. COSY spectrum ( $500 \mathrm{MHz}, \mathrm{CDCl}_{3}$ ) and HSQC spectrum (400 MHz, CDCl 3 ) of (R, R,R,S)-3ad. 
(2S)-2-((tert-Butyldimethylsilyl)oxy(diphenylmethyl)-1-((2R,6R)-6-butyltetrahydro-2H-pyran-2yl)pyrrolidine 3ad

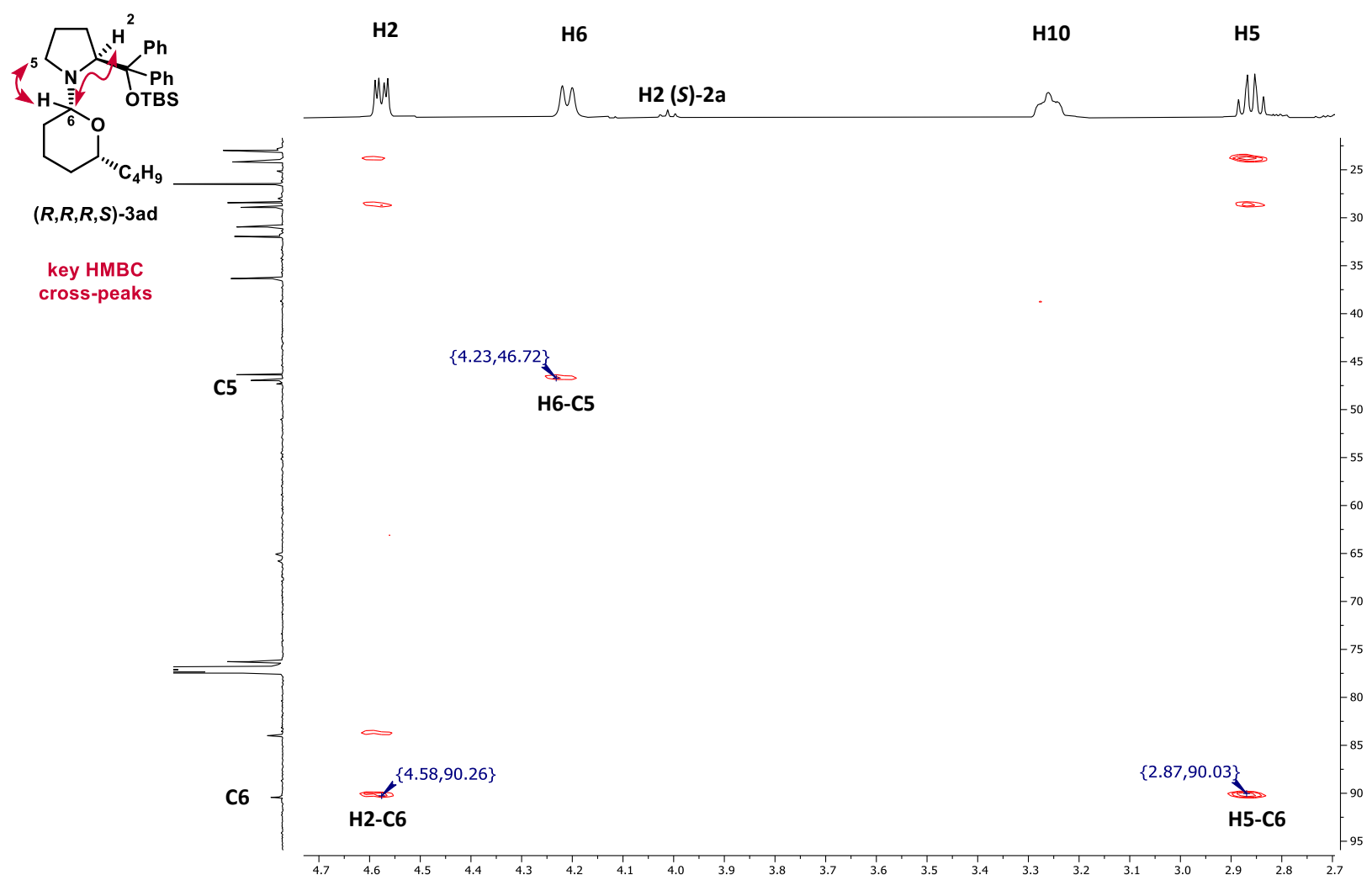

Figure S77. $H M B C$ spectrum (400 MHz, $\left.C D C l_{3}\right)$ of $(R, R, R, S)-3 a d$. 
(2S)-2-((tert-Butyldimethylsilyl)oxy(diphenylmethyl)-1-((2R,6R)-6-pentyltetrahydro-2H-pyran-2yl)pyrrolidine 3ae
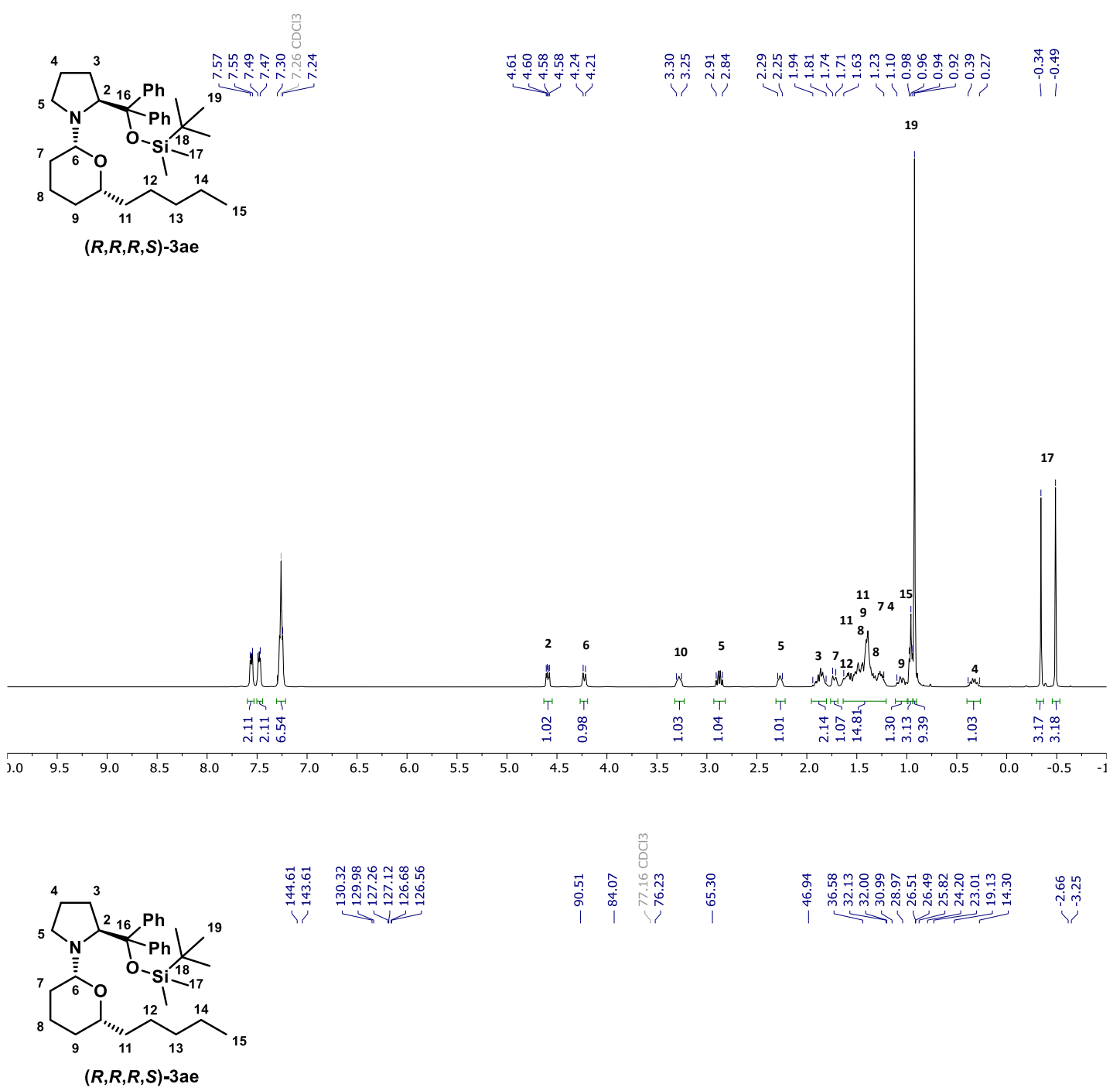

نั
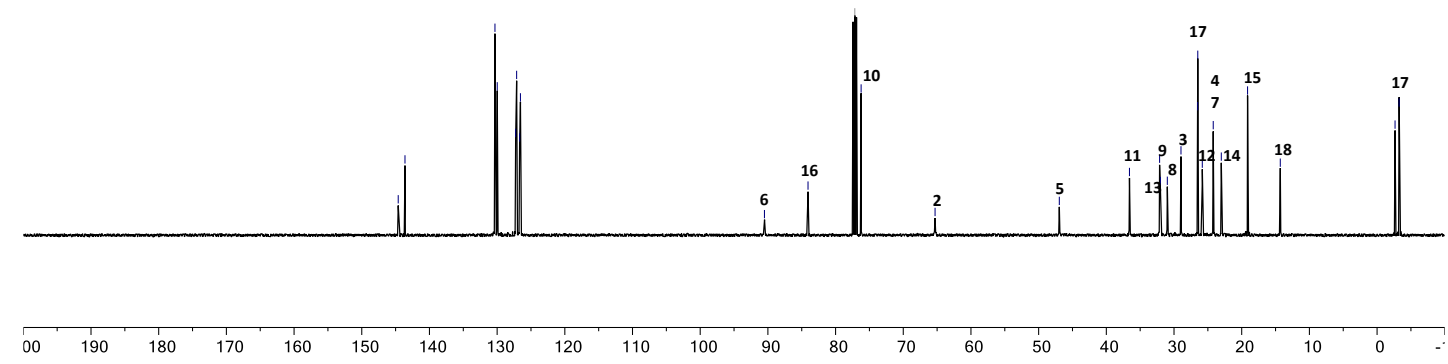

Figure S78. ${ }^{1} \mathrm{H} N M R$ spectrum $(500 \mathrm{MHz}, \mathrm{CDCl} 3)$ and ${ }^{13} \mathrm{C}\{1 \mathrm{H}\} \mathrm{NMR}$ spectrum $(126 \mathrm{MHz}, \mathrm{CDCl} 3)$ of $(R, R, R, S)-3 a e$. 
(2S)-2-((tert-Butyldimethylsilyl)oxy(diphenylmethyl)-1-((2R,6R)-6-pentyltetrahydro-2H-pyran-2yl)pyrrolidine 3ae
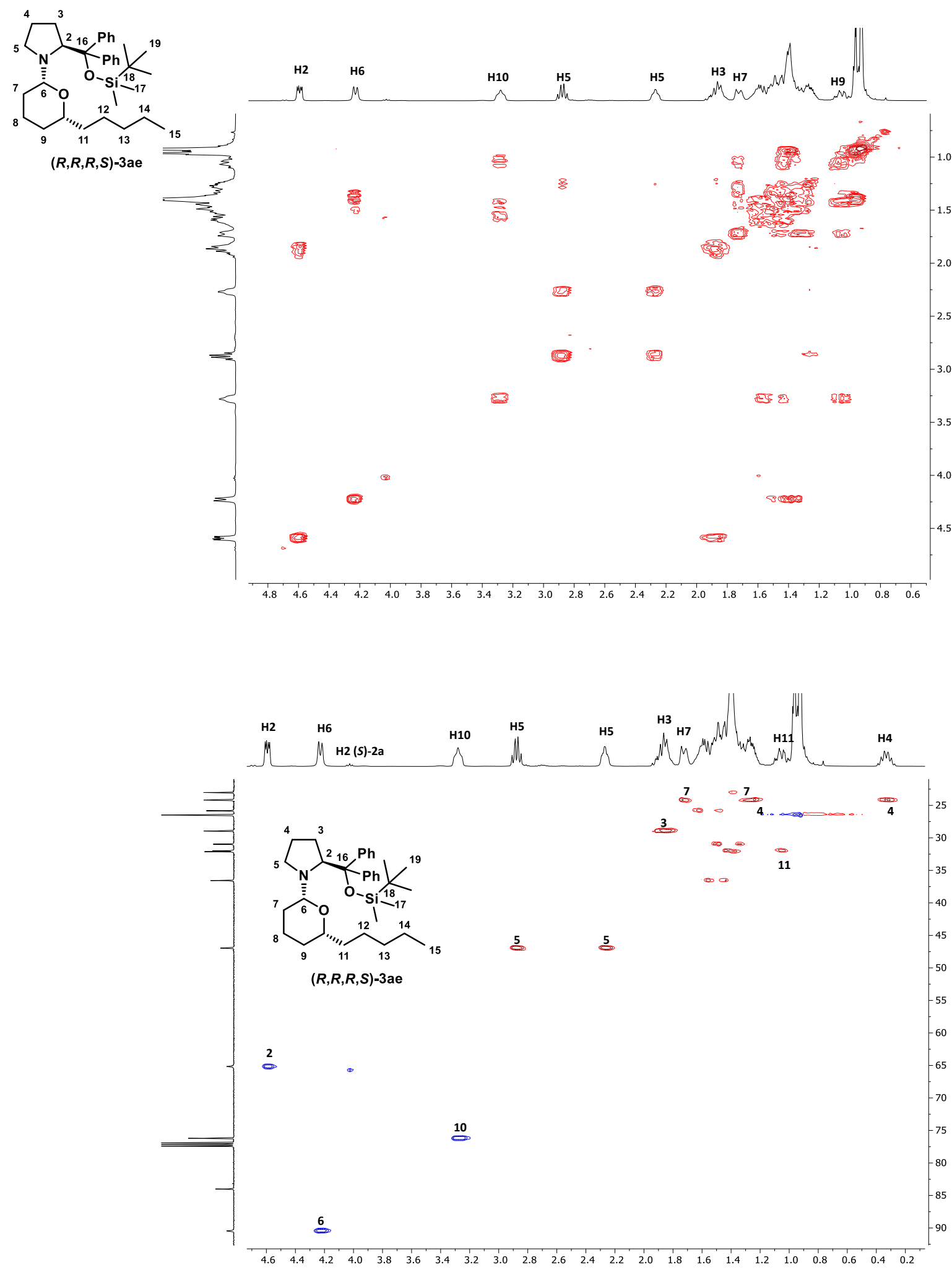

Figure S79. COSY spectrum ( $\left.400 \mathrm{MHz}, \mathrm{CDCl}_{3}\right)$ and HSQC spectrum (400 MHz, CDCl 3 ) of (R,R,R,S)-3ae. 
(2S)-2-(((tert-Butyldimethylsilyl)oxy(diphenylmethyl)-1-((5R,6R)-6-pentyltetrahydro-2H-pyran-2yl)pyrrolidine 3ae

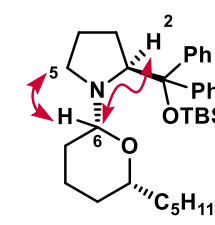

$(R, R, R, S)-3$ ae

key HMBC cross-peaks

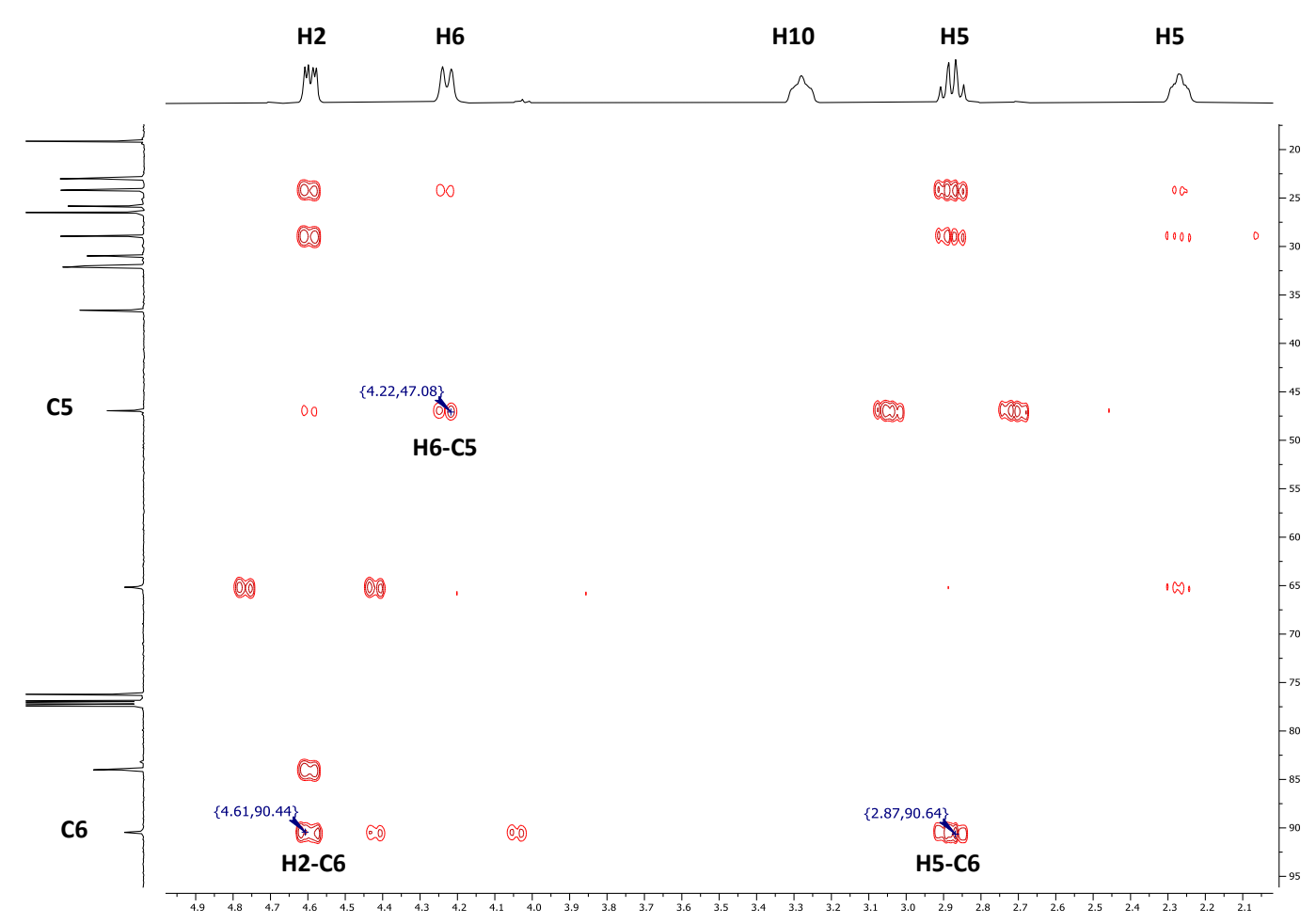

Figure S80. HMBC spectrum (400 MHz, CDCl $)$ of $(R, R, R, S)$-3ae. 
(2S)-2-(((tert-Butyldimethylsilyl)oxy)diphenylmethyl)-1-((2R,6R)-6-hexyltetrahydro-2H-pyran-2yl)pyrrolidine 3 af
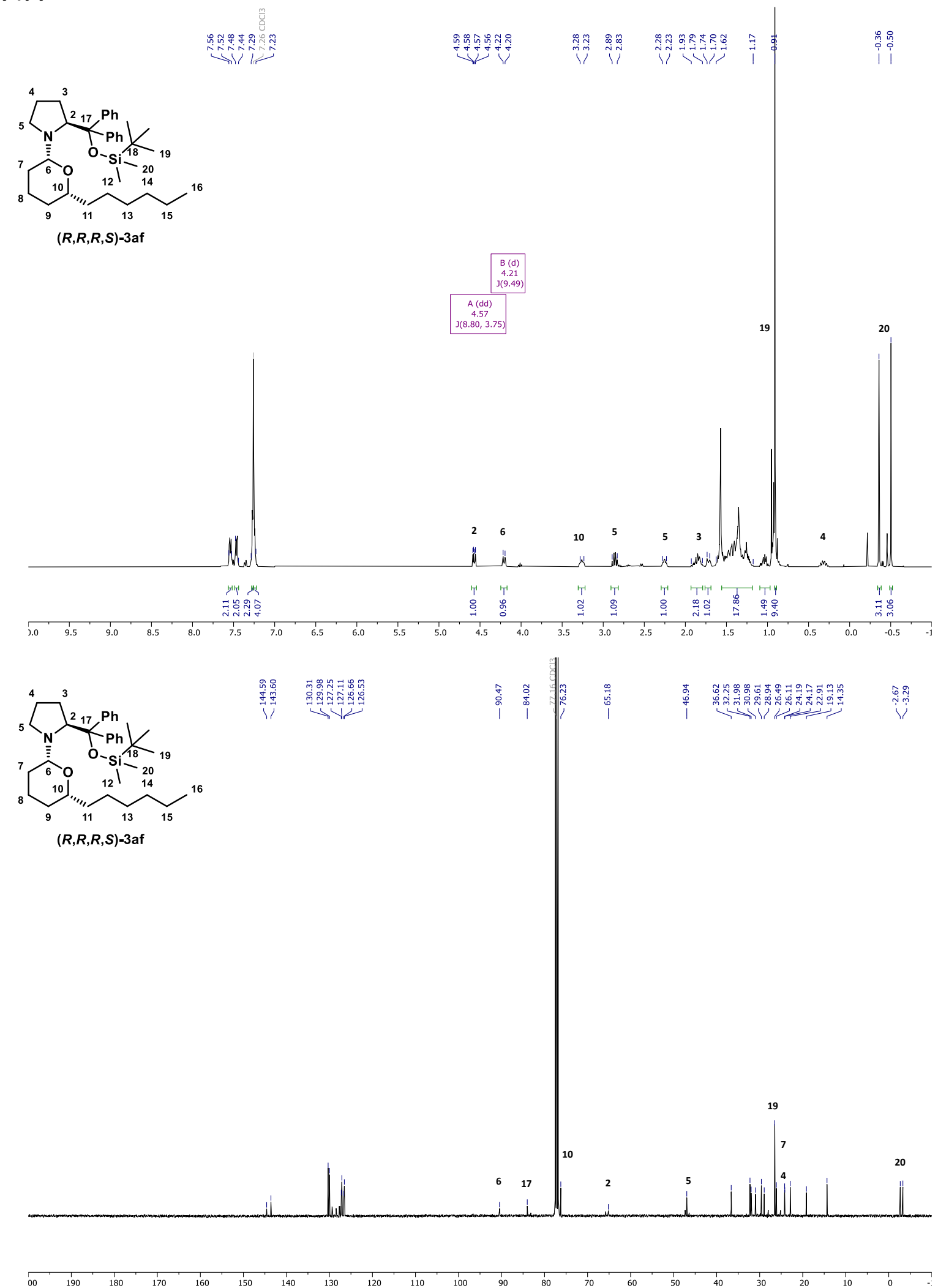

Figure S81. ${ }^{1} \mathrm{H} N M R$ spectrum $\left(500 \mathrm{MHz}, C D C l_{3}\right)$ and ${ }^{13} \mathrm{C}\{1 \mathrm{H}\} \mathrm{NMR}$ spectrum $\left(126 \mathrm{MHz}, \mathrm{CDCl} \mathrm{I}_{3}\right)$ of $(R, R, R, S)-3 a f$. 
(2S)-2-((tert-Butyldimethylsilyl)oxy)diphenylmethyl)-1-((2R,6R)-6-hexyltetrahydro-2H-pyran-2yl)pyrrolidine 3 af
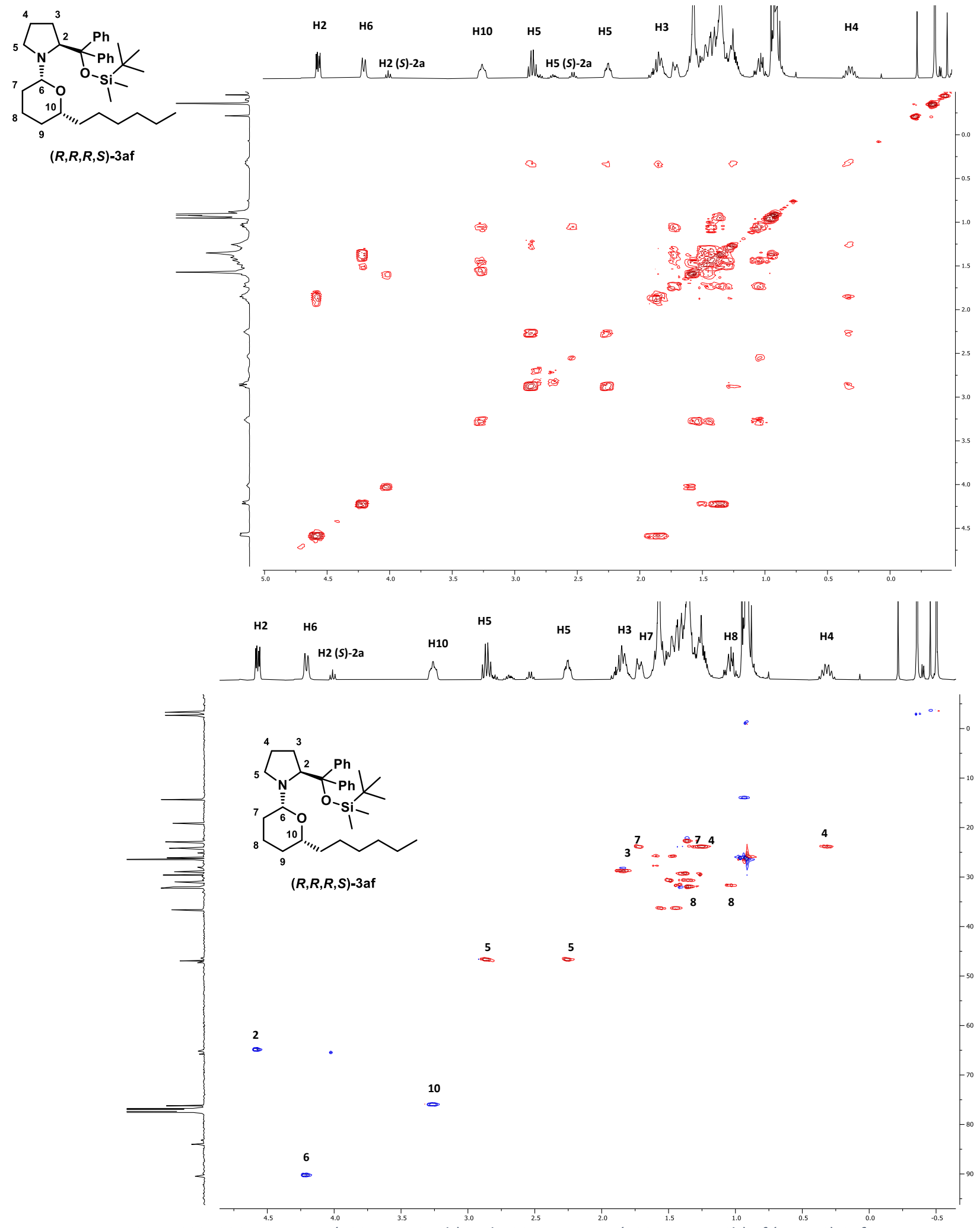

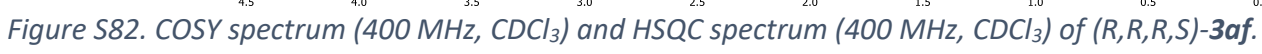


(2S)-2-(((tert-Butyldimethylsilyl)oxy)diphenylmethyl)-1-((2R,6R)-6-hexyltetrahydro-2H-pyran-2yl)pyrrolidine 3af

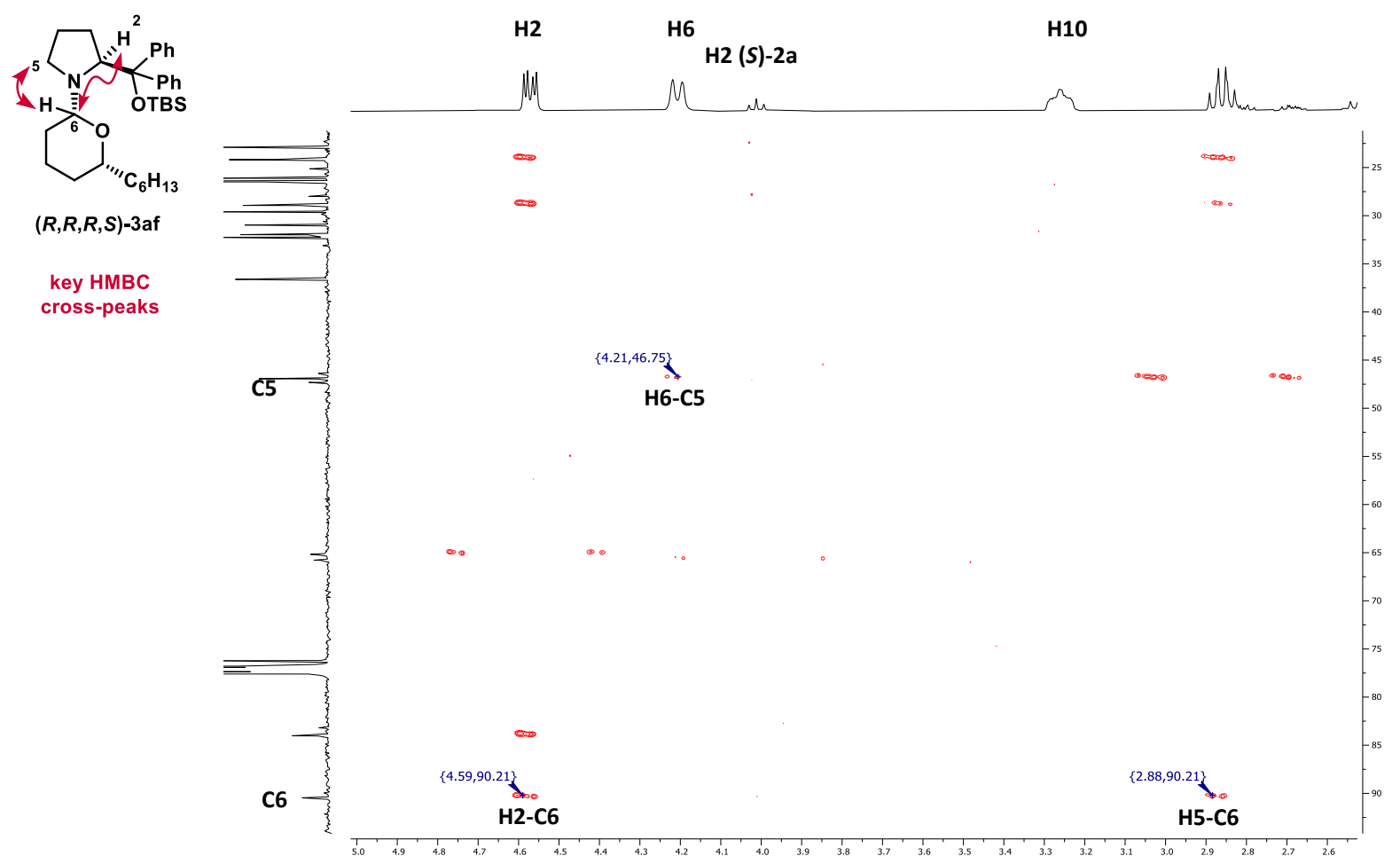

Figure S83. $\mathrm{HMBC}$ spectrum (400 $\left.\mathrm{MHz}, \mathrm{CDCl}_{3}\right)$ of $(R, R, R, S)$-3af. 
(R)-5-Hydroxyhexanal oxime $4 \mathrm{~b}$

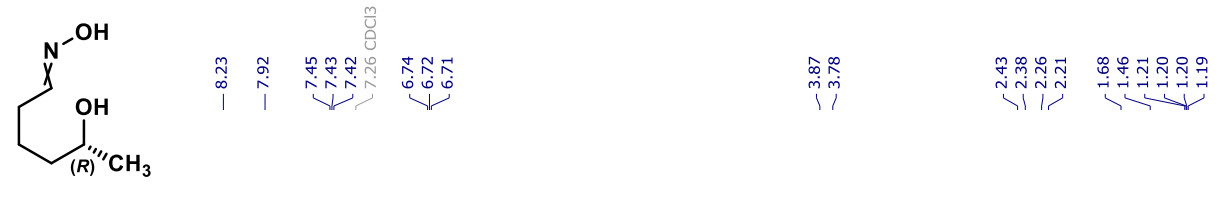

(R)-4b
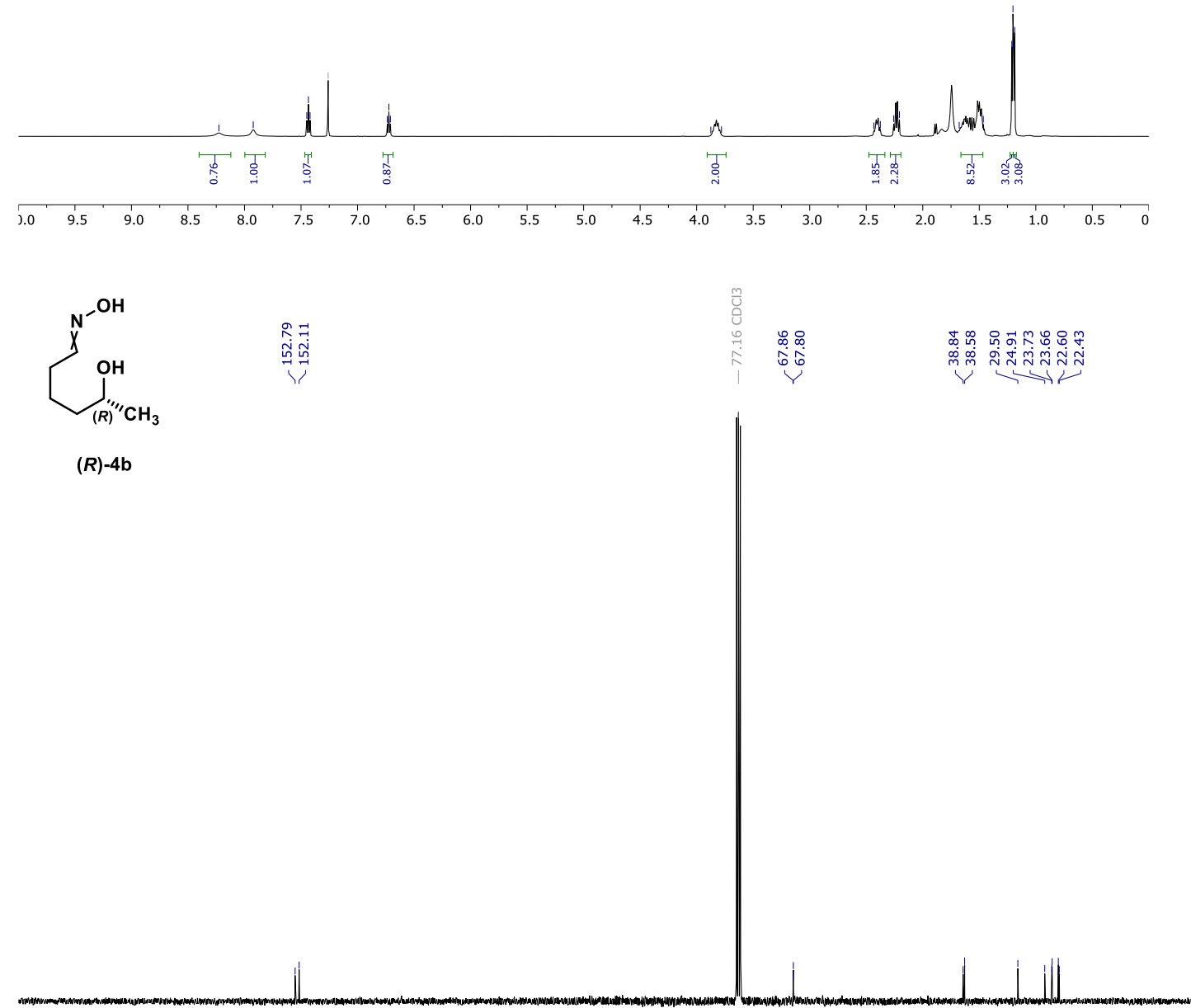

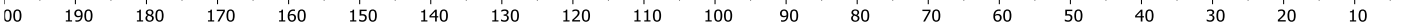

Figure S84. ${ }^{1} \mathrm{H} N \mathrm{NM}$ spectrum $\left.(400 \mathrm{MHz}, \mathrm{CDCl})_{3}\right)$ and ${ }^{13} \mathrm{C}\{1 \mathrm{H}\} \mathrm{NMR}$ spectrum $(101 \mathrm{MHz}, \mathrm{CDCl})_{3}$ of $(R)-4 b$. 
(R)-5-Hydroxyoctanal oxime 4c

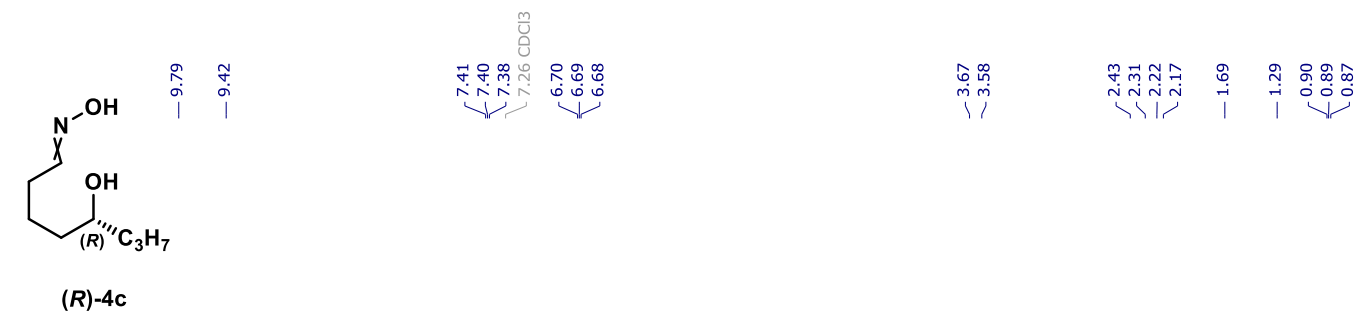

$(R)-4 \mathrm{c}$
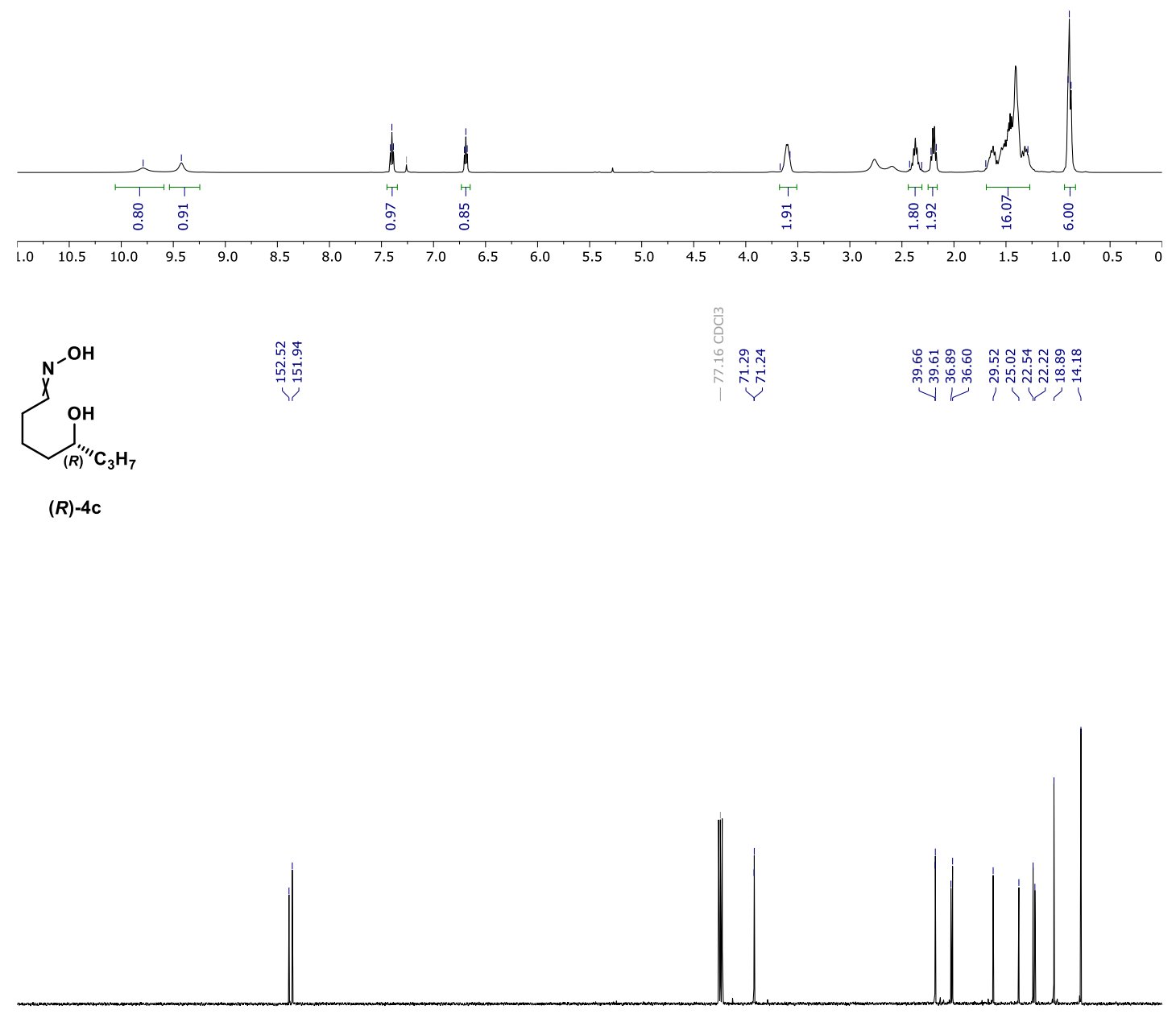

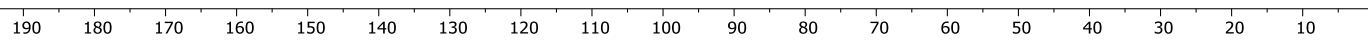

Figure S85. ${ }^{1} \mathrm{H} N M R$ spectrum $\left.(400 \mathrm{MHz}, \mathrm{CDCl})_{3}\right)$ and ${ }^{13} \mathrm{C}\{1 \mathrm{H}\} \mathrm{NMR}$ spectrum $(101 \mathrm{MHz}, \mathrm{CDCl})_{3}$ of $(R)-4 \mathrm{c}$. 
(R)-5-Hydroxynonanal oxime 4d

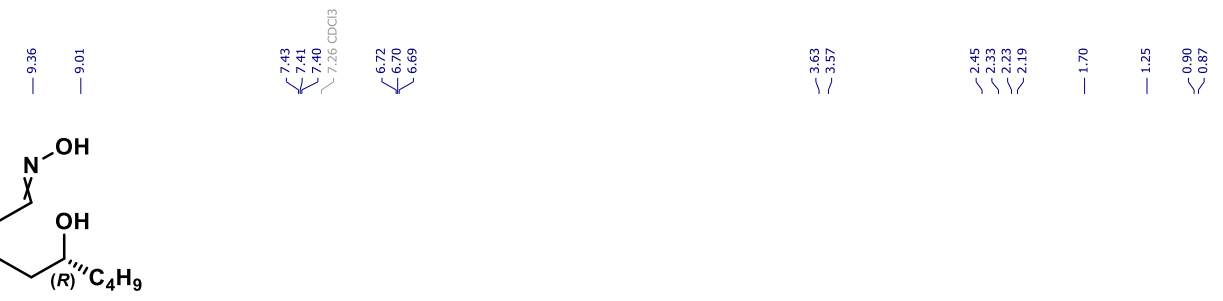

$(R)-4 \mathrm{~d}$
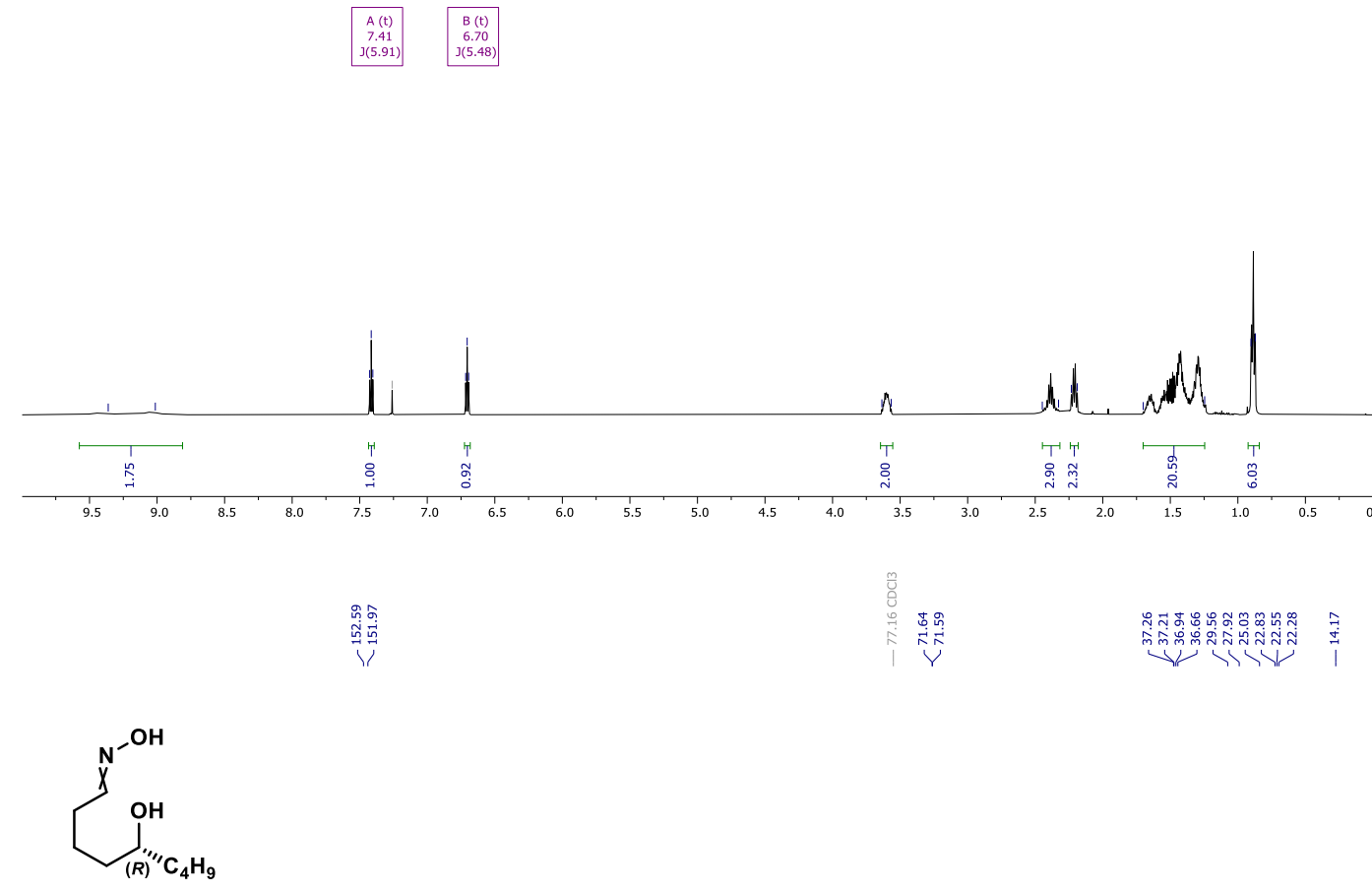

(R)-4d
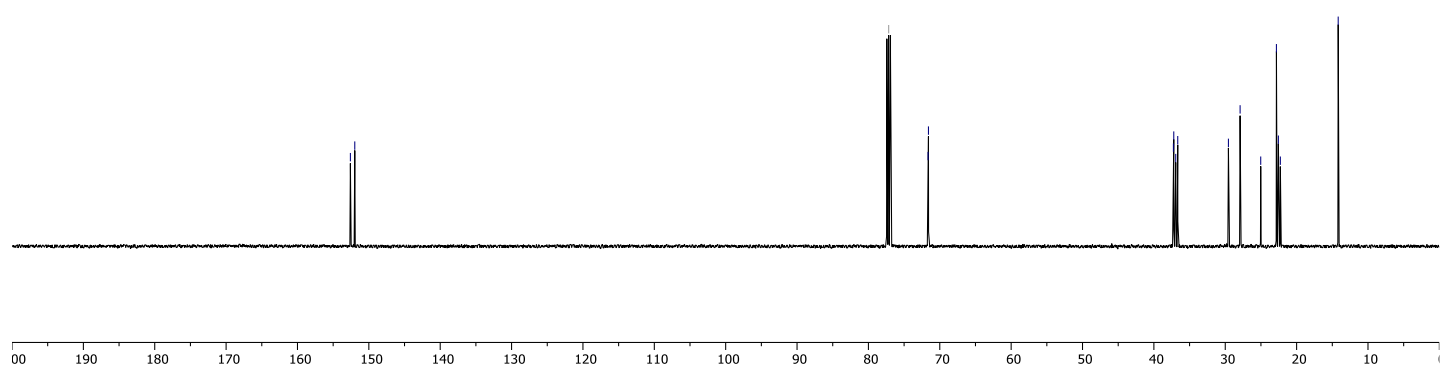

Figure S86. ${ }^{1} \mathrm{H} N M R$ spectrum $\left.(500 \mathrm{MHz}, \mathrm{CDCl})_{3}\right)$ and ${ }^{13} \mathrm{C}\{1 \mathrm{H}\} \mathrm{NMR}$ spectrum $(126 \mathrm{MHz}, \mathrm{CDCl})_{3}$ of $(R)-4 d$. 


\section{(R)-5-Hydroxydecanal oxime 4e}
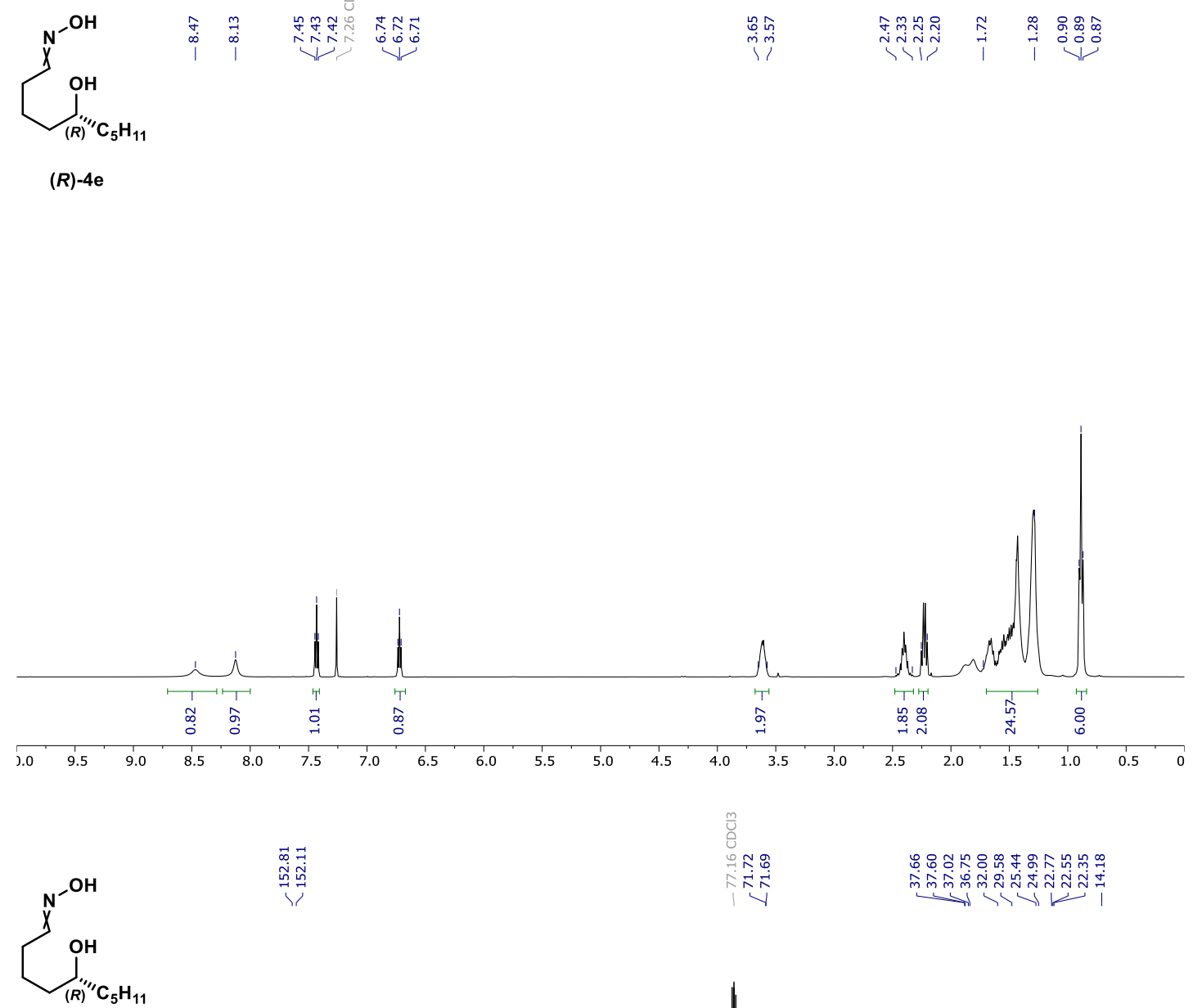

$(R)-4 e$

คิ่ต்

아

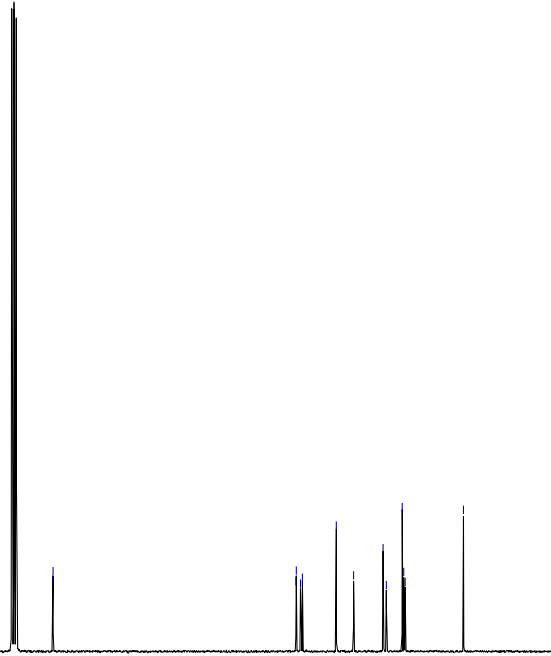

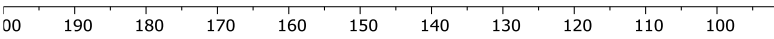

Figure S87. ${ }^{1} \mathrm{H} N \mathrm{NM}$ spectrum $(400 \mathrm{MHz}, \mathrm{CDCl} 3)$ and ${ }^{13} \mathrm{C}\{1 \mathrm{H}\} \mathrm{NMR}$ spectrum $(101 \mathrm{MHz}, \mathrm{CDCl})_{3}$ of $(R)-4 e$. 
$(R)-5-H y d r o x y u n d e c a l ~ o x i m e ~ 4 f$
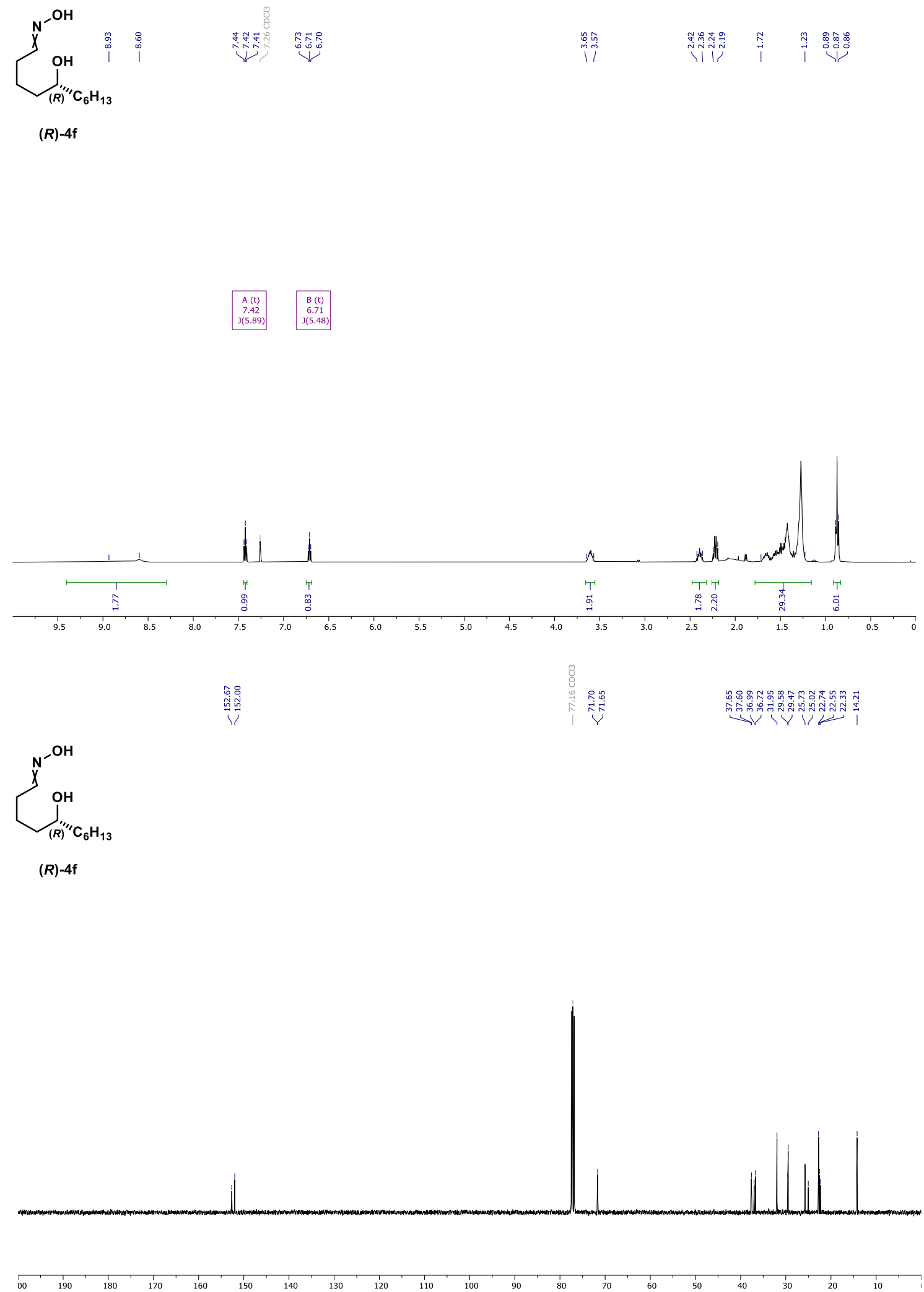

Figure S88. ${ }^{1} \mathrm{H}$ NMR spectrum $\left(500 \mathrm{MHz}, \mathrm{CDCl}\right.$ ) and ${ }^{13} \mathrm{C}\left\{{ }^{1} \mathrm{H}\right\} \mathrm{NMR}$ spectrum $(126 \mathrm{MHz}, \mathrm{CDCl})_{3}$ of $(R)-4 f$. 
$(R)$-Hexane-1,5-diyl dibenzoate $5 b$
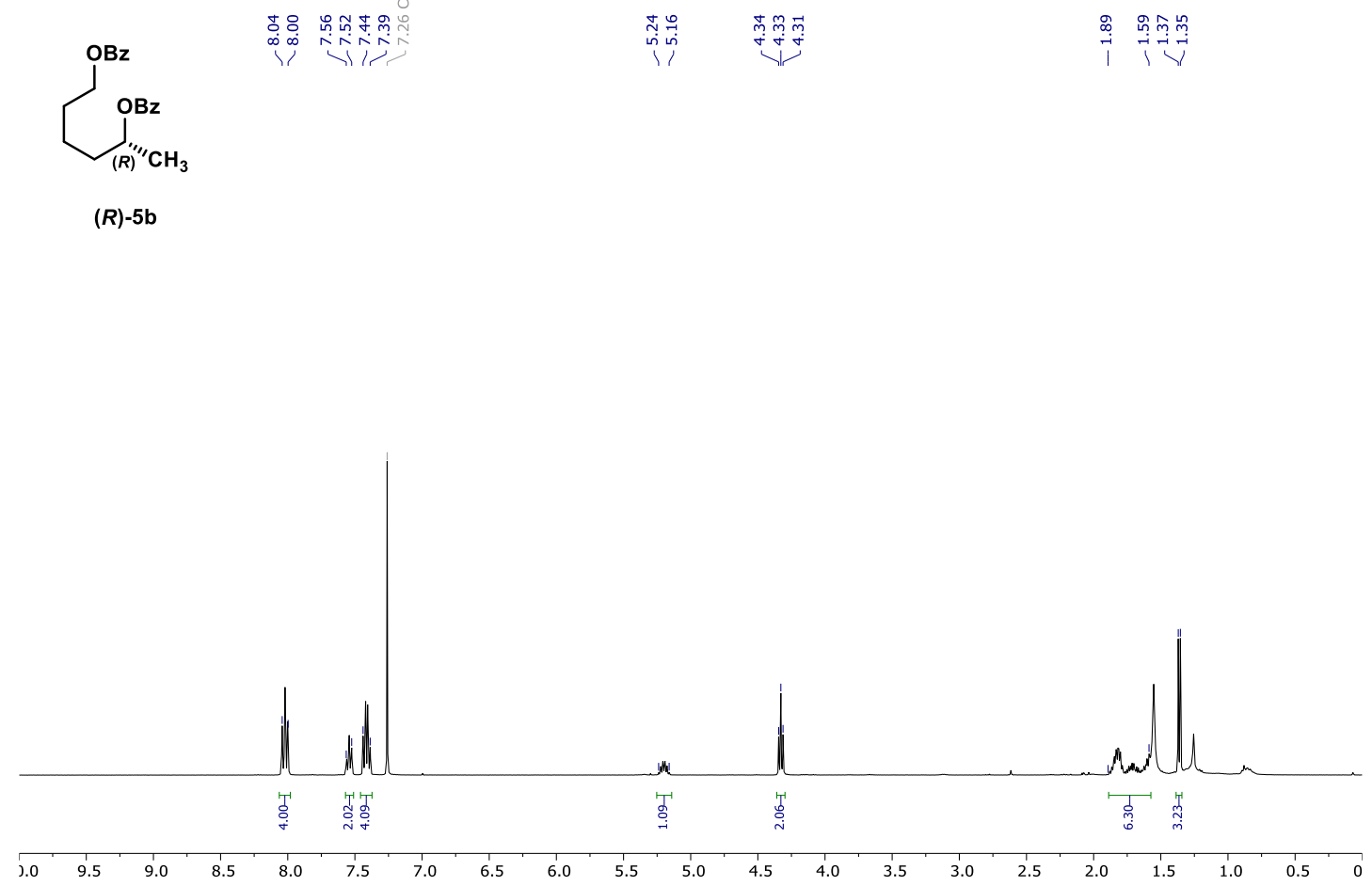

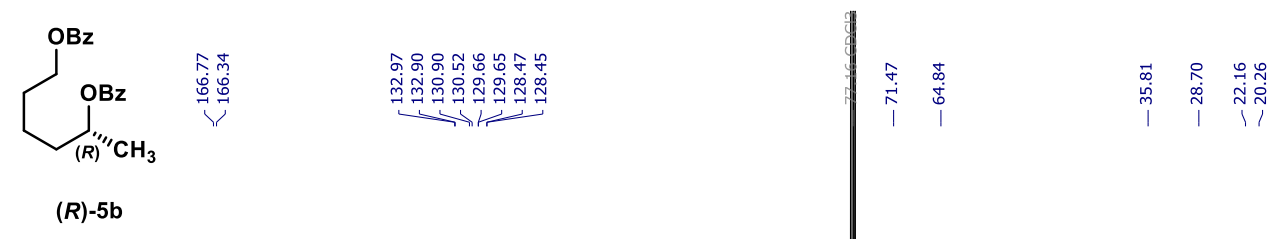

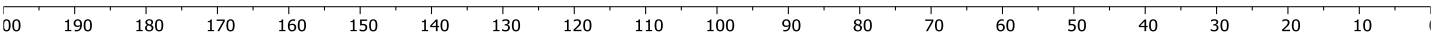

Figure S89. ${ }^{1} \mathrm{H} N M R$ spectrum $(400 \mathrm{MHz}, \mathrm{CDCl} 3)$ and ${ }^{13} \mathrm{C}\left\{{ }^{1} \mathrm{H}\right\} \mathrm{NMR}$ spectrum $(101 \mathrm{MHz}, \mathrm{CDCl} / 3)$ of $(R)-5 b$. 
$(R)$-Octane-1,5-diyl dibenzoate $5 c$
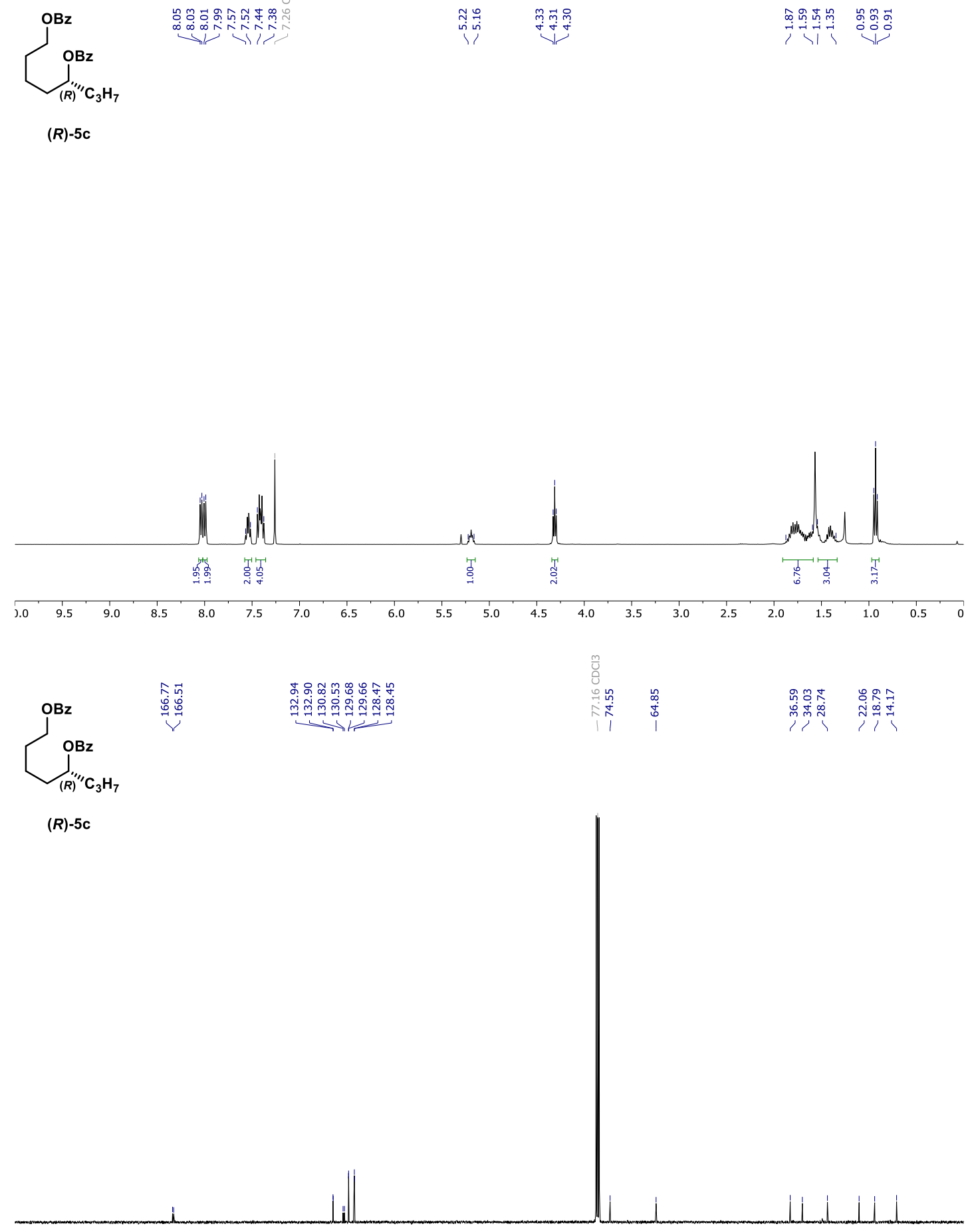

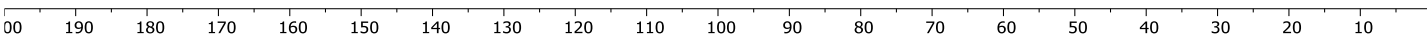

Figure S90. ${ }^{1} \mathrm{H} N M R$ spectrum $(400 \mathrm{MHz}, \mathrm{CDCl} 3)$ and ${ }^{13} \mathrm{C}\left\{{ }^{1} \mathrm{H}\right\} \mathrm{NMR}$ spectrum $(101 \mathrm{MHz}, \mathrm{CDCl} 3)$ of $(R)-5 \mathrm{c}$. 
$(R)$-Nonane-1,5-diyl dibenzoate $5 \mathrm{~d}$

$\int_{(R)^{\prime \prime \prime} C_{4} \mathrm{H}_{9}}^{\mathrm{OBz}}$

(R)-5d

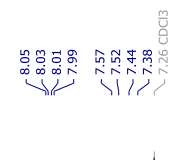

ำ

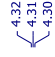

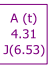
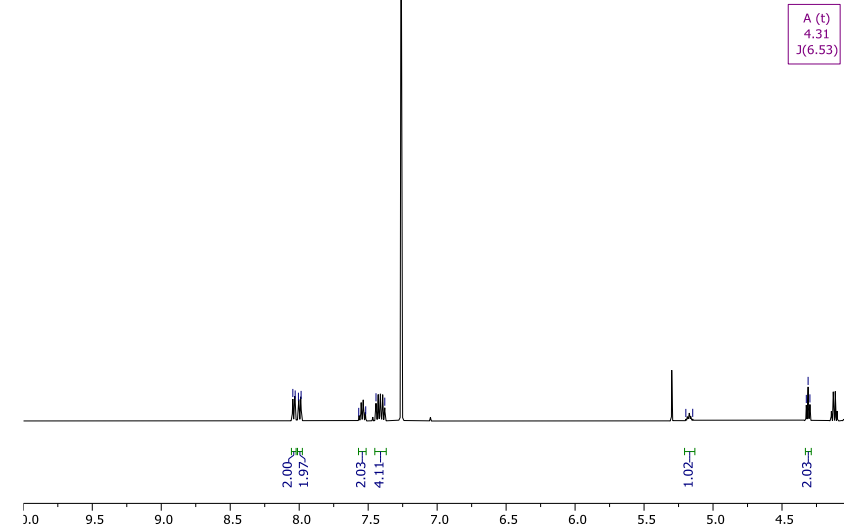

(1)
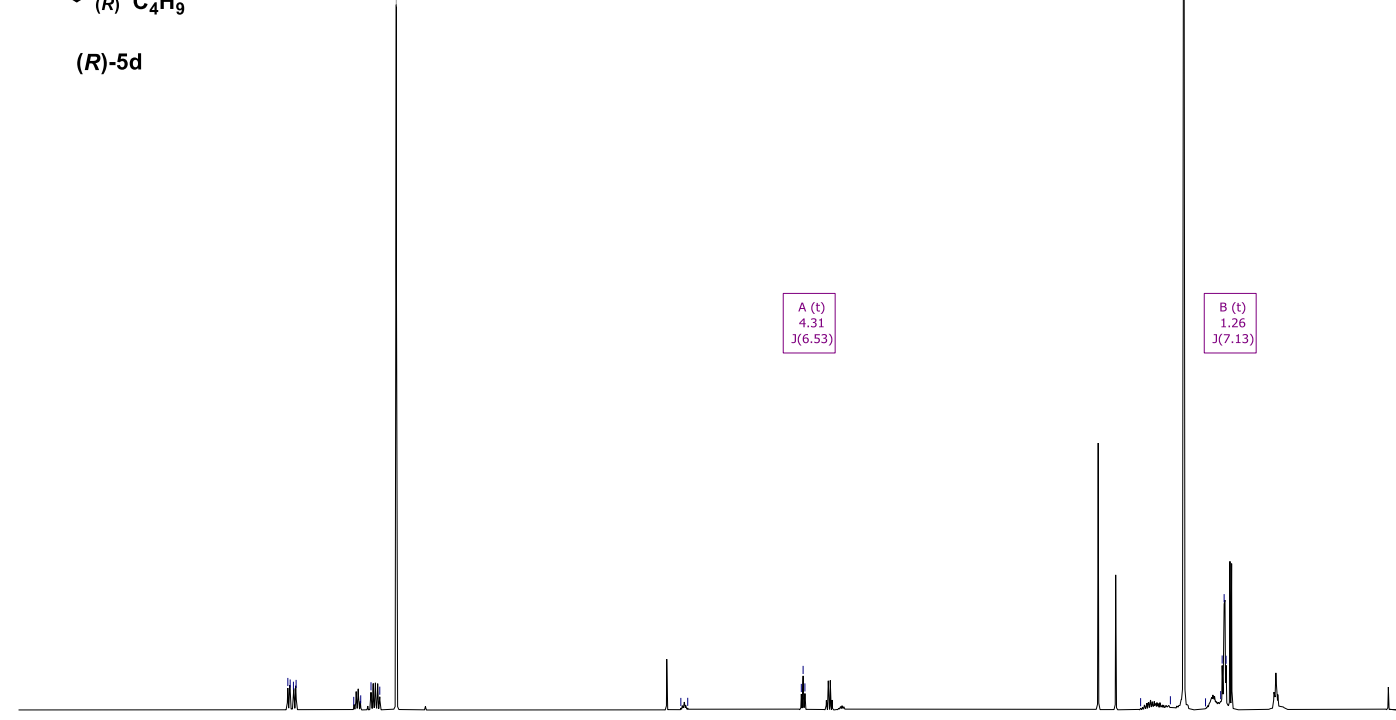

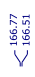

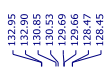

$\mathrm{OBz}$

$\int_{(R)^{\prime \prime \prime} \mathrm{C}_{4} \mathrm{H}_{9}}^{\mathrm{OBz}}$

(R)-5d
1

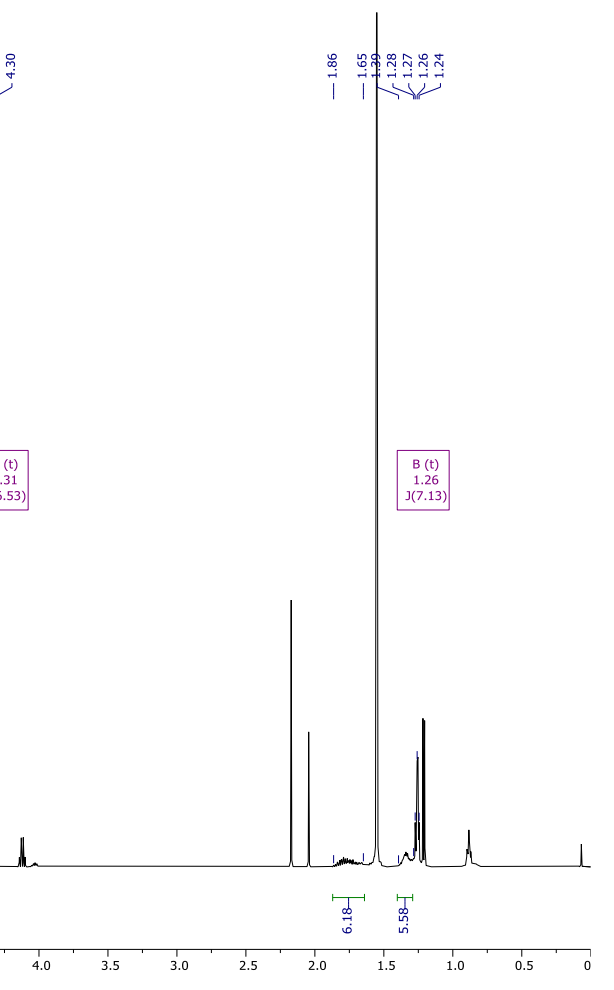

ทัง

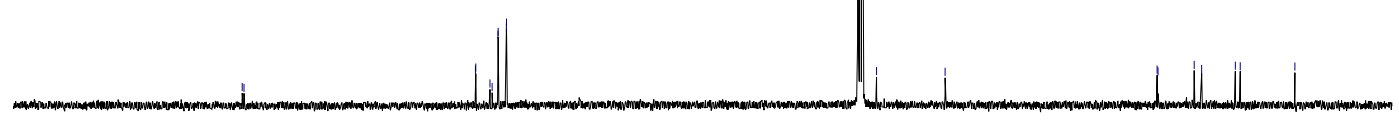

190 190

Figure S91. ${ }^{1} \mathrm{H} N \mathrm{NM}$ spectrum $(400 \mathrm{MHz}, \mathrm{CDCl} 3)$ and ${ }^{13} \mathrm{C}\left\{{ }^{1} \mathrm{H}\right\} \mathrm{NMR}$ spectrum $(101 \mathrm{MHz}, \mathrm{CDCl} 3)$ of $(R)-5 d$ 
(R)-Decane-1,5-diyl dibenzoate $5 e$
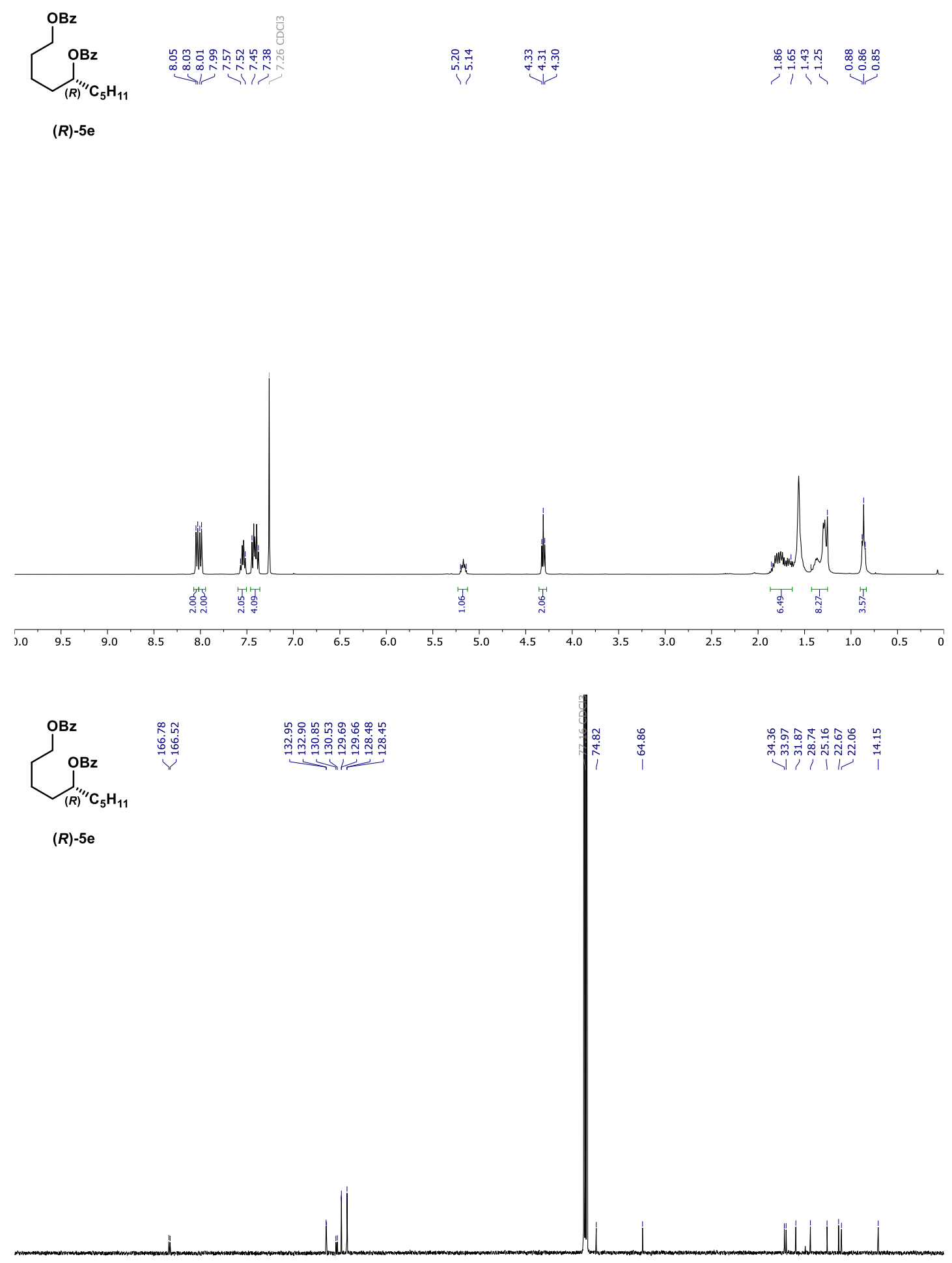

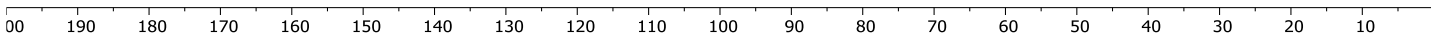

Figure S92. ${ }^{1} \mathrm{H} N \mathrm{NM}$ spectrum $(400 \mathrm{MHz}, \mathrm{CDCl} 3)$ and ${ }^{13} \mathrm{C}\left\{{ }^{1} \mathrm{H}\right\} \mathrm{NMR}$ spectrum $(101 \mathrm{MHz}, \mathrm{CDCl} 3)$ of $(R)-5 e$. 
$(R)$-Undecane-1,5-diyl dibenzoate $5 f$

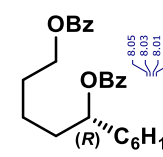

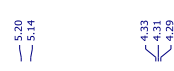

$(R)-5 f$
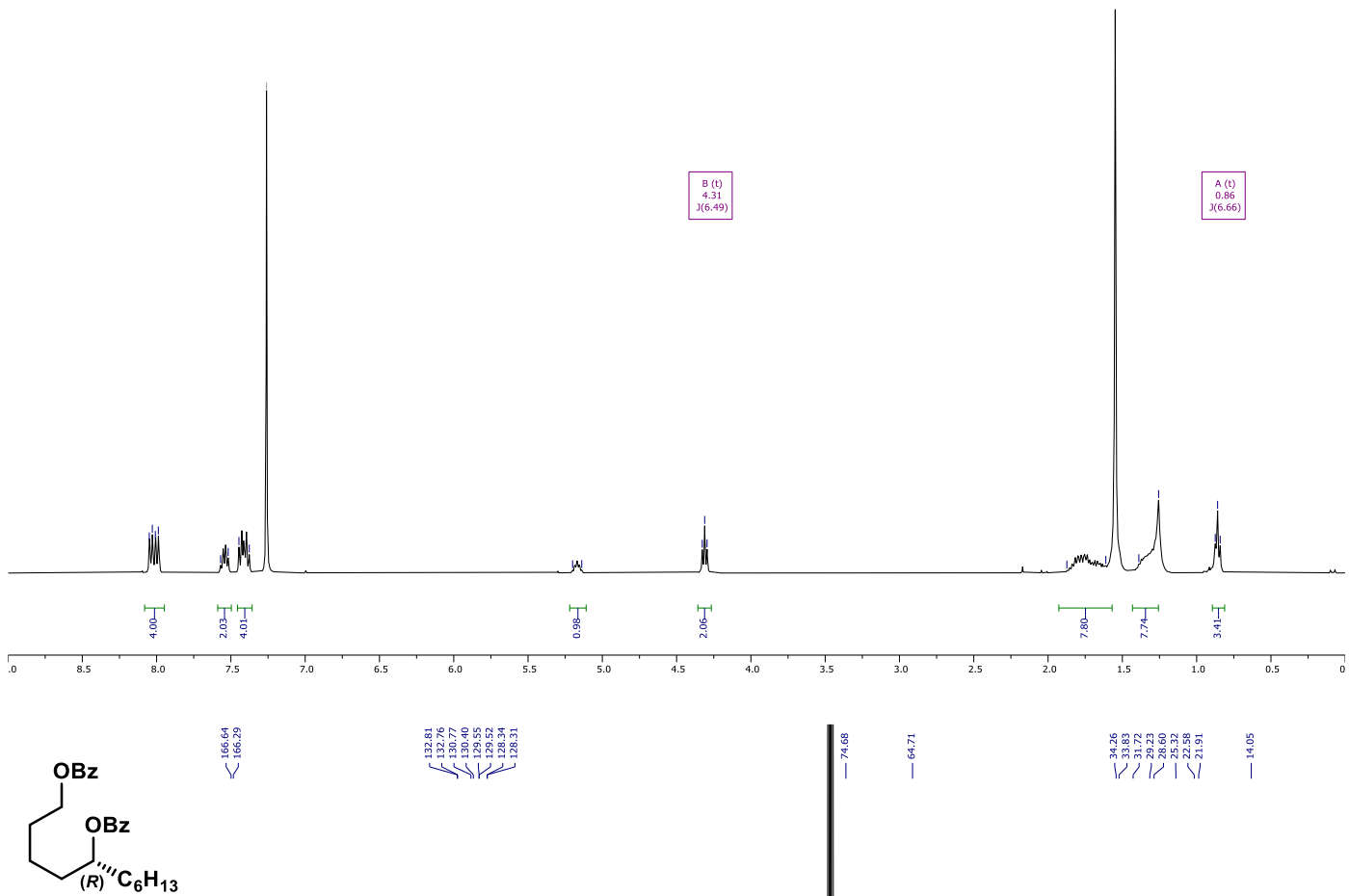

$(R)-5 f$

|
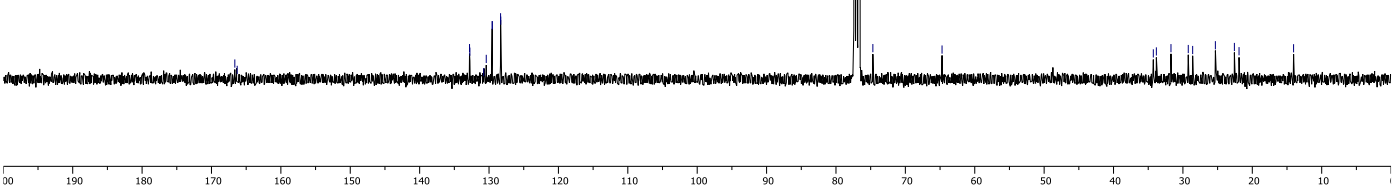

Figure S93. ${ }^{1} \mathrm{H} N M R$ spectrum $\left(400 \mathrm{MHz}, \mathrm{CDCl}_{3}\right)$ and ${ }^{13} \mathrm{C}\left\{{ }^{1} \mathrm{H}\right\} \mathrm{NMR}$ spectrum $\left(101 \mathrm{MHz}, \mathrm{CDCl}_{3}\right)$ of $(R)-5 f$ 


\section{HPLC data}

\subsection{Lactols with high ee}

Derivatization of $\delta$-hexalactol $1 \mathrm{~b}$ to measure the enantiomeric excess by chiral HPLC

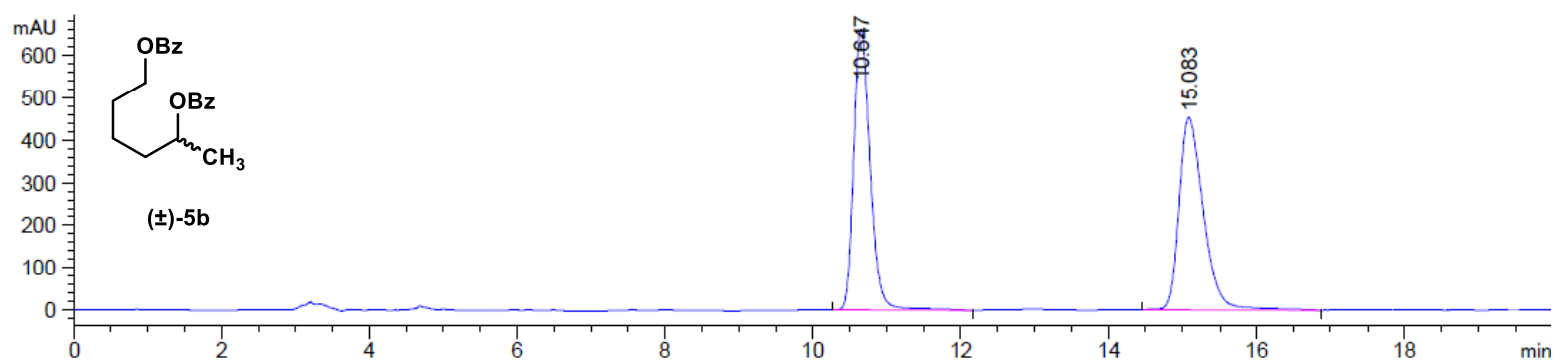

Figure S94. Derivatization of $\delta$-hexalactol ( \pm )-1b.

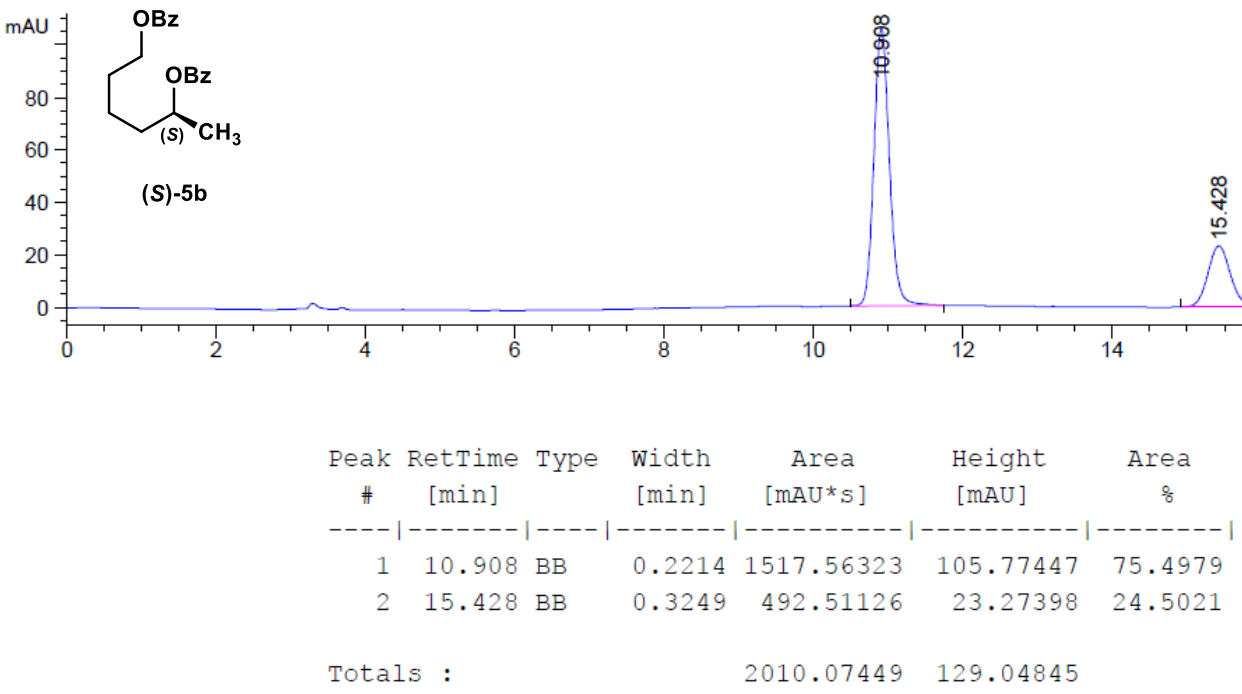

Figure S95. Derivatization of $\delta$-hexalactol (S)-1b. 


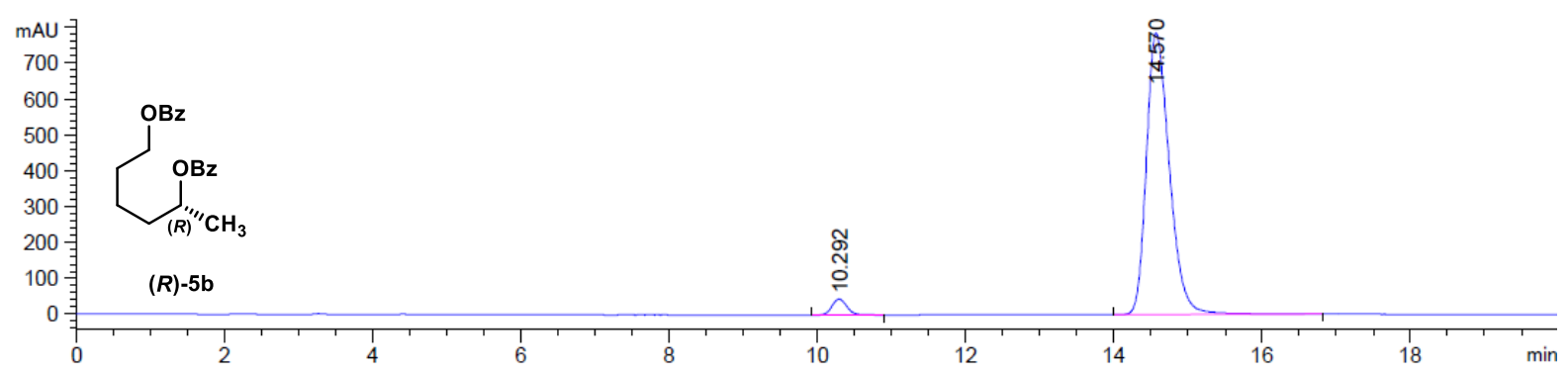

\begin{tabular}{|c|c|c|c|c|c|c|}
\hline $\begin{array}{c}\text { Peak } \\
\#\end{array}$ & $\begin{array}{c}\text { RetTime } \\
\text { [min] }\end{array}$ & Type & $\begin{array}{l}\text { width } \\
\text { [min] }\end{array}$ & $\begin{array}{c}\text { Area } \\
{\left[\mathrm{mAU}^{\star} \mathrm{s}\right]}\end{array}$ & $\begin{array}{l}\text { Height } \\
\text { [mAU] }\end{array}$ & $\begin{array}{c}\text { Area } \\
\quad \frac{8}{6}\end{array}$ \\
\hline \multicolumn{7}{|c|}{$----|-------||----|-------|----------|----------|--------|$} \\
\hline 1 & 10.292 & $\mathrm{BB}$ & 0.2167 & 629.70129 & 44.60478 & 3.5801 \\
\hline 2 & 14.570 & $\mathrm{BB}$ & 0.3321 & $1.69590 e 4$ & 784.68378 & 96.4199 \\
\hline Tota & s : & & & $1.75887 e 4$ & 829.28856 & \\
\hline
\end{tabular}

Figure S96. Derivatization of $\delta$-hexalactol ( $R$ )-1b before partial hydrolysis.

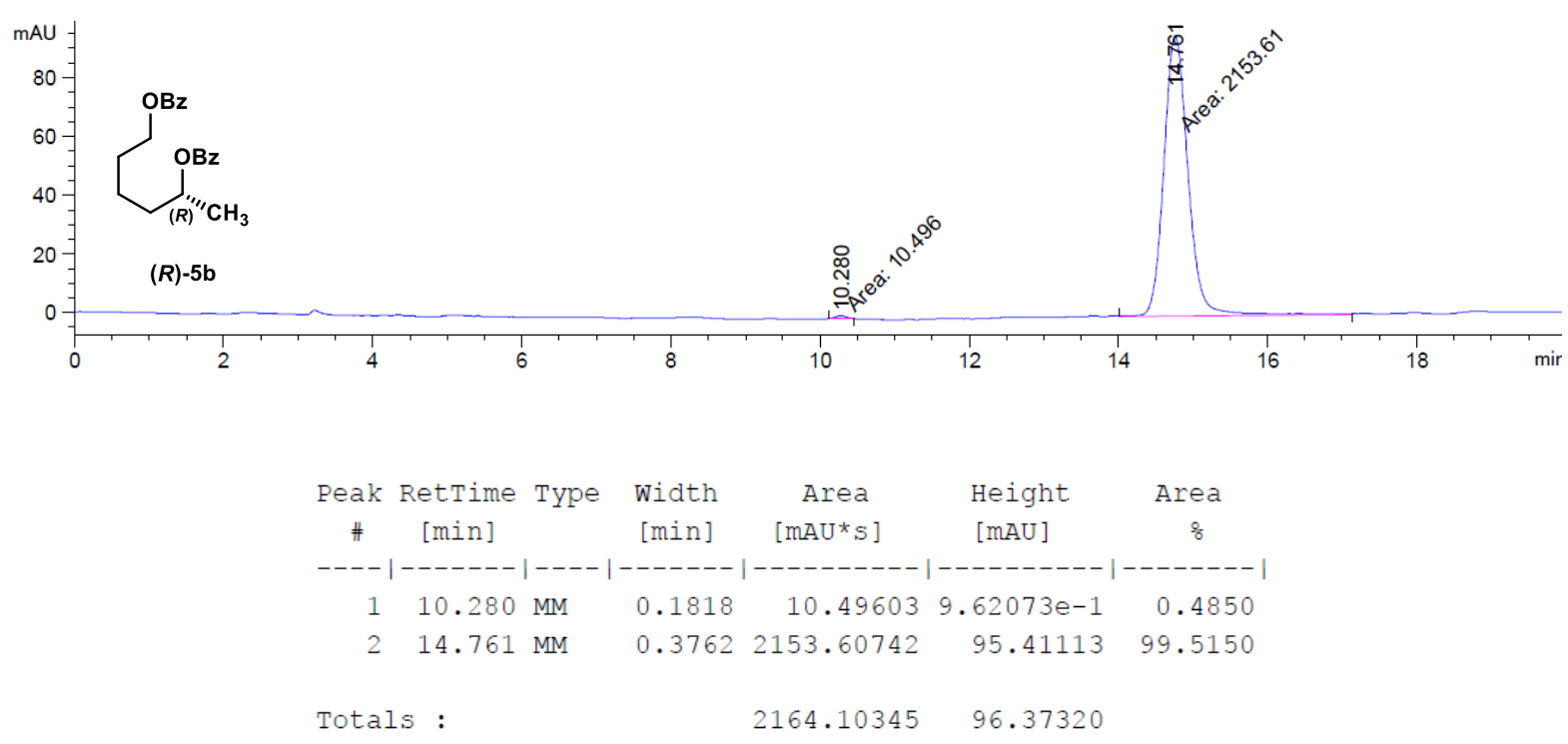

Figure S97. Derivatization of $\delta$-hexalactol ( $R$ )-1b after partial hydrolysis. 
Derivatization of $\delta$-octalactol $1 c$ to measure the enantiomeric excess by chiral HPLC

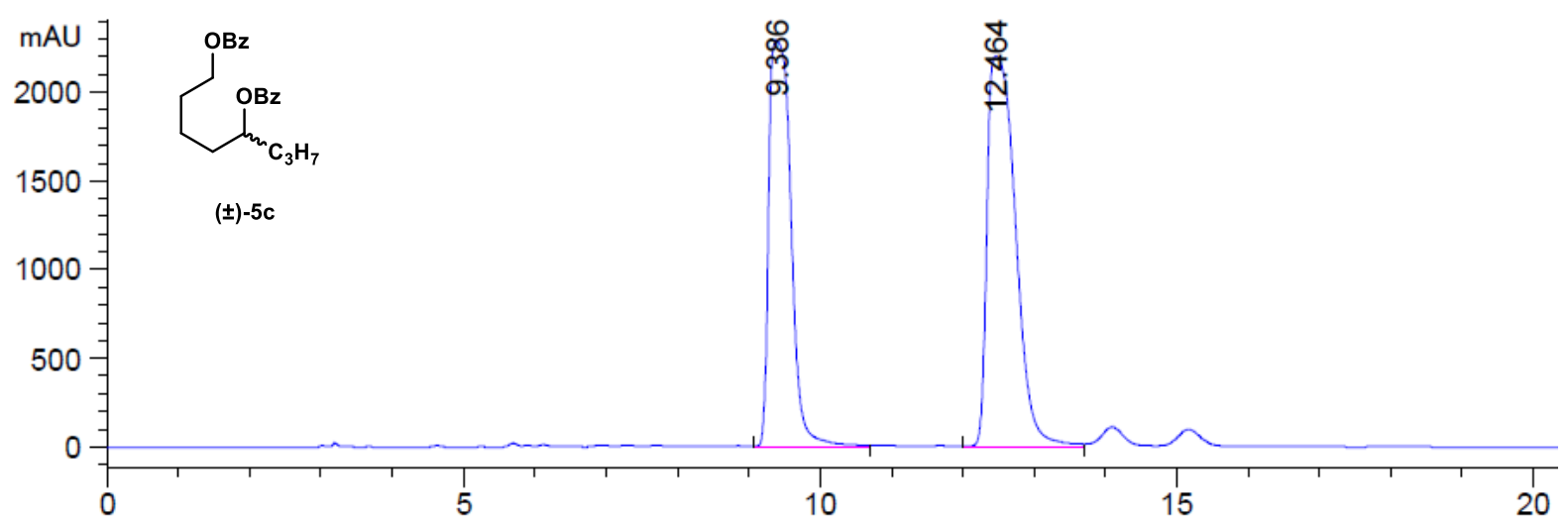

Figure S98. Derivatization of $\delta$-octalactol ( \pm )-1c.

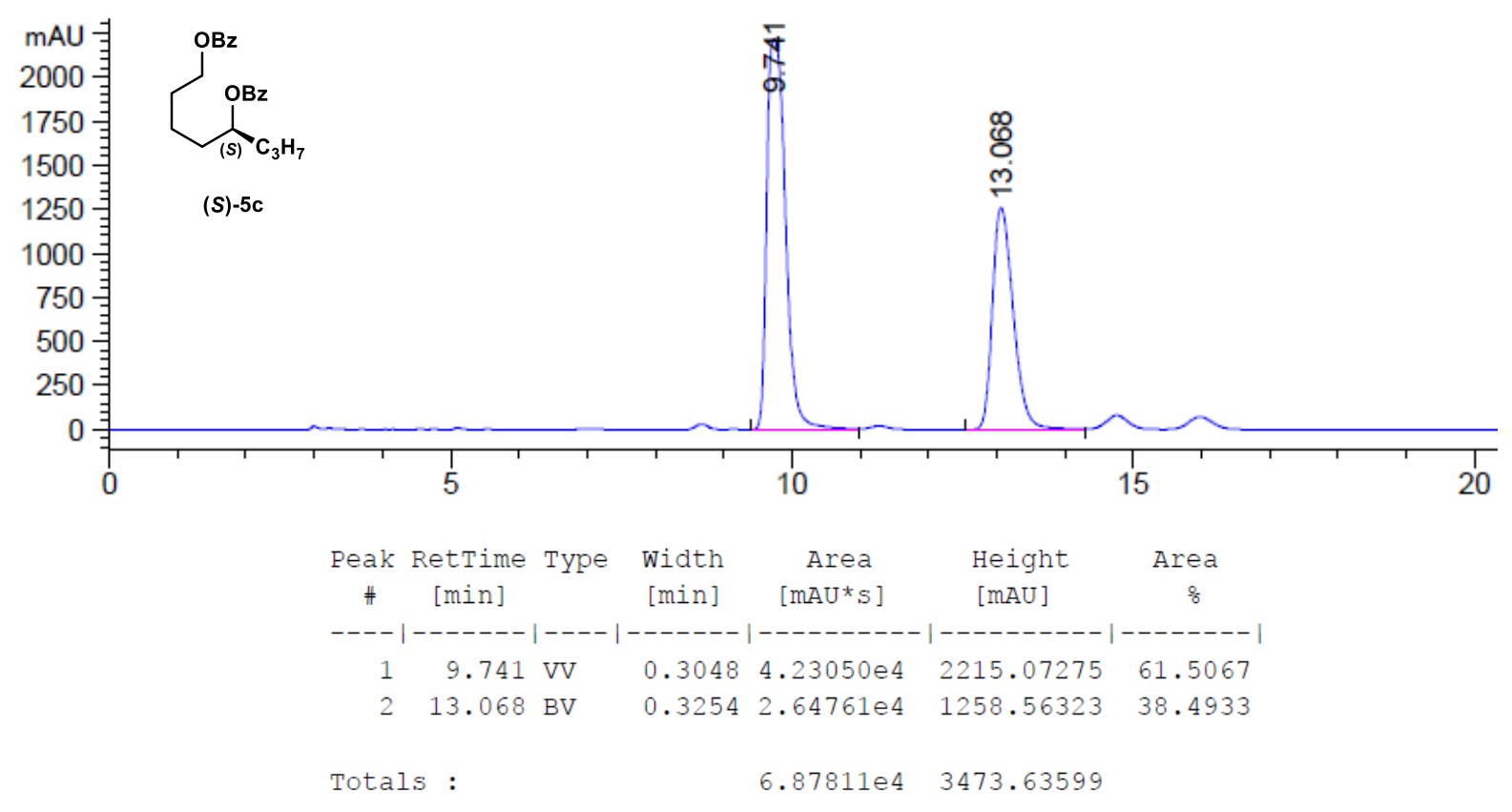




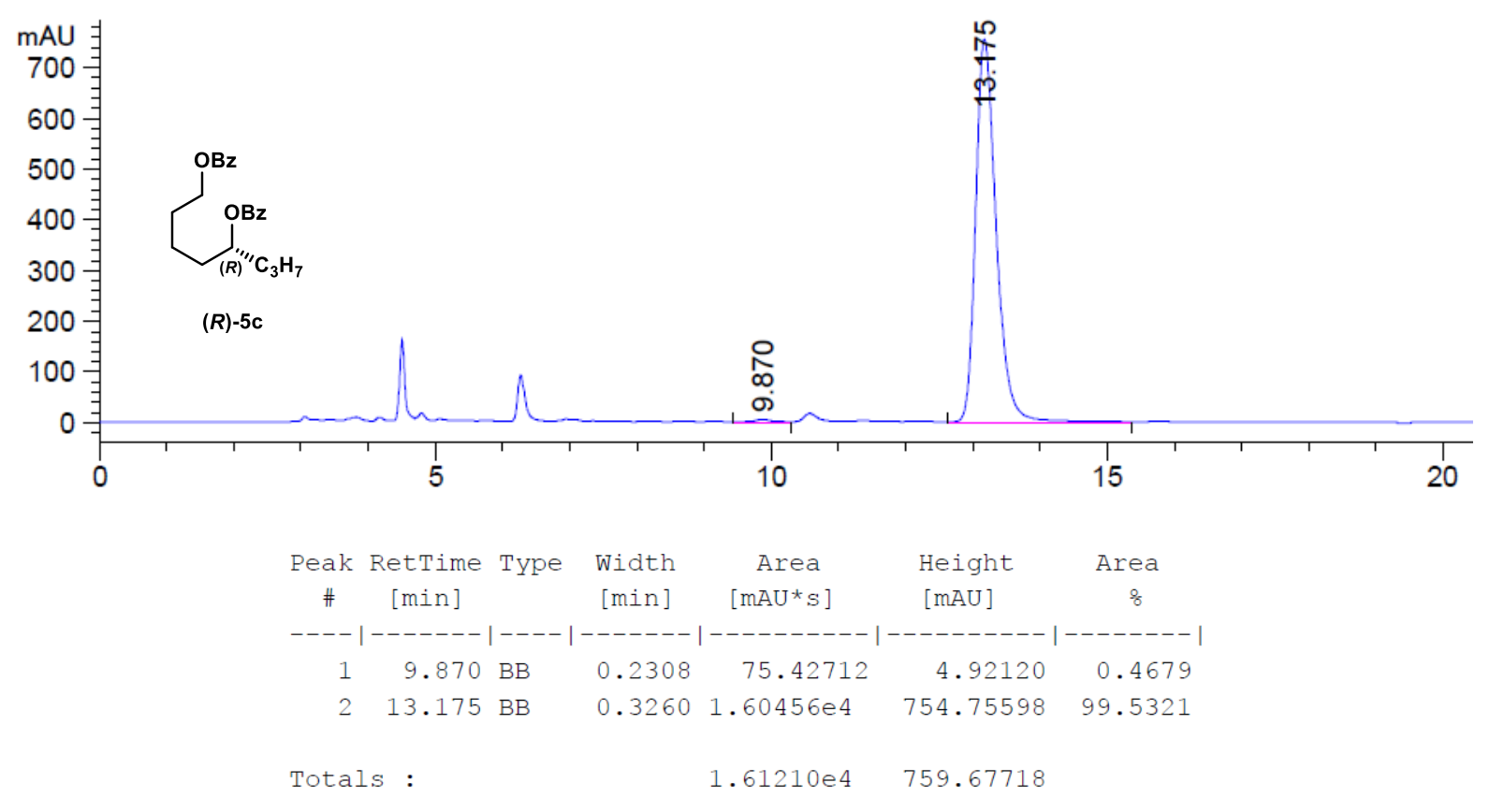

Figure S100. Derivatization of $\delta$-octalactol (R)-1c. 
Derivatization of $\delta$-nonalactol $1 \mathrm{~d}$ to measure the enantiomeric excess by chiral HPLC

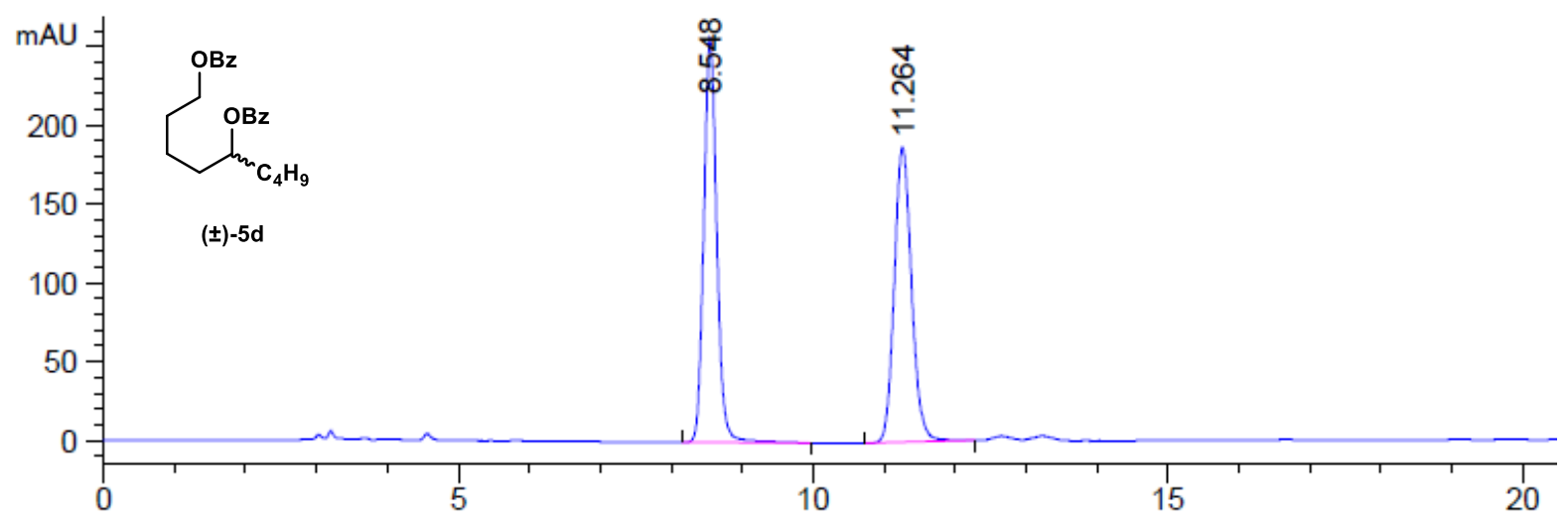

Figure S101. Derivatization of $\delta$-nonalactol ( \pm )-1d.

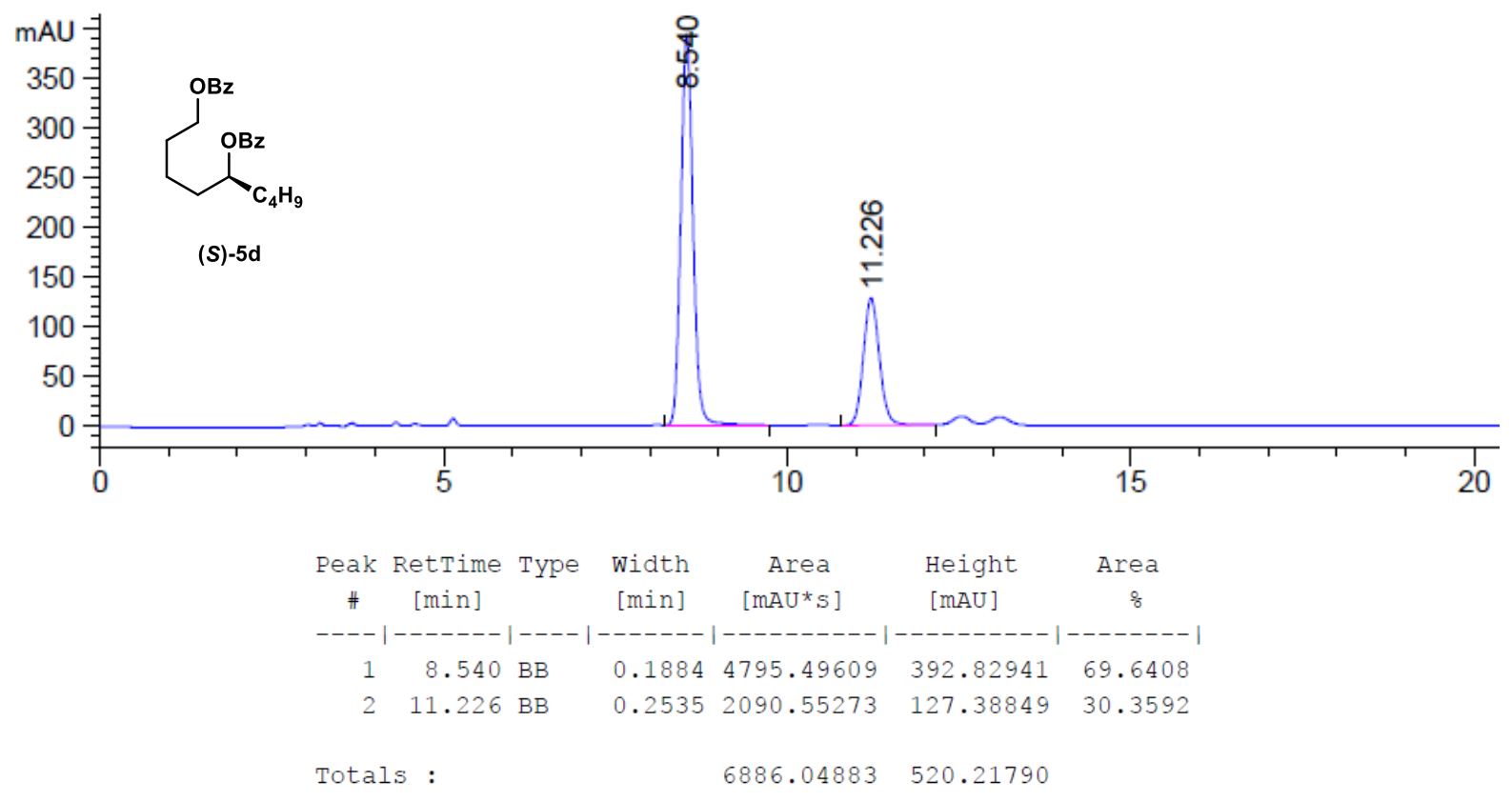

Figure S102. Derivatization of $\delta$-nonalactol (R)-1d. 


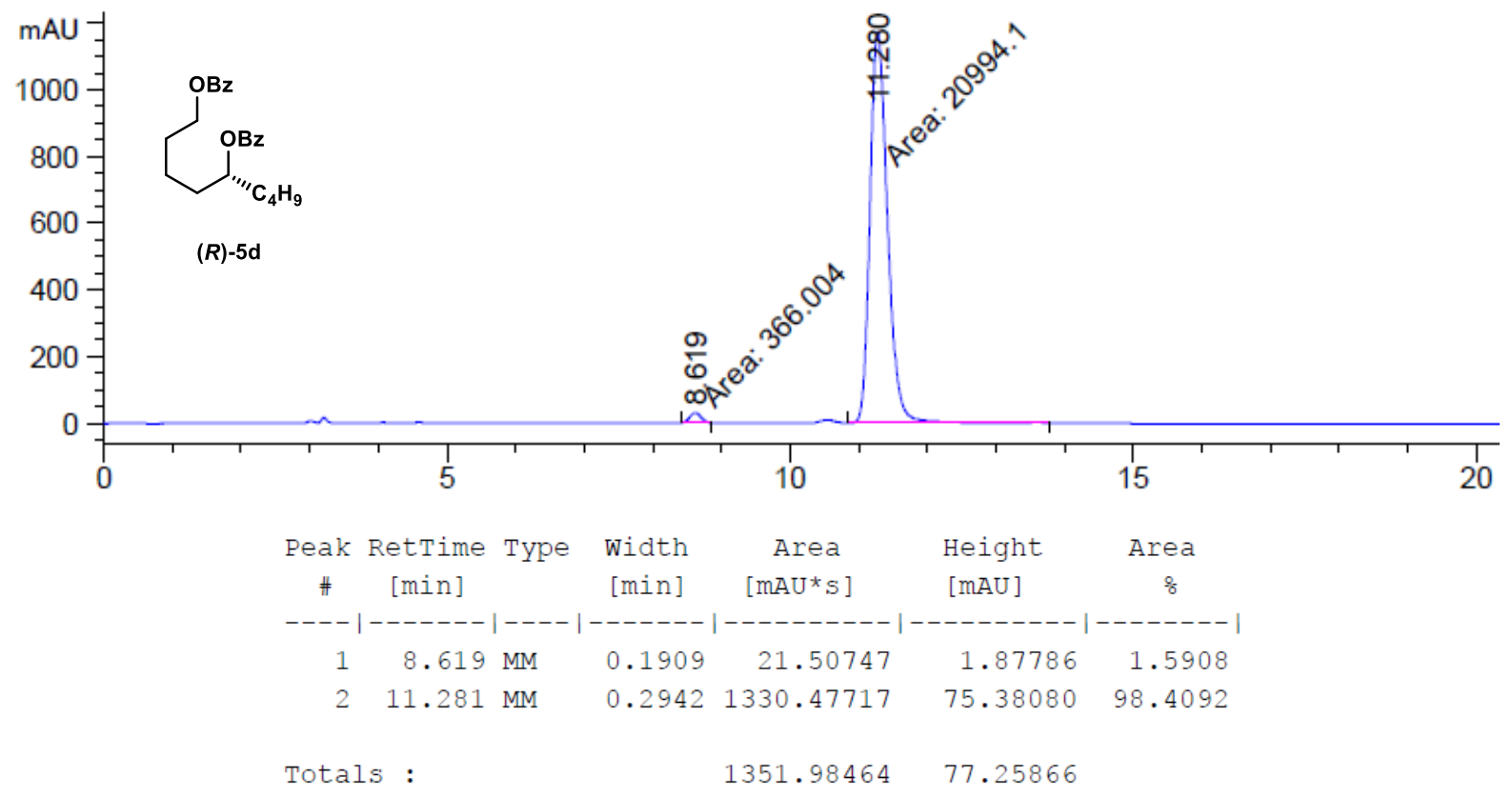

Figure S103. Derivatization of $\delta$-nonalactol (R)-1d. 
Derivatization of $\delta$-decalactol $1 \mathrm{e}$ to measure the enantiomeric excess by chiral HPLC

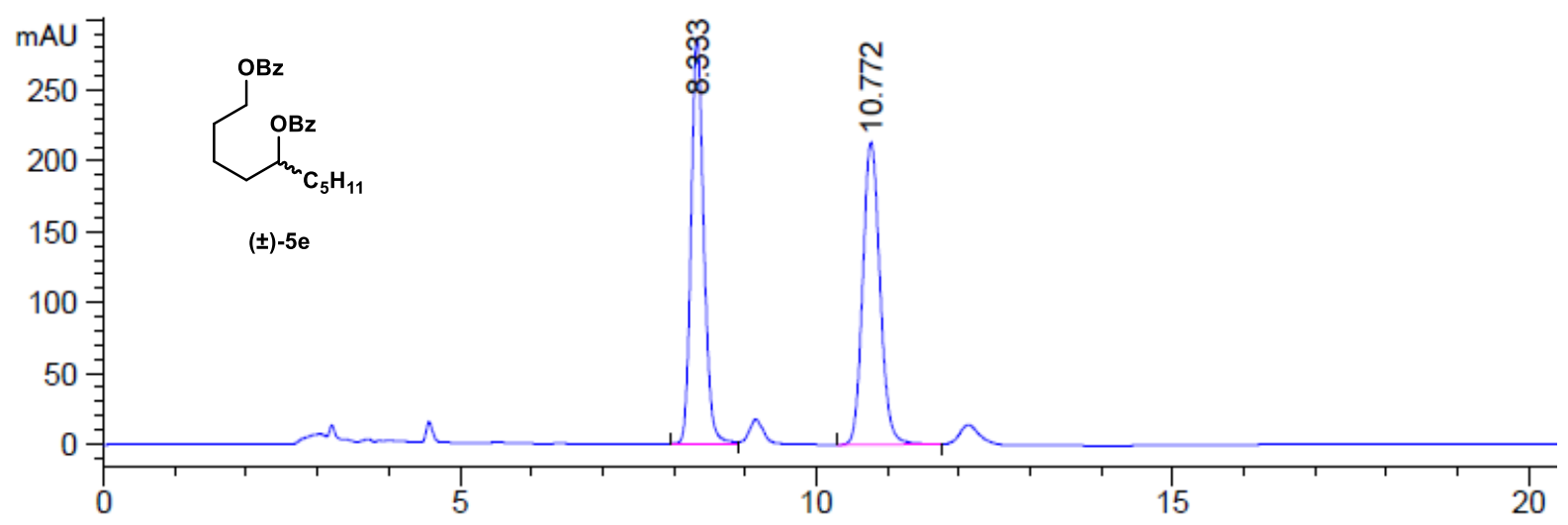

Figure S104. Derivatization of $\delta$-decalactol ( \pm )-1e.

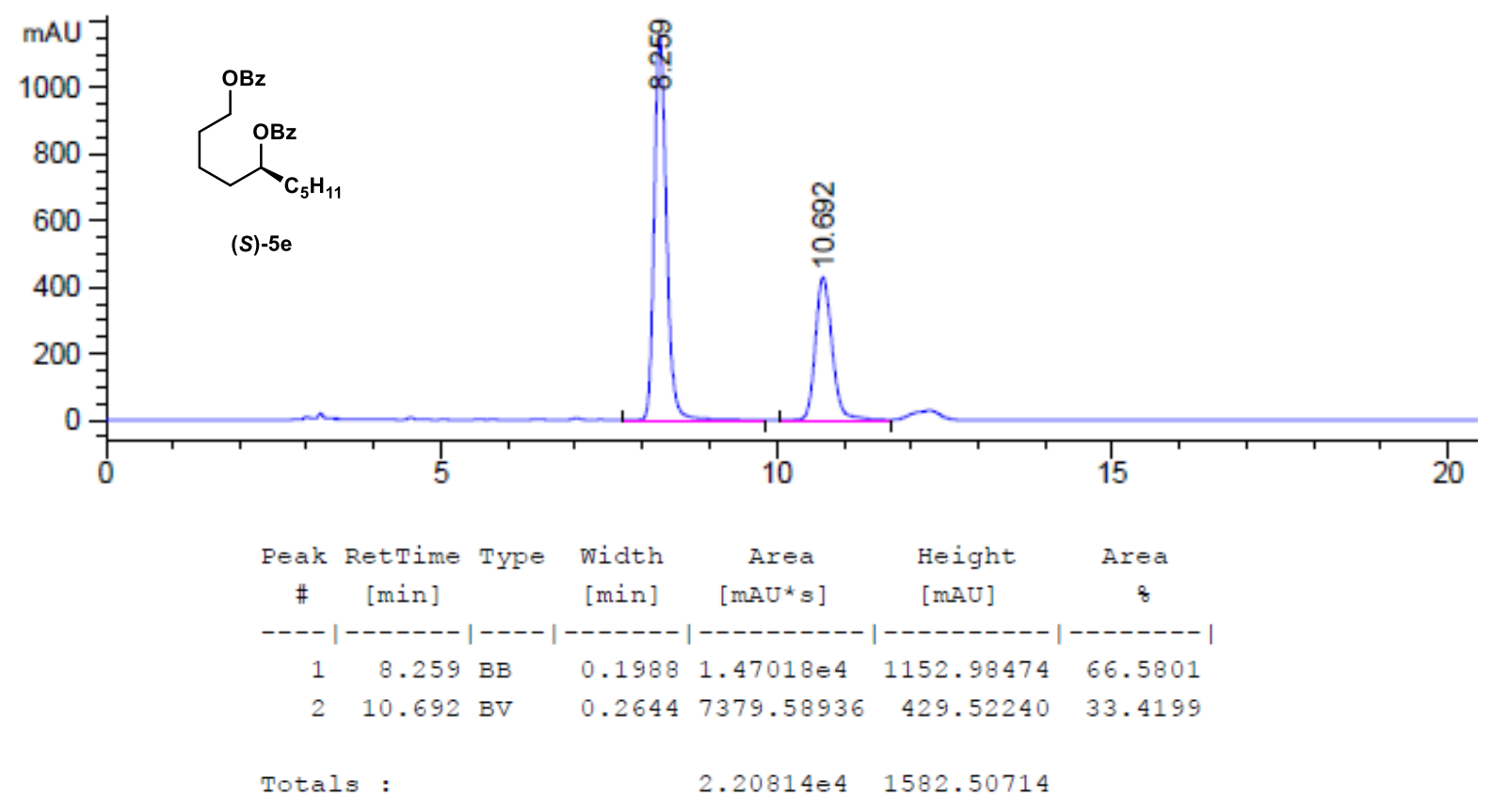

Figure S105. Derivatization of $\delta$-decalactol (S)-1e. 


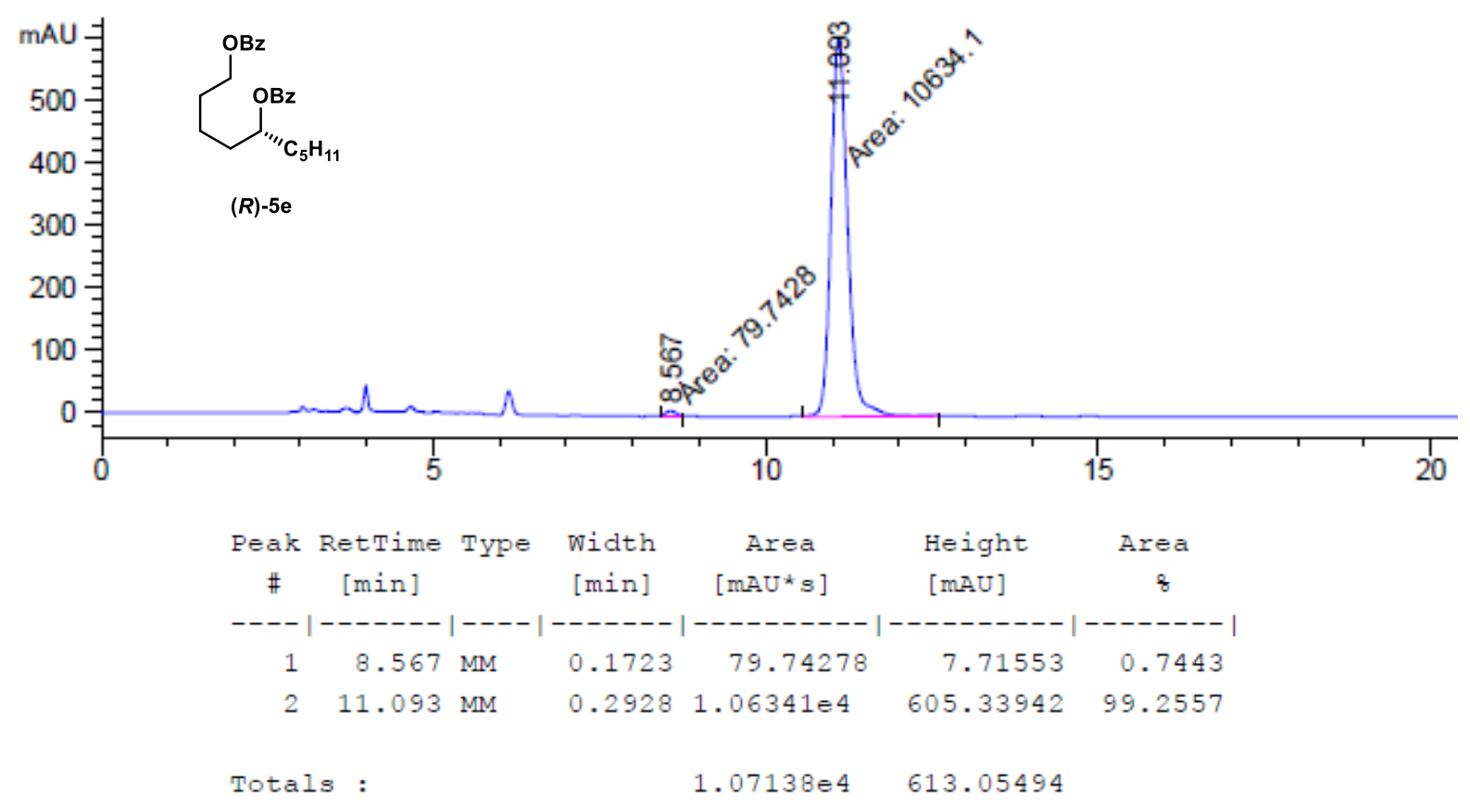

Figure S106. Derivatization of $\delta$-decalactol (R)-1e. 
Derivatization of $\delta$-undecalactol $1 \mathrm{f}$ to measure the enantiomeric excess by chiral HPLC

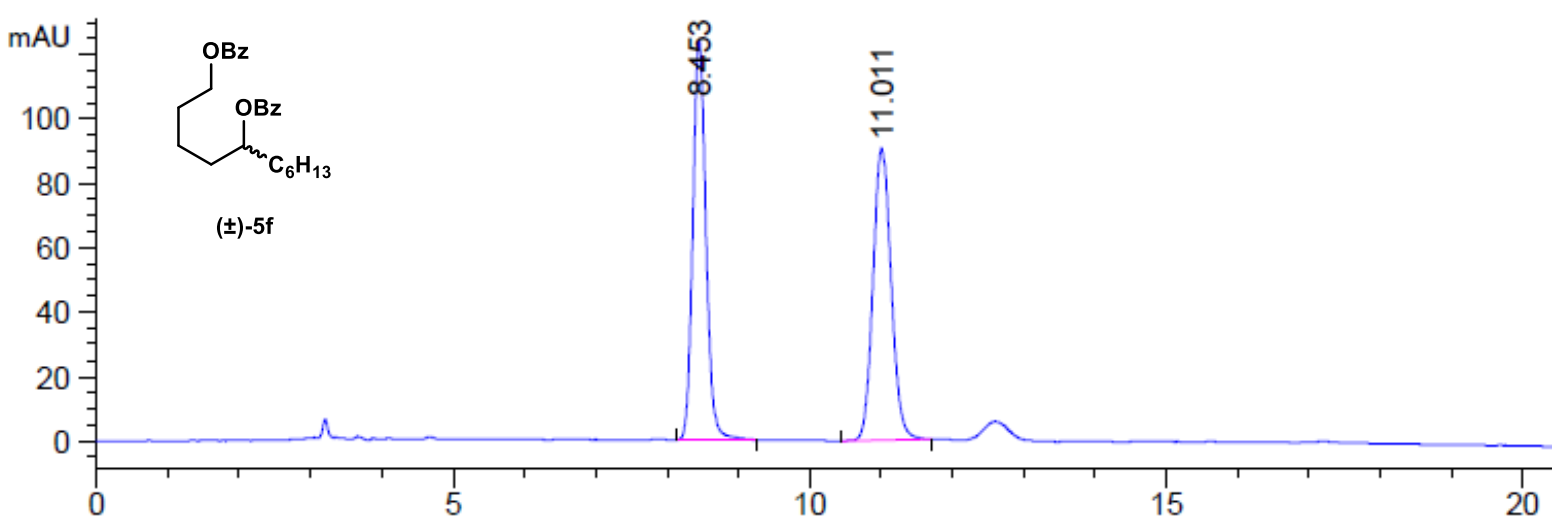

Figure S107. Derivatization of $\delta$-undecalactol ( \pm )-1f.

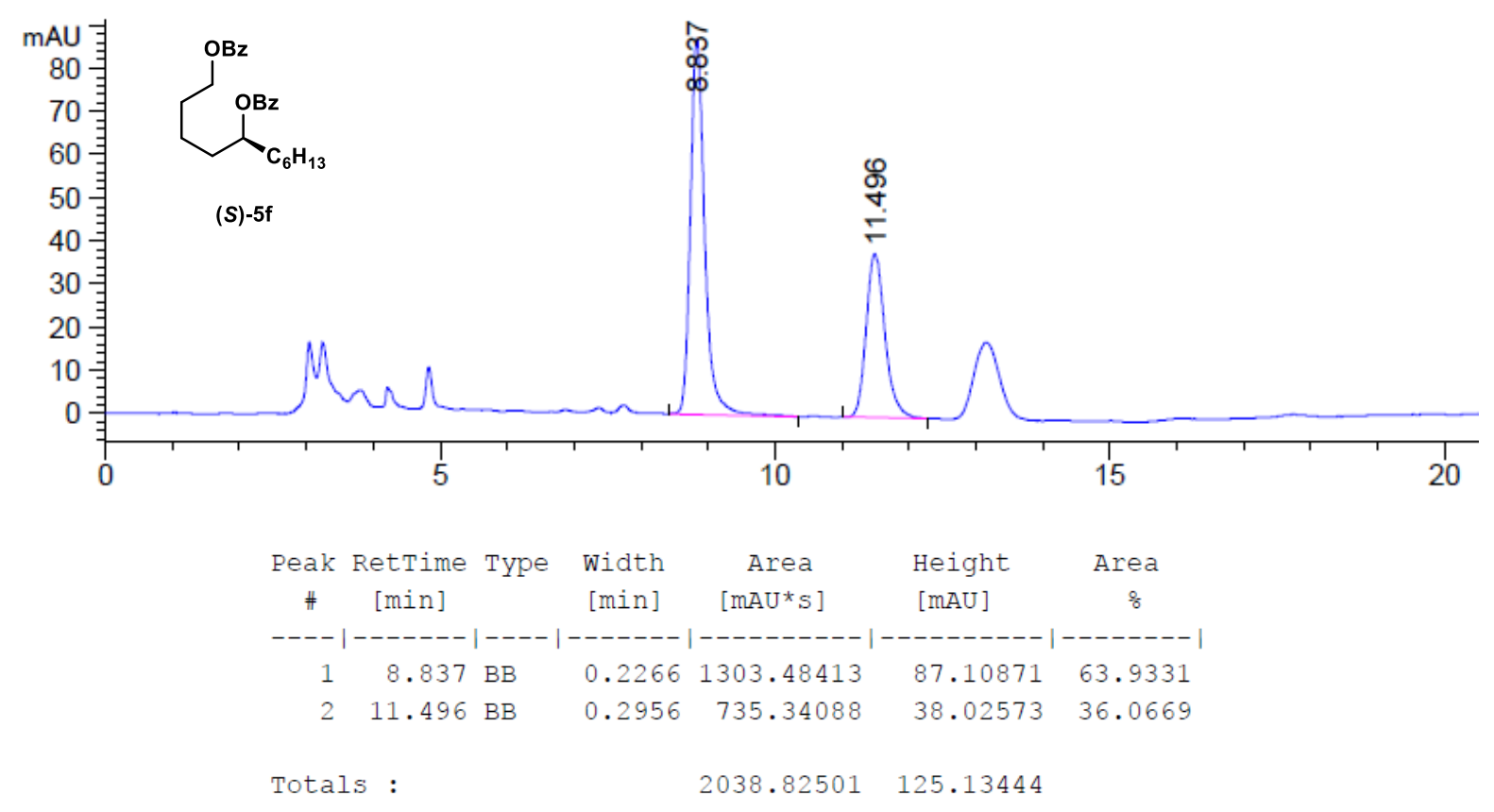

Figure S108. Derivatization of $\delta$-undecalactol (S)-1f. 


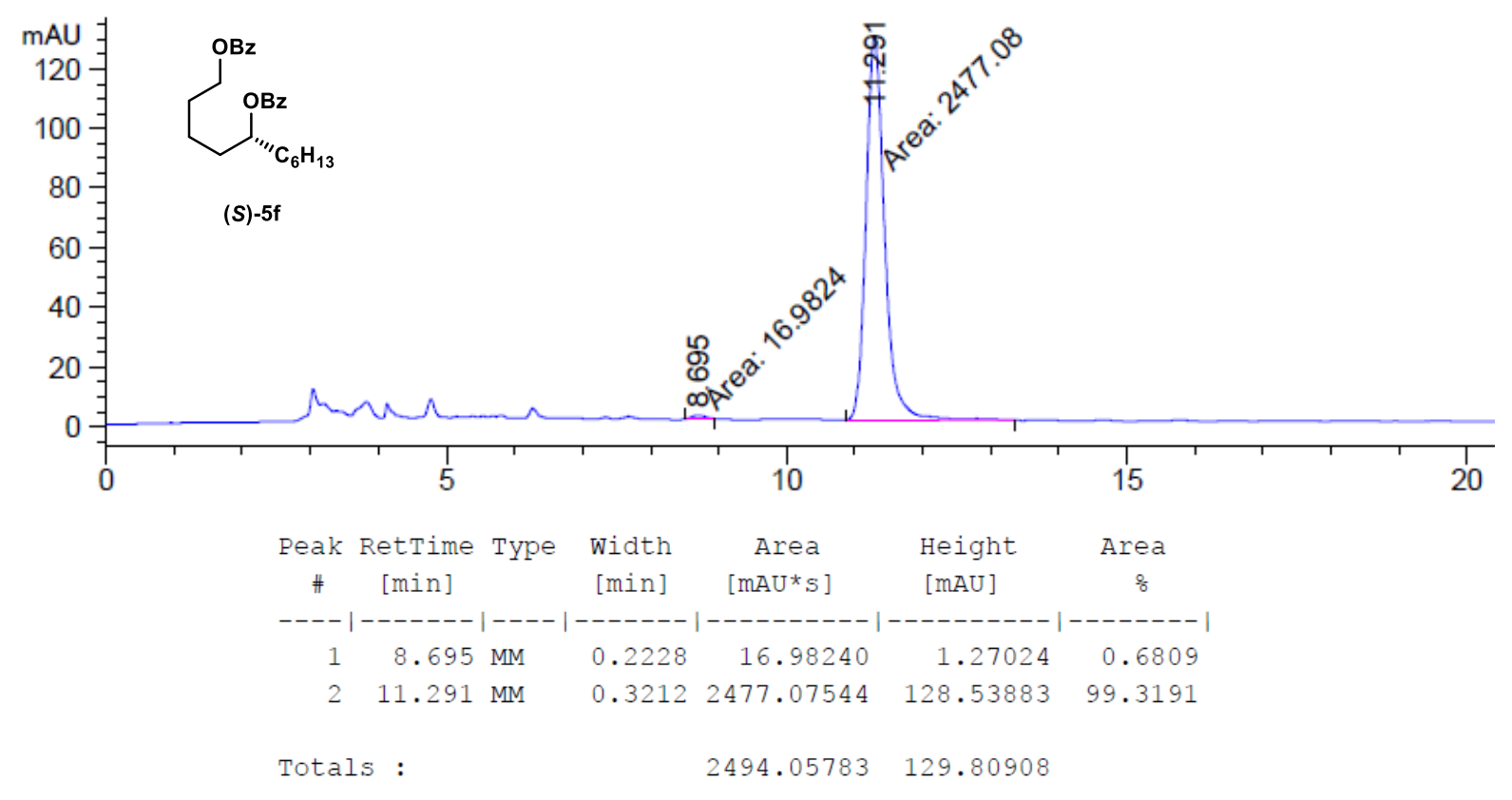




\subsection{Lactols scalemic mixtures}

Derivatization of $\delta$-octalactol 1c to measure the enantiomeric excess by chiral HPLC

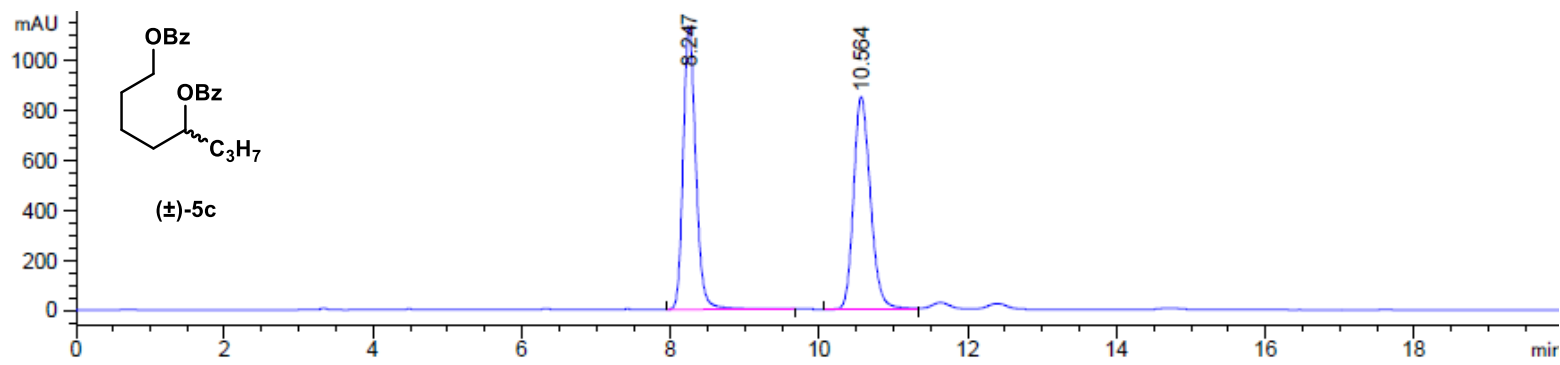

Figure S110. Derivatization of $\delta$-octalactol ( \pm )-1c.

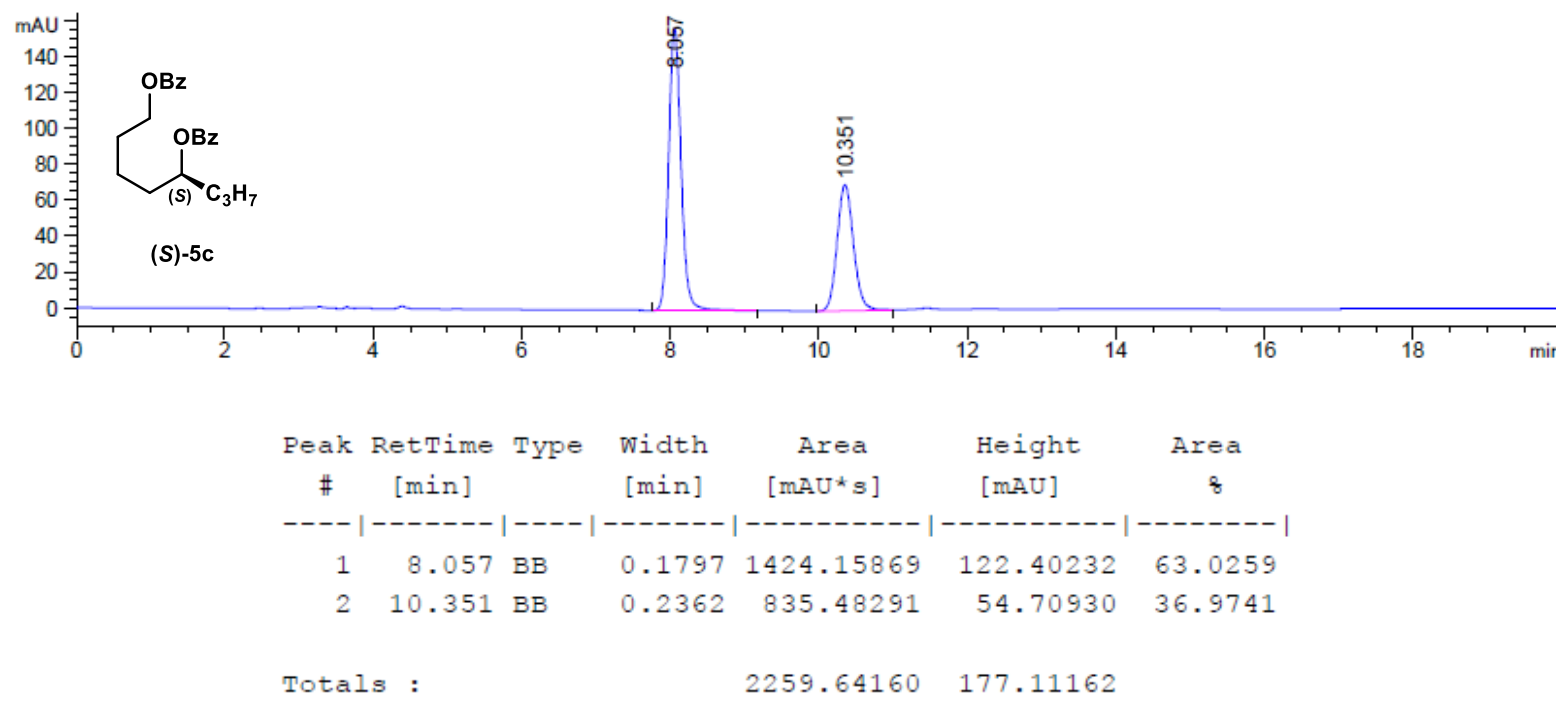

Figure S111. Derivatization of $\delta$-octalactol (S)-1c. 


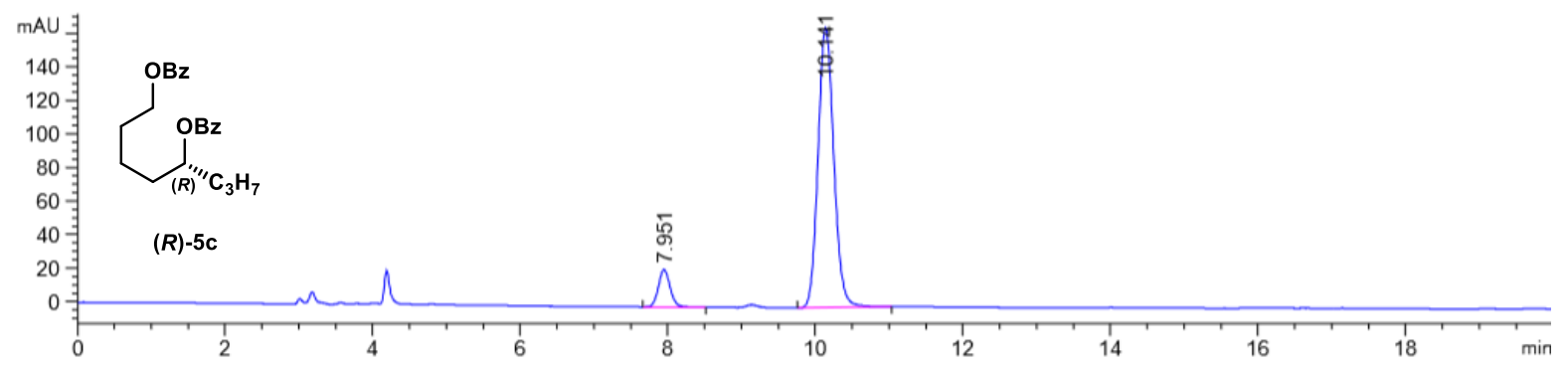

\begin{tabular}{|c|c|c|c|c|c|c|}
\hline $\begin{array}{c}\text { Peak } \\
\#\end{array}$ & $\begin{array}{c}\text { RetTime } \\
\text { [min] }\end{array}$ & Type & $\begin{array}{l}\text { Width } \\
\text { [min] }\end{array}$ & $\begin{array}{c}\text { Area } \\
{\left[\mathrm{mAU}{ }^{\star} \mathrm{S}\right]}\end{array}$ & $\begin{array}{l}\text { Height } \\
\text { [mAU] }\end{array}$ & $\begin{array}{c}\text { Area } \\
\&\end{array}$ \\
\hline 1 & 7.951 & $\mathrm{BB}$ & 0.1691 & 246.76495 & 22.29929 & 9.0407 \\
\hline 2 & 10.141 & BB & 0.2315 & 2482.71875 & 166.95538 & 90.9593 \\
\hline Tota] & Is : & & & 2729.48370 & 189.25468 & \\
\hline
\end{tabular}


Derivatization of $\delta$-decalactol $1 \mathrm{e}$ to measure the enantiomeric excess by chiral HPLC

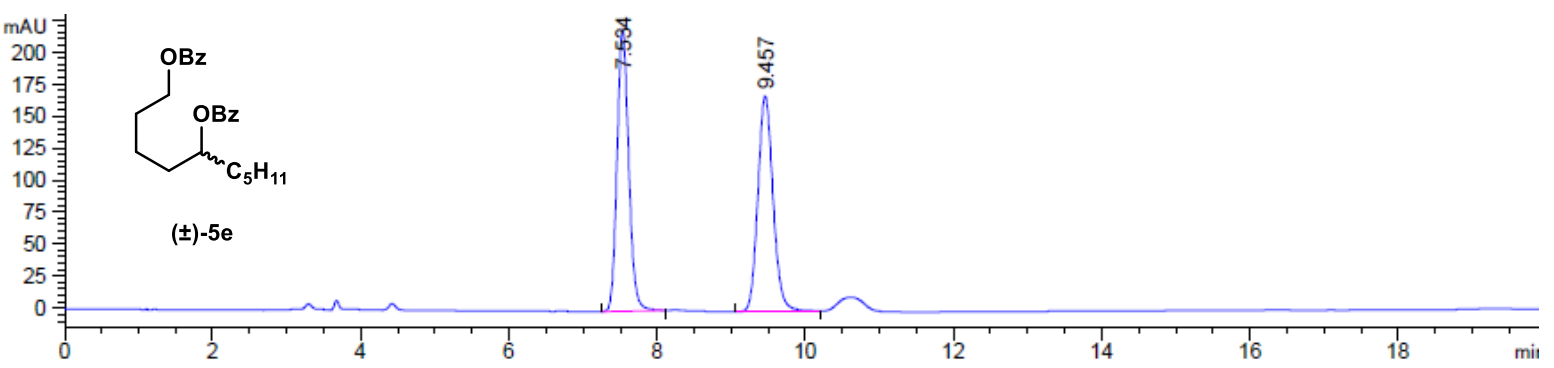

Figure S113. Derivatization of $\delta$-decalactol ( \pm )-1e.

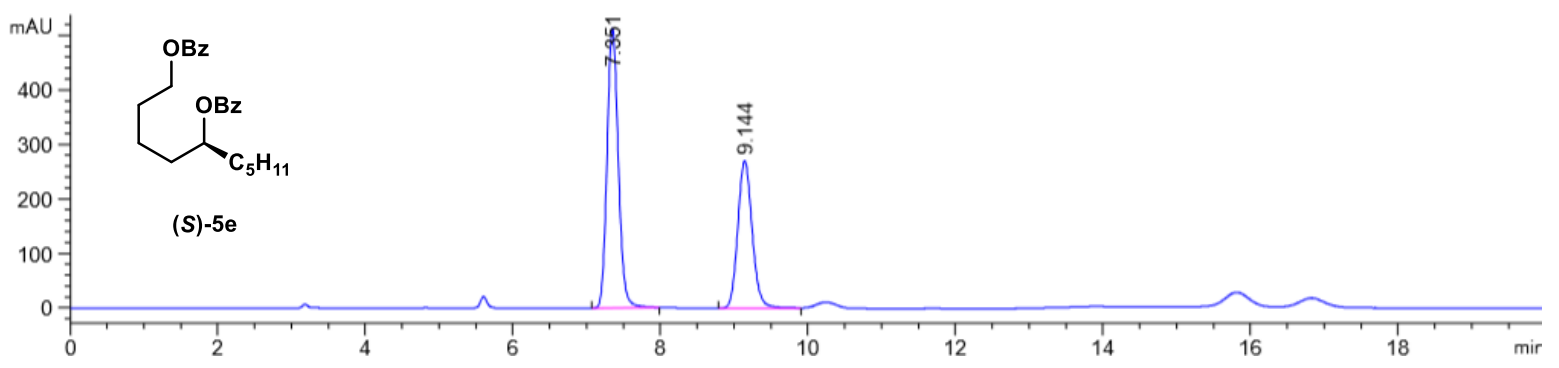

\begin{tabular}{|c|c|c|c|c|c|c|}
\hline $\begin{array}{c}\text { Peak } \\
\#\end{array}$ & $\begin{array}{c}\text { RetTime } \\
\text { [min] }\end{array}$ & Type & $\begin{array}{l}\text { Width } \\
\text { [min] }\end{array}$ & $\begin{array}{c}\text { Area } \\
{\left[\mathrm{mAU}{ }^{\star} \mathrm{s}\right]}\end{array}$ & $\begin{array}{l}\text { Height } \\
\text { [MAU] }\end{array}$ & $\begin{array}{c}\text { Area } \\
\&\end{array}$ \\
\hline 1 & 7.351 & $\mathrm{BB}$ & 0.1632 & 5420.57813 & 513.36786 & 59.5214 \\
\hline 2 & 9.144 & BV & 0.2108 & 3686.36157 & 270.77463 & 40.4786 \\
\hline & & & & 9106.93970 & 784.14249 & \\
\hline
\end{tabular}

Figure S114. Derivatization of $\delta$-decalactol (S)-1e. 


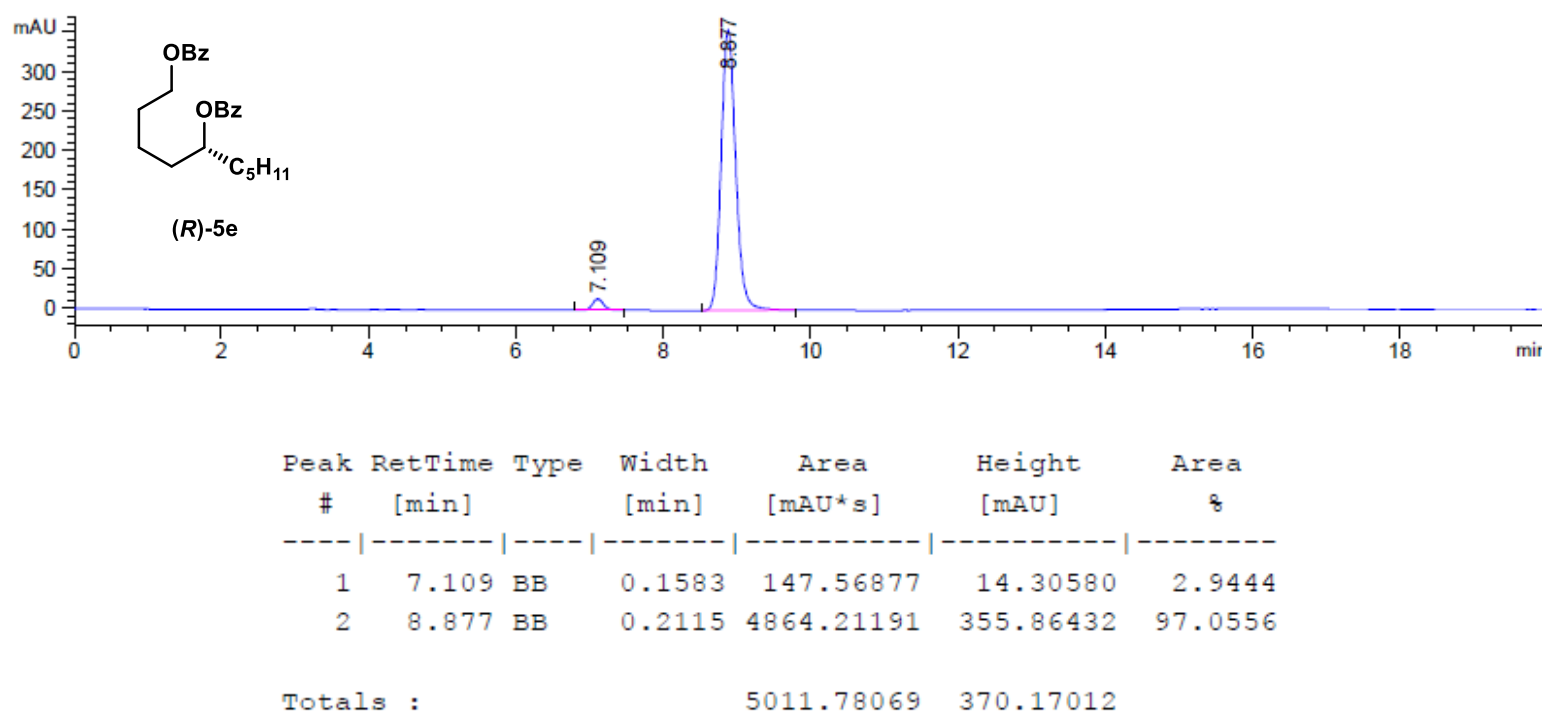

Figure S115. Derivatization of $\delta$-decalactol (R)-1e. 


\section{References}

[1] Hayashi, Y.; Gotoh, H.; Tamura, T.; Yamaguchi, H.; Masui, R.; Shoji, M. Cysteine-Derived Organocatalyst in a Highly Enantioselective Intramolecular Michael Reaction. J. Am. Chem. Soc. 2005, $127,16028-16029$.

[2] Stiller, J.; Poulsen, P. H.; Cruz, D. C.; Dourado, J.; Davis, R. L.; Jørgensen, K. A. Organocatalytic [4+2] addition reactions via tetraenamine intermediate. Chem. Sci. 2014, 5, 2052-2056.

[3] Peelen, T. J.; Chi, Y.; Gellman, S. H. Enantioselective Organocatalytic Michael Additions of Aldehydes to Enones with Imidazolidinones: Cocatalyst Effects and Evidence for an Enamine Intermediate. J. Am. Chem. Soc. 2005, 127, 11598-11599.

[4] Dai, L.; Hou, Y.; Zhang, L.; Chen, Z.; Zeng, X.; Zhong, G. Construction of tetrahydropyranoquinoline derivatives via an asymmetric organocatalytic aza-Michael-IED/HAD cascade reaction. Org. Biomol. Chem. 2017, 15, 9630-9637.

[5] Sahoo, G.; Rahaman, H.; Madarász, Á.; Pápai, I.; Melarto, M.; Valkonen, A.; Pihko, P. M. Dihydrooxazine Oxides as Key Intermediates in Organocatalytic Michael Additions of Aldehydes to Nitroalkenes. Angew. Chem. Int. Ed. 2012, 51, 13144-13148.

[6] Song, A.; Zhang, X.; Song, X.; Chen, X.; Yu, C.; Huang, H.; Li, H.; Wang, W. Construction of Chiral Bridged Tricyclic Benzopyrans: Enantioselective Catalytic Diels-Alder Reaction and a One-Pot Reduction/Acid-Catalyzed Stereoselective Cyclization. Angew. Chem. Int. Ed. 2014, 53, 4940-4944.

[7] Paz, B. M.; Klier, L.; Næsborg, L.; Lauridsen, V. H.; Jensen, F.; Jørgensen, K. A. Enantioselective Organocatalytic Cascade Approach to Different Classes of Benzofused Acetals. Chem. Eur. J. 2016, 22, 16810-16818.

[8] Duschmalé, J.; Wiest, J.; Wiesner, M.; Wennemers, H. Effects of internal and external carboxylic acids on the reaction pathway of organocatalytic 1,4-addition reactions between aldehydes and nitroolefins. Chem. Sci. 2013, 4, 1312-1318.

[9] Wang, Z.-Y.; Wong, W.-T.; Yang, D. Organocatalyzed Asymmetric Synthesis of Dihydrodibenzofurans Based on a Dienamine Process. Org. Lett. 2013, 15, 4980-4983.

[10] Burés, J.; Armstrong, A.; Blackmond, D. G. Curtin-Hammett Paradigm for Stereocontrol in Organocatalysis by Diarylprolinol Ether Catalysts. J. Am. Chem. Soc. 2012, 134, 6741-6750.

[11] Bertelsen, S.; Marigo, M.; Brandes, S.; Dinér, P.; Jørgensen, K. A. Dienamine Catalysis: Organocatalytic Asymmetric $\gamma$-Amination of $\alpha, \beta$-Unsaturated Aldehydes. J. Am. Chem. Soc. 2006, 128, 12973-12980.

[12] Santangelo, E. M.; Liblikas, I.; Mudalige, A.; Törnroos, K. W.; Norrby, P.-O.; Unelius, C. R. Asymmetric Synthesis of Iridoid Derivatives Using Resolved 2-Phenylindoline as a Chiral Auxiliary. Eur. J. Org. Chem. 2008, 5915-5921. 
[13] Tan, S. M.; Willis, A. C.; Paddon-Row, M. N.; Sherburn, M. S. Multicomponent DieneTransmissive Diels-Alder Sequences Featuring Aminodendralenes. Angew. Chem. Int. Ed. 2016, 55, 3081-3085.

[14] Weber, A. K.; Schachtner, J.; Fichtler, R.; Leermann, T. M.; Neudörfl, J. M.; Jacobi von Wangelin, A. Modular synthesis of cyclic cis- and trans-1,2-diamine derivatives. Org. Biomol. Chem. 2014, 12, 5267-5277.

[15] Selva, V.; Larrañaga, O.; Castelló, L. M.; Nájera, C.; Sansano, J. M.; de Cózar, A. Diastereoselective [3+2] vs [4+2] Cycloadditions of Nitroprolinates with $\alpha, \beta$-Unsaturated Aldehydes and Electrophilic Alkenes: An Example of Total Periselectivity. J. Org. Chem. 2017, 82, 6298-6312.

[16] Allef, P.; Kunz, H. Glycosylation-Induced Asymmetric Synthesis of 1-Substituted Tetrahydroisoquinolines. Heterocycles 2007, 74, 421-436.

[17] Kranke, B.; Hebrault, D.; Schultz Kukula, M.; Kunz, H. Arabinosylamine in Asymmetric Syntheses of Chiral Piperidine Alkaloids. Synlett 2004, 4, 671-674.

[18] Brunhofer, B.; Kunz, H.; Schollmeyer, D. CCDC 823688: CSD Communication 2011, DOI: $10.5517 /$ ccwn316.

[19] Schulz-Kukula, M.; Kunz, H.; Schollmeyer, D. CCDS 814819: CSD Communication 2012, DOI: 10.5517/ccwbwhk.

[20] Zhao, Y.; Wang, G.; Zhou, S.; Li, Z.; Meng, X. Diastereoselective formation of aziridines from diazocarbonyl compounds and $\mathrm{N}$-(O-pivaloylated D-galactosyl)benzylideneamines and ring-opening reactions with p-toluenethiol. Org. Biomol. Chem. 2014, 12, 3362-3365.

[21] Weymann, M.; Schultz-Kukula, M.; Kunz, H. Auxiliary-controlled stereoselective enolate protonation: Enantioselective synthesis of cis and trans annulated decahydroquinoline alkaloids. Tetrahedron Lett. 1998, 39, 7835-7838.

[22] Sondhi, S. M.; Kolodziejczyk, P.; Ball, R. G.; Lown, J. W. Naphtho[2,1-b]thiophene-linked 1,2dithia-5,8-diazacyclodecanes and imidazolidino[1,2-d]dithiazepines: synthesis, structure proof by $x$ ray diffraction analysis, and DNA binding properties. J. Org. Chem. 1988, 53, 4310-4314.

[23] Zech, G.; Schollmeyer, D.; Kunz, H. CCDS 862354: CSD Communication 2012, DOI: $10.5517 /$ ccxybw1.

[24] Boeckman, R. K.; Wang, H.; Rugg, K. W.; Genung, N. E.; Chen, K.; Ryder, T. R. A Scalable Total Synthesis of (-)-Nakadomarin A. Org. Lett. 2016, 18, 6136-6139.

[25] Cassani, C.; Melchiorre, P. Direct Catalytic Enantioselective Vinylogous Aldol Reaction of $\alpha$ Branched Enals with Isatins. Org. Lett. 2012, 14, 5590-5593.

[26] Kranke, B.; Kunz, H. Stereoselective syntheses of piperidinones and their modification by organometallic coupling reactions. Org. Biomol. Chem. 2007, 5, 349-357. 
[27] Seebach, D.; Sun, X.; Ebert, M.-O.; Schweizer, W. B.; Purkayastha, N.; Beck, A. K.; Duschmalé, J.; Wennemers, H.; Mukaiyama, T.; Benohoud, M.; Hayashi, Y.; Reiher, M. Stoichiometric Reactions of Enamines Derived from Diphenylprolinol Silyl Ethers with Nitro Olefins and Lessons for the Corresponding Organocatalytic Conversions - a Survey. Helv. Chim. Acta 2013, 96, 799-852.

[28] Seebach, D.; Sun, X.; Sparr, C.; Ebert, M.-O.; Schweizer, W. B.; Beck, A. K. 1,2-Oxazine N-Oxides as Catalyst Resting States in Michael Additions of Aldehydes to Nitro Olefins Organocatalyzed by $\alpha, \alpha-$ Diphenylprolinol Trimethylsilyl Ether. Helv. Chim. Acta 2012, 95, 1064-1078.

[29] Liu, X.-W.; Le, T. N.; Lu, Y.; Xiao, Y.; Ma, J.; Li, X. An efficient synthesis of chiral phosphinyl oxide pyrrolidines and their application to asymmetric direct aldol reactions. Org. Biomol. Chem. 2008, 6, 3997-4003.

[30] Gurubrahamam, R.; Chen, Y. m.; Huang, W.-Y.; Chan, Y.-T.; Chang, H.-K.; Tsai, M.-K.; Chen, K. Dihydrooxazine $\mathrm{N}$-Oxide Intermediates as Resting States in Organocatalytic Kinetic Resolution of Functionalized Nitroallylic Amines with Aldehydes. Org. Lett. 2016, 18, 3046-3049.

[31] Chi, R. Y.; Gellman, S.; Guzei, I. A. CCSD 901258: CSD Communication 2012, DOI: $10.5517 /$ ccz7tvv.

[32] Zu, L.; Zhang, S.; Xie, H.; Wang, W. Catalytic Asymmetric oxa-Michael-Michael Cascade for Facile Construction of Chiral Chromans via an Aminal Intermediate. Org. Lett. 2009, 11, 1627-1630.

[33] Ramachary, D. B.; Shiva Prasad, M.; Vijaya Laxmi, S.; Madhavachary, R. Asymmetric synthesis of drug-like spiro[chroman-3,3'-indolin]-2'-ones through aminal-catalysis. Org. Biomol. Chem. 2014, $12,574-580$.

[34] Gerasyuto, A. I.; Hsung, R. P.; Sydorenko, N.; Slafer, B. A Formal [3 + 3] Cycloaddition Reaction. 5. An Enantioselective Intramolecular Formal Aza-[3 +3] Cycloaddition Reaction Promoted by Chiral Amine Salts. J. Org. Chem. 2005, 70, 4248-4256.

[35] (a) Yang, X. H.; Wang, K.; Zhu, S. F.; Xie, J. H.; Zhou, Q. L. Remote Ester Group Leads to Efficient Kinetic Resolution of Racemic Aliphatic Alcohols via Asymmetric Hydrogenation. J. Am. Chem. Soc. 2014, 136, 17426-17429. (b) Chen, G.; Franck, R. W.; Yang, G.; Blumenstein, M. Anomeric effects of sulfones. Can. J. Chem. 2002, 80, 894-899. 